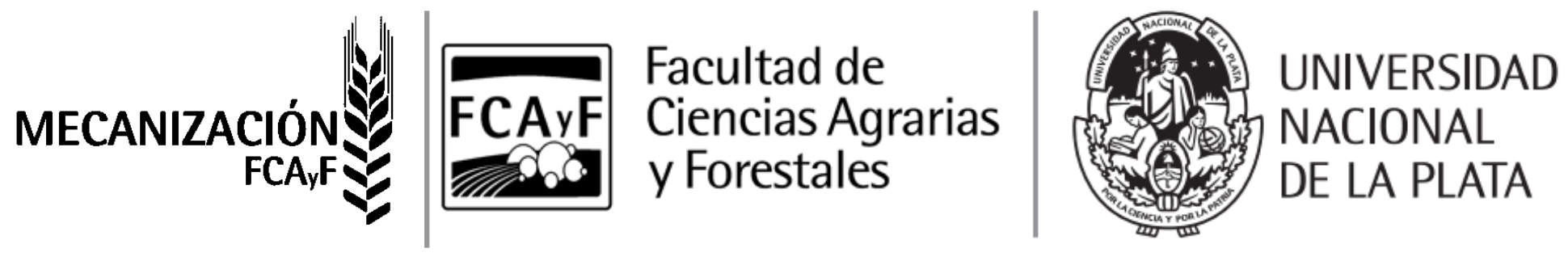

\title{
DISTRIBUCIÓN ESPACIAL DE LA PULVERIZACIÓN GENERADA POR DIFERENTES DISEÑOS DE PASTILLAS HIDRÁULICAS
}

Tesis para optar por el título de Magister en Mecanizacion agrícola de la FACyF, UNLP.

Victor Hugo Merani

Ing. Agr. UNLP 2021

Director:

Ing Agr. Roberto H. Balbuena 
Yo vivo de preguntar, saber no puede ser lujo... Si saber no es un derecho, seguro será un izquierdo...

Silvio Rodriguez 
Dedicada a Flor.

Todo es mas fácil de a dos. 
Agradecimietos:

A Roberto Balbuena, mi director, por confiar en mí. Por ayudarme, por enseñarme y por sobretodo por su guía, académica y no tanto.

A los chicos de la catedra de mecanización compañeros y amigos Matilde, Facundo, Mariano, Juan Manuel y Telmo. Por la enorme ayuda y apoyo a lo largo de toda la tesis.

A los evaluadores, por su tiempo y dedicación.

A la Universidad pública y gratuita, que me brindó la posibilidad de estudiar y crecer sin olvidar de donde se viene y teniendo en claro hacia donde se va.

A la Facultad de Cs Agrarias y Forestalesde la UNLP y a todos sus integrantes.

A mis amigos, Guille, Luciano, Dany y Nico, por el aguante constante y la ayuda.

A mis viejos y a mi familia por estar siempre. 


\section{RESUMEN}

Con la difusión de la siembra directa y el ingreso de cultivos genéticamente modificados la aplicación de productos fitosanitarios en la Argentina ha tomado gran importancia y se realiza en gran parte de los sistemas extensivos e intensivos con máquinas hidráulicas de botalón. La misma es compleja y afectada por una combinación de factores de difícil manejo. La aplicación de herbicidas sobre malezas de distinta altura y la capacidad de penetración en cultivos densos plantean nuevos desafíos. Frente a esto, los parámetros que afectan la pulverización, diseño de pastilla, presión de trabajo, altura de botalón, disposición de las pastillas y velocidad de trabajo se vuelven fundamentales para volver más eficiente la práctica y reducir las posibilidades de pérdida de producto. Con dicho objetivo se realizaron ensayos para evaluar la prestación de diferentes pastillas de pulverización en diferentes sectores y características de blancos que afectan la deposición del producto aplicado. Fueron ensayadas 5 pastillas de pulverización de $0,81 \mathrm{~min}^{-1}$, dos de ellas con angulación anteroposterior y diseño diferente sobre el botalón (Deflectora Turbo Teejet TT11002VP (TT), abanico plano XR11002VP (AP), cono hueco TXA8002VK (CC), Abanico angulado simple Defy 3D10002 (DD) y Doble abanico plano aire inducido GAT11002 (DAP)). Dispuestas sobre una máquina de botalón Hatsuta HS400 que circuló dentro de un galpón cerrado. Se utilizaron bancos de madera con un diseño tridimensional para simular diferentes objetivos sobre los que se colocaron, en posiciones verticales y horizontales, tarjetas hidrosensibles Syngenta ${ }^{\circledR}$ y papel de filtro Whatman $40^{\circledR}$, para la recolección del líquido asperjado. Sobre estas tarjetas se evaluaron los parámetros, Densidad de impactos, cobertura, eficiencia, tasa de recuperación, DV0,5, DV0,1, DV0,9, 
amplitud relativa y coeficiente de dispersión. Los resultados arrojaron que la disposición relativa de los objetivos es determinante de la calidad de pulverización obteniendo aumentos de $178-735 \%$ en el parámetro Densidad de impactos entre los objetivos horizontales y los verticales, y valores que aumentaron del $3,8-4,7 \%$ al $61-71 \%$ en Eficiencia de aplicación para la misma relación de objetivos. La angulación de las pastillas no necesariamente posee un efecto mejorador de las aplicaciones en cuanto a Densidad de impactos y Cobertura, pero presenta una mayor uniformidad entre caras anteriores y posteriores verticales del objetivo. La altura del botalón posee un efecto marcado en la calidad de pulverización con el uso de pastillas DD presentando aumentos en la eficiencia de $30 \%$ en objetivos horizontales y alrededor de $200 \%$ en Verticales para una disminución de la altura de botalón de 0,7 m a 0,5 m. Los objetivos verticales presentan mayores dificultades para alcanzar una adecuada calidad de control o pulverización en base a la Densidad de impactos, la cobertura y la eficiencia de aplicación y tasa de recuperación. La eficiencia de aplicación depende de la metodología de evaluación, y presenta diferentes resultados en función de la pastilla evaluada.

Palabras clave: Pastillas abanico, pastillas anguladas, calidad de pulverización, trazador 


\section{ABSTRACT}

Generated by the spread of non-tillage and inclusion of genetically modified crops, the application of phytosanitary products have gained great importance in Argentina and is carried out with boom sprayers in a large number of extensive and intensive systems. The application of phytosanitary products is many-sided and is additionally affected by a combination of factors which are difficult to manage. The application of herbicides on weeds of different heights and their ability to penetrate dense crops imply new challenges. Accordingly, parameters affect spraying, such as nozzle design, working pressure, boom height, nozzle arrangement, and work speed, become essential to make practice more efficient and reduce the chances of product loss. To accomplish the aforementioned objective, tests were performed to evaluate the behavior of different spray nozzle in different sectors and characteristics of the targets and how this affect the deposition of the applied product. Five (5) spray nozzle of $0.8 \mathrm{I}$ min-1 were tested, two of them with alternating forward and backward directions and different design on the boom (Turbo Teejet deflector TT11002VP (TT), XR11002VP flat fan (AP), TXA8002VK hollow cone (CC), Defy 3D10002 flat angled fan (DD) and GAT110-02 induced air double flat fan (DAP)). The nozzles were placed on a Hatsuta HS400 boom machine which was circulated within a closed hangar. Wooden benches with three-dimensional design were used to simulate different targets. Syngenta ${ }^{\circledR}$ hydrosensitive cards and Whatman $40^{\circledR}$ filter paper were placed on the benches in vertical and horizontal positions to collect sprayed liquid. On these cards, the parameters impact density, coverage, efficiency, recovery rate, DV0.5, DV0.1, DV0.9, relative amplitude and dispersion coefficient were evaluated. Increases of 
178-735\% were obtained in the Impact Density parameter between horizontal and vertical targets, and in Application Efficiency for the same relation of targets the values increased from $3.8-4.7 \%$ to $61-71 \%$ thus the relative arrangement of the targets is a determining factor in the spray quality, it was demonstrated by the results. In terms of Impact Density and Coverage, the angulation of the nozzle does not necessarily have an applicationenhancing effect, but they do have greater uniformity between the vertical front and back faces of the target. Boom height has a remarkable effect on spray quality using DD nozzles showing efficiency increases of $30 \%$ on horizontal targets and for a decrease boom height of $0.7 \mathrm{~m}$ to $0.5 \mathrm{~m}$ around $200 \%$ on vertical targets. Wide difficulties to achieve an adequate control or spraying quality based on impact density, coverage and application efficiency and recovery rate were presented by the vertical targets. The efficiency of the application relies on the evaluation methodology, and depending on the evaluated nozzle they present different results.

Keywords: fan nozzles, angled nozzles, spray quality, tracer 


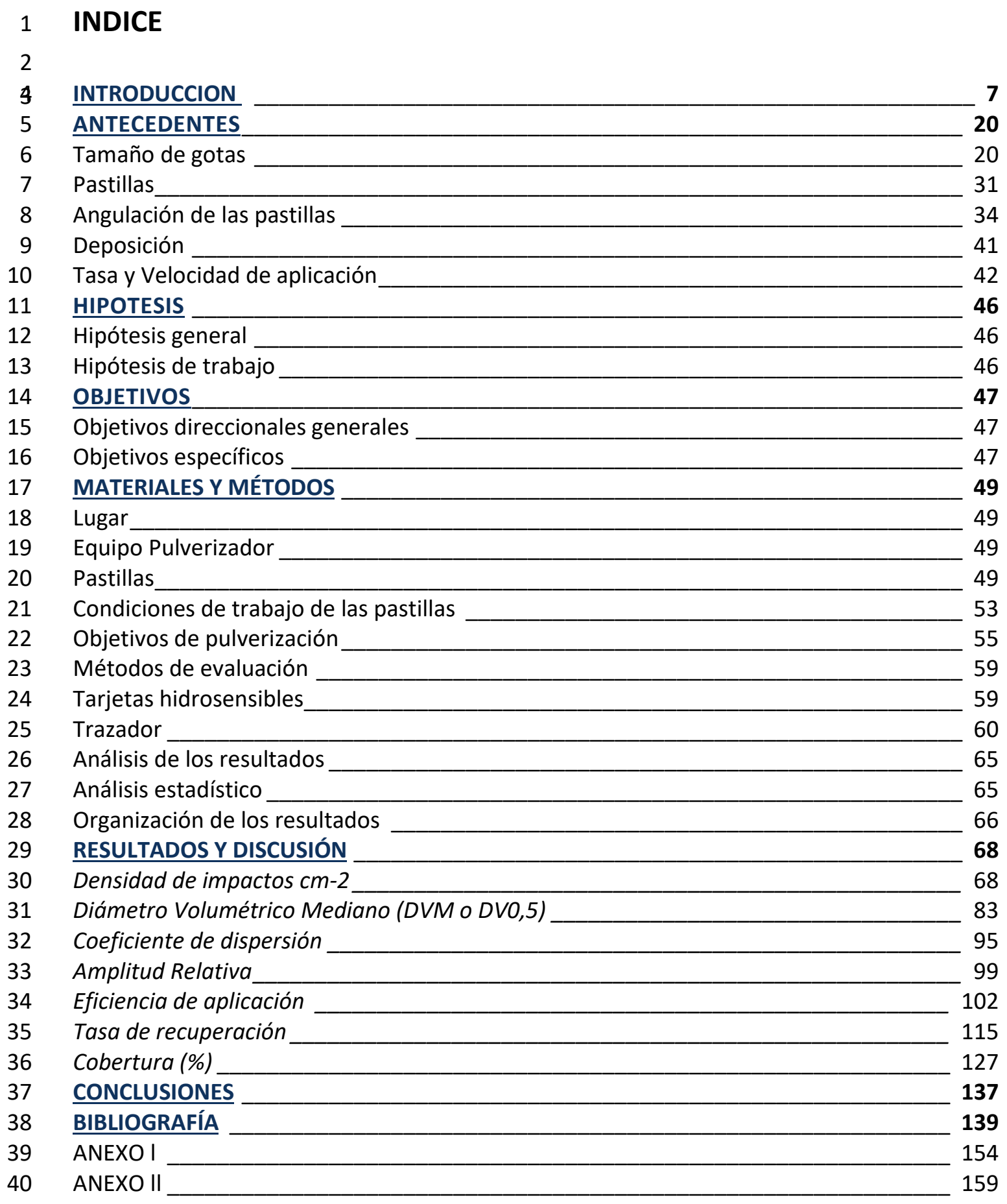




\section{ÍNDICE DE FOTOS}

Foto 1: Perfil de distribución del doble abanico y la pastilla DD.................................................. 53

Foto 2: Disposición de las pastillas DD, intercaladas en el botalón ............................................ 54

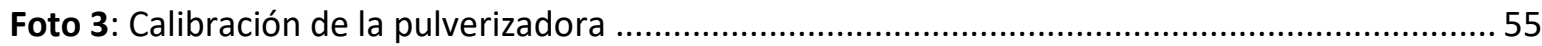

Foto 4: disposición de las tarjetas en los bancos de pulverización y disposición de los bancos sobre

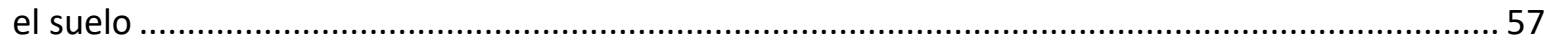

Foto 5: disposición de las tarjetas en los bancos de pulverización................................................. 58

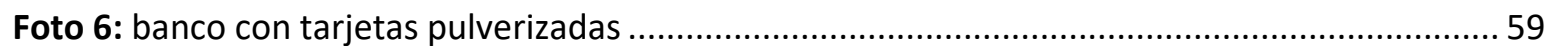

Foto 7: Aplicacion de colorante sobre los diferentes papeles................................................ 61

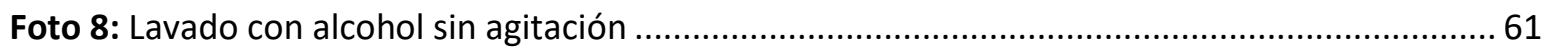

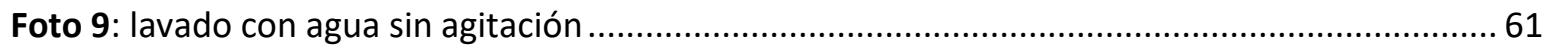

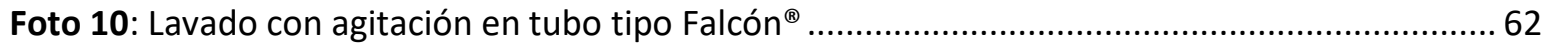

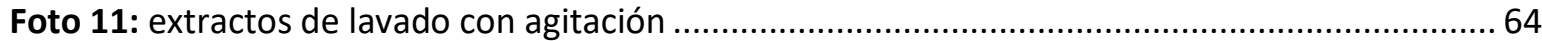

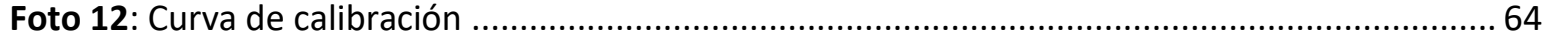

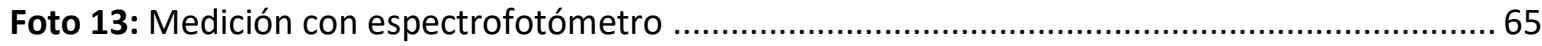




\section{ÍNDICE DE IMAGENES}

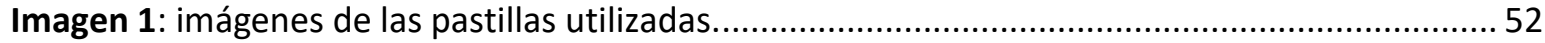

Imagen 2: Esquema de los bancos objetivos con medidas...................................................... 56

Imagen 3: Esquema de distancias entre de los bancos objetivos en el suelo. ............................ 56

Imagen 4: Esquema distribución tarjetas hidrosensibles y papel Whatman sobre los bancos........ 57

Imagen 5: Esquema de cortes de distribución de tarjetas hidrosensibles y papel Whatman sobre

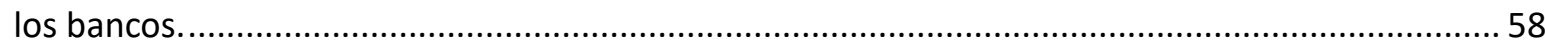

Imagen 6: angulación de las pastillas sobre objetivos verticales ................................................. 78

Imagen 7: Coeficiente de dispersión de agua en papel sensible al agua medido por el $\mathrm{MgO}$ y el

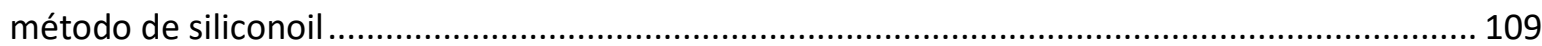

Imagen 8: Valores calculados para el tamaño de gota real $(\mu \mathrm{m})$ a partir del tamaño de la mancha usando las ecuaciones de Coeficiente de dispersión de tres sistemas de imágenes 110 


\section{INDICE DE TABLAS}

Tabla 1: Pastillas características descripción.

Tabla 2: Tamaño de gotas según especificaciones de BCPC y en conformidad con la norma S572.1 de ASABE (2009) a la fecha de impresión de este documento. (Teejet, 2014).

Tabla 3: Densidad de gotas (gotas $\mathrm{cm}^{-2}$ ) obtenidas en función del diámetro de gotas $(\mu \mathrm{m})$ y de la tasa de aplicación $\left(I\right.$ ha $\left.^{-1}\right)$

75

Tabla 4: Valores de Densidad de impactos (Media, Desvió Estándar, Coef. De Variación y Valores mínimos y máximos) para las distintas posiciones verticales. AdV (adelante vertical), AtV (atrás vertical), $\mathrm{D}$ (derecha), I (izquierda).

Tabla 5: Características de la familia de gotas a la salida de la pastilla y evaluadas sobre los objetivos 90

Tabla 6: Factores de corrección de diámetros de gotas desde impronta en papel hidrosensible Syngenta 109 


\section{INDICE DE FIGURAS}

Figura 1: Densidad de impactos $\mathrm{cm}^{2}$ promedio de todas las posiciones del banco objetivo........... 69

Figura 2: Densidad de impactos $\mathrm{cm}^{-2}$. Particionado por posiciones Verticales y Horizontales dentro del banco objetivo. 70

Figura 3: Densidad de impactos $\mathrm{cm}^{-2}$ particionada por posiciones relativas dentro del banco para objetivos horizontales y verticales. 71

Figura 4: Uniformidad de Densidad de impactos por $\mathrm{cm}^{2}$. Particionado por pastillas para todas las posiciones relativas dentro del banco objetivo.. 80

Figura 5: Diámetro Volumétrico Mediano promedio de todas las posiciones del banco objetivo.. 85

Figura 6: Diámetro Volumétrico Mediano particionado por posiciones Verticales y Horizontales dentro del banco objetivo. 86

Figura 7: Diámetro Volumétrico Mediano particionado por todas las posiciones relativas dentro del banco objetivo. 88

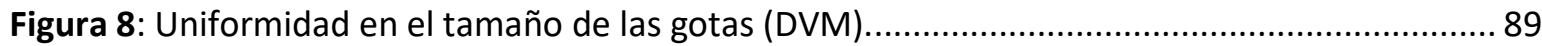

Figuras 9: Coeficiente de dispersión. Promedio de todas las posiciones del banco objetivo. 95

Figura 10: Coeficiente de Dispersión particionado por todas las posiciones relativas dentro del banco objetivo .96

Figura 11: Uniformidad en el Coeficiente de Dispersion. 97

Figura 12: Amplitud Relativa. Promedio de todas las posiciones del banco objetivo. 100

Figura 13: Amplitud Relativa. Particionado por todas las posiciones relativas dentro del banco objetivo.. 101

Figuras 14: Eficiencia (\%). Promedio de todas las posiciones del banco objetivo. 103

Figuras 15: Eficiencia (\%) particionada en posiciones Horizontales y Verticales dentro del banco objetivo. 105

Figuras 16: Eficiencia (\%). Particionado para todas las posiciones horizontales dentro del banco objetivo. 108

Figuras 17: Eficiencia (\%). Particionado para todas las posiciones Verticales dentro del banco objetivo.. 112

Figuras 18: Tasa de Recuperación TR (\%). Promedio de todas las posiciones del banco objetivo..116 
Figura 19: Tasa de Recuperación TR (\%). Particionado por posiciones Verticales y Horizontales dentro del banco objetivo.

Figuras 20: Tasa de Recuperación TR (\%) particionado por todas las posiciones relativas dentro del banco objetivo 119

Figura 21: Uniformidad en la Tasa de Recuperacion TR (\%).

Figura 22: Tasa de Recuperación TR (\%) versus Eficiencia (\%). Particionado por las posiciones relativas dentro del banco objetivo 125

Figura 23: Cobertura (\%). Promedio de todas las posiciones del banco objetivo. 128

Figura 24: Cobertura (\%). Particionado por posiciones Verticales y Horizontales dentro del banco objetivo. 129

Figuras 25: Cobertura (\%) particionada por todas las posiciones relativas dentro del banco objetivo. 130

Figuras 26: Uniformidad en la Cobertura (\%)... 133

Figuras 27: Eficiencia (\%), Cobertura (\%) y Densidad de impactos (Impactos $\mathrm{cm}^{-2}$ ) entre diferentes pasadas con las pastillas DD con diferentes alturas de botalón $70 \mathrm{~cm}$ y $50 \mathrm{~cm}$. 155

Figuras 28: Tarjetas de las diferentes posiciones relativas, en las dos alturas de botalón utilizadas. 


\section{INTRODUCCIÓN}

En los últimos 50 años la actividad humana ha modificado los ecosistemas con mayor rapidez y amplitud que en cualquier otro período equivalente en la historia (FAO, 2007). En los tres últimos decenios, la productividad de los principales cereales, arroz, trigo y maíz ha aumentado como resultado de la incorporación de los progresos científicos en fitogenética junto con tecnologías que han permitido aprovechar al máximo el rendimiento potencial de los cultivos. Este proceso fue conocido a nivel mundial como revolución verde. En África la producción de alimentos se incrementó en 140 \%, en América Latina 200 \% y en Asia $280 \%$. Un caso muy especial es el de China que solo durante dos décadas (1980 y 1990) quintuplicó su producción agrícola. Por su parte, si bien en los países industrializados la producción comenzó a crecer a partir de una base superior, en EEUU se duplicó en los últimos 40 años y Europa occidental creció el 68 \% (Pretty, 2008).

Este proceso tecnológico fue acompañado por un aumento en el uso de productos

fitosanitarios y fertilizantes que completaban el paquete filogenético, siendo esta introducción de los agroquímicos para el control de las adversidades biológicas, una de las alternativas tecnológicas de más rápida adopción en la historia de la agricultura mundial (March et al., 2010). Consecuentemente a estos progresos científicos, los sectores comerciales que suministran insumos a la agricultura se han visto favorecidos por un notable crecimiento (FAO, 1996). 
El volumen de plaguicidas formulados en el mundo en 2005 alcanzó casi 6.000 .000 toneladas (t) (Carvalho, 2006) siendo las perspectivas de continuar en aumento. Tilman et al., (2002) estimaron que, de no ocurrir cambios en el manejo de plagas, en 2020 se alcanzarán las 6.500.000 t de ingredientes activo, por otro lado FAO (2020) menciona que durante el año 2019 se alcanzaron 4.120.000 t. Por su parte, las ventas mundiales se incrementaron constantemente desde los 40 billones de dólares en el año 2007 hasta 46,7 billones de dólares en el 2009 (BBC Research, 2010). La Agencia de Protección Ambiental de USA (EPA), estimó que la venta mundial en 2017 es de 68.500.000.000 USD (Dólar americano) con una tasa de aumento del 5,5 \% en los próximos cinco años, mientras que según Saccone (2018) el mercado mundial de fitosanitarios creció un 93 \% en los últimos 10 años. Los principales países con mayor crecimiento en el uso de los plaguicidas serían China, India, Japón, Brasil y Argentina.

A nivel nacional, la producción de los principales granos, soja, maíz, trigo y girasol, creció hasta mediados de la década del '90 comenzando entonces un despegue que convirtió a la producción agrícola en una actividad con creciente peso sobre la economía asociado al paquete tecnológico de la siembra directa, cultivos transgénicos y el glifosato, el cual marcó otro hito en esta historia. En la Argentina de los últimos 25 años, la producción de soja acaparó casi el 62 \% del total de los productos aplicados.

Un informe elaborado por el Instituto Nacional de Estadística y Censos (INDEC, 2019) señaló que durante el año 2018 las exportaciones aumentaron un 3,6 \% con respecto al año anterior y alcanzaron un valor de USD 61.559.407 (dólares americanos), de las cuales USD 22.885.417 ingresados al país corresponden a ventas del complejo oleaginoso y 
cerealero; la producción agropecuaria representa aproximadamente el 32 \% del PBI argentino, el $60 \%$ de las exportaciones y el $90 \%$ de los alimentos que se consumen en el país (Pórfido, 2014). Dicho crecimiento se debe tanto al incremento de los rendimientos por hectárea como a la expansión de la frontera agrícola, la cual significó el reemplazo de los cultivos más tradicionales (algodón en el Chaco, poroto en el noroeste) y la deforestación del bosque original, hasta ese momento utilizado para ganadería extensiva y la extracción de madera. En el norte del país la expansión de la soja ocupó en pocos años más de 1,6 millones de hectáreas y la deforestación entre 1995 y 2005 llegó a no menos de un millón de hectáreas (Adámoli \& Solbrig, 2008; Grau et al., 2008). Cabe destacar, que uno de los factores que más ha dinamizado la expansión de la soja en Argentina es la rápida adopción por parte de la gran mayoría de los productores de las semillas de cultivos genéticamente modificados (OGM) y el uso del glifosato como herbicida (Paul \& Steinbrecher, 2003; Branford, 2004; Otero, 2008). Argentina es el tercer país en superficie sembrada con OGM (ISAAA, 2012), luego de EE.UU. y Brasil. Por otro lado, el aumento de la producción agrícola y especialmente la producción en monocultivos ha creado un aumento extraordinario de insectos-plagas y enfermedades en estos cultivos (Brechelt, 2004).

El consumo de fitosanitarios y fertilizantes en la Argentina se incrementó 5,6 \% en 2017, en relación con el año anterior, alcanzando un total estimado de 3,8 millones de toneladas según IES Consultores (CASAFE, 2018); dentro del mercado de agroquímicos los herbicidas lideran el volumen de ventas con el $87 \%$, seguido por los insecticidas con $6 \%$, fungicidas con el $3 \%$ y cura-semillas $1 \%$ (CASAFE, 2015), y poseen los primeros una gran 
incidencia en los costos de producción. Es importante mencionar la destacada participación del glifosato dentro del segmento de herbicidas, representando el 62 \% de la cantidad comercializada (CASAFE, 2015). Esto se debe a que el glifosato representa el $76 \%$ del total de productos químicos utilizados para el cultivo de soja. Este uso no solo aumenta en cantidad sino también en concentración, puesto que durante la última década el principio activo que se usa en su elaboración pasó de una concentración del 48 \% a una de entre 66 \% y $74 \%$. En nuestro país, en el año 1991 se utilizaban cerca de 100 millones de litros de formulado, mientras que en el año 2012 se aplicaron cerca de 317 millones (Muzlera, 2018).

Los principales cultivos antes mencionados, más los controles de malezas entre cultivos sucesivos, conocidos por barbechos químicos, concentraron en 2009 el $81 \%$ de la facturación de plaguicidas, mientras que el 19 \% restante se utilizó para maní, frutales de pepita y carozo, cítricos, pasturas, hortalizas, papa, algodón, tabaco, caña de azúcar, arroz, vid, poroto, granos almacenados y otros (Bedmar, 2011). El mercado de agroquímicos generó una actividad comercial de USD 2.500.000.000 (dólares americanos) en la campaña 2016/2017, lo que significó un crecimiento de $25 \%$ en comparación con la anterior; para la campaña 2017/2018, las estimaciones proyectaron un incremento de 18 \% de este mercado, con lo cual rondaría los USD 3.000.000.000 (Montesanto, 2018).

A pesar de los beneficios obtenidos por el uso de los plaguicidas, estos productos químicos no dejan de plantear problemas. La aplicación de estos insumos no es neutral en sus consecuencias para el medio ambiente, tanto en las posibilidades de contaminación, la reducción de la biodiversidad, como en sus consecuencias sanitarias por la exposición a 
agentes químicos (Simoniello et al., 2010; Carriquiriborde, 2010; Bernardos \& Zaccagnini, 2011; Guzmán-Plazola et al., 2016; Ibarra et al., 2019; Calle Salvador, 2019; Cajamarca Carrazco et al., 2020).

La producción agropecuaria en su conjunto ha producido profundos efectos en el medio ambiente durante el último siglo. La agricultura moderna intensiva, como consecuencia de los altos insumos de plaguicidas y fertilizantes sintéticos y de la especialización del monocultivo, tuvo un impacto nocivo sobre la diversidad de los recursos genéticos, el agua, el suelo y el aire (FAO, 2015).

Como ya se mencionó, la producción agrícola argentina, impulsada por el aumento de la demanda mundial de materias primas agrícolas, en los últimos años, se ha intensificado y expandido hacia áreas no cultivadas, lo que produjo un aumento en el uso de los agroquímicos (Sarandón, 2002). Si bien este crecimiento de la producción agropecuaria representa un éxito productivo y económico, se ha profundizado la preocupación por los impactos de esta actividad en el medio ambiente (Flores \& Sarandón, 2002; Viglizzo et al., 2006; Cabrini et al., 2013). En la actualidad el riesgo de contaminación por el uso inadecuado de agroquímicos se destaca como uno de los temas más sensibles, entre los problemas ambientales asociados a la producción agropecuaria pampeana (Cabrini et al., 2014).

Las normativas vigentes a nivel de la República Argentina varían actualmente a nivel provincial y municipal. Por lo general, no especifican mayores restricciones en relación a la velocidad del viento para las aplicaciones alejadas de los centros urbanos, sino que las mismas son limitadas a que no se realicen aplicaciones en condiciones ventosas. En 
algunas ocasiones, se indica que deben respetarse las condiciones indicadas por el fabricante del producto agroquímico. Sin embargo, en las etiquetas de los productos en general no hay mayores precisiones sobre aquellos aspectos relacionados a las condiciones atmosféricas al momento de aplicación, como tampoco tienen en cuenta parámetros como las tasas de aplicación y el tamaño de gota.

La pulverización es la forma más difundida de aplicación de fitoterápicos. El concepto pulverizar hace alusión a dosificar y distribuir un líquido en forma de gotas, las cuales pueden obtenerse mediante diversos sistemas, el más empleado en las aplicaciones agrícolas extensivas, utiliza la energía hidráulica donde el líquido sometido a presión es obligado a atravesar por un pequeño orificio calibrado hacia el exterior; la vena líquida perturbada por la expansión, termina por romperse en gotas (Onorato \& Tesouro, 2006).

Según Leiva (1996), los procesos involucrados al realizar una pulverización son: a) el proceso de formación de gotas, b) la deriva de gotas hacia otros sitios, c) la capacidad de esas gotas para depositarse sobre el blanco alcanzado y d) la cobertura, medida como número de impactos por centímetro cuadrado (impacto $\mathrm{cm}^{-2}$ ), que actúa como un parámetro conjunto entre la uniformidad de distribución del producto y la dosis de principio activo que se deposita sobre el blanco. Se consideran factores climáticos que inciden como: e) la temperatura, f) la humedad relativa, h) la velocidad del viento.

Como ya ha sido mencionado, la formación de las gotas se produce por diferencia de presión entre el interior del sistema de pulverización y el ambiente en el que se libera la vena líquida. Cuanto mayor sea la diferencia de presión entre el líquido y el medio donde 
se produce la pulverización, se obtendrá más cantidad de gotas y de menor tamaño. Las gotas producidas por energía hidráulica poseen diferentes tamaños y su caracterización se conoce como espectro de distribución (Onorato \& Tesouro, 2006). El estudio de las características de dichas gotas resulta imprescindible para determinar la calidad y eficiencia de aplicación de los productos fitosanitarios, ya que ellas son el medio que permiten transportar el principio activo hasta el objetivo, pero su estudio es complejo dado que existe variabilidad de tamaños entre ellas.

La deriva de la pulverización se puede considerar como la parte de la aplicación de un pesticida que se desvía del área objetivo por la acción del viento. El aerosol se puede perder en el momento de la aplicación, ya sea como gotas o como vapores. Para el equipo de aplicación terrestre en particular, es probable que la pérdida de vapor sea más importante en el período posterior a la aplicación, cuando tanto el portador (comúnmente agua) como los componentes de la formulación se evaporan de las superficies dentro del área objetivo. El control de la deriva es importante debido a la posible exposición a plaguicidas de organismos y estructuras fuera de la zona de tratamiento y donde existe la posibilidad de que dichos organismos sean sensibles a cantidades muy pequeñas de los materiales plaguicidas (Matthews et al., 2014). La deriva puede ser clasificada de diferentes formas, Matthews et al., (2014) la divide en dos, por un lado, la deriva como resultado de las gotas más grandes que se desviaron de una nube de pulverización durante la aplicación, y caen fuera del flujo de aire generado por el viento depositándose sobre superficies horizontales no muy alejadas la cual se denomina comúnmente deriva de sedimentación. Por otro lado, menciona la deriva como gotitas transportadas por el 
aire que tienden a comprender la fracción de gota más pequeña que se extrae de la nube de aspersión y que pueden ser transportadas a grandes distancias y se denomina deriva transportada por el aire. Esta última presenta riesgos particulares para cultivos aledaños. Según algunos autores (Etiennot, 1990; Bulacio et al., 2005; Ramos et al., 2010) pueden distinguirse dos tipos de deriva, la endoderiva, que consiste en el desplazamiento del asperjado fuera del objetivo, pero en áreas próximas a él y también al suelo, llegando directamente o escurriendo desde el follaje, y la exoderiva que es la que determina que el asperjado es transportado principalmente por viento a distancias considerables del objetivo a tratar. Este tipo de pérdidas externas es uno de los principales factores responsables del daño causado a otros cultivos sensibles y de la contaminación ambiental. Cuando solo se usa el término deriva, generalmente se refiere a la exoderiva.

La deposición de las gotas sobre el objetivo es un parámetro muy importante a fin de conseguir eficiencia biológica del tratamiento y disminuir la contaminación de suelo y agua. Stoletniy Bergalli (2013), menciona que tanto la deposición como la uniformidad de la aplicación dependen del tipo y forma de la planta, el tamaño de gota, el volumen de aplicación y la presencia o ausencia de adyuvante. Matthews et al., (2014) por su lado, agrega a estos parámetros las condiciones ambientales.

Del parámetro anterior se deriva la cobertura del objetivo con el producto sanitario, este parámetro debe ser suficiente y homogéneo. Matthews et al., (2014) menciona que las variaciones en la distribución tienen menos efecto en el control de plagas cuando se aplica un pesticida sistémico pero la distribución de pesticidas de contacto es mucho más importante. El parámetro cobertura suele ser evaluado como densidad de impactos por 
unidad de superficie (impactos $\mathrm{cm}^{-2}$ ) (Weber, 1982), también se lo puede encontrar expresado como \% de la superficie cubierta (Cid et al., 2010).

Dentro de los parámetros ambientales que intervienen en el proceso de pulverización, la temperatura del aire en el que se pulverizan los pesticidas y la temperatura de la superficie sobre la que se aplican, son importantes. La temperatura del aire y de la superficie influye directamente en la deposición de plaguicidas y en la velocidad a la que los plaguicidas se volatilizan del suelo y la superficie de las plantas. Por otro lado el aumento de temperatura generalmente disminuye la humedad relativa del aire y, por lo tanto, aumenta la tasa de evaporación del componente acuoso de las gotas de pesticida. La diferencia entre la temperatura de la superficie y la del aire inmediatamente sobre la superficie también es muy importante. Ya que dicta la estabilidad de la atmósfera y, a su vez, afecta el potencial de que los pesticidas en el aire se eleven y se diluyan o permanezcan concentrados cerca de la superficie (Tepper, 2014).

La humedad relativa $(\mathrm{RH})$ es la relación entre la cantidad real de vapor de agua en el aire y la cantidad que puede contener cuando está saturado. La capacidad del aire para retener vapor de agua aumenta a medida que aumenta la temperatura del aire. $\mathrm{A} 30^{\circ} \mathrm{C}$, la capacidad es más del triple que a $10^{\circ} \mathrm{C}$; en consecuencia, mientras que la cantidad de vapor de agua en el aire puede ser estática, la humedad relativa disminuye a medida que aumenta la temperatura. Esto incidirá directamente en la velocidad con que la gota de caldo sede su componente a la atmósfera en forma de vapor de agua (Tepper, 2014). Si bien la rapidez con que se evapora una gota depende del componente acuoso, si estas reducen drásticamente su tamaño, se verán afectadas por el parámetro viento. 
El viento es simplemente aire en movimiento tridimensional. Muchos factores conducen a la deriva de la pulverización, pero en última instancia es causada por vientos horizontales y verticales que promueven la transferencia de pesticidas a la atmósfera. Para la mayoría de los propósitos, el viento horizontal puede describirse adecuadamente como un promedio de la velocidad y dirección del aire que fluye en paralelo a la superficie de la tierra. Los pronósticos y observaciones de la Oficina de Meteorología se refieren a la velocidad y dirección del viento horizontal promediadas durante 10 minutos a 10 metros sobre el suelo. Al considerar la aplicación de pesticidas, los vientos verticales más importantes son los asociados con los gradientes térmicos (Tepper, 2014).

Se debe tener en cuenta que dentro de los factores que inciden sobre la pérdida de producto podemos agrupar a aquellos que corresponden a las características de la aspersión, las técnicas de aplicación, a las condiciones de tiempo atmosférico y a los equipos y accesorios específicos (Leiva, 1995). Arvidsson et al., (2011), coinciden en parte con este agrupamiento, pero incorporan también a la habilidad y atención del operador y a las características del ambiente, además de las condiciones meteorológicas.

La combinación de gotas pequeñas, viento, baja humedad relativa y temperatura ambiente elevada, puede provocar graves pérdidas de producto. Esto se relaciona a los efectos negativos de los procesos de desplazamiento del producto pulverizado por viento fuera del objetivo (Tepper, 2014).

Por otro lado, las aplicaciones de alto volumen tienen como objetivo cubrir toda el área de aplicación. Al asperjar toda el área de un cultivo, muchas gotas pueden caer entre el follaje y en especial en el espacio que queda entre los surcos. Las que impactan sobre 
las hojas, pueden unirse a tal grado que no permanecen retenidas y el líquido excedente gotea a las hojas inferiores y de allí al suelo. Bajo estas condiciones puede perderse en el suelo hasta un tercio de la sustancia aplicada a los cultivos, especialmente en aquellos de follaje denso en donde se busca colocar el producto en las hojas basales incrementando los volúmenes de aplicación. La fracción de una aplicación que puede derivar alcanza valores de hasta el $90 \%$ del producto arrojado sobre un cultivo (Hang, 2010)

La selección del volumen de líquido en que se debe aplicar un pesticida, en alguna medida, queda a criterio del usuario, ya que los márgenes de aplicación de los productos suelen ser amplios, a veces en el orden del $20 \%$ al $70 \%$ de incremento entre el valor mínimo recomendado y el valor máximo. En la práctica, se usan caudales similares para una amplia variedad de plagas y los mismos son usualmente determinados por aspectos vinculados a la eficiencia operativa de la máquina pulverizadora. Estas decisiones no controladas ni reguladas tienen una fuerte incidencia sobre la pérdida de producto.

Todas estas características del proceso de pulverización conllevan la necesidad de adentrarse en la construcción de sistemas de buenas prácticas de manejo. Para esto es necesario ahondar en el estudio de las prácticas de pulverización, teniendo siempre la mirada en disminuir los riesgos de contaminación y pérdidas de producto, manteniendo la eficiencia de aplicación, lo que permitirá a su vez disminuir costos y volúmenes de producto activo utilizado.

La uniformidad en la distribución de los caldos aplicados, en las aplicaciones de productos fitosanitarios, se halla dada por las condiciones de preparación y operación del equipo, como pueden ser la selección de la tecnología de aplicación, incluyendo en la 
misma la selección de distintas pastillas, el espaciamiento entre ellas, la altura del botalón, el ángulo de apertura de las pastillas, la presión de trabajo (Perecin et al., 1994) y la velocidad de desplazamiento del conjunto (Wolf et al., 2000; Liu et al., 2006; Maski \& Durairaj, 2010; Cavalieri et al., 2015).

La penetración en el dosel de cultivo es importante para la eficacia de los pesticidas, especialmente para el control de plagas de invertebrados y hongos. Los aerosoles mal distribuidos en el canopeo reducen la efectividad de una aplicación por aspersión (Uk \& Courshee, 1982; Wolf et al., 2000; Domper et al., 2015; Mur et al., 2017; Mur et al., 2018a; Mur et al., 2018b), lo que puede provocar que se deba volver a aplicar para lograr un control adecuado de las plagas. Por ejemplo, la eficacia de los herbicidas postemergentes está directamente relacionada con la capacidad de penetrar a través del canopeo de los cultivos (Knoche, 1994).

Downer et al. (1997) afirman que el objetivo de muchas investigaciones es reducir la cantidad de producto aplicado con dosis y volúmenes reducidos, sin que la uniformidad en la distribución sea afectada; de lo contrario, la dosis que llegue al blanco puede ser insuficiente para causar el efecto biológico deseable, o la dosis puede ser excesiva, determinando el desperdicio de producto. En concordancia con ello, Boller (2011) afirma que se busca obtener la máxima eficiencia del producto fitosanitario con el menor volumen de caldo posible, lo que es una variable de gran importancia en el momento de seleccionar las pastillas de pulverización.

Para disminuir el volumen de caldo y al mismo tiempo proporcionar la cobertura deseada en el objetivo, se puede reducir el tamaño de gota de una pulverización 
(Srivastava et al., 2006). Esto se corrobora ya que para un mismo volumen de caldo, cada vez que se disminuye el diámetro de gota en un $50 \%$, el número de ellas se multiplica por 8 y el área cubierta sobre el objetivo se duplica. Pese a esto gotas muy finas, poseen dificultades para depositar una cantidad adecuada de producto en el objetivo por ser más vulnerables a la pérdida por deriva y la evaporación y en consecuencia, pueden proporcionar un menor control (Durão \& Boller, 2017).

Por lo tanto, el volumen de caldo influye directamente en el nivel de cobertura del objetivo biológico, pero su aumento resulta en un mayor gasto de tiempo para el reabastecimiento de las máquinas aplicadoras, entre otros aspectos (Moltoni et al., 2008; Valenzuela, 2016). En este sentido, se busca utilizar siempre los menores volúmenes de caldo posibles, pero cabe destacar que hay diferencias de eficiencia según el tipo de producto fitosanitario. De modo general, los herbicidas sistémicos presentan mejores resultados cuando el volumen de caldo es reducido, pero los fungicidas tienden a ser más exigentes con respecto a la cobertura del objetivo, necesitando por lo tanto un mayor volumen de caldo (Iriarte Barbosa et al., 2013).

Los controles con fitosanitarios en Argentina poseen esta impronta de reducción de la tasa de aplicación a volúmenes bajos (menores a $50 \mathrm{I}$ ha ${ }^{-1}$ ); para conseguir esto se procede habitualmente a trabajar a altas velocidades de avance, entre 5,5 $\mathrm{m} \mathrm{seg}^{-1}$ y 6,9 m $\operatorname{seg}^{-1}\left(20 \mathrm{~km} \mathrm{~h}^{-1}\right.$ a $\left.25 \mathrm{~km} \mathrm{~h}^{-1}\right)$, con presiones de trabajo medias a altas y gotas finas a medias. Esta configuración de los parámetros de aplicación, sumado al trabajo de barbechos en su gran mayoría sobre superficies bajo el sistema de producción de siembra directa, conlleva a la necesidad de trabajar con una altura de botalón muchas veces muy 
elevada. Por otro lado, debe de tenerse en cuenta que el aumento de especies resistentes al herbicida glifosato ha generado el escape de muchas malezas a las aplicaciones realizadas habitualmente, generando en muchos casos la necesidad de realizar controles sobre plantas de una gran diversidad de tamaños y apuntando a mejorar los controles tempranos (Barros \& Freixial, 2010; Vigna et al., 2012; Metzler et al., 2013).

Estas características del sistema de trabajo dificultan la calidad de las pulverizaciones y aumenta sustancialmente las posibilidades de pérdida de producto por deriva.

\section{$\underline{\text { ANTECEDENTES }}$}

\section{$\underline{\text { Tamaño de gotas }}$}

Una de las razones principales por la cual la deriva es un problema, es la contaminación que produce a zonas cercanas y alejadas al sitio de aplicación. Dentro de los sistemas de pulverización hidráulica, el tamaño de las gotas es uno de los factores más influyentes relacionados con la deriva (Bird et al., 1996; Ozkan et al., 1997; Carlsen et al., 2006; Nuyttens et al., 2007a). Las gotas producidas por las pastillas de la pulverizadora según Dombrowski \& Johns (1963), salen de las mismas a velocidades en el rango de 15 m $\mathrm{s}^{-1}$ a $25 \mathrm{~m} \mathrm{~s}^{-1}$. Esta velocidad a la que cae una gota cuando se libera en el aire, alcanzará un punto de equilibro que se conoce como velocidad de sedimentación y está fuertemente relacionado con su diámetro (Elliott \& Wilson, 1983; Bache \& Johnstone, 1992;). Sidahmed et al. (1999) concluyeron que la velocidad de las gotas en su formación depende del diámetro de las mismas, y que estas velocidades son bastante constantes para los 
diferentes tamaños de gotas mayores a $70 \mu \mathrm{m}$ aproximadamente. Para estas gotitas, se midieron velocidades en el rango de $16 \mathrm{~m} \mathrm{~s}^{-1}$ a $18 \mathrm{~m} \mathrm{~s}^{-1}$ dependiendo del tipo de boquilla concordando con las velocidades citadas por Dombrowski \& Johns (1963). Por debajo de los $70 \mu \mathrm{m}$, las velocidades de las gotas disminuyeron constantemente con la reducción en el tamaño de las mismas, hasta velocidades de $10 \mathrm{~m} \mathrm{~s}^{-1}$ a $12 \mathrm{~m} \mathrm{~s}^{-1}$ para las más pequeñas. Por otro lado, Nuyttens et al. (2009) mencionan que, realizando mediciones a una distancia de 0,50 m de la boquilla, se puede concluir que las gotas se desaceleran como resultado del la resistencia del roce contra el aire, y que los tamaños de gotas más pequeños se ralentizan más rápidamente en comparación con las gotas más grandes, debido al efecto de la resistencia del aire. Esta problemática es abordada por muchos autores desde varios enfoques aproximandose de forma diferente al estudio del problema. En este sentido Goering et al. (1972) describen que las fuerzas externas que actúan sobre una gota en movimiento incluyen las fuerzas de Van der Waal, la termoforesis, la difusioforesis, la fotoforesis, el efecto Basset, la gravedad, la flotabilidad, el arrastre y las fuerzas debidas a los gradientes eléctricos y de presión externos, éstas últimas solo se observan si son generadas artificialmente, lo cual no es común en sistemas de pulverización tradicional sin aire asistido. Para pulverizaciones agrícolas tradicionales solo revisten importancia las fuerzas de gravedad y flotabilidad o empuje, y se analizan en conjunto mediante la siguiente ecuación:

$$
W=g\left(\rho_{l}-\rho_{a}\right) \frac{\pi D_{p}^{3}}{6} \quad \text { Ec: } 1
$$

Dónde:

$\mathrm{W}=$ Peso Neto $(\mathrm{N})$ $\mathrm{g}=$ constante gravitacional $\left(9,81 \mathrm{~m} \mathrm{~s}^{-2}\right)$ 
$\rho_{a}=$ densidad del aire $\left(\mathrm{kg} \mathrm{m}^{-3}\right)$
$\rho_{\mathrm{l}}=$ densidad de la gota $\left(\mathrm{kg} \mathrm{m}^{-3}\right)$
$D_{\mathrm{p}}=$ Diámetro de la partícula $\left(\mathrm{m}^{2}\right)$

Como $\mathrm{W}$ es el peso neto de la gota en el aire; podemos decir que, $\mathrm{W}$ es la fuerza de gravedad menos la fuerza de flotabilidad. King et al. (1953), por otro lado presentó la ecuación clásica para la fuerza de arrastre sobre una partícula de la siguiente manera:

$$
D_{f}=\frac{C_{d} \rho_{a} A V_{r}^{2}}{2} \quad \text { Ec: } 2
$$

\section{Dónde:}

$D_{\mathrm{f}}=$ fuerza de arrastre $(\mathrm{N})$

$\mathrm{C}_{d}=$ coeficiente de arrastre adimensional

$\mathrm{V}_{\mathrm{r}}=$ velocidad de la partícula relativa al medio (aire) $\left(\mathrm{m} \mathrm{s}^{-1}\right)$

$\rho_{\mathrm{a}}=$ densidad del aire $\left(\mathrm{kg} \mathrm{m}^{-3}\right)$

$\mathrm{A}=$ área proyectada de la partícula $\left\{\left(\pi D p^{\wedge} 2\right) / 4\right\}\left(\mathrm{m}^{2}\right)$

El coeficiente de arrastre varía con el número de Reynolds y de acuerdo con Goering et al. (1972), el efecto de la aceleración sobre el coeficiente de resistencia debe ser considerado cuidadosamente.

Por lo tanto, una gota que se libera en el aire estacionario se acelera hasta que el arrastre aerodinámico y las fuerzas gravitacionales están en equilibrio, en cuya etapa la gota caerá a una velocidad uniforme, velocidad de sedimentación (Vs'). Hughes \& Gilliland (1952) utilizaron una solución matemática para el caso, y una cámara de alto número de fotogramas como guía para evaluar los efectos de la aceleración. Sus datos muestran que el efecto de la aceleración es insignificante si la densidad del líquido en la gota es mucho mayor que la densidad del medio en el que cae la gota. Las gotas en la pulverización no comienzan su movimiento desde cero sino que son sometidas a una presión para su formación. Así, Farooq et al. (2001) mencionan que el aumento de la presión del líquido de pulverización, con la mayoría de los diseños de boquillas, no solo da como resultado 
una pulverización más fina, sino que también aumenta la velocidad de las gotas que abandonan la región de formación de la pulverización. El tiempo en el que una gota se ajusta a la velocidad de sedimentación ( $\left.\mathrm{Vs}^{\prime}\right)$ se denomina tiempo de relajación. Este tiempo de relajación, es el tiempo en el que una partícula se ajusta a una fuerza aplicada. Durante el tiempo de relajación, la partícula recorre una distancia conocida como distancia de frenado o de parada (Ds), una distancia que se halla asociada con la inercia de la partícula. Los efectos de la inercia se vuelven significativos en situaciones en las que el movimiento de las partículas no es uniforme, por ejemplo, la desaceleración después de la expulsión de una boquilla de pulverización. La distancia de parada, Ds (m), de las gotas liberadas en aire estacionario se puede calcular utilizando la siguiente ecuación de Bache \& Johnstone (1992):

$$
D_{S}=\frac{v_{o} d^{2} \rho_{l}}{18 v_{a} \rho_{a}} \quad \text { Ec: } 3
$$

Dónde:

Ds= Distancia de parada $(\mathrm{m})$

$\mathrm{v}_{0}=$ Velocidad inicial de la gota a la salida de la pastilla $\left(\mathrm{m} \mathrm{s}^{-1}\right)$

$\mathrm{d}=$ Diámetro de la gota $(\mathrm{m})$

$\rho_{\mathrm{I}}=$ densidad de la gota $\left(\mathrm{kg} \mathrm{m}^{-3}\right)$

$\rho_{\mathrm{a}}=$ densidad del aire $\left(\mathrm{kg} \mathrm{m}^{-3}\right)$

$v_{a}=$ viscosidad cinemática del aire $\left(\mathrm{m}^{2} \mathrm{~s}^{-1}\right)$

Nuyttens et al. (2009) calculan, suponiendo una densidad del aire $\left(\rho_{\mathrm{a}}\right)$ de $1,24 \mathrm{~kg} \mathrm{~m}^{-3}$, una viscosidad cinemática del aire $\left(v_{a}\right)$ de $1,5 \times 10^{-5} \mathrm{~m}^{2} \mathrm{~s}^{-1}$ y una velocidad de gota a la salida de la boquilla $\left(V_{0}\right)$ de $17 \mathrm{~m} \mathrm{~s}^{-1}$, una distancia de parada (Ds) de 0,50 m para gotas de aproximadamente $100 \mu \mathrm{m}$.

Por otro lado, la velocidad de sedimentación (Vs') para gotas menores a $50 \mu \mathrm{m}$ según Bache \& Johnstone (1992) puede ser expresada como: 
$v_{s}^{\prime}=\frac{g d^{2}\left(\rho_{l}-\rho_{a}\right)}{18 v_{a} \rho_{a}} \quad$ Ec: 4

Dónde:

Vs`= velocidad de sedimentación $\left(\mathrm{m} \mathrm{s}^{-1}\right)$

$\mathrm{g}=$ constante gravitacional $\left(9,81 \mathrm{~m} \mathrm{~s}^{-2}\right)$

$\mathrm{d}=$ Diámetro de la gota $(\mathrm{m})$

$\rho_{\mathrm{I}}=$ densidad de la gota $\left(\mathrm{kg} \mathrm{m}^{-3}\right)$

$\rho_{\mathrm{a}}=$ densidad del aire $\left(\mathrm{kg} \mathrm{m}^{-3}\right)$

$v_{a}=$ viscosidad cinemática del aire $\left(\mathrm{m}^{2} \mathrm{~s}^{-1}\right)$

Para gotas de hasta $100 \mu \mathrm{m}$, se puede hacer una estimación aproximada de la velocidad de sedimentación con la siguiente ecuación simplificada (Elliott \& Wilson, 1983):

$$
v_{s}^{\prime}=\left(3 \times 10^{7}\right) d^{2} \quad \text { Ec: } 5
$$

$V s^{`}=$ velocidad de sedimentación $\left(\mathrm{m} \mathrm{s}^{-1}\right)$

$\mathrm{d}=$ Diámetro de la gota $(\mathrm{m})$

$3 \times 10^{7}=$ Factor numérico resultado de la simplificación de la Ec: $4\left(\mathrm{~m}^{-1} \mathrm{~s}^{-1}\right)$

Usando estas ecuaciones Nuyttens et al. (2009) calcularon velocidades de sedimentación teóricas de 0,3 y 0,075 $\mathrm{m} \mathrm{s}^{-1}$ para tamaños de gota de $100 \mu \mathrm{m}$ y $50 \mu \mathrm{m}$ respectivamente. En su trabajo Nuyttens et al. (2009) concluyen que los mecanismos de movimiento de las gotas debajo de una boquilla son complejos. En general, los tamaños de gota más grandes se corresponden con velocidades de gota más altas, y las gotas pequeñas con velocidades de gota más bajas. Para los tamaños de gota más grandes (> $400 \mu \mathrm{m}$ ), las velocidades de gota a 0,50 m de la salida de la boquilla fueron relativamente constantes para la misma combinación de presión y boquilla, y variaron de aproximadamente $4,5 \mathrm{~m} \mathrm{~s}^{-1}$ a $8,5 \mathrm{~m} \mathrm{~s}^{-1}$ dependiendo del tipo y tamaño de la boquilla. Por debajo de los $400 \mu \mathrm{m}$, la velocidad de las gotas se redujo en relación con la disminución del tamaño de las gotas. También menciona que para tamaños de gotas pequeños, las 
velocidades fueron diferentes para un mismo rango de tamaño de gota, y variaron de 0,5 $\mathrm{m} \mathrm{s}^{-1}$ a $2 \mathrm{~m} \mathrm{~s}^{-1}$ dependiendo del tamaño y tipo de boquilla.

De Cock et al. (2017) en su estudio de la dinámica del transporte de gotas utilizando modelos de deposición y retención, han demostrado que el tamaño de una gota afecta su trayectoria. Cuanto más fina es la gota, más tiempo pasa en el aire, lo que la hace más sensible a la evaporación y la deriva. A fin de mejorar estas condiciones menciona que el tiempo medio de vuelo de una gota, se puede acortar disminuyendo la altura de liberación o aumentando la velocidad de salida de la misma. Esta última opción posee efectos moderados sobre las gotas finas. Sin embargo, para las gotas gruesas, el aumento de la velocidad de liberación aumenta la velocidad de la gota en el dosel y, por lo tanto, su resultado durante el impacto.

Al incorporar al modelo la velocidad del viento, encontraron que, el mismo aumenta la distancia media recorrida por las gotas en forma lineal y la distancia máxima cuadráticamente. Encontraron, además, que el umbral de rotura sobre una hoja de trigo se alcanzó con gotas de más de $400 \mu \mathrm{m}$ cuando la altura de liberación es de 0,5 m y la velocidad de salida de la gota de $10 \mathrm{~m} \mathrm{~s}^{-1}$. Con estas condiciones también, se observó un rebote para gotas entre $270 \mu \mathrm{m}$ y $400 \mu \mathrm{m}$. Concluyeron entonces que las gotas con un diámetro de $200 \mu \mathrm{m}$ a $270 \mu \mathrm{m}$ tienen un bajo potencial de deriva y es posible que no se rompan ni reboten sobre las hojas de trigo. En resumen, la disminución de la deriva de la pulverización puede ser dificultosa cuando el diámetro medio de las gotas es demasiado pequeño o demasiado grande, ya que aumentaría la deriva o reduciría la retención. 
En este sentido, Leiva (1995) menciona que las gotas pequeñas mejoran la retención por parte de las hojas, así como la cobertura, ofreciendo también una mejor penetración en el cultivo y la posibilidad de alcanzar la cara inferior de las hojas y los tallos. Su principal desventaja es que, por su menor peso, están más propensas a ser transportadas por el viento (deriva) y por su elevada superficie expuesta, en relación al volumen, a sufrir una intensa evaporación antes de depositarse, reduciendo su volumen y aumentando aún más su tiempo de caída. La práctica indica que, trabajando con agua como dispersante, gotas menores a $150 \mu \mathrm{m}$ están muy expuestas a la evaporación y deriva, y aquellas mayores a $350 \mu \mathrm{m}$ no proveen una adecuada cobertura y caen generalmente al suelo, arrastrando con ellas al agroquímico. Según el autor, se considera que un adecuado balance se obtiene utilizando gotas entre 200-250 m de diámetro. Por otro lado, según Márquez (1997), el valor promedio efectivo de diámetro volumétrico mediano (DMV) es de $300 \mu \mathrm{m}$. Esto evita problemas de escorrentía que generalmente ocurren con gotas mayores de $600 \mu \mathrm{m}$, y problemas de exoderiva que ocurren con gotas menores de $100 \mu \mathrm{m}$. Pese a ello, por lo general, se recomienda el uso de pastillas que producen gotas finas para las aplicaciones de post-emergencia, que requieren una cobertura excelente del objetivo deseado.

El espectro de tamaños de gotas depende del tipo y tamaño de pastilla, de las propiedades del líquido y la presión de pulverización (Klein \& Johnson, 2002). Cuando la presión aumenta, las pastillas generan un menor tamaño de gota (Ozkan, 1998). El tamaño, la velocidad y la dirección de las gotas influyen en el potencial de deriva; las gotas más grandes mantienen su impulso durante más tiempo $\mathrm{y}$, por lo tanto, son menos propensas a sufrir deriva por viento. Aunque no existe un rango de tamaño de gota 
específico que sea propenso a la deriva en todas las condiciones, muchos investigadores han considerado que gotas más pequeñas que $75 \mu \mathrm{m}$ (Hobson et al., 1993), $100 \mu \mathrm{m}$ (Bode, 1984), $150 \mu \mathrm{m}$ (Combellack et al., 1996) o $200 \mu \mathrm{m}$ (Bouse et al., 1990) son las más propensas a la deriva.

Las pastillas más comúnmente utilizadas en la agricultura son aquellas que producen gotas medias. Estas pueden utilizarse para herbicidas de contacto y sistémicos, herbicidas de pre-emergencia incorporados al suelo, insecticidas y fungicidas (Teejet, 2014).

Las preocupaciones sobre la deriva de las aspersiones, han llevado a la adopción de pastillas que buscan aumentar el tamaño de las gotas para reducir este riesgo, recurriéndose, entre otros, a sistemas Venturi de inducción de aire, de precámara y pastillas deflectoras (Ferguson et al., 2015). En general, el tamaño de gota es el factor más importante que afecta la deriva de pulverización en cultivos de cobertura (Hewitt, 1997) y las gotas con diámetros menores de $100 \mu \mathrm{m}$ tienen la mayor tendencia a la deriva (Grover et al., 1978; Byass \& Lake, 1977). Cuando el diámetro de la gota es inferior a $200 \mu \mathrm{m}$, la deposición está influenciada principalmente por los efectos atmosféricos y de estela del pulverizador (Spillman, 1984), que a menudo provocan el ingreso de las gotas en la parte superior de un dosel (Uk \& Courshee, 1982). Por otro lado, según los principios de la física, un objeto proyectado con más masa bajo la influencia de la gravedad, experimentaría un mayor impulso, que debería hacer que se moviera más profundamente en doseles densos (Spillman, 1984).

A su vez Boller \& Schlosser (2010), mencionan que la diferencia de velocidad entre la barra en desplazamiento y el aire atmosférico sobre el cultivo ejerce un efecto de freno, 
que se opone a la velocidad de caída de las gotas finas de las boquillas de pulverización. Matthews et al., (2014) explican que una gota seguirá una dirección resultante dependiente de los efectos combinados de la gravedad, la velocidad media del viento y la turbulencia. Encontraron que las gotas grandes (> $200 \mu \mathrm{m})$ se depositarán rápidamente por sedimentación, por lo que la deriva por pulverización no será un problema y serán menos afectadas por la turbulencia que las gotas más chicas.

La clasificación del tamaño de gota se basa en un estándar desarrollado por el British Crop Protection Council (Southcombe et al., 1997), que ha sido actualizado y aprobado por la Sociedad Americana de Ingenieros Agrícolas y Biológicos (ASABE) en acuerdo con el estándar S572.1 (ASABE, 2009). Las clases de tamaño de gota según el estándar ASABE son: extremadamente fino, muy fino, fino, medio, grueso, muy grueso, extremadamente grueso y ultra grueso. La delimitación exacta de las clases de tamaño se basa en un conjunto de pastillas de referencia certificadas y en el sistema de medición de gotas de cada laboratorio (ASABE, 2009).

Knoche (1994) sugiere que los efectos del tamaño de la gota y el volumen del caldo representaron el resultado integrado de las interacciones entre la solución de pulverización y las características de la planta en las etapas de penetración del dosel, impacto de las gotas, retención de gotas y, posiblemente, absorción foliar e inducción de una respuesta biológica. Los datos demostraron que la disminución del tamaño de las gotas generalmente aumentaba el rendimiento del herbicida, mejorando a medida que disminuyó el tamaño de las mismas, y lo relaciona con una mejora de la penetración en el dosel; una relación óptima entre el tamaño de la gota y el impacto que ésta genera; una 
disminución de la variabilidad de los depósitos y una disminución de la probabilidad de error; mejor retención de gotas en hojas difíciles de mojar y mayor eficiencia de la respuesta biológica para herbicidas con movilidad limitada dentro del tejido foliar.

Otro parámetro que evaluó fue el volumen de caldo, pero los resultados fueron menos consistentes y sugirieron una relación óptima. A altos volúmenes de vehículo, la eficiencia de control del herbicida aumentó a medida que disminuyó el volumen de vehículo, mientras que, a volúmenes bajos de vehículo, la eficiencia disminuyó a medida que disminuyeron los volúmenes de vehículo. Esta respuesta fue probablemente el resultado neto de varios procesos opuestos. La disminución del volumen del vehículo resultó en, mayor variabilidad de la deposición y mayor probabilidad de error, mayor retención de gotas en superficies de plantas difíciles de mojar y una disminución de la eficiencia de la respuesta biológica a herbicidas con movilidad limitada en el tejido foliar debido a la disminución de la cobertura. Los efectos del tamaño de las gotas y los efectos del volumen de los portadores estaban interrelacionados, lo que sugiere que cualquiera de los factores podría sustituir parcialmente al otro.

Muchos de los estudios evaluados en la revisión efectuada por Knoche (1994) ocurrieron mucho antes de que se desarrollara la tecnología de boquilla Venturi. Las pastillas Venturi condujeron a depósitos más altos en un dosel de maní (Arachis hypogaea L.), en comparación con pastillas no Venturi, en tres alturas de colectores, y especialmente en el colector inferior (Zhu et al., 2004). Este resultado también fue observado por Derksen et al., (2008) donde las pastillas de calidad de pulverización fina, redujeron los depósitos en comparación con las de calidad de pulverización gruesa. 
En algunos casos, un menor volumen de aplicación puede aumentar tanto la cobertura como la eficacia (Fritz et al., 2007). Las gotas más pequeñas tienden a tener una mayor afinidad por las superficies de las plantas, especialmente en las de crecimiento erectófilo, como las gramíneas, debido a su orientación principalmente vertical (Lake, 1977; Spillman, 1984), pero esto no parece afectar la eficacia de los herbicidas. En el $56 \%$ de los estudios examinados por Knoche (1994) una disminución en el volumen de la aplicación condujo a una mejora o a ningún efecto sobre la eficacia de los herbicidas. Massaro et al., (2014) evaluaron diferentes pastillas de características antideriva, deflectoras y de inducción de aire, y volúmenes de aplicación, 40 y 60 I ha ${ }^{-1}$; y determinaron una adecuada eficiencia para las tres técnicas planteadas, con valores de control del 90,4 \% al 94,2\%, aún con un número de impactos de 21 gotas $\mathrm{cm}^{-2}$. Esto es consistente con otros estudios, realizados posteriormente (McMullan, 1995; Etheridge et al., 1999; Ramsdale \& Messersmith, 2001). Según los mismos, el cambio en el tamaño de la gota de pulverización afecta la deposición, pero el efecto sobre la cobertura no alcanzó similares niveles de correlación (Hanna et al., 2009; Wolf \& Daggupati, 2009).

Gálvez et al., (2005) trabajaron evaluando la penetración del asperjado con diversas pastillas en el control de roya de la soja. Obtuvieron como conclusión que la densidad de impactos producida por la boquilla cono hueco a $150 \mathrm{I} \mathrm{ha}^{-1}$, fue significativamente superior al resto de pastillas, tanto en el estrato superior como en el inferior. Una serie de combinaciones de pastillas y caudales (XR a 120 y $150 \mathrm{I} \mathrm{ha}^{-1}$, porta-pastillas Twin cap $^{\circledR}$ con 2 pastillas XR a $150 \mid \mathrm{ha}^{-1}$, cono hueco a 120 y cono lleno a $150 \mid \mathrm{ha}^{-1}$ ) mostraron un desempeño similar en el estrato inferior sin diferencias significativas entre ellas, pero peor 
desempeño que las pastillas de cono hueco a $150 \mathrm{I} \mathrm{ha}^{-1}$. Para el caso de doble abanico no obtuvieron una mayor penetración por debajo de los $0,2 \mathrm{~m}$ superiores del follaje del cultivo. Las únicas pastillas con las que obtuvieron un número aceptable de impactos (50 gotas $\mathrm{cm}^{-2}$ ) fueron las de cono hueco a 120 y $150 \mathrm{I} \mathrm{ha}{ }^{-1}$. Por otro lado, Domper et al., (2015) destacan que un mayor volumen de aplicación por sí mismo, no es una garantía de un alto número de impactos dentro del follaje, sino que está relacionado con las características de las pastillas en cuanto al modo de generación de gotas. En el caso de cono hueco, el DVM estuvo por debajo del valor ideal de 200-250 $\mu \mathrm{m}$ mencionado por Leiva (1995) y los resultados muestran que las gotas finas generadas por estas pastillas fueron las que mejor performance presentaron con respecto a la penetración.

\section{Pastillas}

Las variables de mayor relevancia en las aplicaciones hidráulicas son proporcionadas por las pastillas, siendo de gran importancia conocer las peculiaridades de cada una, a fin de seleccionar la que mejor se adecua a cada circunstancia en particular. Las pastillas, son el órgano responsable de la emisión de las gotas y, por lo tanto, son consideradas el componente más importante del equipo pulverizador, ya que determina diversos factores relacionados a la calidad de la aplicación, entre ellos el caudal, el cual debe presentar la menor variación posible a lo largo del botalón (Bauer \& Raetano, 2004); además, determinan el volumen aplicado por hectárea (cantidad), las características de la población de gotas (calidad) y la uniformidad de distribución del líquido (uniformidad) (Masiá \& Cid, 2010). 
La selección de las pastillas sirve para adecuar el pulverizador al tipo de aplicación que será realizada, buscando optimizar el resultado biológico y la capacidad de trabajo de la máquina. Los criterios para su selección deben considerar las condiciones ambientales durante la aplicación, la calidad adecuada de pulverización para cada clase de producto fitosanitario, en términos de tamaño de gota, la densidad de impactos (gotas por unidad de área), la reducción de pérdidas por deriva o por escurrimiento, la uniformidad de distribución (coeficiente de distribución a lo largo del botalón) y el volumen de caldo pulverizado, sin olvidar las características del objetivo biológico (Boller, 2011). En la actualidad los catálogos de pastillas de pulverización ofrecen una gran variedad de productos; existen no menos de cuatro materiales de fabricación, con presencia cada vez más fuerte del plástico y la cerámica (Masiá \& Cid, 2010)

Se pueden identificar tres patrones de distribución de las gotas producidas por las pastillas: cono hueco, cono lleno y abanico plano. Las pastillas con patrón de abanico plano son las que presentan mayor cantidad de modelos y rangos de variación, que en algunos casos pueden surgir de la combinación de dos modelos diferentes (Masiá \& Cid, 2010).

Matthews et al., (2014) también explican que el espectro de gotas dependerá de la salida, el ángulo de pulverización de la boquilla y la presión de funcionamiento, y esto determinará la calidad de la pulverización. Por lo tanto, la correcta elección de la boquilla es esencial para garantizar que los plaguicidas se apliquen de manera efectiva a la velocidad correcta. La clasificación que realizan de las pastillas es: deflectora o espejo, 
abanico plano, abanico plano rango extendido, Twin o abanico doble, cono hueco, cono lleno, abanico antideriva con pre orificio, abanico plano baja presión e inducción de aire.

Por otro lado, cada una de ellas posee un patrón de distribución característico, que determina la altura de la pastilla en relación al blanco y el espaciamiento entre ellas en la barra pulverizadora (Galli et al., 1983; Matthews, 2000). A partir del patrón de distribución de pastillas individuales, se puede simular la superposición de varias pastillas, tal como ocurre en la barra pulverizadora, calculando entonces el coeficiente de variación (CV) de la superposición resultante; según Christofoletti (1997), cuanto menor sea ese valor, menos desuniforme será la distribución.

Boller (2011) menciona que muchas veces los fabricantes informan solamente si un modelo de boquilla es adecuado para un herbicida, insecticida o fungicida, considerando los modos de acción de contacto o sistémico. La situación más pobre ocurre cuando el fabricante informa solamente la salida de la boquilla en función de la presión, dificultando de sobremanera una selección racional de pastillas, ya que no solo el caudal de la boquilla varía con la presión. La presión más alta influye en el tamaño de la gota y en el ritmo de desgaste del orificio. Cuando la presión aumenta, el tamaño de la gota disminuye y el ritmo de desgaste del orificio aumenta (Teejet, 2014). En función de esto, muchas veces la regulación de la presión de pulverización puede ser suficiente para obtener la cobertura deseada, sin que haya necesidad de sustituir las pastillas, cuando se pasa de una aplicación de herbicida sistémico a una aplicación de herbicida de contacto (Boller, 2011).

Los patrones de deposición individual de las pastillas se determinan en bancos o mesas de prueba, donde el caldo es acumulado en canales que lo recolectan a distancias 
predeterminadas y lo depositan en recipientes individuales (Chapple et al., 1993). En Argentina es frecuente el uso de barras pulverizadoras dotadas de pastillas espaciadas a 0,35; 0,52 y 0,70 m entre sí; sin embargo, dependiendo del tipo de pastilla de pulverización, de la altura de la barra y de la presión de trabajo, estos espaciamientos pueden resultar no adecuados para la mejor distribución del líquido.

\section{Angulación de las pastillas}

Distintos autores han mencionado que los parámetros de calidad de aplicación se hallan relacionados también a los ángulos de incidencia del chorro de pulverización (Matthews, 2004; Rodrigues et al., 2010; Wolf \& Peng, 2011).

Se considera que el ángulo de pulverización de $0^{\circ}$ en relación a la posición vertical entre el suelo y la pastilla, es el más frecuentemente utilizado (Jensen, 2007). Pese a ello, las pastillas que presentan abanico simple con ángulos hacia adelante o hacia atrás, simétricos o asimétricos se utilizan tratando de buscar mayor penetración y uniformidad de deposición en el cultivo; todos los trabajos se refieren a la angulación anteroposterior de la pastilla de manera diferente; para tratar de aclarar y mejorar la comparación entre trabajos se ha decidido tomar $0^{\circ}$ como la posición vertical más común y los ángulos con valor positivos tomados desde la posición vertical $\left(0^{\circ}\right)$ hacia la dirección de avance y los valores negativos desde la posición vertical en sentido contrario a la dirección de avance.

Dorr (1990) evaluó el ángulo de incidencia del abanico de pulverización de tres pastillas diferentes de abanico plano y uno con doble abanico plano, encontrando incrementos en la deposición del caldo de pulverización cuando utilizó el ángulo de $+45^{\circ}$ en relación con la vertical. 
Friesen \& Wall (1991) estudiaron el ángulo de pulverización $\left(+45^{\circ}\right.$ y $\left.0^{\circ}\right)$ de pastillas para determinar la eficiencia de fluasifop-p-butyl en el control de Setaria viridis, Avena fatua L., Hordium vulgare y Triticum aestivum, en el cultivo del lino. Se observó que la orientación del pico de pulverización $+45^{\circ}$, presentó un mayor control sobre Avena fatua L., H. vulgare y T. aestivum, siendo las diferencias mayores para las menores dosis del producto y en condiciones de estrés hídrico.

Tomazella (2001), trabajando con trazador Colorante Azul brillante en una concentración de 3.000 ppm, y lavando las plantas, encontró, en un ensayo con 2 pastillas (XR 110.02VS y DG 110.02 VS) y 5 ángulos $\left(15^{\circ} ; 30^{\circ} ;-15^{\circ}\right.$ y $-30^{\circ}$ y $\left.0^{\circ}\right)$, que para la pastilla XR 110.02VS ocurrieron incrementos del depósito en el orden de 7,0 \%; $21,0 \% ; 6,0 \%$ y 10,0 $\%$, para los ángulos de $15^{\circ} ; 30^{\circ} ;-15^{\circ}$ y $-30^{\circ}$, respectivamente en relación a lo encontrado para el ángulo de $0^{\circ}$. Sin embargo, la pastilla DG 110.02 VS produjo aumentos en el orden de $21,0 \% ; 16,0 \%$ y $6,0 \%$ para los ángulos de $15^{\circ} ; 30^{\circ}$ y $-15^{\circ}$, respectivamente, y un descenso en torno al 8,0 \% para el ángulo de $-30^{\circ}$. Tomando como estándar la boquilla DG 110.02VS observó que ocurrieron incrementos para la boquilla XR 110.02VS de alrededor del $36,0 \%, 14,0 \%, 15,0 \%, 1,0 \%$ y $20,0 \%$ para los ángulos de $-30^{\circ} ;-15^{\circ}, 0^{\circ}, 15^{\circ}$ y $30^{\circ}$ respectivamente. En un análisis general, la pastilla DG 110.02VS presentó una tendencia a la disminución de los depósitos sobre las plantas $\left(\mathrm{I} \mathrm{ha}^{-1}\right)$ para los ángulos negativos.

En esta misma línea de investigación, Shaw et al. (2000) estudiaron el efecto del volumen de pulverización $\left(56\right.$ I ha ${ }^{-1}, 112$ I ha ${ }^{-1}$ y 169 I ha $\left.a^{-1}\right)$, el diámetro de gotas $(250 \mu \mathrm{m}$, $350 \mu \mathrm{m}$ y $450 \mu \mathrm{m})$ y el ángulo de incidencia del chorro de pulverización $\left(0^{\circ},-45^{\circ}\right.$ y $\left.-90^{\circ}\right)$, para determinar la eficiencia del acifluorfen en el control de Xanthium estrumariu. 
Obtuvieron mayor deposición cuando utilizaron el volumen de caldo de pulverización de 56 I ha ${ }^{-1}$, diámetro de gota de $350 \mu \mathrm{m}$ y el ángulo de incidencia del chorro de pulverización de $-45^{\circ}$. Este efecto también se observó con gotas de $450 \mu \mathrm{m}, 56 \mathrm{I} \mathrm{ha-1}$ y ángulo de $0^{\circ}$, mientras que para el resto de los tratamientos no hubo diferencias entre ellos y presentaron aproximadamente, en promedio, un $72 \%$ menos que en el ángulo de $0^{\circ}$ y un $67 \%$ menos que con el ángulo de $-45^{\circ}$. Jensen \& Nielsen (2014) tampoco encontraron diferencias en el uso de pastillas con angulaciones de $+45^{\circ}$ y $-90^{\circ}$.

Tomazella (1997) al evaluar los depósitos de trazadores en el suelo y en las plantas de Brachiaria plantaginea, trabajando con el ángulo del chorro de pulverización a -30, $15^{\circ}, 0^{\circ},+15^{\circ} \mathrm{y}+30^{\circ}$ encontró que los ángulos de pulverización de $15^{\circ}, 30^{\circ},-15^{\circ}$ y $-30^{\circ}$ proporcionaron incrementos en el porcentaje de depósito en las plantas de B. plantaginea alrededor de $53 \%$, $70 \%, 55 \%$ y $40 \%$, respectivamente, en relación al ángulo de $0^{\circ}$, correspondiendo los mayores aumentos para las pastillas de pulverización situadas a $30^{\circ}$ y $15^{\circ}$. De la misma forma, Silva (2000) al estudiar los depósitos de trazadores sobre el suelo y en las plantas de Cyperus rotundus L. , trabajando con ángulos de incidencia del chorro de pulverización de $-30^{\circ},-15^{\circ}, 0^{\circ},+15^{\circ} \mathrm{y}+30^{\circ}$, constató que los mayores valores de los depósitos en las plantas fueron proporcionados para los ángulos de $+15^{\circ} \mathrm{y}+30^{\circ}$, donde éstos tuvieron incrementos de $26 \%, 34 \%, 50 \%$ y $60 \%$, respectivamente, en el depósito de almidón en las plantas, comparados al ángulo de $0^{\circ}$.

Panneton et al., (2000), encontraron, en un ensayo con cortina de aire, que una velocidad de aire superior a $25 \mathrm{~m} \mathrm{~s}^{-1}$ acoplada con un ángulo de chorro de aire de $+20^{\circ} \mathrm{y}$ 
una pulverización fina, aumenta tanto la cobertura de partes ocultas de las plantas como la penetración de rociado hacia el fondo del dosel.

De Souza Christovam et al., (2010) realizaron 2 ensayos con cuatro niveles de aire 0 $\mathrm{m} \mathrm{s}^{-1}, 2,5 \mathrm{~m} \mathrm{~s}^{-1}, 3 \mathrm{~m} \mathrm{~s}^{-1}$ y $8 \mathrm{~m} \mathrm{~s}^{-1}$ combinados en dos ángulos de boquilla $\left(0^{\circ} \mathrm{y}+30^{\circ}\right)$ usando pastillas Delavan 80-3R a 3,9 bar para obtener gotas de $230 \mu \mathrm{m}$ de DVM. El segundo experimento se llevó a cabo en el mismo lugar y los tratamientos fueron con la misma disposición que el experimento anterior, pero con pastillas Delavan $80-5 R$ a 1,5 bar para obtener gotas de $400 \mu \mathrm{m}$ de DVM, incluyendo como tratamiento de control plantas no tratadas. Utilizaron un trazador cúprico y la cantidad de depósitos se determinó mediante un espectrofotómetro. La boquilla en ángulo de $+30^{\circ}$ combinada con la velocidad máxima del aire promovió los más altos depósitos de pulverización en el cultivo de soja.

Scudeler \& Raetano (2006), trabajando también con asistencia de aire y tres ángulos $0^{\circ},+30^{\circ}$ y $-30^{\circ}$ con conos huecos, encontraron que los ángulos de ataque de $0^{\circ} \mathrm{y}+30^{\circ}$, en presencia de asistencia de aire, proporcionaron los mayores depósitos de pulverización en la superficie abaxial de las hojas de papa.

Bauer \& Raetano (2004), evaluaron la distribución en ancho del abanico creado por las pastillas Teejet ${ }^{\circledR}$ XR 8004, TP 8004 y "TwinJet" TJ60-8004, en un banco de prueba a 0,3 m, 0,4 m, y 0,5 m de altura de la mesa colectora, sometidas a presión de 2 bar y 3 bar, y colocadas con ángulos de $0^{\circ},+30^{\circ},-30^{\circ},+45^{\circ}$ y $-45^{\circ}$. Las puntas TJ60-8004 se analizaron en las mismas alturas, pero sólo en posición vertical $\left(0^{\circ}\right)$; las pastillas se hicieron funcionar sobre el banco de pruebas compuestos por probetas cada 0,05 $\mathrm{m}$ y se evaluó la distribución del abanico seguido de un análisis de superposición de las pastillas realizadas 
por un programa informático. Los resultados obtenidos indican que la angulación de las pastillas en la barra pulverizadora causa una disminución en la superposición de los abanicos generados, independientemente de la presión. Por lo tanto, recomiendan modificar la distancia entre pastillas cuando se trabaja con pastillas anguladas, y concluyen que la uniformidad de la distribución de la pulverización es menos influenciada por la altura de la barra cuando se usan menores espaciamientos entre boquillas.

En función de lo expuesto, existen escasos antecedentes vinculados a la eficiencia de deposición de diferentes pastillas con ángulos de aspersión positivos y negativos en el control de malezas, puesto que la mayoría de los ensayos se refieren a la capacidad de penetración en cultivos de follaje denso y disposición de sus hojas formando un escollo difícil de superar para las gotas. Esta situación no ha sido revertida en los últimos años, siendo escasos aún aquellos trabajos que brindan resultados contundentes en condiciones de siembra directa y malezas resistentes, por lo que se vuelve difícil de predecir un comportamiento y valorar adecuadamente los beneficios y contras de la angulación de las pastillas sobre el botalón.

La condición de siembra directa de cultivos, con residuos de diferentes características y alturas, presenta también inconvenientes para el control de malezas con las pastillas habitualmente recomendadas para ese tipo de tratamientos. A ello se agrega la presencia de malezas resistentes y o de diferente altura, que producen un efecto de sombra de las de mayor tamaño sobre las de menor tamaño que se encuentran por detrás, en el sentido de avance. 
Un principio de diseño que beneficia a las boquillas de doble abanico es la adecuación del ángulo de la pluma de pulverización entre la boquilla y la planta, con la intención de aumentar el depósito de la pulverización. Es bien sabido que la deposición por pulverización se maximiza cuando el objetivo es perpendicular a la trayectoria de la gota (Elliott \& Mann, 1997; Richardson \& Newton, 2000).

En función de esto, diferentes investigaciones han demostrado que la deposición y la eficacia de las gotas se mejoran en los objetivos verticales (por ejemplo, pastos) cuando se realizan pulverizaciones con un ángulo de aplicación hacia delante o hacia atrás (Combellack \& Richardson, 1985; Richardson, 1987; Dorr, 1990; Jensen, 2007; Jensen \& Nielsen, 2008; Jensen 2010; Jensen, 2012).

Wolf \& Caldwell (2013) han demostrado que el uso de boquillas dobles que proyectan dos abanicos, uno hacia adelante y el otro hacia atrás, aumenta la deposición de pulverización sobre objetivos verticales. Trabajando con pastillas dobles asimétricas TeeJet Al3070, hallaron que las mismas proporcionaban depósitos más grandes y más uniformes en objetivos verticales que otras boquillas probadas simples o dobles, y que este beneficio era independiente de la velocidad de desplazamiento de hasta 4,44 $\mathrm{m} \mathrm{s}^{-1}$. Por otro lado, hallaron que el uso de una altura de botalón baja maximizó el beneficio de la boquilla.

Gadea (2018) menciona que las estructuras vegetativas orientadas verticalmente, tales como hojas erectas, tallos o pecíolos, típicamente reciben dosificaciones mucho más bajas en comparación con los objetivos orientados horizontalmente. Wolf \& Peng, (2011) estudiaron los efectos de 5 angulaciones $\left(-60^{\circ},-30^{\circ}, 0^{\circ},+60^{\circ} \mathrm{y}+30^{\circ}\right)$ con 2 pastillas (Teejet 
XR8005 y ABJ 11005 Aire Inducido) con 3 velocidades de desplazamiento (2,1 m s${ }^{-1}, 3,2 \mathrm{~m}$ $\mathrm{s}^{-1}$, y 4,2 $\mathrm{m} \mathrm{s}^{-1}$ ) y altura de botalón de $0,45 \mathrm{~m}$; hallaron que una combinación de boquillas inclinadas hacia adelante, espectro de pulverización más grueso, altura de pluma más baja y una velocidad de desplazamiento más rápida aumentó la retención de rociado en objetivos verticales en más del $100 \%$. La angulación de la pulverización mejoró significativamente la deposición en comparación con la orientación de la boquilla vertical. La ventaja de orientar la boquilla hacia atrás fue más notable en el lado orientado hacia adelante y viceversa, pero la magnitud del beneficio fue mayor cuando el aerosol estaba orientado hacia adelante y con el mayor beneficio para el ángulo $+60^{\circ}$.

Las empresas han presentado en los últimos años diferentes diseños de pastillas anguladas, las cuales no han sido probadas adecuadamente en cuanto a su eficiencia de aplicación, cobertura y demás parámetros que hacen a la calidad de una pulverización. Por otro lado, uno de los últimos avances tecnológicos presentados en el mercado por las empresas consiste en intercalar dentro del botalón pastillas anguladas, una en el sentido de avance y otra en sentido inverso.

En el año 2015 Syngenta $^{\circledR}$ desarrolló una boquilla en ángulo, con colocación alternada hacia delante y hacia atrás a lo largo del botalón, de tal forma que proporcionara una cobertura uniforme en la parte delantera y posterior de los objetivos, y con una altura de botalón de 0,5 m para obtener mejores resultados.

Otro ejemplo de estos diseños es la pastilla "Guardián ${ }^{\circledR ”}$ para insecticidas y fungicidas, con aspersión inclinada de $20^{\circ}$ que mejoraría la calidad de la aplicación independientemente de las características del objetivo, cuyo fabricante recomienda 
colocar en forma alternada hacia adelante y hacia atrás para crear un efecto de doble pulverización y mejorar la penetración y cobertura del dosel (John Deere $\left.{ }^{\circledR}, 2017\right)$.

El rociado inclinado está diseñado para instalarse alternando hacia adelante y hacia atrás a lo largo del botalón para proporcionar una cobertura tridimensional en los blancos verticales, tales como hierbas, terrones y copas de hojas amplias (Hypro Pentair ${ }^{\circledR}, 2017$ )

\section{$\underline{\text { Deposición }}$}

Vázquez \& Rodrigues (2010) mencionan que el estudio de la deposición involucra la cuantificación del producto depositado sobre el objetivo, pudiendo ser expresado en relación al área foliar. La cobertura es la parte de la superficie del área del objetivo cubierta por el producto fitosanitario. Productos de acción sistémica pueden ser aplicados con una cobertura un poco menor (que los de contacto), pero que sea suficiente para propiciar una buena eficiencia, con gotas mayores, que presentan mayor resistencia a la deriva. En cambio, los productos de contacto deben ser aplicados con una pulverización más fina, que proporcione una cobertura más eficiente del objetivo.

Una forma de estimar la cobertura del objetivo puede ser el número de impactos de pulverización por unidad de área. Buena parte de las recomendaciones técnicas de aplicación son basadas en este criterio, informándose un rango o un número mínimo de gotas necesarias para un buen control (Weber, 1982). Deposición y cobertura pueden ser analizados de diferentes formas, utilizándose objetivos naturales o artificiales. En el caso de los objetivos naturales se adoptan criterios basados en el análisis de distribución del producto fitosanitario o de un trazador (colorante, sal, material radioactivo, entre otros) sobre el objetivo. La espectrofotometría se refiere a la determinación de la concentración 
de una sustancia por la medida de la absorción relativa de la luz, tomándose como referencia la absorción de la sustancia en una concentración definida. Con relación al uso de trazadores, el primer paso importante se refiere a su elección. Esta debe tener en cuenta la estabilidad a la luz solar, temperatura, almacenamiento y $\mathrm{pH}$, el nivel de detección, la toxicidad, la persistencia y la solubilidad. Tampoco debería afectar las propiedades y resultados de control de los fitosanitarios a aplicar (Vázquez \& Rodrigues, 2010).

Palladini et al., (2005) mencionan que los trazadores que se utilizan para evaluar la eficacia de pulverización, normalmente modifican la tensión superficial de soluciones acuosas, pero no ocurre dicho problema con el Azul Brillante (FD\&C $N^{\circ}-1$ ) el cual no altera la tensión de las soluciones.

Otros estudios desarrollados en el área de tecnología de aplicación de fitosanitarios hallaron que el efecto biológico de los productos se halla fuertemente influenciado por la calidad de la aplicación en términos de cobertura, tamaño de gotas y número de impactos (Knoche, 1994; Cawood et al., 1995; Enfält et al., 1997; Jensen, 1999; Jensen et al., 2001) y estos parámetros se hallan relacionados también, a los ángulos de incidencia del chorro de pulverización (Matthews, 2004; Rodrigues et al., 2010; Wolf \& Peng, 2011).

\section{Tasa y Velocidad de aplicación}

En los sistemas de pulverización en la región pampeana se ha avanzado hacia técnicas de aplicación que implican bajas tasas de aplicación (15-30 | ha ${ }^{-1}$ ) con altas velocidades de la máquina $\left(5,5 \mathrm{~m} \mathrm{~s}^{-1}-6,9 \mathrm{~m} \mathrm{~s}^{-1}\right)$. Frola (2013) menciona que, para cualquier aplicación, la elección del tamaño de la gota está determinada por la cobertura y la 
dificultad de llegar al objetivo. Para un barbecho sobre rastrojo de sorgo, donde la maleza está cubierta por el mismo, indica que el tamaño de la gota debería rondar los $200 \mu \mathrm{m}$. Si el rastrojo es de soja, la dificultad para alcanzar la maleza es menor y trabajando a una presión de 3 bar y con gota de $250 \mu \mathrm{m}$ se cumplirían los objetivos. Recalca, además, en relación al uso del agua y la concentración del producto, que no es lo mismo aplicar altos y bajos volúmenes, ya que en estos últimos la concentración mayor del producto aumenta la eficiencia del mismo. Asimismo, para que la técnica de aplicación sea válida deben mantenerse premisas como el respeto del tamaño y el número de impactos, pero también el monitoreo de las condiciones ambientales. Establece que se debe trabajar con temperatura inferior a $30^{\circ} \mathrm{C}$, humedad relativa superior a $40 \%$, y vientos con velocidades menores a $5-5,5 \mathrm{~m} \mathrm{~s}^{-1}$ y tener en cuenta que cuando estas condiciones no son buenas se debe recurrir al uso de coadyuvantes antievaporantes, que ayuden a proteger la gota que se está generando. Estas características de pulverización implican para velocidades de avance entre 3,8 y $7,7 \mathrm{~m} \mathrm{~s}^{-1}$ tasas de aplicación entre 33 y $17 \mathrm{I} \mathrm{ha}{ }^{-1}$.

En relación con la técnica de bajo volumen, Leiva \& Picapietra (2012) citan experiencias de contratistas y productores que han obtenido buenos resultados con volúmenes de 40-50 I ha ${ }^{-1}$, tomando en cuenta la mejora en la penetración en el canopeo, por disminución del tamaño de gota, un aumento de la concentración del principio activo, la disminución en el uso de agua y la reducción de costos por un aumento en la autonomía del equipo pulverizador y la capacidad de trabajo (Moltoni et al., 2008).

Chorbadjian \& Kogan (2001) indican que el volumen de aplicación fue determinante en la actividad del glifosato, más aún con dosis bajas del herbicida, dadas por un efecto de 
dilución del surfactante que posee el producto comercial y por el aumento de la posibilidad de formación del complejo herbicida-suelo-arcilla-materia orgánica.

Esta disminución en las tasas de aplicación, sumada a las bajas precauciones de los aplicadores y en muchos casos al desconocimiento de las relaciones físicas que conforman el proceso de pulverización, han convertido a la labor en un proceso peligroso para el ambiente y la salud. Por otro lado, actualmente existe muy poca información sobre las características de muchas de las pastillas que existen en el mercado en cuanto a su prestación en campo para cada una de las posibilidades de regulación o alistamiento. Esta información podría ayudar en la disminución del daño que se genera en el proceso de aplicación de agroquímicos.

Las características de los residuos remanentes, su altura y disposición sobre el terreno inciden sobre la llegada del producto al objeto de aplicación que puede ubicarse tanto por delante, detrás, encima o al costado de los obstáculos que dichos residuos constituyen con respecto a las malezas. Asimismo, las propias malezas cuando se desarrollan en sectores determinados del terreno, se transforman en obstáculos para malezas cercanas, más pequeñas y ocultas por otras según la dirección y sentido de avance de la pulverizadora. La incidencia de estas relaciones espaciales será distinta en acuerdo con las posiciones relativas del abanico de pulverización con respecto al objetivo, constituyendo un amplio y complejo sistema de relaciones que afectará a la eficiencia de aplicación.

Por tal motivo se cree relevante el avance en el estudio de las características de comportamiento de diferentes pastillas hidráulicas de pulverización, teniendo en cuenta 
los relativamente pocos estudios que han explorado el efecto del tipo de boquilla y la angulación anteroposterior de las mismas, en las tasas de recuperación de producto y la calidad de deposición de la pulverización en aplicaciones con presencia de obstáculos a las gotas.

Es en este marco de análisis se establecen las siguientes hipótesis y objetivos de trabajo. 


\section{HIPOTESIS}

\section{Hipótesis general}

- Los diferentes diseños de pastillas de pulverización anguladas generan, en iguales condiciones de trabajo, diferentes características de pulverización sobre las diferentes caras de los objetivos.

\section{Hipótesis de trabajo}

- La orientación de los abanicos de pulverización en relación a la disposición de los objetivos es determinante de la calidad de pulverización en cuanto a la densidad de impactos y la cobertura.

- Las pastillas con angulación anteroposterior producen mayor cobertura y Densidad de impactos, independientemente del ángulo que posean en objetivos sombreados y verticales.

- Las pastillas anguladas con disposición alternada sobre el botalón generan mayor uniformidad entre las caras anteriores y posteriores del objetivo.

- Las pastillas anguladas con disposición alternada sobre el botalón generan similares condiciones de tamaño, densidad de gotas y cobertura en todas las caras del objetivo.

- La altura del objetivo tiene una relación directa con la eficiencia de aplicación sobre el sector de sombra. 
- La cobertura y Densidad de impactos en los objetivos verticales es menor que en los horizontales independientemente de la tecnología de aplicación utilizada o diseño y disposición de pastillas usada.

- El espectro de gotas que alcanza los objetivos verticales es más uniforme que en los objetivos horizontales.

- El uso de trazador indica una menor tasa de recuperación que la estimada por medio de tarjetas hidrosensibles.

\section{OBJETIVOS}

\section{Objetivos direccionales generales}

- Propender a una mayor eficiencia de aplicación en el control de malezas.

\section{Objetivos especificos}

- Evaluar características de aplicación de pastillas con diferentes angulaciones anteroposterior sobre objetivos con orientaciones verticales y horizontales.

- Determinar la uniformidad de distribución de la pulverización generada por pastillas, con diferentes características generales y diseños de angulación anteroposterior, sobre distintos objetivos.

- Verificar la viabilidad de la utilización de pastillas con angulación alterna para mejorar la relación de depósitos entre las caras anteriores y posteriores.

- Determinar la incidencia de la altura del objetivo sobre la uniformidad de aplicación anteroposterior. 
- Establecer la correspondencia de las evaluaciones de la tasa de recuperación efectuadas a través de metodologías de análisis de imágenes y la valoración colorimétrica de la solución.

- Determinar las características del blanco artificial que permiten detectar diferencias entre diferentes diseños de pastillas. 


\section{MATERIALES Y MÉTODOS}

\section{Lugar:}

El ensayo fue llevado a cabo en la Estación Experimental Julio Hirschhörn perteneciente a la Facultad de Ciencias Agrarias y Forestales de la Universidad Nacional de La Plata, Buenos Aires, Argentina $34^{\circ} 35$ S, $57^{\circ} 57$ O. La evaluación se realizó dentro de un galpón cerrado y asfaltado de $40 \mathrm{~m}$ de longitud y $24 \mathrm{~m}$ de ancho, dividido en 2 módulos de $12 \mathrm{~m}$ cada uno, en condiciones semicontroladas, sin viento y sin desuniformidad de la superficie de terreno con el objetivo de disminuir la variabilidad que las irregularidades del terreno producen sobre la posición del botalón y eliminar la incidencia del viento atmosférico sobre la dirección del abanico de pulverización durante la realización de los ensayos.

\section{Equipo Pulverizador:}

Se utilizó una máquina pulverizadora montada, Hatsuta HS400 de 400 I de capacidad, con bomba de pistón membrana de 3 cuerpos, transmisión de potencia por barra cardánica a la TPP a 56,55 $\mathrm{rad} \mathrm{s}^{-1}$ (540 rpm). Se trabajó con un botalón seco, de aluminio, con portapicos con sistema de revólver para tres pastillas, separados a 0,52 m entre sí.

La pulverizadora fue montada en un tractor de diseño convencional, marca New Holland modelo TT55, de 40,45 kW (55 CV) en el motor y una masa de $2220 \mathrm{~kg}$.

\section{Pastillas}

Se seleccionaron pastillas de similar caudal, correspondiente al que registra mayores ventas en la Argentina en los últimos 10 años (Casal, com. per., 2018) y que responden a las tasas de aplicación usuales en la aplicación de herbicidas sobre barbecho a nivel 
extensivo. Los diferentes diseños seleccionados generan características de pulverización diferentes, en cuanto a la disposición con respecto a los objetivos y/o a los tamaños de gota que las mismas producen. Se eligieron, por ello, dos pastillas de abanico plano, una convencional y otra de impacto, deflectora, que producen diferente tamaño de gotas (Finas y Medianas) y ángulos de proyección del abanico de pulverización, 2 pastillas de proyección hacia adelante y hacia atrás, de abanico angulado de disposición alterna y de doble abanico plano con inducción de aire (de gotas Finas y Medianas respectivamente). Por último, se incluyó una pastilla de cono hueco, de amplia difusión para el trabajo con volúmenes reducidos de aplicación, de tamaño de gota Fino, identificadas como adecuadas para aumentar la cobertura del objeto de aplicación. Todas las pastillas trabajaron en iguales condiciones de presión y velocidad de desplazamiento a fin de obtener idénticas tasas de aplicación en I ha-1 ${ }^{-1}$ Las pastillas seleccionadas fueron de un caudal unitario normalizado de 0,79 $1 \mathrm{~min}^{-1}$ trabajando a 3 bar de presión (Standard I.S.O, 2018), si bien este tamaño de pastillas tiende a generar gotas de tamaño $F$ (fina) y M (media) (ASABE, 2009) en la actualidad la tendencia en aplicaciones con sistemas neumáticos es a disminuir las tasas de aplicación (menores a 50 । ha ${ }^{-1}$ ) y trabajar con velocidades de aproximadamente $5,5 \mathrm{~m} \mathrm{~s}^{-1}$ a $7 \mathrm{~m} \mathrm{~s}^{-1}$. En estas condiciones resulta imposible conseguir tasas de aplicación de esas características, a esas velocidades, con pastillas de mayor caudal. Es por eso que se optó por seleccionar este tamaño de pastillas, buscando producir condiciones de trabajo lo más similares a las utilizadas posible. Las características de las pastillas se describen en la Tabla $\mathrm{N}^{\circ} 1$.

Tabla 1: Pastillas características descripción. 


\begin{tabular}{|l|c|c|c|c|c|c|c|}
\hline Pastillas & $\begin{array}{c}\text { Ángulo } \\
\text { Antero- } \\
\text { posterior }\end{array}$ & $\begin{array}{c}\text { Ángulo de } \\
\text { apertura } \\
\text { abanico }\end{array}$ & $\begin{array}{c}\text { Caudal } \\
\left(\mathbf{I ~ m i n}^{-1}\right)\end{array}$ & Tipo & Marca & $\begin{array}{c}\text { Altura } \\
\text { botalón } \\
(\mathbf{m})\end{array}$ & $\begin{array}{c}\text { tamaño de } \\
\text { gota *** }\end{array}$ \\
\hline 3D Defy & $30^{*}$ & $100^{\circ}$ & 0,79 & Abanico & Hypro & 0,75 & $\mathrm{~F}$ \\
\hline XR11002VP & 0 & $110^{\circ}$ & 0,79 & Abanico & Teejet & 0,75 & $\mathrm{~F}$ \\
\hline GAT110-02 & $+30-30$ & $110^{\circ}$ & 0,79 & Abanico Al** & Hypro & 0,75 & $\mathrm{M}$ \\
\hline TXA8002VK & 0 & $80^{\circ}$ & 0,79 & Cono Hueco & Teejet & 0,75 & $\mathrm{~F}$ \\
\hline TT11002VP & 0 & $110^{\circ}$ & 0,79 & $\begin{array}{c}\text { Abanico } \\
\text { deflectora }\end{array}$ & Teejet & 0,75 & $\mathrm{M}$ \\
\hline
\end{tabular}

* Intercalada hacia adelante y hacia atrás sobre el botalón según indicaciones del fabricante.

** Aire Inducido

*** Ver Tabla 2 (Clasificación de tamaño de gota según ASABE (2009)

Tabla 2: Tamaño de gotas según especificaciones de BCPC y en conformidad con la norma S572.1 de ASABE (2009) a la fecha de impresión de este documento (Teejet, 2014).

\begin{tabular}{|l|c|c|}
\hline Categoría & Símbolo & Dv $_{0.5}$ aproximado (VMD) \\
\hline Extremadamente Fina & XF & $\approx 50$ \\
\hline Muy Fina & VF & $<136$ \\
\hline Fina & F & $136-177$ \\
\hline Mediana & M & $177-218$ \\
\hline Gruesa & C & $218-349$ \\
\hline Muy Gruesa & VC & $349-428$ \\
\hline Extremadamente Gruesa & XC & $428-622$ \\
\hline Ultra Gruesa & UC & $>622$ \\
\hline
\end{tabular}


En la imagen 1 se visualizan las diferentes pastillas utilizadas en el ensayo. Imagen 1: imágenes de las pastillas utilizadas.

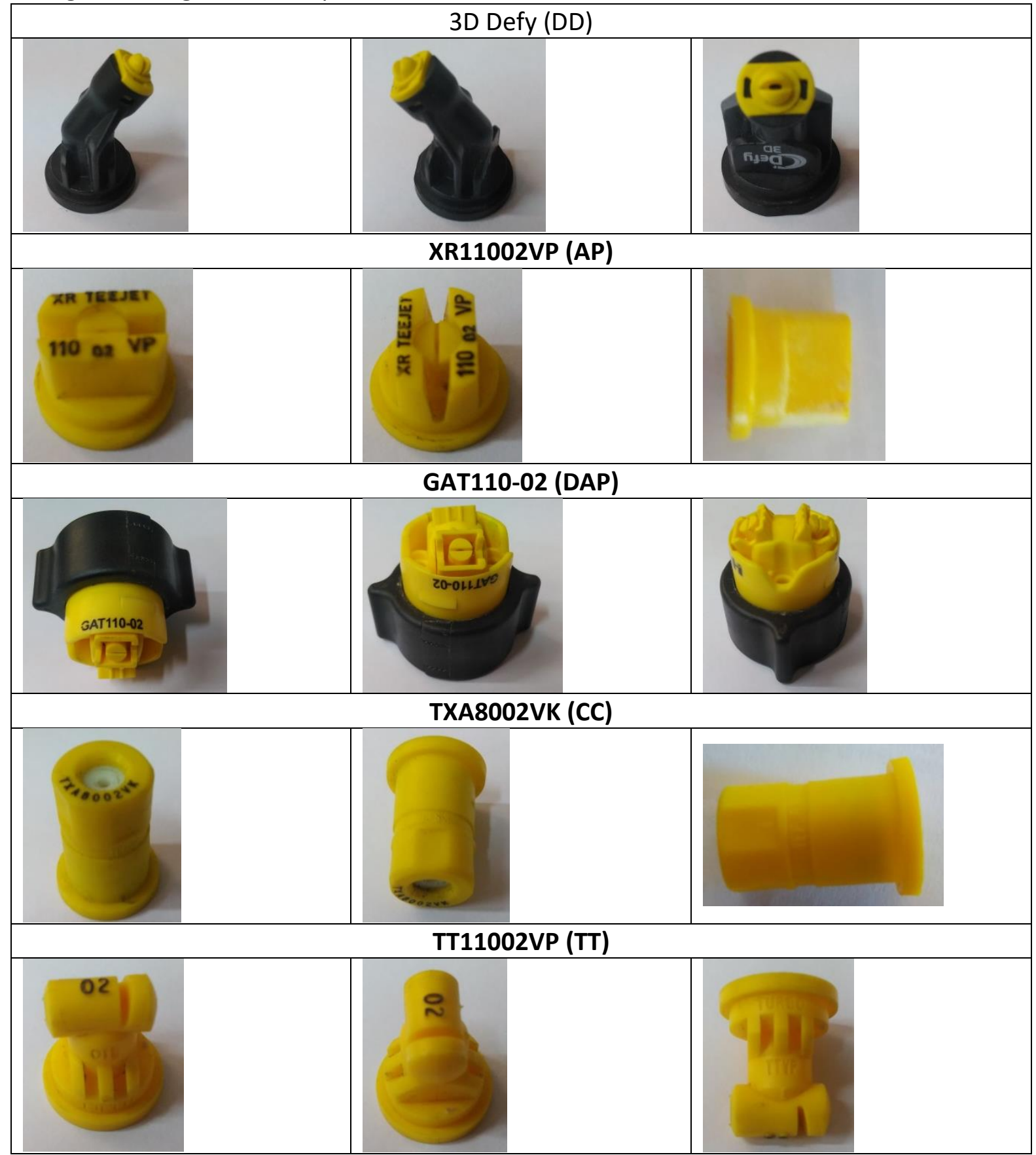




\section{Condiciones de trabajo de las pastillas:}

Las pastillas fueron evaluadas trabajando a 2,5 bar de presión y a una velocidad de trabajo de $4,72 \mathrm{~m} \mathrm{seg}^{-1}\left(17 \mathrm{~km} \mathrm{~h}^{-1}\right)$. El botalón se trasladó por encima de los objetivos de pulverización a una distancia de $0,75 \mathrm{~m}$ de altura, con respecto a la superficie del suelo, en todas las pastillas, buscando balancear las alturas de trabajo habituales en el medio agrícola y cumplir con las recomendaciones de los fabricantes. Para las pastillas Defy 3D (DD) se indica un rango de altura de 0,5 a 0,75 m; para las pastillas de $110^{\circ}$ de ángulo de aspersión se sugiere una distancia mayor a $0,5 \mathrm{~m}$ y para la pastilla de cono hueco una altura mínima de 0,75 m, relacionadas a su ángulo de aspersión (Teejet, 2014; Hypro Pentair, 2017).

Las pastillas DD fueron colocadas en el botalón en forma intercalada con su angulación hacia adelante y hacia atrás Fotos 1 y 2.
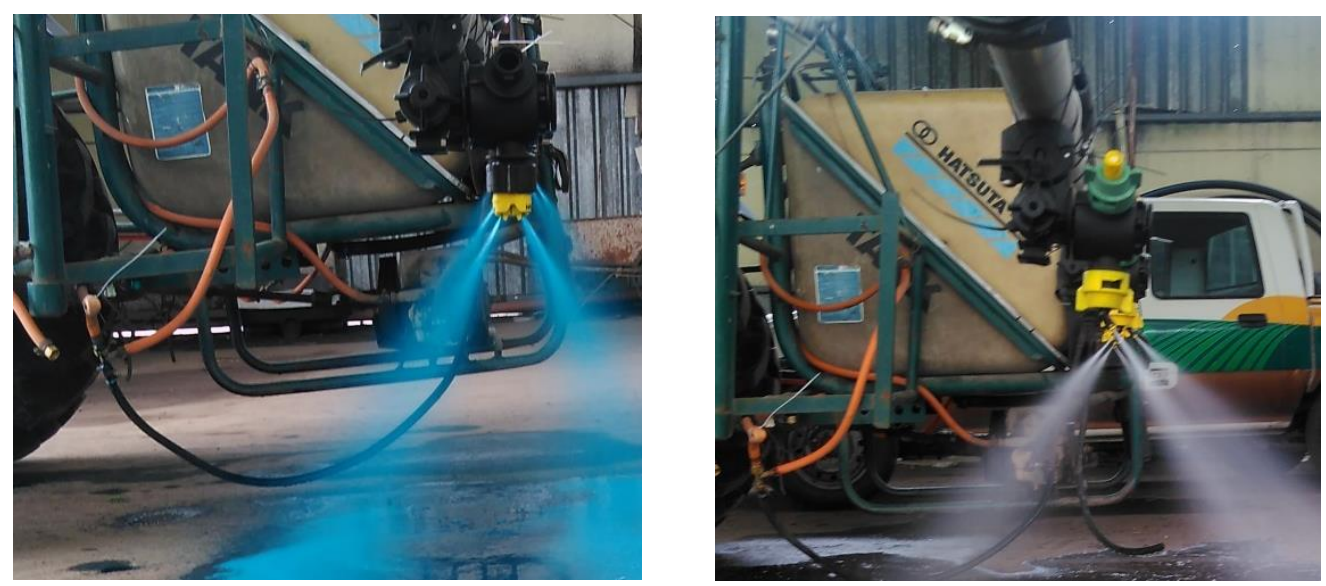

Foto 1: Perfil de distribución del doble abanico y la pastilla DD2 


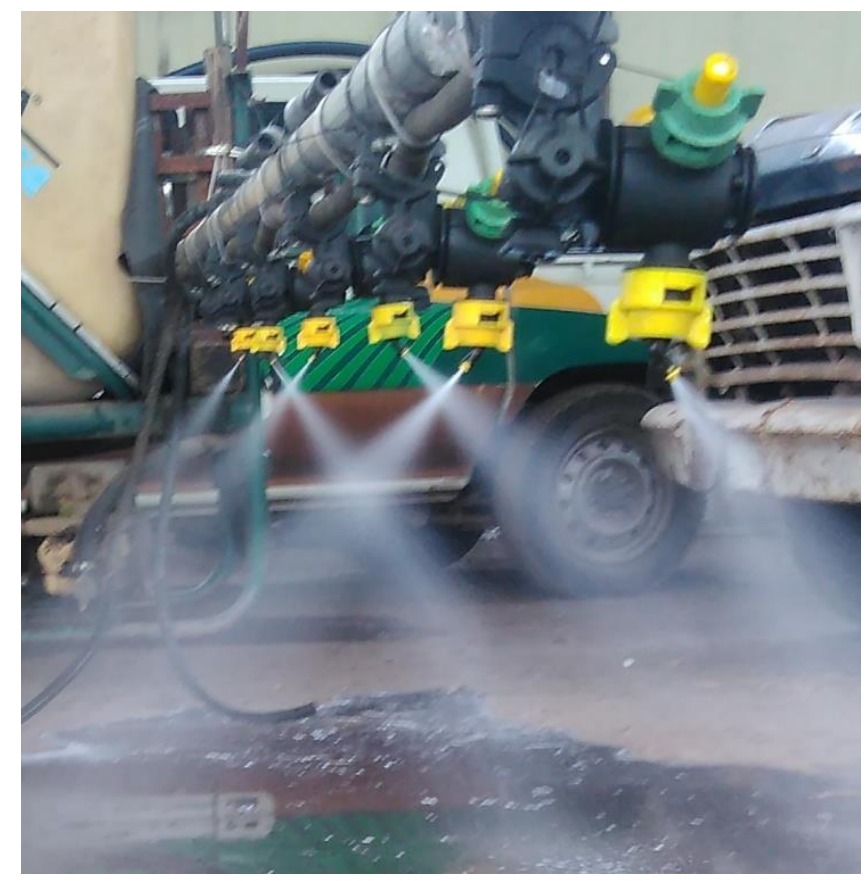

Foto 3: Disposición de las pastillas DD, intercaladas en el botalón hacia adelante y hacia atrás.

La tasa de aplicación lograda con estas condiciones fue de 50 I ha ${ }^{-1}$, habitual en aplicaciones de herbicidas sistémicos en la región pampeana (Leiva \& Picapietra, 2012; Frola, 2013).

Previo a las pasadas a todas las pastillas se les realizaron los controles pertinentes de caudal mediante la utilización de un caudalímetro electrónico digital Marca Spot On, modelo SC-1 y jarra graduada (Foto 3). Se corroboró que las pastillas utilizadas no difirieran en más de un $10 \%$ del caudal con respecto a una pastilla nueva a la presión de 3 bar, tanto por exceso como por defecto, siendo en ambos casos reemplazada por otras que cumplieran con dicho requisito. 

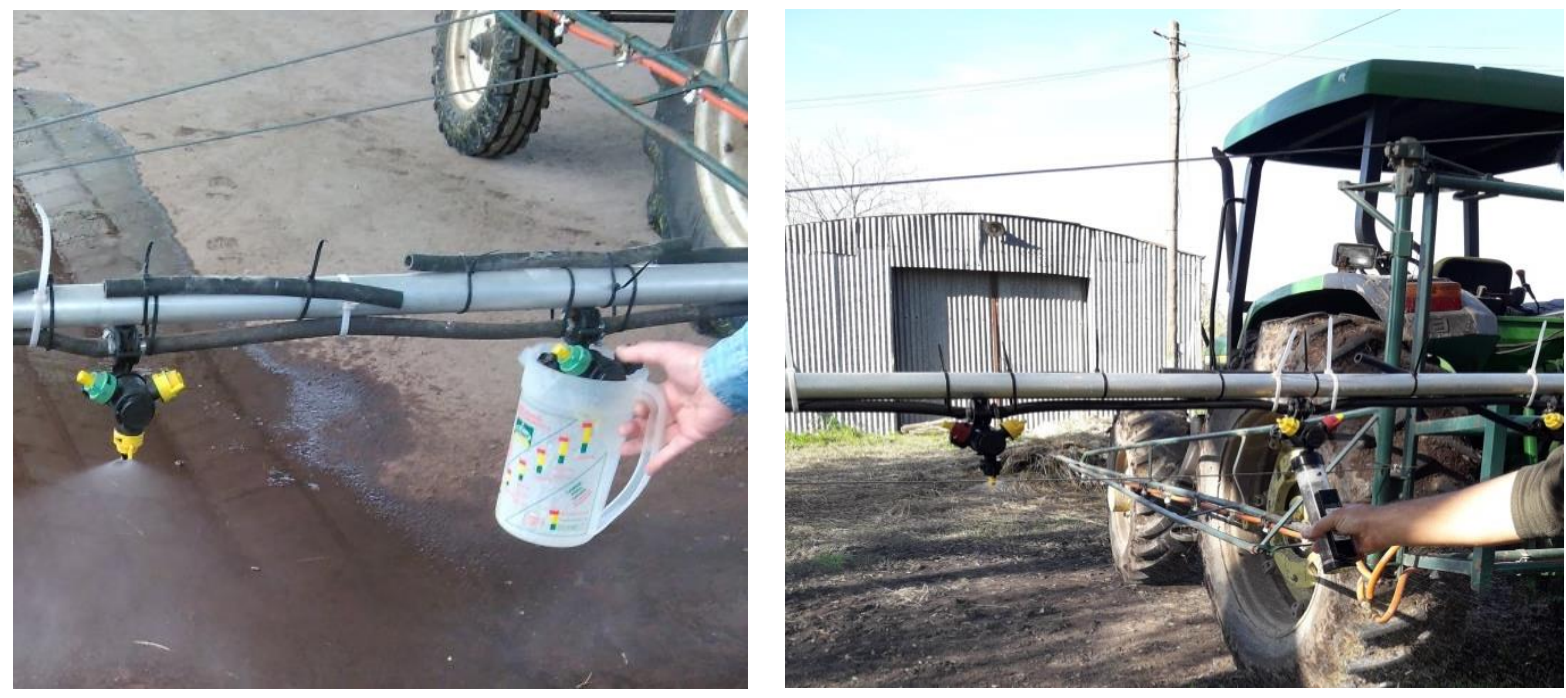

Foto 4: Calibración de la pulverizadora

Durante la realización del ensayo se efectuaron mediciones de las condiciones ambientales, temperatura, velocidad de viento y humedad relativa por medio de una estación meteorológica Kestrel modelo 3500DT. La humedad relativa se mantuvo en valores del 89 al $99 \%$, la velocidad del viento varió de 0 a $0,5 \mathrm{~m} \mathrm{seg}^{-1}$ y la temperatura se halló entre $15,2^{\circ} \mathrm{C}$ y $18,4^{\circ} \mathrm{C}$.

\section{Objetivos de pulverización:}

Los distintos objetivos de pulverización fueron colocados sobre pequeños bancos de madera de $519 \mathrm{~mm}$ de largo por $147 \mathrm{~mm}$ de ancho con 2 prismas rectangulares de diferentes dimensiones que constituyeron sectores objetivos de la aplicación (Figura 1). A través de los mismos se simuló la existencia de obstáculos, de diferente altura, que actuaron como posibles interferencias al objeto de la aplicación, ya sea residuo remanente o malezas de características diferentes en su porte o disposición, que pudiesen causar la intercepción de parte de la aplicación, reduciendo la deposición sobre el sector 
denominado como trasero o de sombra, según sea el sentido de la proyección de la pulverización.

Imagen 2: Esquema de los bancos objetivos con medidas.

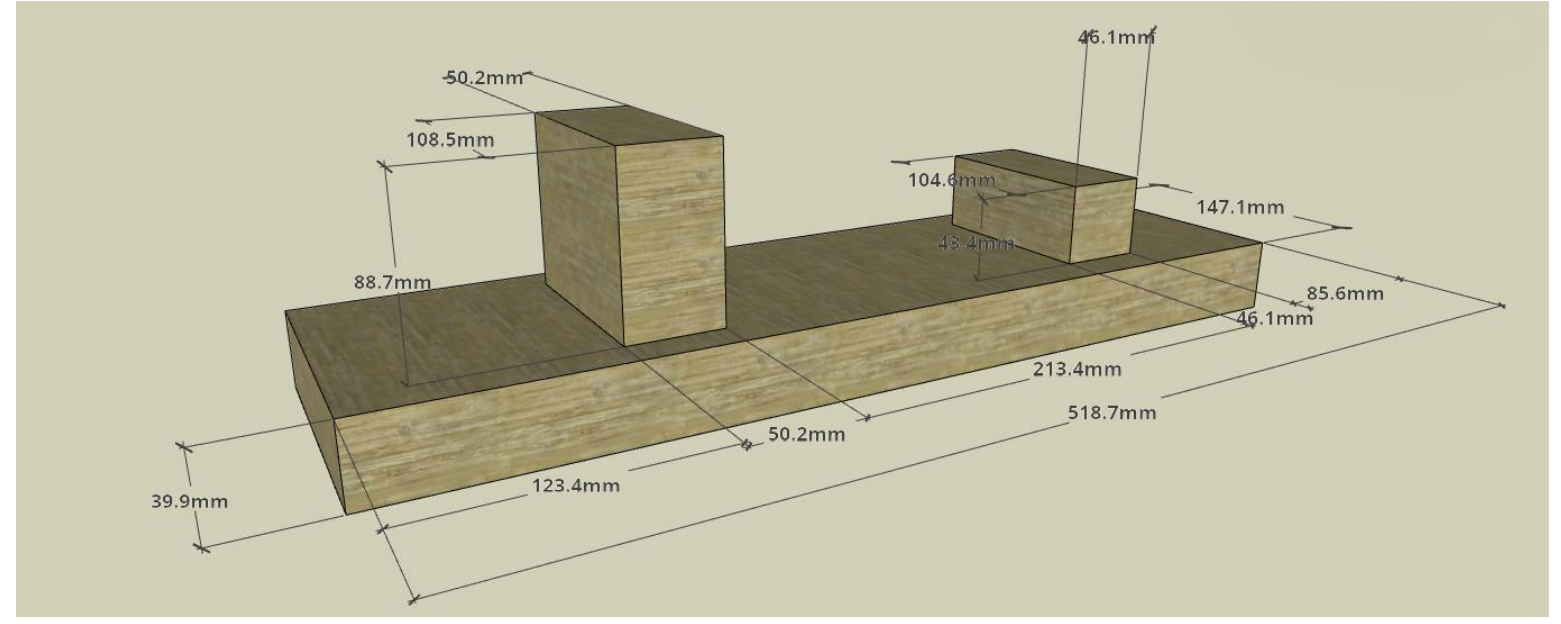

Se colocaron 3 series de 2 bancos de prueba, distanciadas entre sí 2 m en la dirección de avance y separadas en forma transversal a la dirección de avance 0,75 m (Figura $\mathrm{N}^{\circ} 4$ y Foto 4). Con ésta disposición transversal se pretende reducir la variabilidad producto de la coincidencia entre los picos y los objetivos.

Imagen 3: Esquema de distancias entre los bancos objetivos en el suelo.

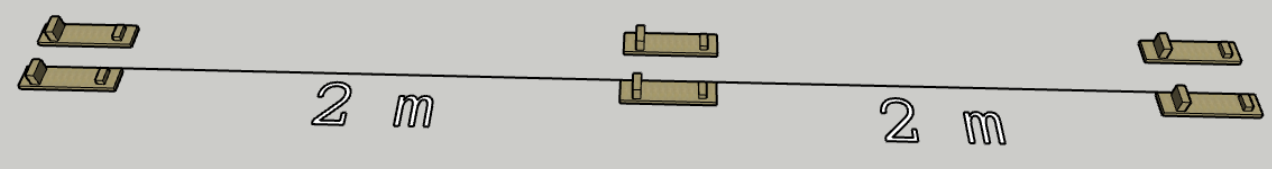




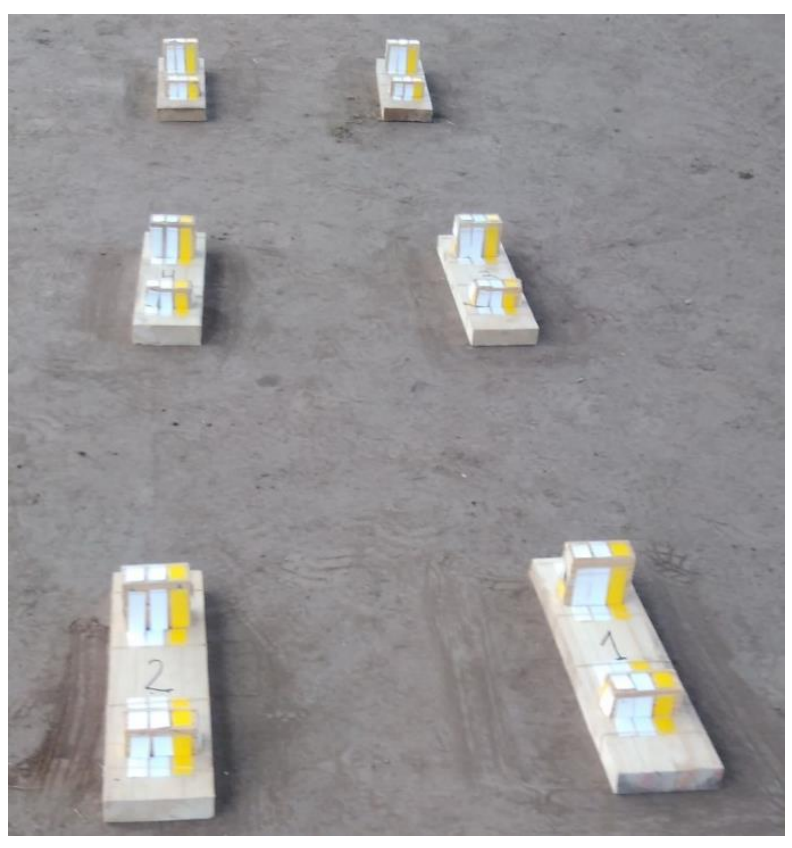

Foto 5: disposición de las tarjetas en los bancos de pulverización y disposición de los bancos sobre el suelo.

Se utilizaron dos tipos de objetivos de pulverización, en el primero se evaluaron todas las características de la población de gotas y en el segundo se recogió trazador colorimétrico a fin de poder comparar valores de eficiencia entre las dos metodologías. Los objetivos utilizados fueron tarjetas hidrosensibles Syngenta ${ }^{\circledR}(0,026 \mathrm{~m} \times 0,076 \mathrm{~m})$ y papel absorbente tipo Whatman ${ }^{\circledR} \mathrm{N}^{\circ} 40$, del mismo tamaño $(0,026 \mathrm{~m} \times 0,076 \mathrm{~m})$, para la recolección del trazador, colocadas en todas las caras de los prismas rectangulares y por delante y detrás de los mismos en posición horizontal (imagen 4 y 5, foto 4 y 5 ).

Imagen 4: Esquema de distribución de tarjetas hidrosensibles y papel Whatman sobre los bancos. 


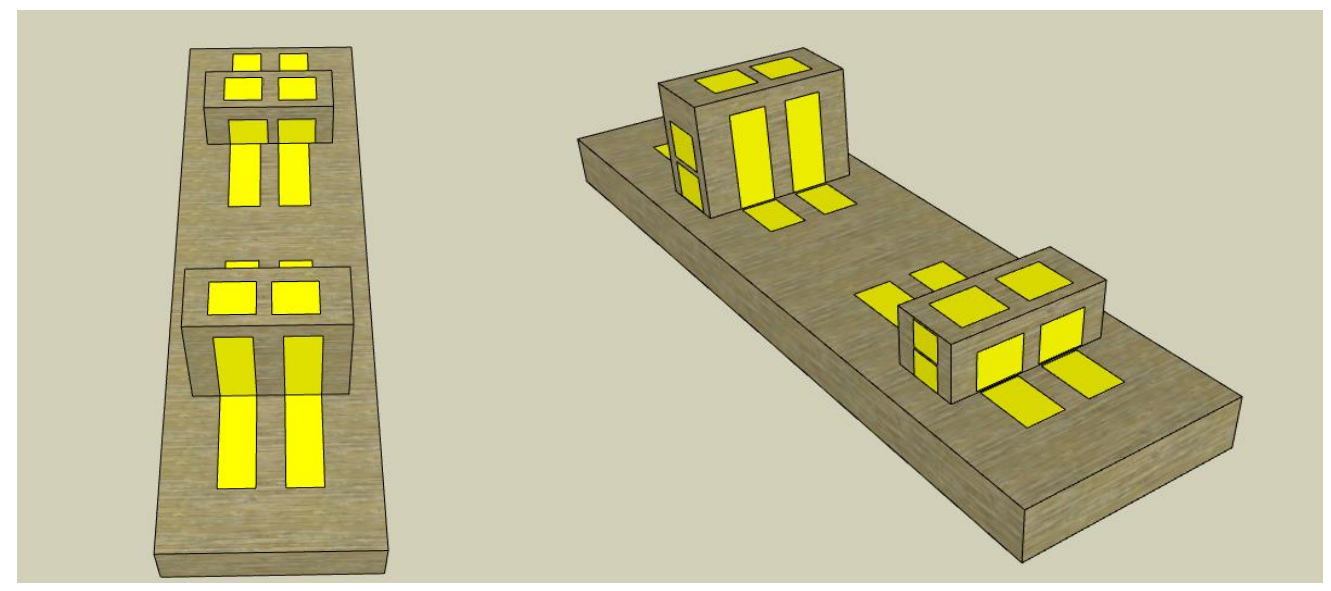

Imagen 5: Esquema de cortes de distribución de tarjetas hidrosensibles y papel Whatman sobre los bancos.
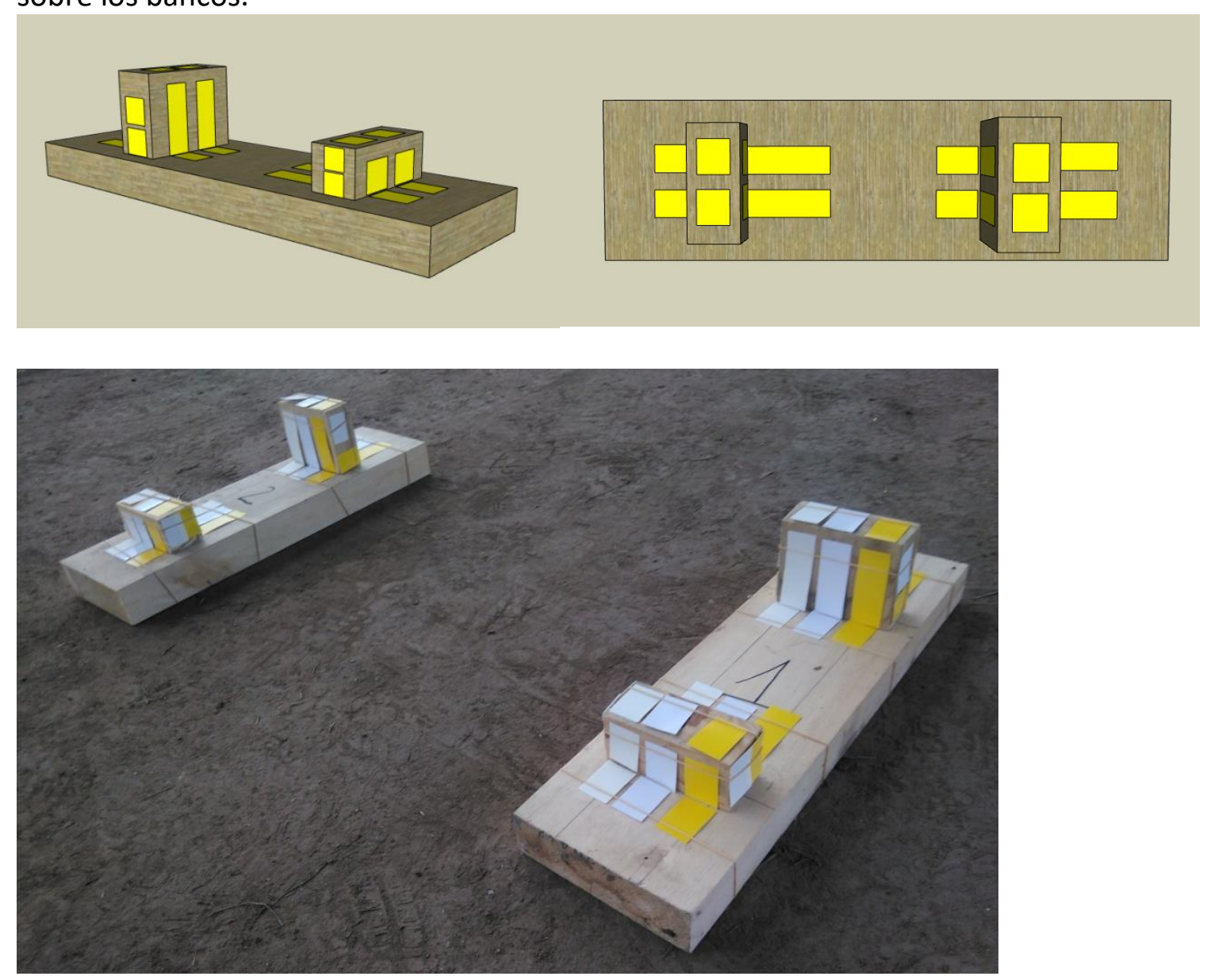

Foto 6: disposición de las tarjetas en los bancos de pulverización

En la foto 6 Se observa la deposición de la solución con colorante sobre los distintos medios utilizados para la evaluación de las variables respuesta. 

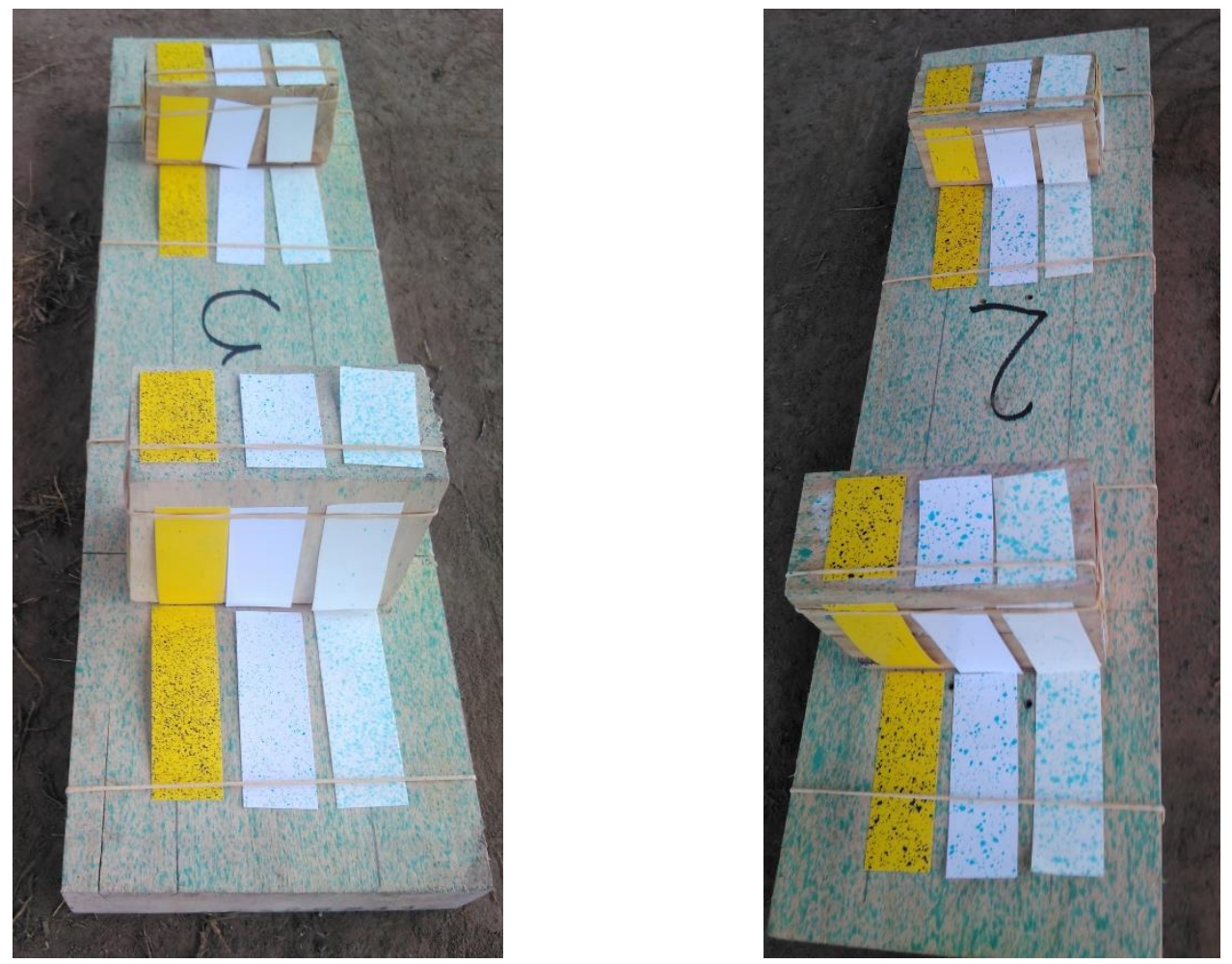

Foto 7: banco con tarjetas pulverizadas

\section{Métodos de evaluación:}

\section{Tarjetas hidrosensibles}

Luego del pasaje de la máquina, las tarjetas hidrosensibles fueron extraídas y colocadas en un ambiente libre de humedad hasta el procesamiento de las mismas. Posteriormente se procedió a la digitalización de las tarjetas por medio de un Scanner Canon LiDE $90^{\circledR}$ con una resolución de 1200 dpi. La evaluación de las imágenes se efectuó con el programa CIR 1,5 (Editor), obteniendo los siguientes parámetros que constituyeron, en parte, las variables respuesta:

- Densidad de impactos: número de improntas $\mathrm{cm}^{-2}$.

- Diámetro Volumétrico Mediano ( $\left.\mathrm{DV}_{0,5} \circ \mathrm{DVM}\right),(\mu \mathrm{m})$ : Diámetro de gota que divide el volumen pulverizado a la mitad.

- Diámetro numérico mediano (DNM) $(\mu \mathrm{m})$ : Diámetro de gota que divide el número de improntas halladas a la mitad. 
- $\mathrm{DV}_{0,9}(\mu \mathrm{m})$ : Diámetro de gota por debajo del cual se encuentra el $90 \%$ del volumen total del líquido recolectado.

- $\operatorname{DV}_{0,1}(\mu \mathrm{m})$ : Diámetro de gota por debajo del cual se encuentra el $10 \%$ del volumen total del líquido recolectado.

- Eficiencia (\%): relación entre el volumen recogido en el objetivo y el volumen aplicado.

- Área de Cobertura (\%): Porcentaje del área de la tarjeta cubierta por los impactos.

- Coeficiente de dispersión o Coeficiente de homogeneidad: relación entre el DVM y $\operatorname{DNM}\left(F D=\frac{D V M}{D N M}\right)$

- Amplitud relativa: variación del tamaño de gotas, $\left(\mathrm{AR}=\frac{\mathrm{DV} 0,9-\mathrm{DV} 0,1}{\mathrm{DV} 0,5}\right)$

\section{Trazador}

El trazador utilizado fue colorante alimenticio azul brillante (FD\&C $N^{\circ}-1$ ) ya que el mismo mantiene la tensión superficial de soluciones acuosas y cumple con las características necesarias en un trazador colorimétrico de no degradarse con la luz y el tiempo (Palladini et al., 2005) con una concentración de 0,1\% (1 $\left.\mathrm{grl}^{-1}\right)$.

Para la recolección y posterior evaluación del trazador se usaron hojas de papel de filtro Whatman ${ }^{\circledR}$ de igual tamaño que las tarjetas hidrosensibles Syngenta ${ }^{\circledR}$, que luego del pasaje de la máquina se dejaron secar para su posterior manipulación. Luego fueron guardadas en forma independiente, protegidos de la luz solar, en bolsas de color negro, y colocadas en recipientes conservadores a baja temperatura.

Para determinar la metodología de lavado y el papel a utilizar, previamente fueron realizados ensayos en laboratorio con dosis conocidas de trazador sobre papel de filtro con diferente tamaño de poro (tipo Whatman $40^{\circledR}, 8 \mu \mathrm{m}$ pasaje medio y Whatman $41^{\circledR}$, 20-25 $\mu \mathrm{m}$ pasaje rápido). Los diferentes papeles se colocaron en cajas de Petri y se les colocó una cantidad conocida de agua con trazador en igual concentración a la que se utilizaría en el ensayo y se dejó secar (Fotos 7, 8 y 9). 


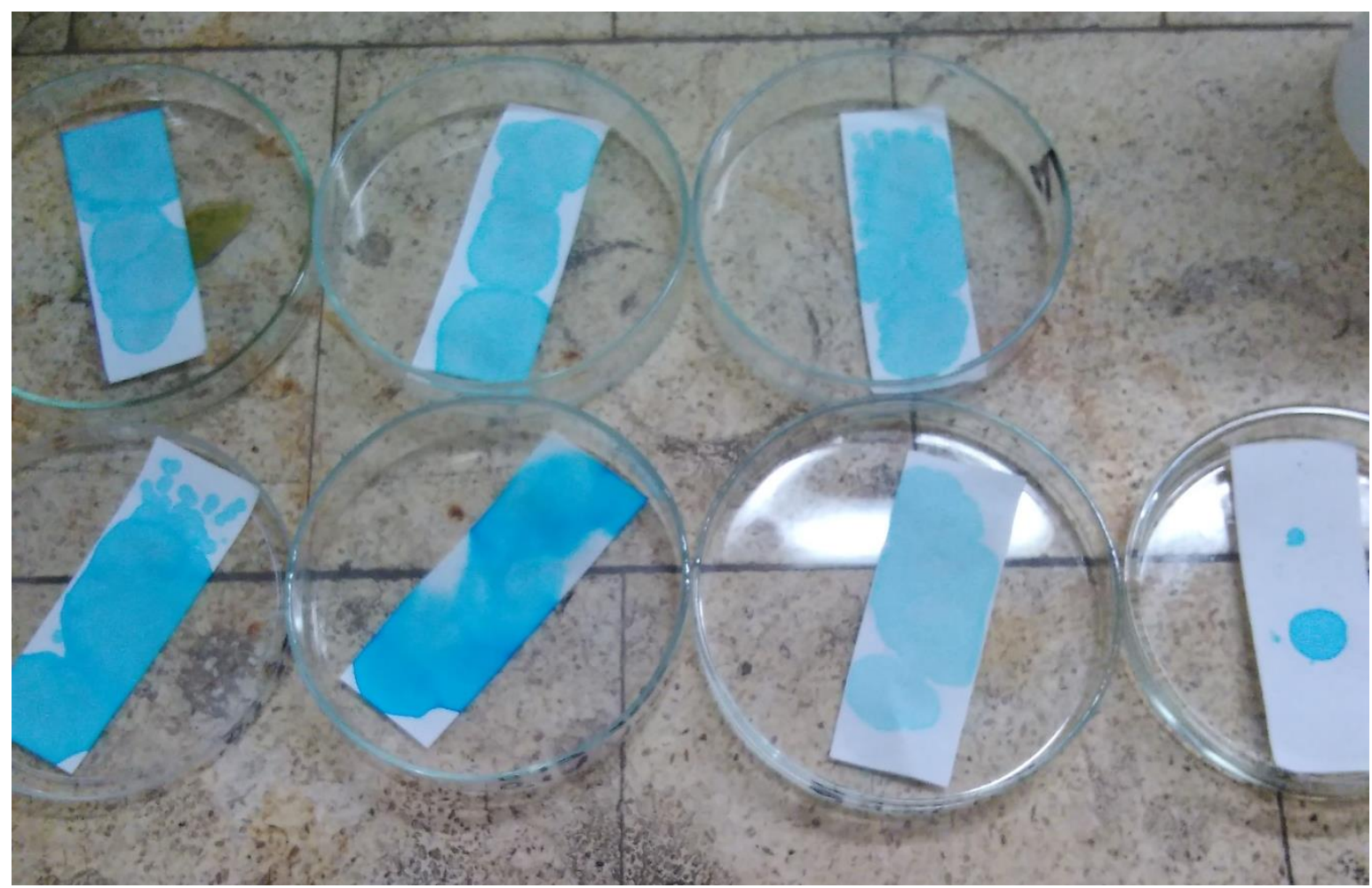

Foto 8: Aplicación de colorante sobre los diferentes papeles

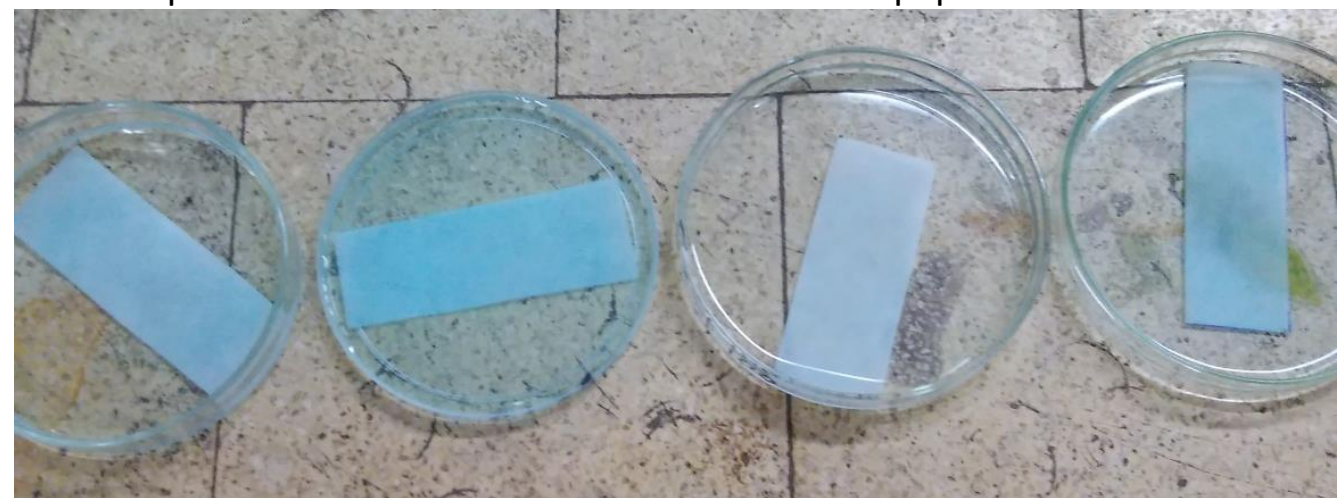

Foto 9: Lavado con alcohol sin agitación

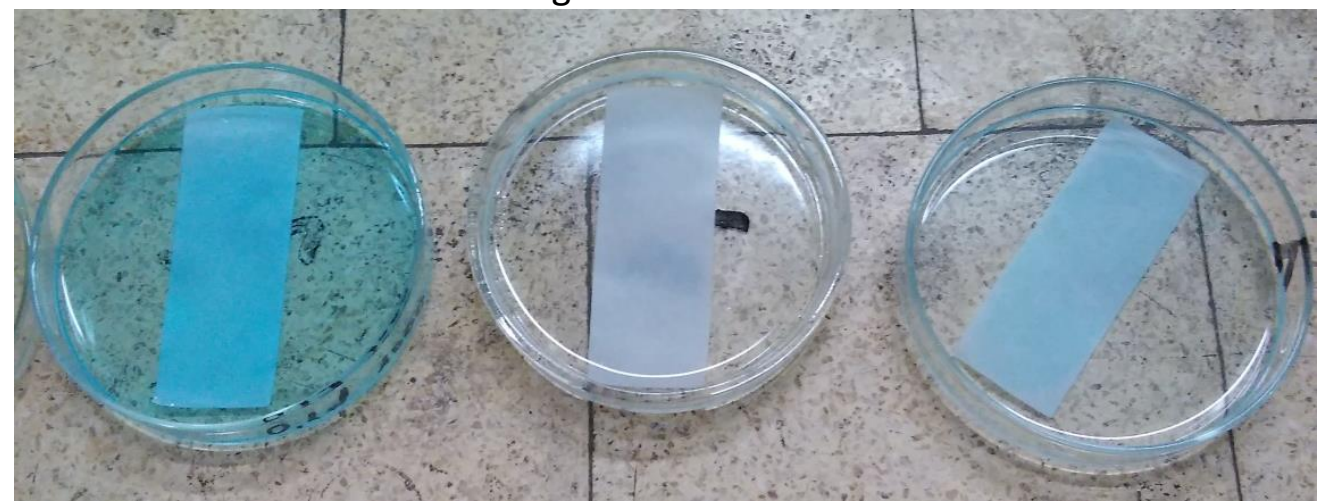

Foto 10: lavado con agua sin agitación 
Posteriormente se procedió a lavar con diferentes solventes (agua, alcohol $96 \%$ y alcohol $70 \%$ ) con diferentes niveles de agitación y reposo (sin agitación y reposo de 15 minutos, con agitación vaivén de 180 golpes por minuto, durante 5 minutos, y agitación con vaivén de 180 golpes por minuto, por 1 minuto); la agitación se realizó con agitador automático en tubos Falcon ${ }^{\circledR}$ de $50 \mathrm{ml}$ de capacidad con $20 \mathrm{ml}$ de solvente, ya que esta cantidad era adecuada para las concentraciones esperadas en las tarjetas, permitiendo obtener un buen color para su posterior medición (Foto 10).

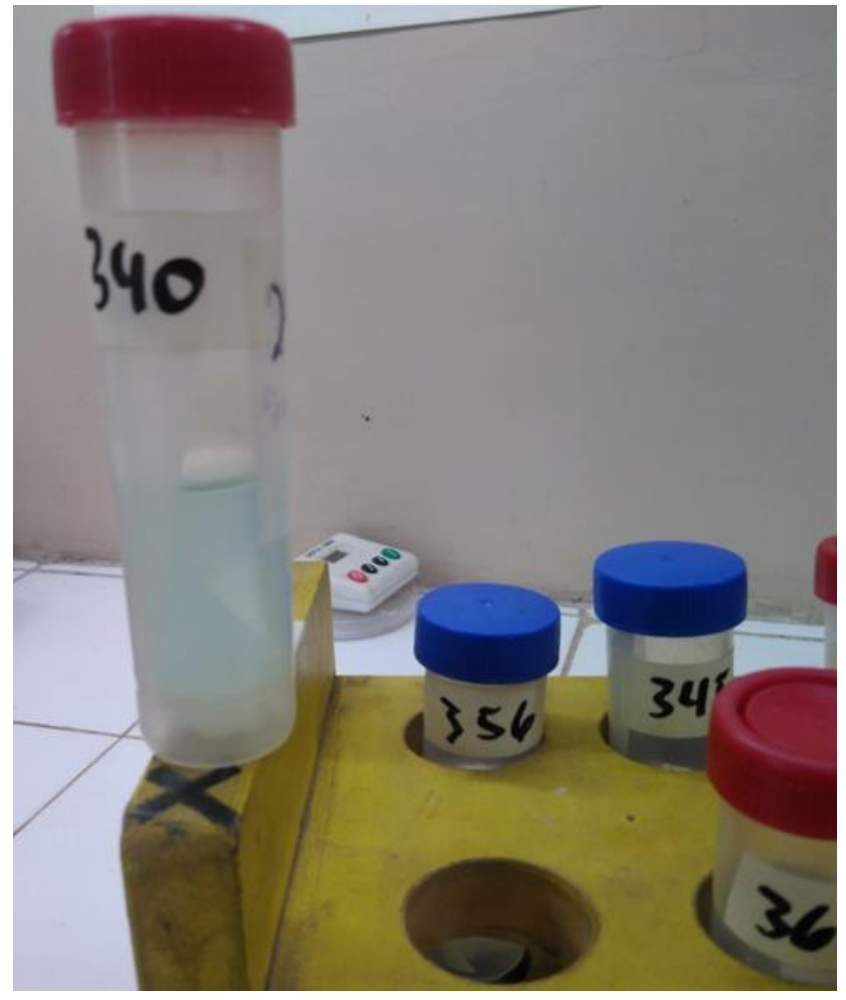

Foto 11: Lavado con agitación en tubo Falcon ${ }^{\circledR}$

El siguiente paso consistió en cuantificar la concentración del trazador colorimétrico sobre el solvente de extracción, por medio de un fotómetro de absorción molecular y una curva de calibración de concentraciones conocidas. Esta concentración fue contrastada contra las concentraciones iniciales colocadas en los papeles. 
La combinación de papel Whatman 41 con agitación generó residuos del papel en el solvente, en tanto que la ausencia de agitación produjo menores porcentajes de extracción del solvente al igual que la extracción con alcohol en ambas concentraciones. Los resultados arrojaron que la mejor combinación consistió en papel Whatman 40 con 1 minuto de agitación con agua como solvente.

La metodología utilizada arrojó valores de 99-100 \% de extracción del colorante del papel con una concentración suficiente para ser cuantificada por una curva de calibración.

El procesamiento de estas tarjetas se realizó en dos etapas:

1- Extracción del trazador de las tarjetas de papel de filtro por medio de lavado con $20 \mathrm{ml}$ de agua destilada, dentro de tubos Falcon ${ }^{\circledR}$ de $50 \mathrm{ml}$, con sumersión del papel y agitación vaivén del tubo en posición horizontal (180 golpes por minuto) por 1 minuto para asegurar la correcta extracción y recuperación de la solución resultante. Posteriormente fue trasvasado a tubos de ensayo y guardados en condiciones de oscuridad y baja temperatura, para garantizar que no se degrade el colorante (Fotos 11 y 12 ). 


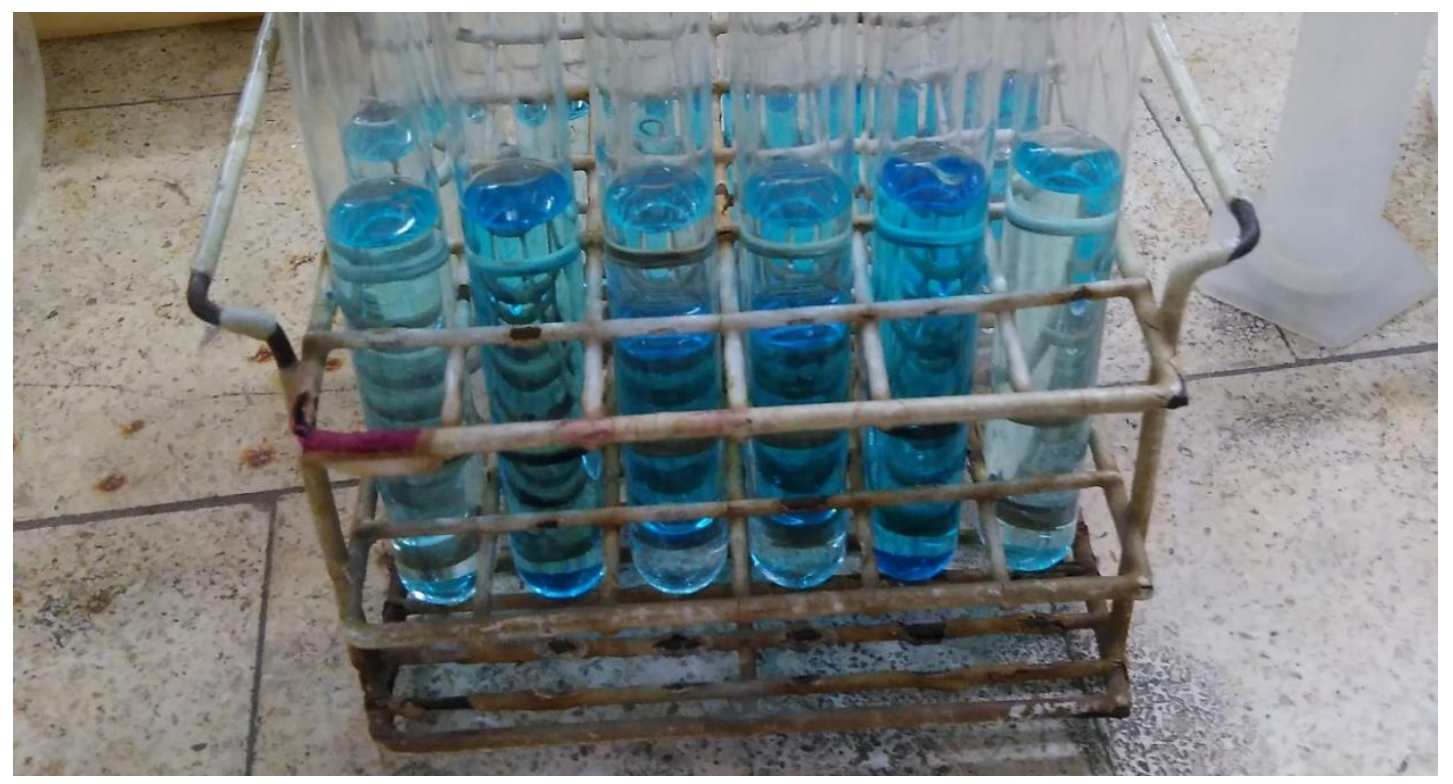

Foto 12: extractos de lavado con agitación

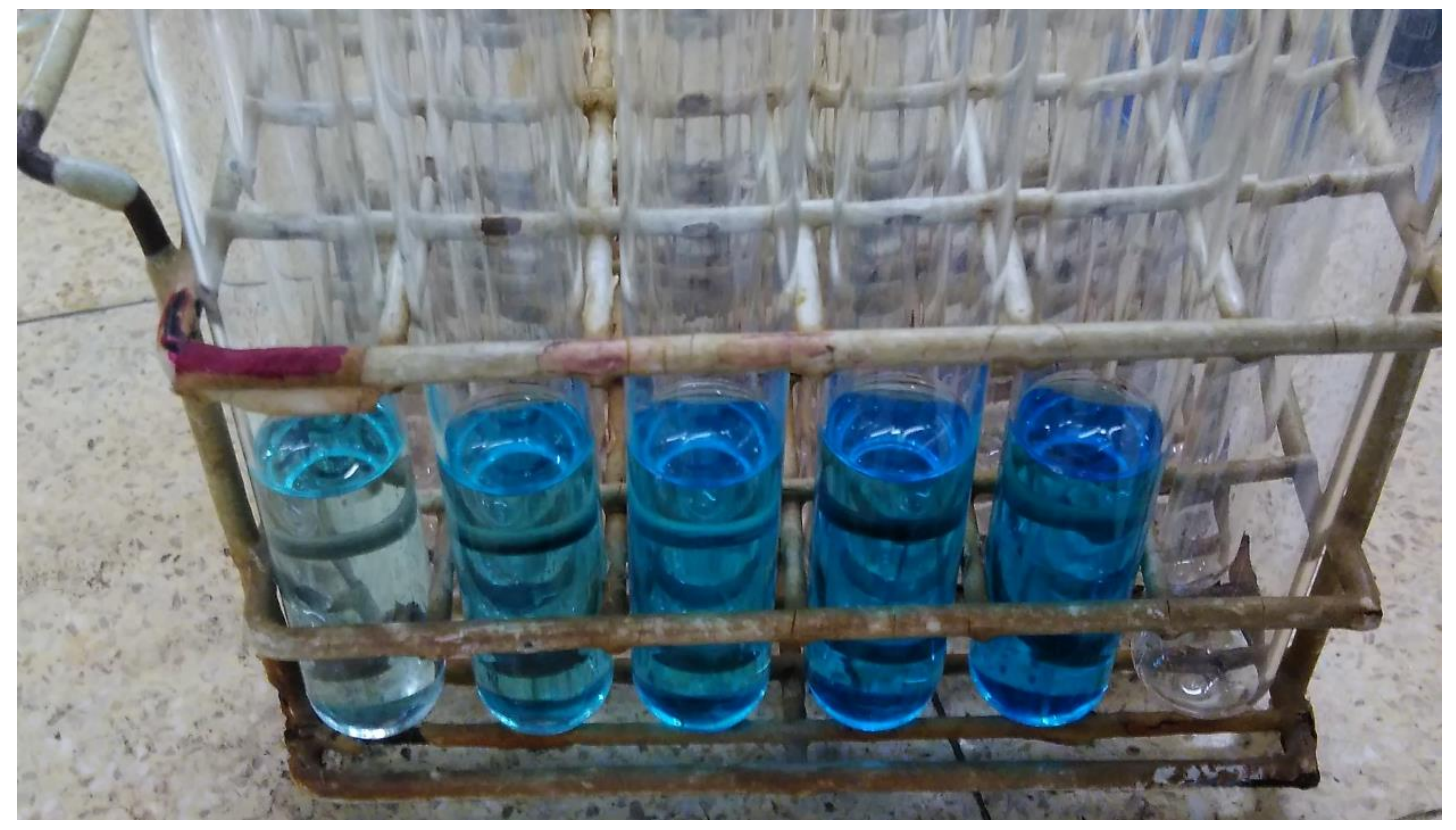

Foto 13: Curva de calibración

2- Cuantificación por colorimetría con un espectrofotómetro Metrolab 325 (Palladini et al., 2005) (Foto 13). 


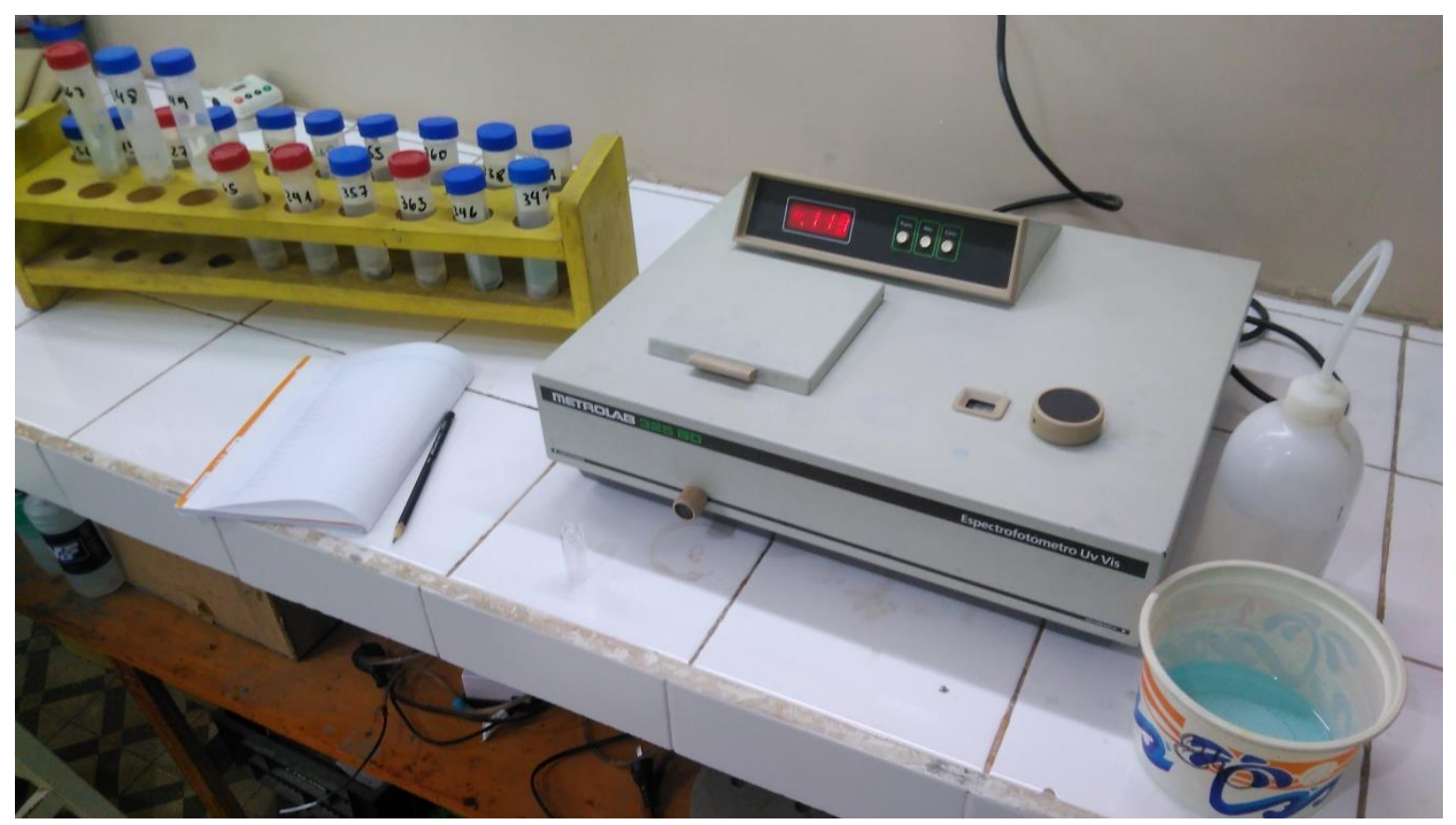

Foto 14: Medición con espectrofotómetro

\section{Análisis de los resultados}

\section{Análisis estadístico}

Se colocaron 6 bancos en cada pasada de pulverización, con todas las tarjetas objetivos en sus respectivas posiciones, estos funcionaron como repeticiones para cada una de las posiciones. Se colocaron en cada posición tarjetas de papel Whatman ${ }^{\circledR} \mathrm{N}^{\circ} 40$ por duplicado, ya que al ser una metodología nueva se entendió necesario constatar los valores y el lavado en el laboratorio destruye la tarjeta no permitiendo detectar errores. Se realizó una única pasada por encima de los bancos con las condiciones de trabajo ya mencionadas y una tasa de aplicación a razón de 50 I ha-1 .

Todos los datos obtenidos fueron volcados en planillas Excel y procesados estadísticamente mediante el software estadístico Infostat $^{\circledR}$ (2018). Se realizaron los análisis de residuos de los datos y, sobre estos, las pruebas de normalidad, por gráficos de 
cuantiles teóricos (Q-Q plot), el contraste de hipótesis de Shapiro-Wilk y las pruebas de independencia y homocedasticidad. Los datos de la totalidad de las variables no cumplieron con el principio de normalidad por lo que se efectuaron las transformaciones de los mismos en acuerdo con el tipo de variable (logaritmo (In y Log10)), raíz cuadrada (SQRT) y potencias $\left(x^{2}\right.$ y $\left.x^{3}\right)$, sin alcanzar los requisitos para efectuar los análisis de la varianza. Por lo que se decidió realizar un análisis de la varianza no paramétrico por el método de la prueba de $\mathrm{H}$ de Kruskal Wallis y comparación de medias por el test basado en ranks de Kruskal Wallis con una significancia de $5 \%(p \leq 0,05)$. El estadístico de la prueba $(\mathrm{H})$ se basa en la suma de los rangos (ranks) asignados a las observaciones dentro de cada tratamiento. Su distribución exacta es obtenida a partir de la consideración de todas las configuraciones posibles de los rangos (ranks) de $\mathrm{N}$ observaciones en $\alpha$ grupos de $n_{i}$ observaciones cada uno, si existen diferencias significativas entre los grupos permite realizar una prueba post hoc de a pares. InfoStat permite solicitar comparaciones de a pares entre las medias de los rangos (ranks) de tratamientos y/o contrastes entre medias de los rangos (ranks) de tratamientos. El procedimiento usado para juzgar la significancia de las comparaciones múltiples y los contrastes postulados es el descripto en Conover (1999). Si bien las comparaciones entre tratamientos se realizan a través de las diferencias entre las medias de los rangos (ranks), InfoStat permite también visualizar las diferencias entre tratamientos a nivel de medias y medianas de los valores originales de las variables (Balzarini et al., 2008; Di Rienzo et al., 2017).

Organización de los resultados 
Para el análisis de resultados se procedió en primera instancia a evaluar en forma conjunta la totalidad de las posiciones, a fin de determinar si existen diferencias entre pastillas, y verificar si alguna consigue mejores resultados en el banco completo.

Se realizó un segundo análisis comparando los resultados de las tarjetas que fueron colocadas en el objetivo más bajo del banco versus las tarjetas colocadas en el objetivo más alto. Este análisis no presentó diferencias estadísticas para ninguna variable por lo tanto se decidió tomar las tarjetas de estas posiciones como repeticiones (Tabla $\mathrm{N}^{\circ} 1$ del Anexo II).

En un tercer análisis se procedió a dividir los mismos, según cada una de las posiciones relativas dentro del banco de prueba en las que fueron colocadas las tarjetas, a fin de evaluar cuál de las pastillas consigue los mejores resultados en cada sector del objetivo y poder analizar de esa forma las características de la población de gotas que llegan a cada sitio.

Esta forma de separación y análisis también se realizó para las posiciones verticales y horizontales en general.

Por último, se realizó el análisis para cada pastilla, de la uniformidad en la distribución del líquido pulverizado entre los distintos objetivos. 


\section{RESULTADOS Y DISCUSIÓN}

\section{Densidad de impactos $\mathrm{cm}^{-2}$}

Como se puede observar en la figura 1 al analizar la Densidad de impactos en todo el banco objetivo, independientemente de la posición relativa de las tarjetas y la altura de los obstáculos, se puede notar que las pastillas CC son las que consiguen la mayor Densidad de impactos, aunque sin llegar a diferenciarse de DD y AP. Los resultados son coincidentes con los informados por Ferguson et al., (2015), Zhu et al., (2004) y Derksen et al., (2008). También guardan relación con las características de la población de gotas que cada pastilla produce según la información de los fabricantes de pastillas (tabla 1) y el DVM de las gotas que alcanzan el objeto de aplicación (figura 5). Las mayores densidades de impactos se registraron para las pastillas que producen un menor tamaño de gota y las menores para las de mayor tamaño. Con la menor Densidad de impactos se puede observar a DAP, lo cual es esperable ya que, si bien estas pastillas están conformadas por dos orificios, que erogan $0,4 \mathrm{I} \mathrm{min}^{-1}$ cada uno, y deberían generar un mayor número de impactos, al inducir aire se aumenta significativamente el tamaño de las gotas y se reduce la densidad de éstas. Por lo tanto, tampoco se esperaría que las pérdidas de gotas por evaporación o efecto del viento en las condiciones del ensayo dentro de galpón fuesen relevantes. 


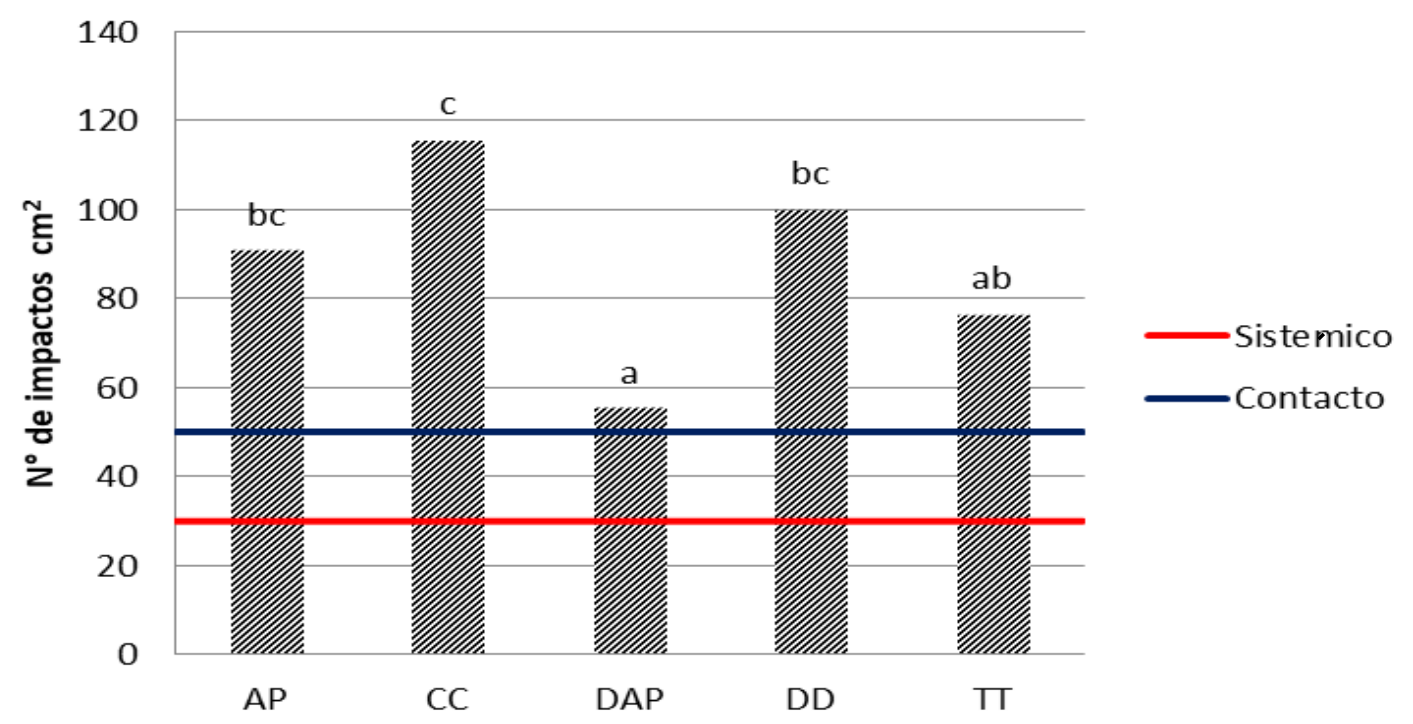

Figura 1: Densidad de impactos $\mathrm{cm}^{-2}$ promedio de todas las posiciones del banco objetivo. Línea roja: número mínimo para control con herbicidas sistémicos; línea azul: número mínimo para control con herbicidas de contacto (Weber, 1982). AP: abanico plano, CC: cono convencional, DAP: doble abanico plano inducido, DD: abanico angulado simple alternado y TT: deflectora. Letras diferentes presentan diferencias significativas ( $p$ value $\leq 0,05)$, para test de Ranks de Kruskal Wallis.

En un punto intermedio, separándose estadísticamente solo de la CC, se hallan las pastillas TT. Resultados similares fueron hallados por Roncaglia (2018) en aplicaciones sobre barbecho con los receptores ubicados por sobre la superficie del mismo. Se puede observar que, si bien existen diferencias bastantes marcadas entre las pastillas, estas no llegan a manifestarse en dicha magnitud en el análisis estadístico. Esto se debe, en parte, a la gran dispersión de los datos debido principalmente a la diferencia de impactos que se pueden observar tanto en lo relativo a la disposición horizontal y vertical, como a su ubicación anterior o posterior. Por lo antedicho, se decidió particionar los datos para mejorar su análisis en objetivos verticales y horizontales (Figura $\mathrm{N}^{\circ} 2$ ) 


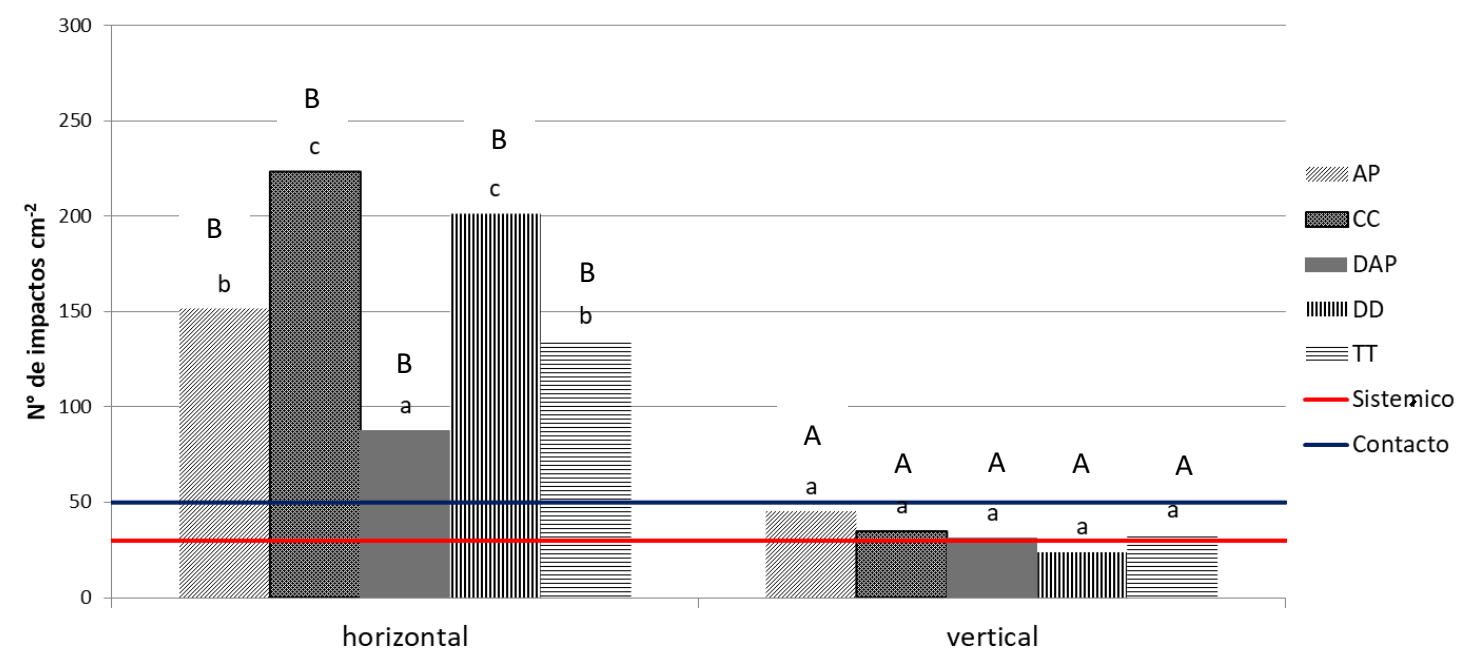

Figura 2: Densidad de impactos $\mathrm{cm}^{-2}$. Particionado por posiciones Verticales y Horizontales dentro del banco objetivo. Línea roja: número mínimo para control con herbicidas sistémico. Línea azul: número mínimo para control con herbicida de contacto (Weber, 1982). AP: abanico plano, CC: cono convencional, DAP: doble abanico plano inducido, DD: abanico angulado simple alternado y TT: deflectora. Letras minúsculas diferentes indican diferencias significativas entre pastillas dentro de cada posición. Letras mayúsculas diferentes presentan diferencias significativas ( $p$-value $\leq 0,05$ ), entre posiciones para cada pastilla según el test de Ranks de Kruskal Wallis.

En la figura 2 se puede observar que las posiciones verticales no muestran diferencias significativas entre sí, pero si una menor Densidad de impactos que en las posiciones horizontales; estas diferencias tan marcadas concuerdan con los trabajos de Wolf \& Peng (2011), Ozkan et al., (2012), Wolf \& Cadwell (2013) y Gadea (2018), demostrando que alcanzar objetivos verticales es una dificultad importante para todas las alternativas tecnológicas evaluadas.

A su vez, a diferencia de lo observado en la Figura 1, las pastillas CC y DD presentan, en las posiciones horizontales, similar prestación y alcanzan significativamente mayor Densidad de impactos que las demás pastillas evaluadas. También, AP y TT no logran diferencias entre sí en este parámetro, pero poseen significativamente mayor número de impactos 
que DAP. Esto en parte concuerda con Gadea (2018) y Sayinci \& Bastaban (2011) y si se observan los DVM de las gotas generadas por cada pastilla (Tabla 5) y se comparan con los cálculos de Teixeira (2010) (Tabla 3), si bien los valores no se ajustan exactamente, la tendencia es lógica para las Densidades de impactos obtenidas para las posiciones horizontales y cada tipo de pastilla.

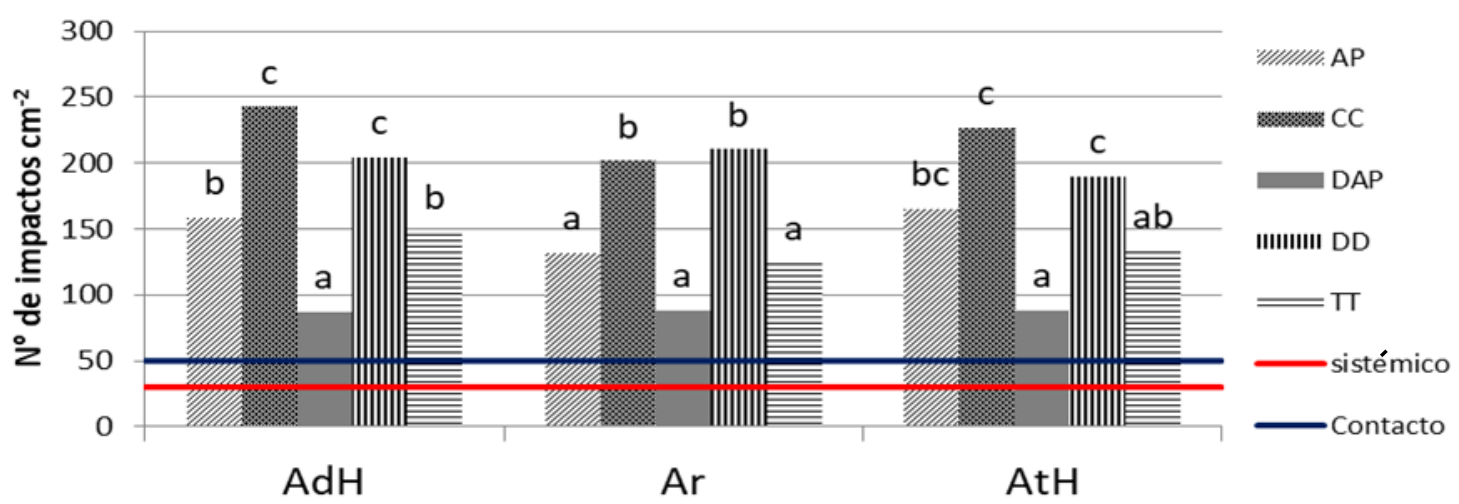

Posiciones Horizontales en el banco objetivo

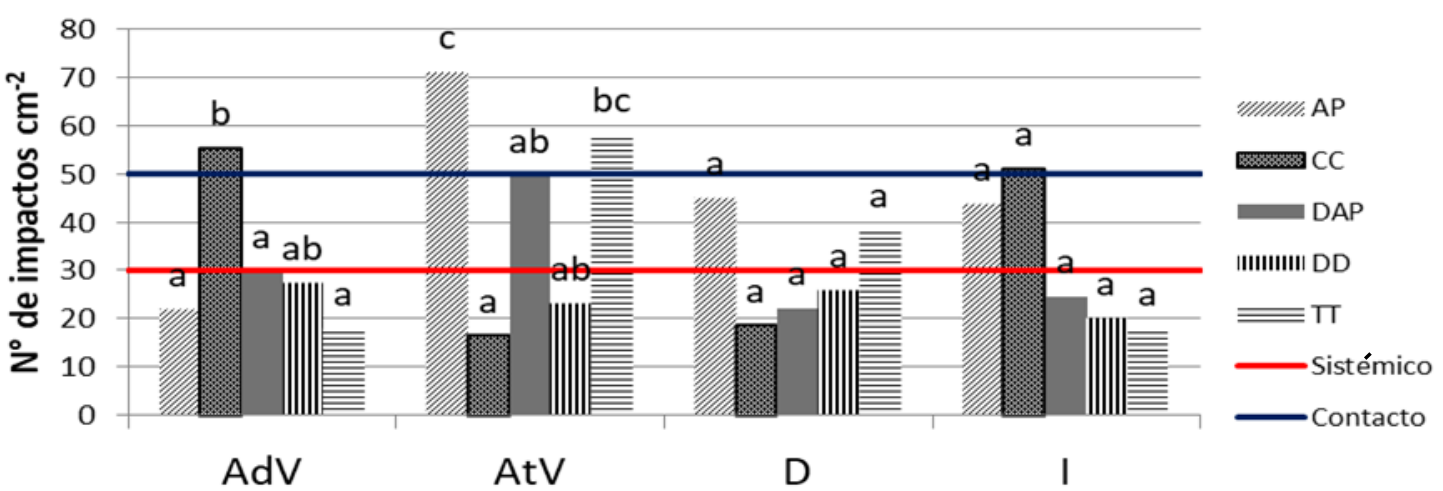

Posiciones Verticales en el banco objetivo

Figura 3: Densidad de impactos $\mathrm{cm}^{-2}$ particionada por posiciones relativas dentro del banco para objetivos horizontales y verticales. Línea roja: número mínimo para control con herbicidas sistémicos. Línea azul: número mínimo para control con herbicidas de contacto. AP: abanico plano, CC: cono convencional, DAP: doble abanico plano inducido, DD: abanico angulado simple alternado y TT: deflectora. AdH: adelante horizontal, Ar: arriba, AtH: atrás horizontal, AdV: adelante vertical, AtV: atrás vertical, D: derecha, I: izquierda. Letras diferentes presentan diferencias significativas ( $p$-value $\leq 0,05$ ), para test de Ranks de Kruskal Wallis, entre pastillas dentro cada posición. 
Si se dividen los resultados en función de cada una de las posiciones relativas del banco de prueba (figura 3) se puede observar que las posiciones horizontales mantienen una tendencia similar a la observada en las figuras 1 y 2, pero con comportamientos levemente diferentes según la posición y la pastilla, que no inciden sobre la prestación general de las distintas alternativas evaluadas.

Todas las pastillas alcanzan en las posiciones horizontales el número mínimo de impactos para control de malezas, tanto para herbicidas sistémicos como de contacto, independientemente de si se encuentran o no parcialmente sombreados por algún obstáculo. Esto implicaría también que la altura de los obstáculos colocados no resultó suficiente para afectar significativamente la Densidad de impactos en el lado de la sombra por detrás de los mismos y que malezas de escaso desarrollo no ocasionarían interferencia en la llegada a otras cercanas de menor tamaño, alcanzando menores eficiencias pero no limitando la aplicación.

La pastilla DAP presentó, independientemente de su ubicación, en la posición horizontal los menores valores, los cuales fueron significativamente inferiores a CC y DD en todas las ubicaciones. También tuvieron diferencias significativas con AP y TT en AdH y con AP en AtH. Estos resultados son en parte esperables y explicables, ya que, por ser una pastilla de aire inducido, debería generar un menor número de gotas con mayores diámetros. Las variaciones en la significancia de las diferencias de DAP con respecto a AP y TT, en las distintas ubicaciones, se produjeron más por cambios en el resto de las pastillas que por modificaciones en la Densidad de impactos de DAP, puesto que la misma fue muy uniforme. 
Las pastillas CC y DD son las de mejor performance, ya que alcanzaron la mayor Densidad de impactos en todas las posiciones horizontales, sin diferencias estadísticas significativas entre sí, en ninguna de las mismas. Este comportamiento también es esperable ya que ambas pastillas poseen un tamaño de gota fino a la presión de trabajo usada en el experimento, generando para un mismo caudal mayor número de gotas. Con respecto a las demás pastillas, alcanzaron valores significativamente mayores que las otras 3 pastillas (AP, TT y DAP) en las posiciones AdH y Ar y que DAP y TT en AtH.

Las pastillas AP y TT tuvieron en todas las posiciones comportamientos similares, sin diferencias estadísticas significativas entre sí, e intermedios entre las pastillas DD y CC, y la pastilla DAP. En función de la posición los valores se acercan más a los obtenidos por DD y CC o a DAP. En la posición Ar, AP y TT se acercan en prestación a DAP y presentan una baja Densidad de impactos, siendo estos valores los más bajos de las posiciones horizontales. En la posición AtH, AP se asemeja más a CC y DD, pero TT se asemeja más a CC. Estas variaciones entre posiciones no son marcadas y la Densidad de impactos de las 2 pastillas supera ampliamente los mínimos recomendados para herbicidas de contacto.

Por lo expuesto, es claro que ninguna pastilla evaluada presenta limitaciones en este factor, tanto para herbicidas sistémicos o de contacto. No obstante, cabe recordar que las condiciones del ensayo fueron con temperatura inferior a los $19^{\circ} \mathrm{C}$, humedad relativa superior al $89 \%$ y velocidad del viento inferior a $1 \mathrm{~m} \mathrm{~s}^{-1}$. Por lo tanto, es posible que, en condiciones no tan favorables para la aplicación de agroquímicos, pueden empeorar los resultados, reduciéndose la Densidad de impactos y acercándose, en algún caso, a los mínimos sugeridos por Weber (1982). 
En las posiciones verticales se pueden observar grandes diferencias entre los objetivos. Las posiciones de I y $D$ no se diferencian estadísticamente pese a que se observan diferencias difíciles de explicar, probablemente por la dispersión de los datos (Tabla $\mathrm{N}^{\circ} 5$ ). Pese a esto, se puede observar que AP consigue similar cantidad de impactos en ambas posiciones, alcanzando la Densidad de impactos mínima para el control de malezas con herbicidas sistémicos, pero no para herbicidas de contacto; CC, en cambio, consigue la Densidad de impactos necesaria para herbicidas de ambas formas de acción, pero solo en la posición I. TT alcanza el número mínimo de impactos solo en la posición D y solo para productos sistémicos.

En la posición AdV el CC es el tratamiento que se diferencia con la mayor cantidad de impactos, alcanzando registros para herbicidas de contacto y sistémicos en esta posición, siendo el resto muy parecido entre sí; esto es llamativo ya que la bibliografía cita que las gotas más grandes y por lo tanto más pesadas son las que impactan mayormente en esta posición (Nordbo, 1992; Wolf \& Peng, 2011; Ozkan et al., 2012). Podría ser posible que este efecto esté más relacionado al mayor número de gotas generado por la pastilla en general. Teixeira (2010) menciona la Densidad de impactos $\mathrm{cm}^{-2}$, en función del volumen de pulverización para un diámetro de gota media, es esperable en función de las ecuaciones:

$N^{\circ}$ de gotas para un litro de producto

$n \cdot \frac{1}{6} \cdot \pi \cdot \mathrm{DV}^{3}=10^{15} \quad$ Ec: 6

Dónde: 
$\mathrm{n}$ : Número de gotas

DV: Diámetro de las gotas, $(\mu \mathrm{m})$

Extrayendo $\mathrm{n}$ de la ecuación 1 se deduce:

$n=\frac{1,9098 \cdot 10^{15}}{\mathrm{DV}^{3}} \quad$ Ec: 7

Dónde:

$\mathrm{n}$ : Número de gotas

DV: Diámetro de las gotas, $(\mu \mathrm{m})$

Considerando una tasa de aplicación de $\mathrm{Q}\left(\mathrm{I} \mathrm{ha}{ }^{-1}\right)$ se puede definir el $\mathrm{N}^{\circ}$ de gotas por unidad de superficie:

$n_{\mathrm{s}}=\frac{1,9098 \cdot 10^{7}}{\mathrm{DVM}^{3}} \cdot Q \quad$ Ec: 8

Dónde:

$\mathrm{n}_{\mathrm{s}}$ : Número de gotas por unidad de superficie (gotas $\mathrm{cm}^{-2}$ )

DVM: Diámetro volumétrico medio de las gotas $(\mu \mathrm{m})$

Q: Tasa de aplicación (I ha ${ }^{-1}$ )

En función de esta Ecuación Teixeira (2010) define la densidad de gotas para distintos tamaños de gotas y tasas de aplicación (Tabla 3).

Tabla 3: Densidad de gotas (gotas $\mathrm{cm}^{-2}$ ) obtenidas en función del diámetro de gotas $(\mu \mathrm{m})$ y de la tasa de aplicación (I ha ${ }^{-1}$ ). Extraído de Teixeira (2010).

\begin{tabular}{|l|c|c|c|c|c|c|c|c|}
\hline Diámetro & \multicolumn{7}{|c|}{ Tasa de aplicación $\left(\mathbf{~ h a}^{-1}\right)$} \\
\hline Gota $(\mu \mathrm{m})$ & $\mathbf{2 5}$ & $\mathbf{4 0}$ & $\mathbf{5 0}$ & $\mathbf{6 0}$ & $\mathbf{8 0}$ & $\mathbf{1 0 0}$ & $\mathbf{1 5 0}$ & $\mathbf{2 0 0}$ \\
\hline 100 & 480 & 765 & 960 & 1150 & 1530 & 1910 & 2870 & 3820 \\
\hline 150 & 140 & 225 & 280 & 340 & 450 & 565 & 830 & 1130 \\
\hline 200 & 60 & 100 & 120 & 150 & 200 & 240 & 360 & 480 \\
\hline 250 & 30 & 48 & 60 & 72 & 96 & 120 & 180 & 240 \\
\hline 300 & 18 & 28 & 36 & 42 & 56 & 71 & 106 & 140 \\
\hline 400 & 8 & 12 & 16 & 18 & 24 & 30 & 45 & 60 \\
\hline 500 & 4 & 6 & 8 & 9 & 12 & 15 & 23 & 30 \\
\hline
\end{tabular}


Según la Tabla $N^{\circ} 3$ y lo observado en la Figura 5 y la Tabla $N^{\circ} 4$, es posible suponer que las pastillas CC generarán casi el doble de gotas que las pastillas AP, DD y TT, y casi 4 veces más que DAP; por lo tanto, es esperable encontrar un mayor Densidad de impactos en muchas posiciones del banco objetivo.

En la posición AtV esto cambia y la pastilla con mayor Densidad de impactos es AP seguida sin diferencias por TT y luego DAP que no se diferencia de los tratamientos TT, DD y CC. Esto contradice a Sayinci \& Bastaban (2011) y Gálvez et al., (2005), que indican a CC como la pastilla adecuada para llegar a zonas difíciles, pero coincide con Díaz de Ackermann \& Kohli (2013) quienes mencionan que las pastillas cono hueco son las de peor comportamiento para alcanzar control de fusariosis en espigas en comparación con pastillas de abanico plano y de doble abanico con diferentes angulaciones, probablemente por su pequeño tamaño de gota. Es factible que esto se deba a la ausencia de viento que ayude al movimiento de las gotas en las condiciones semi-confinadas del ensayo, factor importante en la distribución de gotas pequeñas como la que genera CC (Hardi, 2003; Tepper, 2014).

Los resultados también contradicen la información técnica de las pastillas DD que destaca su aptitud para alcanzar zonas difíciles (Hypro, 2013; Syngenta, 2015; John Deere, 2017). Estas dificultades para alcanzar objetivos verticales ya han sido mencionadas por Nordbo, (1992); Wolf \& Peng, (2011); Ozkan et al., (2012); y Diaz de Ackermann \& Kohli, (2013). 
Otro factor a tener en cuenta, que pudo incidir sobre los resultados, es la altura del botalón. Los ensayos de Wolf \& Peng (2011) demuestran que a mayor altura del botalón, para todas las velocidades estudiadas, peor es la llegada de gotas a los objetivos verticales, al igual que lo encontrado por Wolf \& Caldwell (2013). Siguiendo con este análisis se deberían tener en cuenta dos factores que se generan por la angulación. Por un lado, Jensen (2007) y Bauer \& Raetano (2004) mencionan que al inclinar la boquilla es necesario reducir la altura del botalón si pretendemos mantener la distancia al objetivo ya que la misma aumenta debido a la angulación (Imagen 4) y tiene un efecto marcado en la superposición de los abanicos ya que al recorrer una mayor distancia se produce un mayor solapamiento de los mismos, siempre y cuando la gota sea lo suficientemente grande para mantener la dirección en una distancia mayor. Por otro lado, el efecto de la gravedad en la caída de las gotas en pastillas con angulación generaría, al aumentar la distancia al objetivo, un cambio en la dirección de caída de la gota con pérdida en la angulación con la que se desprendió de la pastilla, propiciando la reducción del efecto buscado por la misma de alcanzar el objetivo de la forma más perpendicular posible (Elliott \& Mann, 1997; Richardson \& Newton, 2000).

Al establecer en el ensayo una única altura de trabajo, compatible con el rango indicado para la totalidad de las pastillas, se modificó la distancia real al objeto de aplicación, incrementándola y posiblemente perjudicando en parte a las pastillas con ángulos diferentes de $0^{\circ}$. Las pastillas, además, son de menor caudal que las utilizadas por Bauer \& Raetano (2004) por lo que las gotas producidas también son más pequeñas, y no 
necesariamente mantienen la dirección a lo largo de toda su trayectoria hasta alcanzar al objetivo.

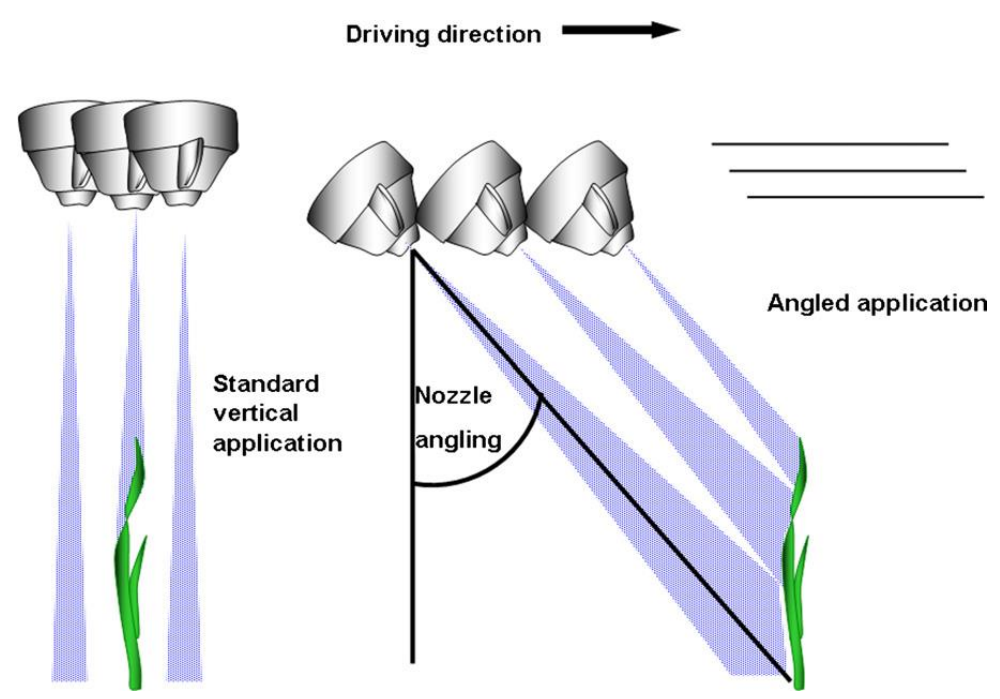

Imagen 6: angulación de las pastillas sobre objetivos verticales Jensen (2012)

Tanto informes técnicos de fabricantes de pastillas (Hypro, 2013; Agrotop, 2008) como trabajos científicos (Matthews, 2004; Jensen, 2007; Rodrigues et al., 2010 y Wolf \& Peng, 2011) mencionan que la salida de las gotas de tamaño medio son impulsadas hacia adelante por la velocidad de avance generada por el tractor, lo cual conlleva la necesidad de colocar las pastillas anguladas hacia atrás para facilitar más la llegada a los objetivos opuestos en relación a los que enfrentan al botalón en su avance. En este ensayo las mayores dificultades fueron para alcanzar los objetivos verticales delanteros en casi todas las pastillas, excepto CC.

DD y DAP resultaron ser las pastillas más uniformes si evaluamos por separado las posiciones verticales y horizontales (Figura 4).

Estos resultados resultan contrapuestos a los mencionados anteriormente, pudiendo atribuirse a la velocidad de avance del conjunto, cercana a los 4,7 $\mathrm{m} \mathrm{s}^{-1}\left(17 \mathrm{~km} \mathrm{~h}^{-1}\right)$ siendo 
muy superior a todas las citadas en todos los ensayos mencionados. Liu et al., (2006) descubrió que velocidades de avance del botalón por encima de los $2,8 \mathrm{~m} \mathrm{~s}^{-1}$ y con una altura al objetivo de 0,7 m, generan que las gotas lleguen al objetivo después de la pasada del botalón. Este comportamiento se observó en pastillas abanico plano desde los 1,6 m s ${ }^{1}$, en conos convencionales desde los $2,2 \mathrm{~m} \mathrm{~s}^{-1} \mathrm{y}$ en pastillas aire inducido desde los $2,7 \mathrm{~m}$ $\mathrm{s}^{-1}$. En función de esos resultados concluyen que la velocidad de avance del pulverizador tiene una influencia significativa en el tiempo de transporte de gotas, mientras que la presión del líquido y el tipo de boquilla poseen un efecto menor en el mismo. Este retardo en el tiempo de transporte podría ayudar a generar un mayor número de impactos en posiciones traseras, tal como encuentran Wolf \& Peng (2011) quienes mencionan que al aumentar la velocidad de $2,1 \mathrm{~m} \mathrm{~s}^{-1}$ a $3,2 \mathrm{~m} \mathrm{~s}^{-1}$ y 4,2 $\mathrm{m} \mathrm{s}^{-1}$ encuentran aumentos significativos en las posiciones traseras de objetivos verticales.

Tabla 4: Valores de Densidad de impactos (Media, Desvío Estándar, Coef. de Variación y Valores mínimos y máximos) para las distintas posiciones verticales. AdV (adelante vertical), AtV (atrás vertical), D (derecha), I (izquierda)

\begin{tabular}{|c|c|c|c|c|c|c|}
\hline Posiciones & Pastilla & Media & D.E. & $\mathrm{CV}$ & Min & Max \\
\hline \multirow{5}{*}{ AdV } & $A P$ & 21,83 & 19,09 & 87,45 & 8 & 80 \\
\hline & $\mathrm{CC}$ & 55,25 & 48,55 & 87,88 & 16 & 162 \\
\hline & DAP & 29,75 & 31,61 & 106,26 & 9 & 99 \\
\hline & DD & 27,42 & 13,85 & 50,53 & 12 & 53 \\
\hline & TT & 18 & 12,12 & 67,34 & 5 & 49 \\
\hline & & & & & & \\
\hline \multirow{5}{*}{ AtV } & AP & 71,08 & 25,18 & 35,42 & 32 & 114 \\
\hline & $\mathrm{CC}$ & 16,42 & 14,68 & 89,39 & 7 & 61 \\
\hline & DAP & 49,67 & 83,4 & 167,91 & 6 & 278 \\
\hline & DD & 23,17 & 12,83 & 55,37 & 10 & 49 \\
\hline & TT & 58,17 & 79,78 & 137,15 & 12 & 289 \\
\hline & & & & & & \\
\hline \multirow{4}{*}{ D } & $A P$ & 44,92 & 57,39 & 127,78 & 9 & 187 \\
\hline & $\mathrm{CC}$ & 18,5 & 14,9 & 80,56 & 7 & 48 \\
\hline & DAP & 22,17 & 17,26 & 77,85 & 11 & 75 \\
\hline & DD & 25,92 & 12,62 & 48,68 & 6 & 55 \\
\hline
\end{tabular}




\begin{tabular}{|c|c|c|c|c|c|c|}
\hline & TT & 38,33 & 39,17 & 102,19 & 9 & 121 \\
\hline \multirow{5}{*}{ I } & $A P$ & 43,83 & 57,53 & 131,26 & 9 & 170 \\
\hline & CC & 51 & 58,72 & 115,14 & 13 & 204 \\
\hline & DAP & 24,58 & 18,5 & 75,24 & 9 & 79 \\
\hline & $\mathrm{DD}$ & 20,17 & 11,72 & 58,09 & 6 & 47 \\
\hline & TT & 17,92 & 8,31 & 46,36 & 7 & 31 \\
\hline
\end{tabular}

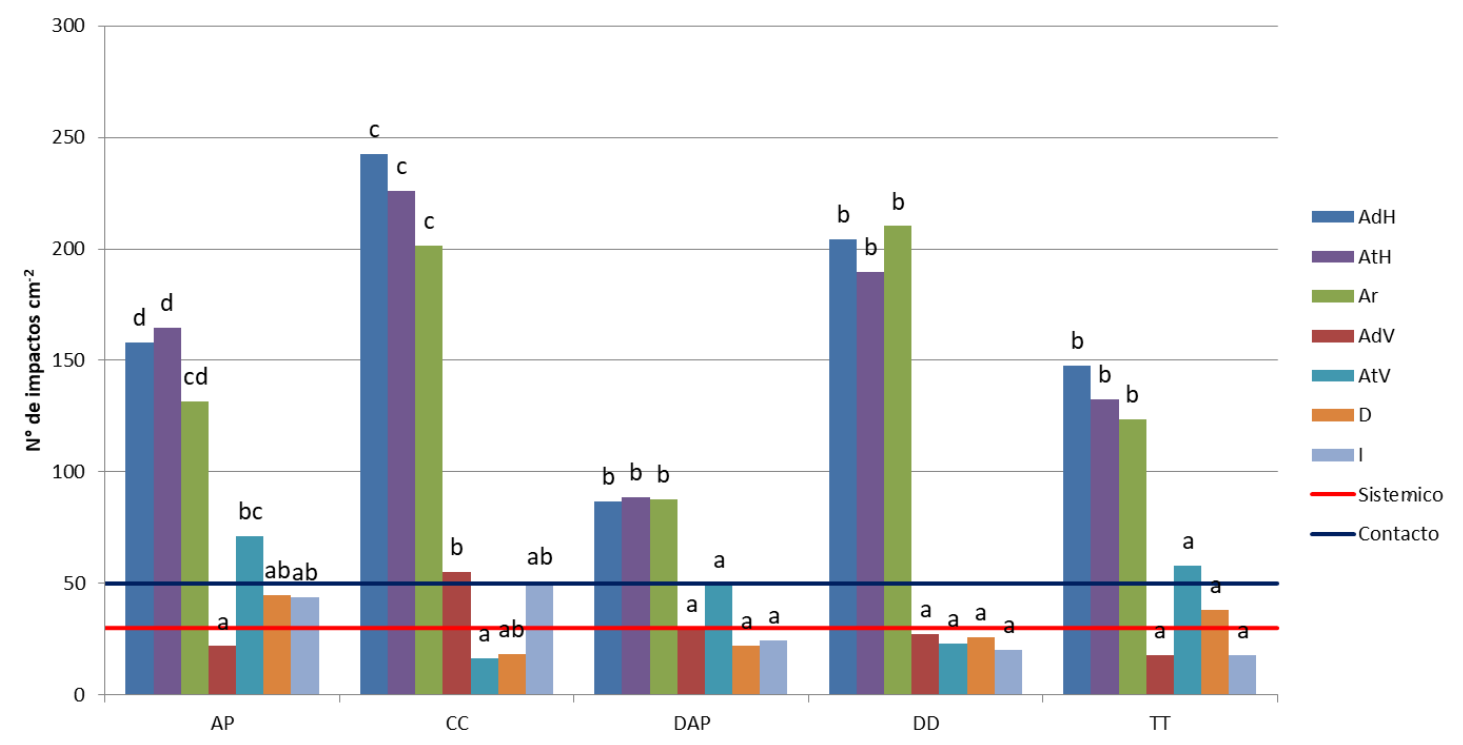

Figura 4: Uniformidad de la Densidad de impactos por $\mathrm{cm}^{2}$ particionada por pastillas para todas las posiciones relativas dentro del banco objetivo. Línea roja $\mathrm{N}^{\circ}$ mínimo para control con herbicidas sistémico, línea azul $\mathrm{N}^{\circ}$ mínimo para control con herbicidas de contacto. AP: abanico plano, CC: cono convencional, DAP: doble abanico plano inducido, DD: abanico angulado simple alternado y TT: deflectora. AdH: adelante horizontal, Ar: arriba, AtH: atrás horizontal, AdV: adelante vertical, AtV: atrás vertical, D: derecha, I: izquierda. Letras diferentes presentan diferencias significativas ( $p$-value $\leq 0,05$ ), para test de Ranks de Kruskal Wallis, entre posiciones dentro de la pastilla.

En la figura 4 se visualiza la Densidad de impactos obtenidos en las diferentes caras de los objetivos. Todas las pastillas en las posiciones horizontales alcanzaron densidades de impactos sin diferencias significativas entre $\mathrm{AdH}, \mathrm{Ar}$ y $\mathrm{AtH}$, lo cual implica que las alturas planteadas como obstáculos no constituyen mayores inconvenientes para alcanzar objetivos traseros horizontales. Por otra parte, es posible notar que DD, TT y DAP 
presentan similar Densidad de impactos en todas las posiciones verticales, sin diferencias significativas. No obstante, al igual que en todas las pastillas, se observan diferencias marcadas entre posiciones verticales y horizontales.

Tal como mencionan Chapple et al., (1993), Masiá \& Cid (2010) y Boller (2011), según el tipo de pastillas se observan diferentes características de distribución, siendo DD la que presenta la mayor uniformidad en las posiciones verticales y DAP, en cambio, en las posiciones horizontales. Esto probablemente se encuentre relacionado a las angulaciones de las pastillas las cuales mejorarían la uniformidad, en acuerdo con Dorr (1990), Etiennot et al., (1998), Nicholson et al., (2003), Jensen (2007), Jensen (2010) y Villalba et al., (2011).

El resto de las pastillas presenta una mayor des uniformidad. TT resulta uniforme, desde el punto de vista estadístico, ya que no presenta diferencias dentro de las 4 posiciones verticales, como así tampoco entre las horizontales, pero tiene diferencias del $300 \%$ entre posiciones delanteras y traseras verticales. AP mantiene similares características que las demás pastillas en los objetivos horizontales, sin diferencias significativas entre las mismas. En los objetivos verticales las diferencias son más marcadas entre la cara delantera y la trasera, sin que ello permita inferir una prestación peor que el resto. Por lo expuesto, uniformidad y Densidad de impactos revelan algunas diferencias en las posiciones horizontales y verticales. La pastilla más uniforme en las posiciones verticales fue la DD, pero también registró los menores valores, por debajo de 30 impactos $\mathrm{cm}^{-2}$, por lo que su uniformidad parece poco relevante en el marco de las posibilidades de control. En forma contraria a lo expuesto, en las posiciones horizontales no existe tal contraposición, ya que todas fueron uniformes y superaron en más de 2, 3 y 4 veces los 
valores requeridos para productos de contacto, salvo para DAP que no llegó a duplicar los mismos.

En función de los resultados obtenidos de Densidad de impactos para las distintas pastillas evaluadas, es posible afirmar que ninguna de ellas presenta dificultades para el control de malezas dispuestas en forma horizontal, aunque se hallen cubiertas por otras de mayor porte en el marco de las alturas planteadas en el ensayo. También es posible afirmar que en estas condiciones de trabajo la angulación de las pastillas no mejora necesariamente la Densidad de impactos en objetivos sombreados.

\section{Conclusiones parciales Densidad de impactos $\mathrm{cm}^{-2}$}

En las condiciones del ensayo es notorio que la Densidad de impactos en objetivos verticales es menor que en los objetivos horizontales. Por lo tanto, en control de malezas cuyas hojas se disponen en posición más vertical casi ninguna pastilla alcanzaría la Densidad de impactos necesarios. Por lo antedicho es posible validar en parte la hipótesis que "La disposición de los objetivos en relación a la dirección de los abanicos de pulverización es determinante de la calidad de pulverización en cuanto a la cantidad de impactos y cobertura".

Para las condiciones de trabajo en este ensayo las pastillas anguladas no mejoran la Densidad de impactos en los objetivos verticales pudiendo rechazar en la hipótesis "Las pastillas con angulación antero posterior producen mayor Cobertura y Densidad de impactos, independientemente del ángulo que posean en objetivos sombreados y verticales". 
No obstante, si se evalúan en forma separada las posiciones verticales de las horizontales, las pastillas con algún tipo de angulación presentan mayor uniformidad en la distribución sobre las diferentes caras en la Densidad de impactos, pudiendo aceptar así la hipótesis, para el parámetro densidad de impactos, que asevera "las pastillas anguladas con disposición alternada sobre el botalón generan mayor uniformidad entre las caras anteriores y posteriores del objetivo"; sin embargo, TT también presenta una buena uniformidad, lo que probablemente puede deberse a su diseño para la formación de gotas, el cual genera un abanico con una salida angulada de $15^{\circ}$, esto indica la necesidad de realizar mayores estudios y es un factor interesante sobre el cual avanzar en futuros experimentos.

\section{Diámetro Volumétrico Mediano (DVM o DV0,5)}

En acuerdo con la Tabla 1, las pastillas evaluadas presentan diferencias en el tamaño y características de la población de gotas. La pastilla CC es habitualmente la de menor tamaño de gota, mientras que TT, al ser una pastilla de impacto, se espera que posea gotas más grandes que los abanicos; y DAP se comporta igual a ésta última, ya que si bien es una pastilla de dos abanicos $0,4 \mathrm{I} \mathrm{min}^{-1}$, posee inducción de aire. Ambas presentan gotas medianas a diferencia de AP y DD, que a 3 bar generan gotas finas.

En la figura 5 se observan los valores de DVM de cada pastilla promedio, en las distintas posiciones, donde CC tuvo los menores valores, con diferencias significativas con la totalidad de las pastillas. AP y DD tuvieron registros similares entre sí y menores que TT y DAP, siendo ésta última la de mayor tamaño. Estos resultados no coinciden con las fichas 
técnicas de los fabricantes (Teejet, 2014; Hypro Pentair, 2017), lo que probablemente se deba a dos factores que interactúan de manera compleja. Por un lado, fue utilizada una presión levemente menor a lo normalizado en la medición de fábrica, lo cual debería haber generado un tamaño de gota mayor para todas las pastillas, cosa que efectivamente no ocurrió. Por otra parte, la evaluación del DVM se realizó a partir de la impronta de las gotas sobre las tarjetas hidrosensibles. Al respecto, Zhu et al., (2011), encontraron que el software de procesamiento de imágenes presenta diferencias respecto a un microscopio estereoscópico cuando se determinaba el tamaño de la gota. También hallaron que esta inexactitud disminuye cuando la gota es más grande. Del mismo modo, Stefanelo et al., (2014) y Bayer et al., (2012), atribuyeron las diferencias a las limitaciones del papel hidrosensible en detectar gotas de tamaño reducido. Otro factor seria la pérdida de gotas chicas, desde la pastilla hasta el sitio donde se colocaron las tarjetas hidrosensibles, aumentando por consecuencia ligeramente el DVM de la población. Pese a esto, los valores resultaron coincidentes, en parte, con los determinados por Matthews, (2000), Cunha et al., (2004), Zhu et al., (2004), Stainier et al., (2006) y Bueno et al., (2013), quienes citan relaciones de tamaños de gotas similares a las observadas. 


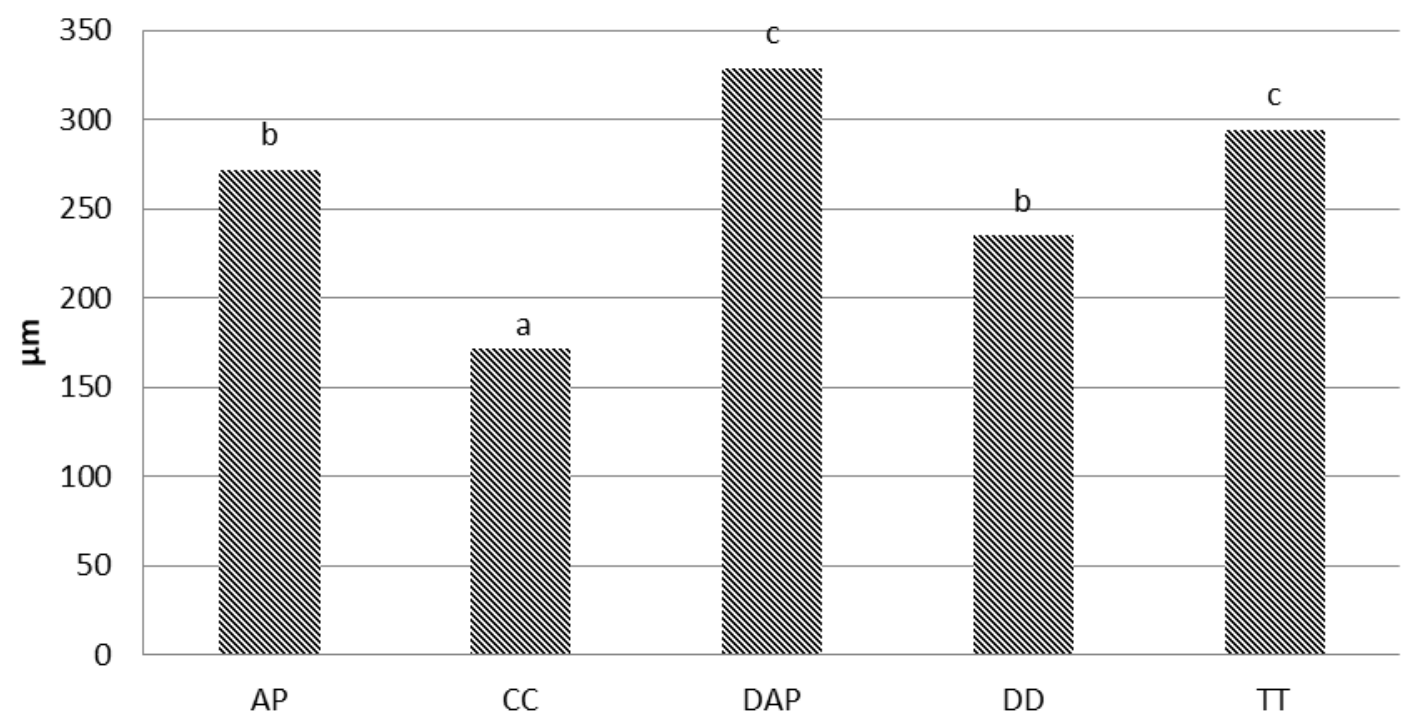

Figura 5: Diámetro Volumétrico Mediano promedio de todas las posiciones del banco objetivo. AP: abanico plano, CC: cono convencional, DAP: doble abanico plano inducido, DD: abanico angulado simple alternado y $\mathrm{TT}$ : deflectora. Letras diferentes presentan diferencias significativas ( $p$-value $\leq 0,05$ ), para test de Ranks de Kruskal Wallis.

Cuando se analizan en forma independiente los datos correspondientes a las posiciones horizontales y verticales, se puede observar que las posiciones horizontales mantienen una tendencia similar a lo observado en la figura 5, pero las pastillas AP y DD ya no son iguales, y todas presentan un DVM levemente mayor al observado en la figura 5 debido a que sus medias no son arrastradas hacia abajo por los valores de DVM de las posiciones Verticales los cuales son siempre menores (figura 6).

Por otro lado, en las posiciones verticales, exceptuando a CC, todas las pastillas presentan un DVM similar y siempre con valores menores a los observados en las posiciones horizontales. Si bien no existen diferencias significativas entre las pastillas la tendencia es semejante a lo observado en la Figura 5. 


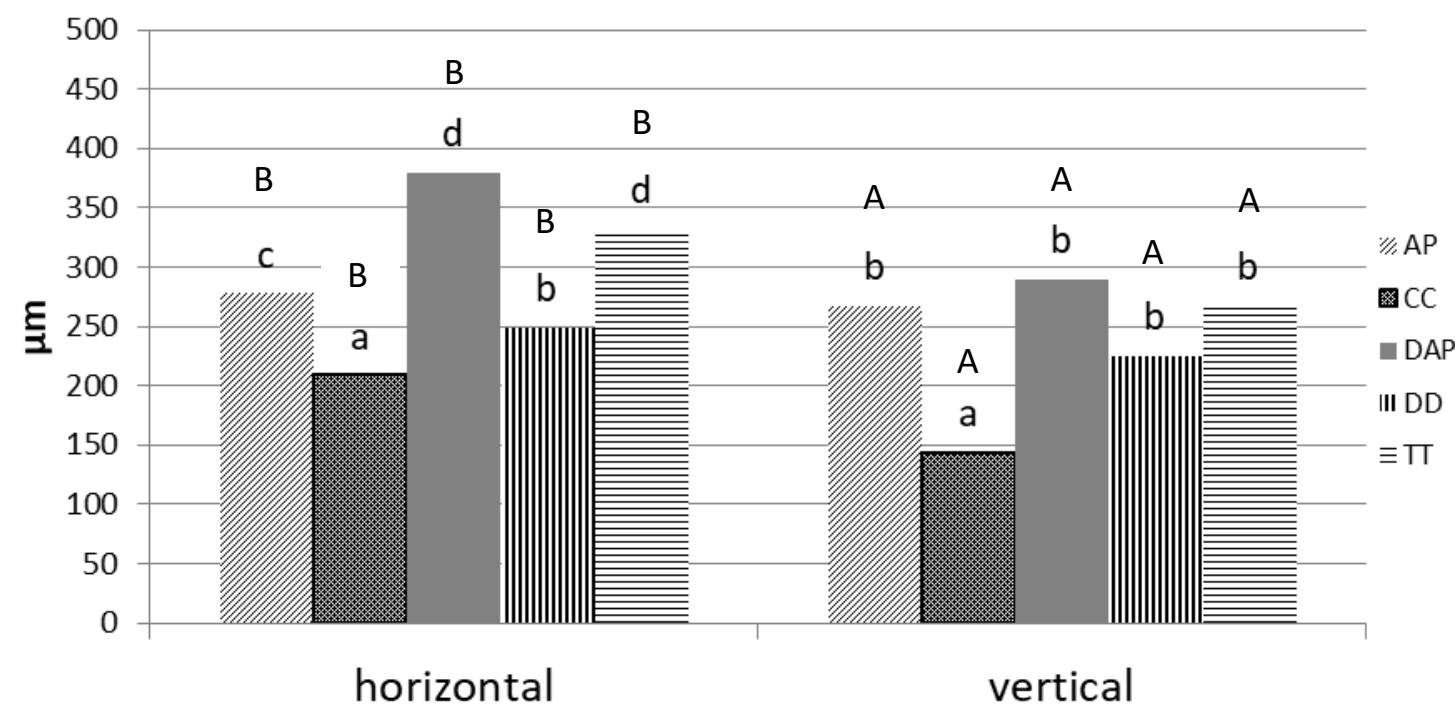

Figura 6: Diámetro Volumétrico Mediano particionado por posiciones Verticales y Horizontales dentro del banco objetivo. AP: abanico plano, CC: cono convencional, DAP: doble abanico plano inducido, DD: abanico angulado simple alternado y TT: deflectora. Letras minúsculas diferentes presentan diferencias significativas ( $p$-value $\leq 0,05$ ), para test de Ranks de Kruskal Wallis, entre pastillas dentro de cada posición. Letras mayúsculas diferentes presentan diferencias significativas ( $p$-value $\leq 0,05)$, entre posiciones para cada pastilla según el test de Ranks de Kruskal Wallis.

En la figura 7 se visualizan los valores medios de DVM de las diferentes pastillas en cada una de las posiciones relativas del banco. Se puede observar que, en las posiciones horizontales, el DVM coincide con lo observado en las figuras 5 y 6.

Las posiciones verticales en cambio difieren para cada una de las pastillas y cada una de las posiciones. DAP y DD son las pastillas que se diferencian del resto en alguna de las dos posiciones AdV y AtV, siendo DAP la de mayor DVM en la posición AdV y DD la de mayor en la posición AtV; este comportamiento coincide en parte con lo citado por Wolf \& Peng (2011) quienes encontraron que las pastillas con angulaciones de $30^{\circ}$ o $60^{\circ}$ alcanzan mejor los objetivos verticales. Aun así, ni DAP ni DD llegan a diferenciarse de AP en ninguna de las posiciones. Esto puede deberse en parte a la altura de botalón con la que se trabajó ya que el efecto de angulación se pierde por una elevada altura de trabajo y como 
mencionan Wolf \& Peng (2011) se produce una reducción de 2,5 a 3,6 veces la deposición de gotas mayores a $200 \mu \mathrm{m}$ al pasar de una altura de botalón de 0,30 m a 0,75 m a velocidades de 4,2 $\mathrm{m} \mathrm{s}^{-1}\left(15,2 \mathrm{~km} \mathrm{~h}^{-1}\right)$, similares a las de este ensayo.

Por otro lado, CC difiere de este comportamiento. Independientemente de la Densidad de impactos, el tamaño de gotas fue similar en todas las posiciones y siempre fue el menor entre todas las pastillas; esto probablemente se debe a que las gotas que alcanzaron los objetivos horizontales registraron valores de DVM inferiores a $210 \mu \mathrm{m}$ mientras que las que se depositaron sobre los verticales fueron menores a $165 \mu \mathrm{m}$. A la vez, también tuvieron los menores Coeficientes de dispersión y amplitud relativa (Figuras 9, 10, 11, 12 y 13) lo cual concuerda en parte por lo hallado por Nuyttens et al. (2007b). 

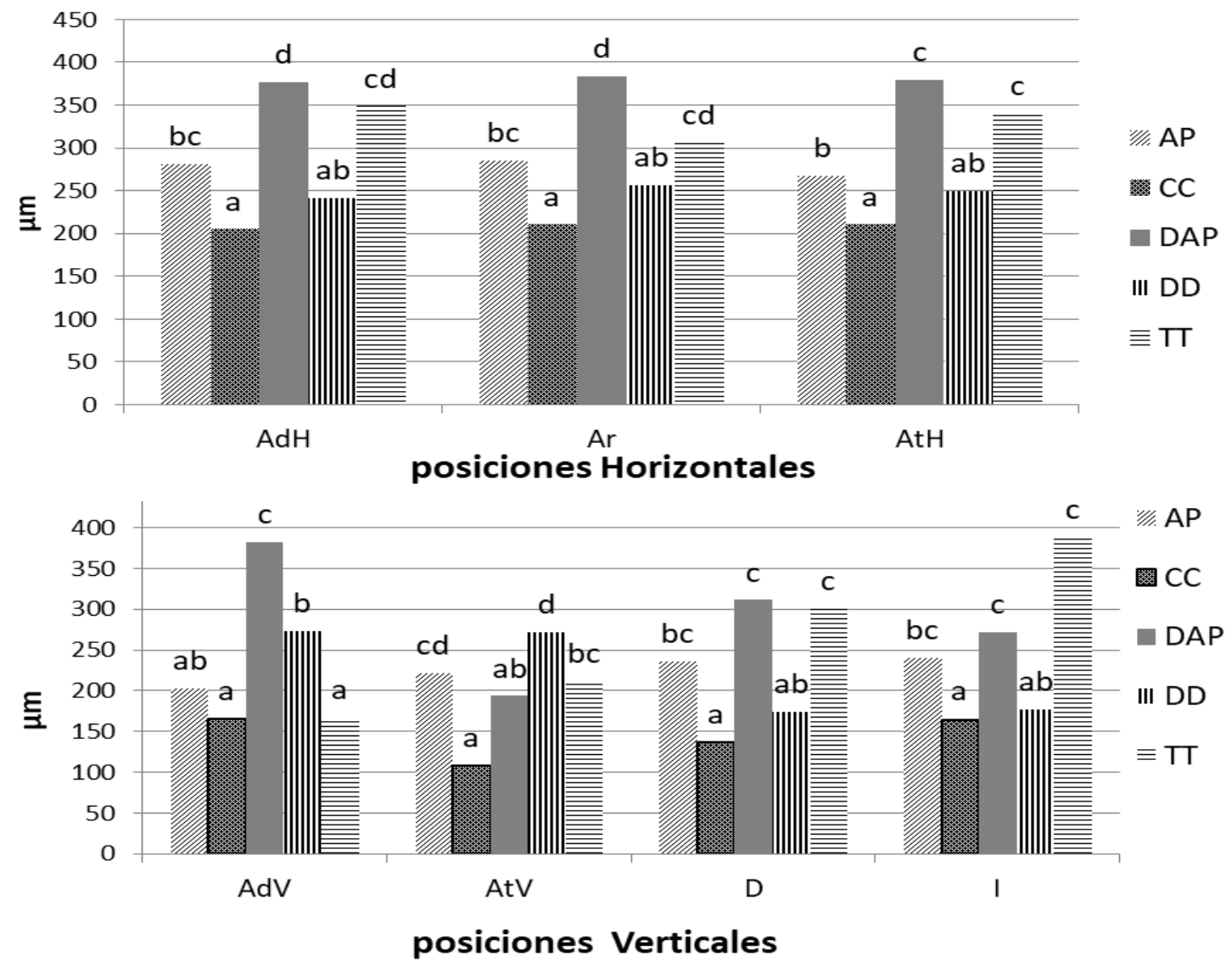

Figura 7: Diámetro Volumétrico Mediano particionado por todas las posiciones relativas dentro del banco objetivo. AP: abanico plano, CC: cono convencional, DAP: doble abanico plano inducido, DD: abanico angulado simple alternado y TT: deflectora. AdH: adelante horizontal, Ar: arriba, AtH: atrás horizontal, AdV: adelante vertical, AtV: atrás vertical, D: derecha, I: izquierda. Letras diferentes presentan diferencias significativas ( $p$-value $\leq 0,05)$, para test de Ranks de Kruskal Wallis, entre pastillas dentro de las posiciones.

Otro parámetro de evaluación es la uniformidad en el tamaño de las gotas (DVM) entre las distintas posiciones objetivos de la aplicación. En la Figura 8 se observa que la pastilla DD es la de mayor uniformidad y alcanza casi todas las posiciones del objetivo con igual tamaño de gotas, solo encontrando diferencias en las posiciones D e I las que presentan gotas más chicas. Es interesante mencionar que las pastillas con mayor tamaño de gotas son las DAP seguido por TT y las de menor tamaño son CC, hallándose AP y DD en 
posiciones intermedias, lo cual es esperable y coincide con los datos aportados por Spraying Systems Co. en los data sheets $N^{\circ} 37043-16 M$, (Spraying Systems Co, en David \& Peña, 2014) 37043-14M, (Spraying Systems Co, 2016.) y 37043-1M (Spraying Systems Co, 1992) y las fichas técnicas de John Deere (2017) (Tabla $N^{\circ} 3$ ). En la misma se puede visualizar que las pastillas DD presentan en el objetivo valores similares a los que erogan las pastillas según indica el fabricante.

Por otro lado podemos observar que $\mathrm{CC}$ es la única pastilla que diferencia estadísticamente todos los objetivos verticales, con gotas chicas, de las gotas con un tamaño algo mayor de todos los objetivos horizontales, pero dentro de un rango de gotas de 100 a $200 \mu \mathrm{m}$; esto probablemente se puede atribuir a la falta de viento que no moviliza las gotas pequeñas direccionándolas a los objetivos verticales y a una mayor uniformidad de la población de gotas, característica habitualmente mencionada para este tipo de pastillas.

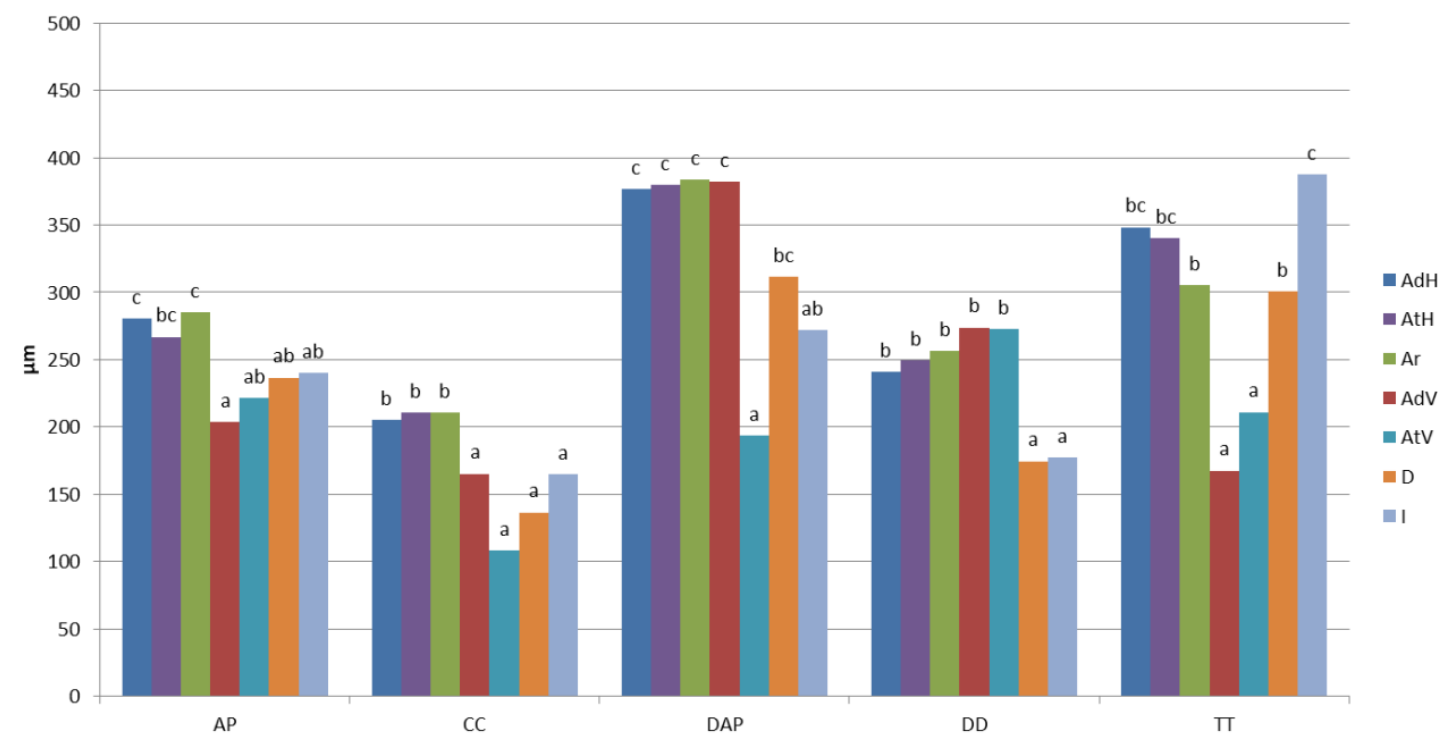

Figura 8: Uniformidad en el tamaño de las gotas (DVM). AP: abanico plano, CC: cono convencional, DAP: doble abanico plano inducido, DD: abanico angulado simple alternado 
y TT: deflectora. AdH: adelante horizontal, Ar: arriba, AtH: atrás horizontal, AdV: adelante vertical, AtV: atrás vertical, D: derecha, I: izquierda. Letras diferentes presentan diferencias significativas ( $p$-value $<0,05$ ), para test de Ranks de Kruskal Wallis, entre posiciones dentro de las pastillas.

Para los objetivos horizontales, DAP y CC, presentan muy buena uniformidad en el tamaño de gotas, pero variable en el caso de DAP para los verticales y más uniforme en CC donde no se observan diferencias significativas, pero si valores con $50 \%$ de diferencia. TT y AP presentan tamaños de gotas muy desuniforme, más parecidos en el caso de las posiciones horizontales y muy dispares en los verticales.

Tabla 5: Características de la familia de gotas a la salida de la pastilla y evaluadas sobre los objetivos.

\begin{tabular}{|c|c|c|c|c|}
\hline \multicolumn{5}{|c|}{ Característica de las gotas a la salida de las pastillas* } \\
\hline Pastilla & DV0,5 & DV0,1 & DV0,9 & AR \\
\hline AP & 229 & 114 & 374 & 1,14 \\
\hline CC & 208 & 102 & 293 & 0,92 \\
\hline TT & 255 & 126 & 546 & 1,65 \\
\hline DD & 240 & 65 & 350 & 1,19 \\
\hline DAP & 300 & 88 & 495 & 1,36 \\
\hline Característica de las gotas evaluadas sobre los objetivos** \\
\hline Pastilla & DV0,5 & DV0,1 & DV0,9 & AR \\
\hline AP & 271,54 & 134,02 & 365,27 & 0,85 \\
\hline CC & 171,66 & 92,75 & 260,49 & 0,98 \\
\hline TT & 294,36 & 143,54 & 449,54 & 1,04 \\
\hline DD & 234,94 & 124,03 & 337,55 & 0,91 \\
\hline DAP & 328,46 & 174,85 & 474,37 & 0,91 \\
\hline
\end{tabular}

*Parámetros extraídos de las fichas tecnicas John Deere (2009) y Data Sheets N³704316M (Spraying Systems Co, s.f. en David \& Peña 2014), 37043-14M (Spraying Systems Co, 2016)., 37043-1M (Spraying Systems Co, 1992).

** Parámetros evaluados sobre el papel hidrosensible con el programa CIR1.5

El menor DVM de la población de gotas de CC debería haber favorecido una mayor eficiencia de deposición según lo informado por Smith et al., (2000) quienes mencionan que las eficiencias previstas disminuyeron a medida que el tamaño de gota aumenta por encima de los $140 \mu \mathrm{m}$. Por otro lado, Lenz et al., (2011) encontraron mayor velocidad de 
absorción del producto con el uso de gotas de menor diámetro, explicando estos resultados por la mayor densidad de gotas $y$, en consecuencia, a la mayor área de contacto planta/producto. Sumado a esto, diversos autores mencionan que las gotas de menores diámetros proporcionan una mayor penetración entre las hojas de los cultivos (Christofoletti, 1992; Santos, 1992; Ozeki \& Kunz, 1998). Sin embargo, la deposición de las gotas, cuantificada a partir de la densidad de impactos, no se vio favorecida sobre la totalidad de los objetivos planteados, cumpliéndose principalmente para los objetivos horizontales. Los objetivos verticales para CC no alcanzan, en general, una mayor deposición de impactos que el resto de las pastillas y la cara que recibió mayor número se corresponde con mayor DVM. La ausencia de mayor densidad de impactos para esta pastilla en las posiciones verticales no puede relacionarse al tamaño de las gotas ni a una mayor interferencia de viento, altas temperaturas, ni baja humedad relativa del aire, indicadas por Christofoletti (1999) dadas las condiciones ambientales del ensayo que no favorecieron pérdidas por deriva y por evaporación. Podría establecerse como hipótesis ad-hoc, que la ausencia de viento habría incidido en forma negativa en el movimiento de las gotas alrededor de los objetivos verticales, dificultando la deposición de gotas de tamaño reducido.

En un análisis general de las poblaciones de gotas que se depositan sobre los distintos objetivos de aplicación (Figura 8, Tabla 5) es posible visualizar que las mismas se encuentran para las distintas pastillas evaluadas en el rango recomendado por Leiva (1995) entre $150 \mu \mathrm{m}$ y de 350, cercanas al indicado como adecuado balance entre 200 y $250 \mu \mathrm{m}$ y de Márquez (1997) de $300 \mu \mathrm{m}$ en promedio. Solamente las pastillas CC, con 
DVM de $174 \mu \mathrm{m}$ se hallan cercanas al límite inferior y por debajo de los $200 \mu \mathrm{m}$, considerados adecuados por el primero de ellos, y las DAP, con DVM de $328 \mu \mathrm{m}$, por encima de lo recomendado por el segundo.

Tomando en cuenta estos valores, no se producirían los inconvenientes mencionados por Klein \& Johnson (2002) quienes indican que tamaños de gotas mayores a $400 \mu \mathrm{m}$ no se mantienen sobre la superficie de la planta, a la vez que proveen de una baja cobertura sobre el objetivo. No obstante, por todo lo mencionado, la utilización de gotas gruesas suele ser considerada de dudosa eficacia biológica, pero es reconocida como positiva desde el punto de vista del control de la deriva y por las consecuentes mejoras en el cuidado del ambiente.

En este ensayo muy pocas pastillas presentaron gotas mayores a los $400 \mu \mathrm{m}$ en posiciones verticales, en el $10 \%$ de volumen aplicado en la pulverización, indicado por los valores de $\mathrm{DV}_{0,9}$, lo que generaría un porcentaje de pérdidas por escurrimiento muy bajo. No obstante, en las posiciones horizontales casi todas las pastillas lo hicieron, a excepción de AP en Ar y AtH y CC en AdH; esto indicaría que, al ser las hojas objetivos con movimiento, ante el impacto de gotas grandes se podrían generar mayores pérdidas por escurrimiento en las pastillas DAP, DD y TT.

Por otro lado, como ya se ha mencionado, las gotas con diámetros inferiores a $100 \mu \mathrm{m}$ son susceptibles a derivarse por efecto del viento y la evaporación (Cunha et al., 2003). Si bien no existe un rango de tamaño de gota específico que sea propenso a la deriva en todas las condiciones, muchos investigadores han considerado que gotas más pequeñas de $75 \mu \mathrm{m}$ (Hobson et al., 1993), 100 um (Byass \& Lake, 1977; Grover et al., 1978 y Bode, 1984), 150 
$\mu \mathrm{m}$ (Leiva, 1995; Combellack et al., 1996) o $200 \mu \mathrm{m}$ (Bouse et al., 1990) como las más propensas a la deriva.

Como se puede observar en la tabla 5, solo las pastillas CC presentan un $10 \%$ del volumen que llega al objetivo $\left(\mathrm{DV}_{0,1}\right)$ con diámetros menores a $100 \mu \mathrm{m}$. Si se tiene en cuenta que las eficiencias de aplicación para objetivos horizontales (Figura 16) en estas condiciones variaron entre el $50 \%$ y el $80 \%$ aproximadamente para todas las pastillas, se podría pensar que pese a que los volúmenes susceptibles a exoderiva son relativamente bajos existe un alto potencial de riesgo, dado que las condiciones atmosféricas en las que se realizó el ensayo minimizaron las pérdidas. En este sentido, si se toman en cuenta los resultados de Combellack et al., (1996), que citan valores de $150 \mu \mathrm{m}$ como tamaño de gotas susceptible a la deriva todas las pastillas, salvo DAP, perderían al menos un $10 \%$ más de producto, por exoderiva y reduciría en la misma proporción la eficiencia de aplicación.

Si las condiciones de aplicación fueran peores y se tomase como base un tamaño de gota de $200 \mu \mathrm{m}$ (Bouse et al., 1990), todas las pastillas podrían perder un $10 \%$ del volumen de aplicación adicional y, las pastillas CC, hasta un $50 \%$ del volumen aplicado, dado que el $\mathrm{DV}_{0,5}$ informado por el fabricante es de $208 \mu \mathrm{m}$ y el medido sobre los objetivos de 171,6 $\mu \mathrm{m}$.

Esto se debe, en parte, a que las gotas más pequeñas (menores a $200 \mu \mathrm{m}$ ), pierden velocidad más rápido que las de mayor tamaño hasta alcanzar la velocidad límite, equilibrio de aceleración y roce entre las gotas y el fluido por el que se mueve (Goering et al., 1972; Nuyttens et al., 2009). Por lo tanto, a mayor masa de la gota mayor velocidad; 
como consecuencia las gotas pequeñas se encuentran mayor tiempo en el aire, expuestas a otras fuerzas tales como el viento, pudiendo desplazarse a otro lugar fuera del objetivo (De Cock et al., 2017). Además, también disminuyen su tamaño por evaporación reduciendo aún más su velocidad de caída. Zhu et al., (2004) mencionan que gotas con tamaño menor a $50 \mu \mathrm{m}$ quedan en el aire por tiempo indefinido o hasta su completa evaporación. En este sentido y como ya se discutió, Leiva (1995) también menciona que las gotas pequeñas mejoran la retención por parte de las hojas así como la cobertura, ofreciendo también una mejor penetración en el cultivo y mayor posibilidad de alcanzar la cara inferior de las hojas y tallos, pero su principal desventaja radica en que por su menor peso están más propensas a ser transportadas por el viento (deriva) y por su elevada superficie expuesta en relación a su volumen sufren una intensa evaporación antes de depositarse, reduciendo su volumen y aumentando aún más su tiempo de caída.

\section{Conclusiones parciales Diámetro Volumétrico Mediano (DVM o DV0,5}

En función de los resultados de la población de gotas recolectada sobre los diferentes sectores de los bancos es posible con este parámetro refutar la hipótesis que las pastillas DD generan similares condiciones de tamaño, densidad de gotas y cobertura sobre todas las caras que actúan como objetivos de aplicación. También es posible rechazar la hipótesis que el espectro de gotas que alcanza los objetivos verticales es de DV0,5 más uniforme que en los objetivos horizontales, ya que en ninguna de las pastillas se visualizó esto. Es posible establecer la hipótesis que en estas condiciones de ensayo, sin corrientes de aire de importancia por el ambiente generado dentro del galpón, no se hallan favorecidos movimientos de las gotas de menor tamaño alrededor de los objetos 
colocados como obstáculos, lado de la sombra contrario al sentido de avance de la maquina pulverizadora.

\section{Coeficiente de dispersión}

El Coeficiente de dispersión es una variable construida por la relación entre el DNM y el $\mathrm{DV}_{0,5}$, el cual permite establecer el grado de homogeneidad de la población de gotas, ésta es mayor cuando el mismo se acerca a 1.

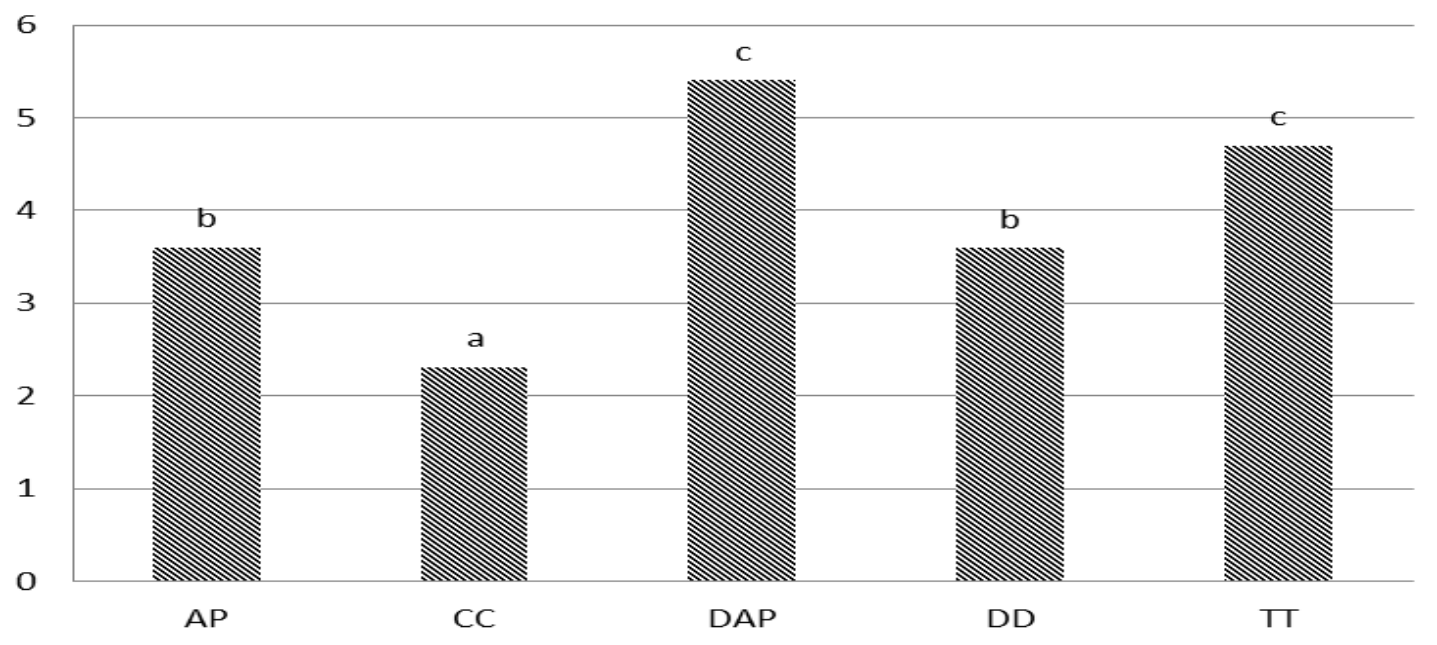

Figuras 9: Coeficiente de dispersión. Promedio de todas las posiciones del banco objetivo. AP (abanico plano), CC (cono convencional), DAP (doble abanico plano inducido), DD (abanico angulado simple intercalado) y TT (deflectora). Letras diferentes presentan diferencias significativas ( $p$-value $\leq 0,05$ ), para test de Ranks de Kruskal Wallis.

Se puede observar que el factor de dispersión presenta diferencias estadísticas entre las pastillas. CC tuvo los menores valores, en correspondencia con el rango indicado por Marquez (2005); las pastillas AP y DD tuvieron valores similares entre sí, e intermedios para con el resto, mientras que DAP y TT que alcanzaron los mayores registros. 


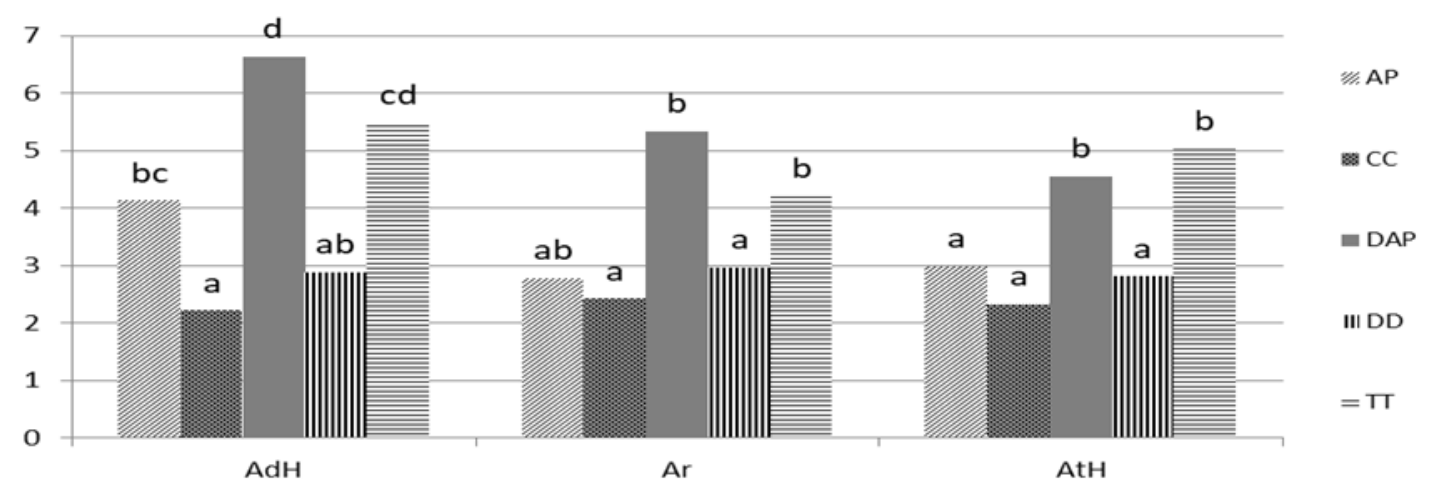

Posiciones Horizontales en el banco objetivo

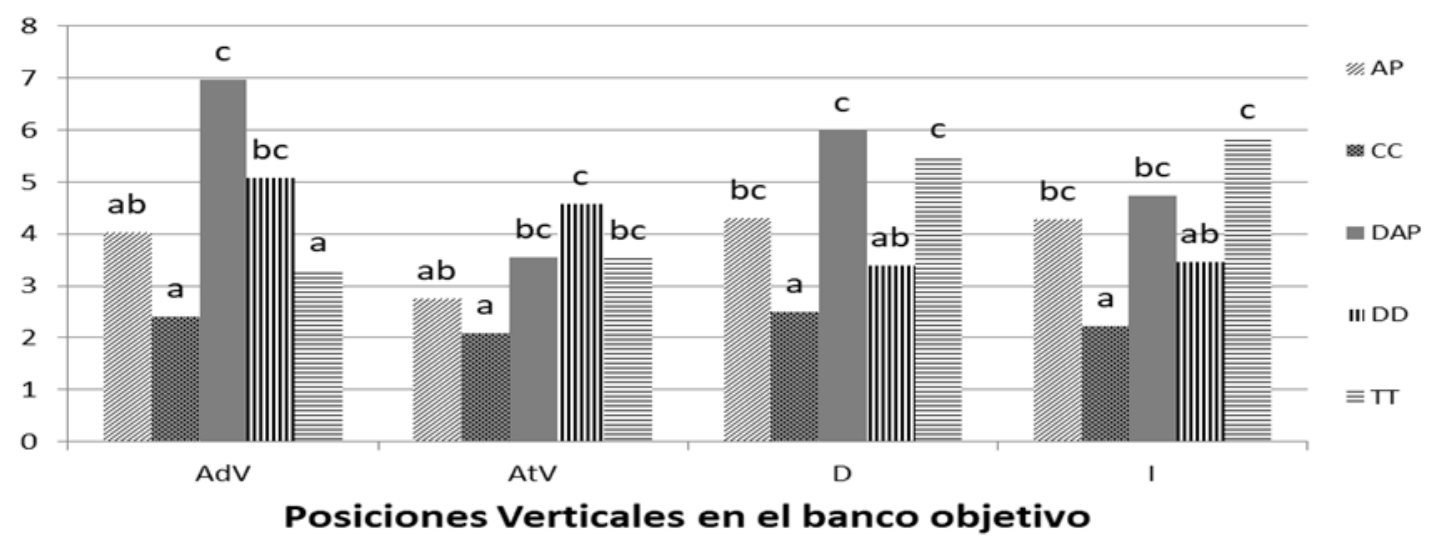

Figura 10: Coeficiente de Dispersión particionado por todas las posiciones relativas dentro del banco objetivo. AP: abanico plano, CC: cono convencional, DAP: doble abanico plano inducido, DD: abanico angulado simple alternado y $\mathrm{TT}$ : deflectora. AdH: adelante horizontal, Ar: arriba, AtH: atrás horizontal, AdV: adelante vertical, AtV: atrás vertical, D: derecha, I: izquierda. Letras diferentes presentan diferencias significativas ( $p$-value $\leq 0,05)$, para test de Ranks de Kruskal Wallis, entre pastillas para cada objetivo de aplicación en cada posición.

En la figura 10 se visualizan los resultados para cada una de las pastillas en cada una de las posiciones. No resulta posible establecer una tendencia dada la gran variabilidad de los datos para cada posición. Pese a esto es posible observar que, en todas las posiciones, tanto verticales como horizontales, $\mathrm{CC}$ es la pastilla con menores valores, acercándose a dos, lo que la ubica como la pastilla más uniforme, en contraposición DAP y TT presentan 
los mayores valores en todas las posiciones horizontales y solo en las posiciones AdV y AtV presentan alguna mejora en su uniformidad.

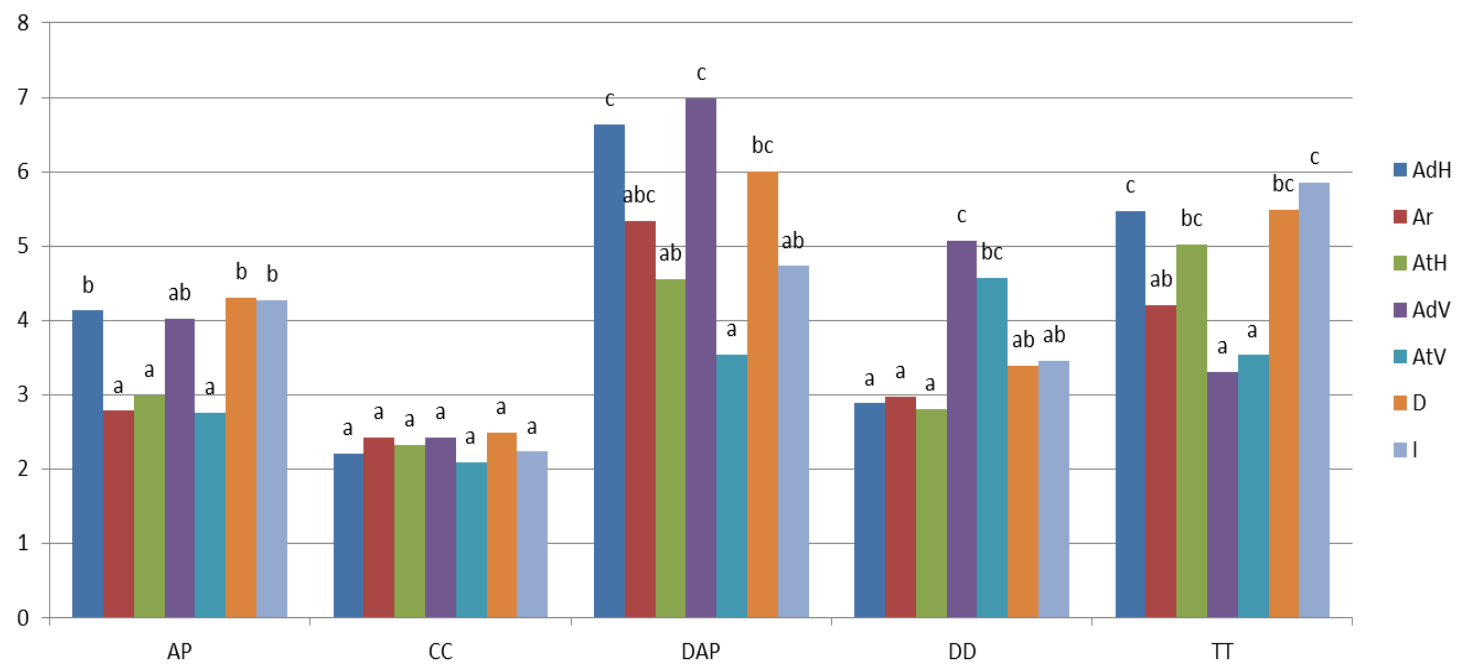

Figura 11: Uniformidad en el Coeficiente de Dispersion. AP: abanico plano, CC: cono convencional, DAP: doble abanico plano inducido, DD: abanico angulado simple alternado у TT: deflectora. AdH: adelante horizontal, Ar: arriba, AtH: atrás horizontal, AdV: adelante vertical, AtV: atrás vertical, D: derecha, I: izquierda. Letras diferentes presentan diferencias significativas ( $p$-value $<0,05)$, para test de Ranks de Kruskal Wallis, entre posiciones dentro de las pastillas

En la figura 11 se puede observar el análisis de cada pastilla para las distintas posiciones.

Como ya se mencionó la pastilla CC, independientemente de la posición relativa, siempre alcanza el objetivo con un tamaño de gota muy parecido, sin diferencias estadísticas significativas entre las distintas posiciones. Ninguna otra alternativa de pastilla alcanza este grado de uniformidad de la población de gotas sobre los distintos objetivos de aplicación. Solamente la pastilla DD presenta una población de gotas uniforme sobre los objetivos horizontales, pero con un coeficiente de dispersión mayor. Las pastillas DAP son las que presentan mayor des uniformidad de la población de gotas, como también mayor variabilidad entre los distintos objetivos en cada una de ellas. Dicha variabilidad y des uniformidad podría asociarse al hecho de ser pastillas con inducción de aire, al impactar 
sobre el objetivo de aplicación, las gotas pueden romperse y generar gotas más pequeñas que originarían esa variabilidad en mayor medida sobre el objetivo y no en la generación y traslado de las mismas desde la pastilla (Masiá \& Cid, 2010).

Por otro lado, se puede observar que las pastillas AP y DD presentan una menor variabilidad entre objetivos que DAP y TT, pero siempre con coeficientes de dispersión superiores a CC. Esta pastilla genera una población de gotas uniformes, lo cual es siempre una característica deseable para predecir cuál será el comportamiento de la pulverización. Cuanto más uniformes sean las gotas más uniforme será su respuesta y su distribución sobre el objetivo. Los riesgos de este tratamiento, claramente se relacionan con su potencial de exoderiva. No solamente esta pastilla produce gotas más uniformes que el resto de las alternativas, sino también menor $\mathrm{DV}_{0,5}$ y $\mathrm{DV}_{0,1}$. Esto contradice a Frola (2013) quien menciona que con una buena uniformidad y gotas de $250 \mu \mathrm{m}$ se pueden conseguir buenas aplicaciones con baja pérdida por deriva y evaporación, y como dicen Moltoni et al., (2008) aumentar las capacidades de trabajo. Si se observan las figuras 14,18 y 22 es notable que, pese a la buena uniformidad y el tamaño de gota cercano a $200 \mu \mathrm{m}$, las pérdidas generadas, en condiciones ambientales óptimas, sin viento y $90 \% \mathrm{HR}$, fueron mayores al $40 \%$; permitiendo hipotetizar que en condiciones de campo estos valores serian aún más elevados lo que generaría que su uso fuese poco recomendable o al menos sumamente riesgoso contradiciendo en parte a Leiva \& Picapietra (2012) y Chorbadjian \& Kogan (2001), ya que solo sería posible obtener buenos resultados en condiciones muy puntuales. 
Por otro lado, se puede observar que existen 3 pastillas (CC, DD y AP) que presentan una buena uniformidad en las posiciones AdV y AtV con valores similares entre las mismas. Esta característica sería un factor importante a tener en cuenta si se busca realizar pulverizaciones sobre objetivos verticales. También se visualiza que la pastilla DD, si bien es más desuniforme que CC, presenta una marcada caracterización del tipo de gota que llega a cada posición; los objetivos horizontales poseen una determinada uniformidad, algo mayor (significativamente menores coeficientes de dispersión), que los de los objetivos verticales $A d V$ y AtV, que no se diferencian entre sí; mientras tanto, D e I presentan valores intermedios muy parecidos entre sí, que no alcanzan diferencias significativas con los objetivos horizontales. Esto permite conocer de antemano la uniformidad en el tamaño de gota para cada posición facilitando la toma de decisiones en función de la labor a realizar.

\section{Amplitud Relativa}

La amplitud relativa es un parámetro que, al igual que el Coeficiente de dispersión, es construido desde otras mediciones realizadas sobre los tamaños de gota $\left(\mathrm{DV}_{0,5} ; \mathrm{DV}_{0,1} \mathrm{~V}\right.$ $\left.\mathrm{DV}_{0,9}\right)$ y también permite generar una idea de la homogeneidad de la familia de gotas; entre más pequeño sea este valor adimensional más uniforme es la familia de gotas. 


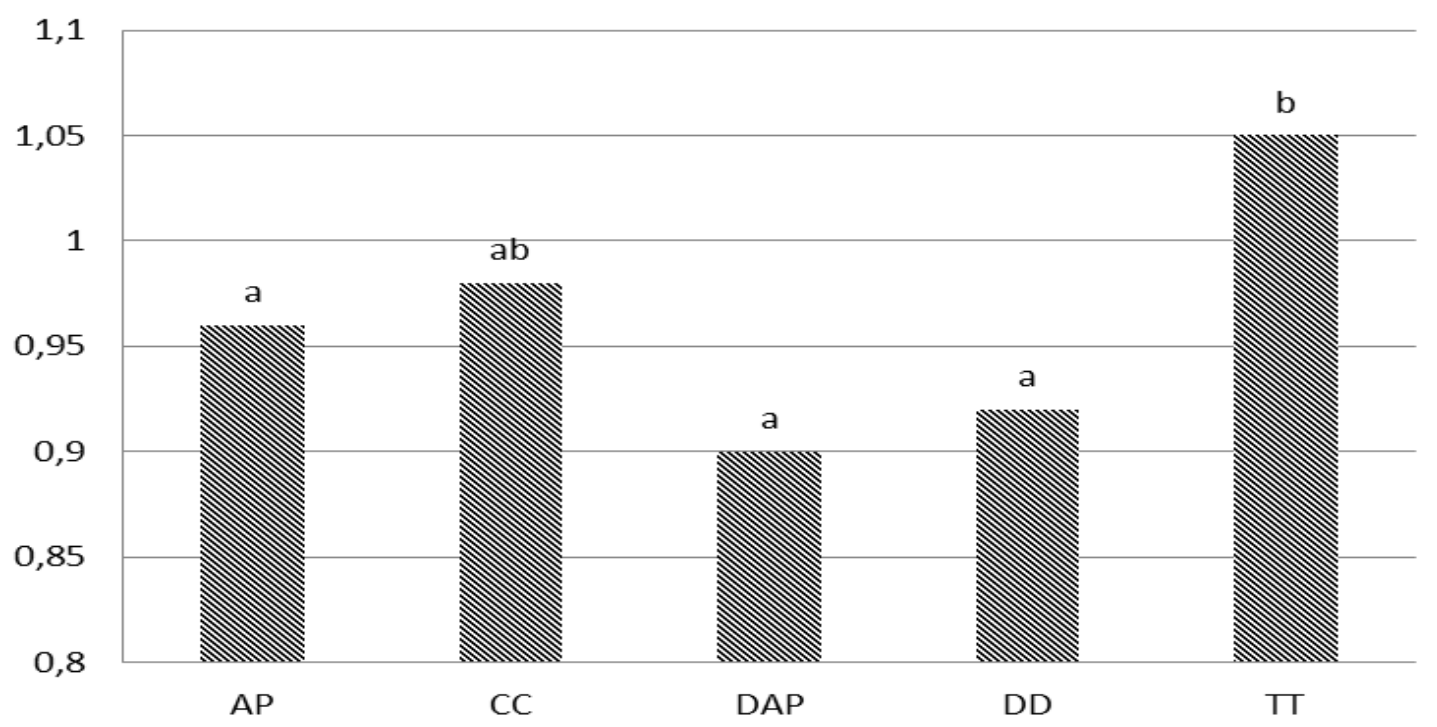

Figura 12: Amplitud Relativa. Promedio de todas las posiciones del banco objetivo. AP: abanico plano, CC: cono convencional, DAP: doble abanico plano inducido, DD: abanico angulado simple alternado y TT: deflectora. Letras diferentes presentan diferencias significativas ( $p$-value $\leq 0,05)$, para test de Ranks de Kruskal Wallis.

En la figura 12 se puede observar que las pastillas AP, DAP y DD son las de mayor uniformidad sin llegar a diferenciarse de CC y la más desuniforme es TT.

En la tabla 5 podemos observar que todas las pastillas presentan valores menores a los medidos a la salida de las mismas a excepción de CC. Esto puede deberse a que la pérdida de gotas más chicas disminuye el valor del numerador sin afectar significativamente el denominador y, entre más desuniforme es la familia de gotas, más afecta la pérdida de gotas chicas en la AR. Como la pastilla CC es la más uniforme en general (figura 9 y figura 12) es de las menos afectadas. 


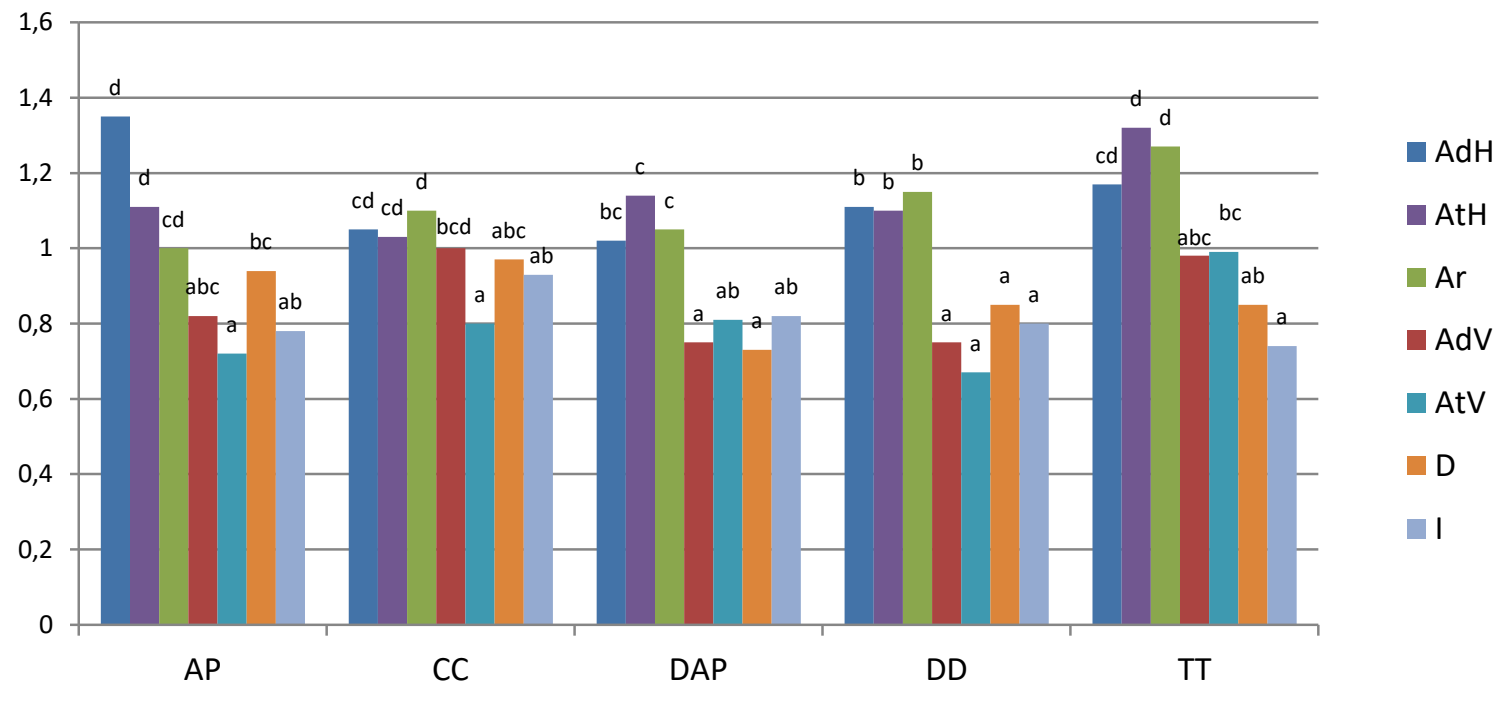

Figura 13: Amplitud Relativa particionado por todas las posiciones relativas dentro del banco objetivo. AP: abanico plano, CC: cono convencional, DAP: doble abanico plano inducido, DD: abanico angulado simple alternado y TT: deflectora. AdH: adelante horizontal, Ar: arriba, AtH: atrás horizontal, AdV: adelante vertical, AtV: atrás vertical, D: derecha, I: izquierda. Letras diferentes presentan diferencias significativas ( $p$-value $\leq 0,05)$, para test de Ranks de Kruskal Wallis, entre posiciones para la misma pastilla.

Al particionar este parámetro entre las posiciones relativas para una misma pastilla se puede observar muy pocas posiciones con diferencias significativas y una tendencia a presentar valores más elevados en las posiciones horizontales.

DD y DAP presentan la mayor uniformidad en los datos si se evalúan en forma separadas las posiciones verticales de las horizontales y $\mathrm{CC}$, que era la pastilla más uniforme en Coeficiente de Dispersión y de valores relativamente bajos en relación a las otras pastillas, presenta mayores valores principalmente en las posiciones verticales, lo que implicaría que ante relativamente bajos valores de $\mathrm{DVM}$ habría mayores diferencias entre el $\mathrm{DV}_{0,9} \mathrm{y}$ el $D V_{0,1}$ para los mismos. 
Se puede observar que, en general, las posiciones horizontales poseen valores más elevados que las verticales, lo que sería un indicador de que las gotas que llegan a las posiciones verticales son de un tamaño más uniforme o de un rango más acotado. No obstante, teniendo en cuenta el conjunto de parámetros de caracterización de la población de gotas no es posible validar que la misma es más uniforme sobre los objetivos verticales en todas sus posiciones.

\section{Eficiencia de aplicación}

Se puede observar en el parámetro eficiencia que los valores medios de las diferentes posiciones para cada pastilla (Figura 14) no presentan diferencias significativas entre las mismas. Ello se debe a la incidencia de los objetivos verticales, anteriores, posteriores y laterales que reducen los valores de eficiencia y aumentan la variabilidad de los resultados, cuando se los toma en forma conjunta. A ello se adjudica que los registros sean inferiores a los indicados por Martens (2012), quien cita para condiciones de barbecho, valores de eficiencia del orden del $60 \%$, y más cercanos a los citados por Courshee (1960) quien sostiene que los valores de caldo que llegan al blanco rondan aproximadamente el $20 \%$. 


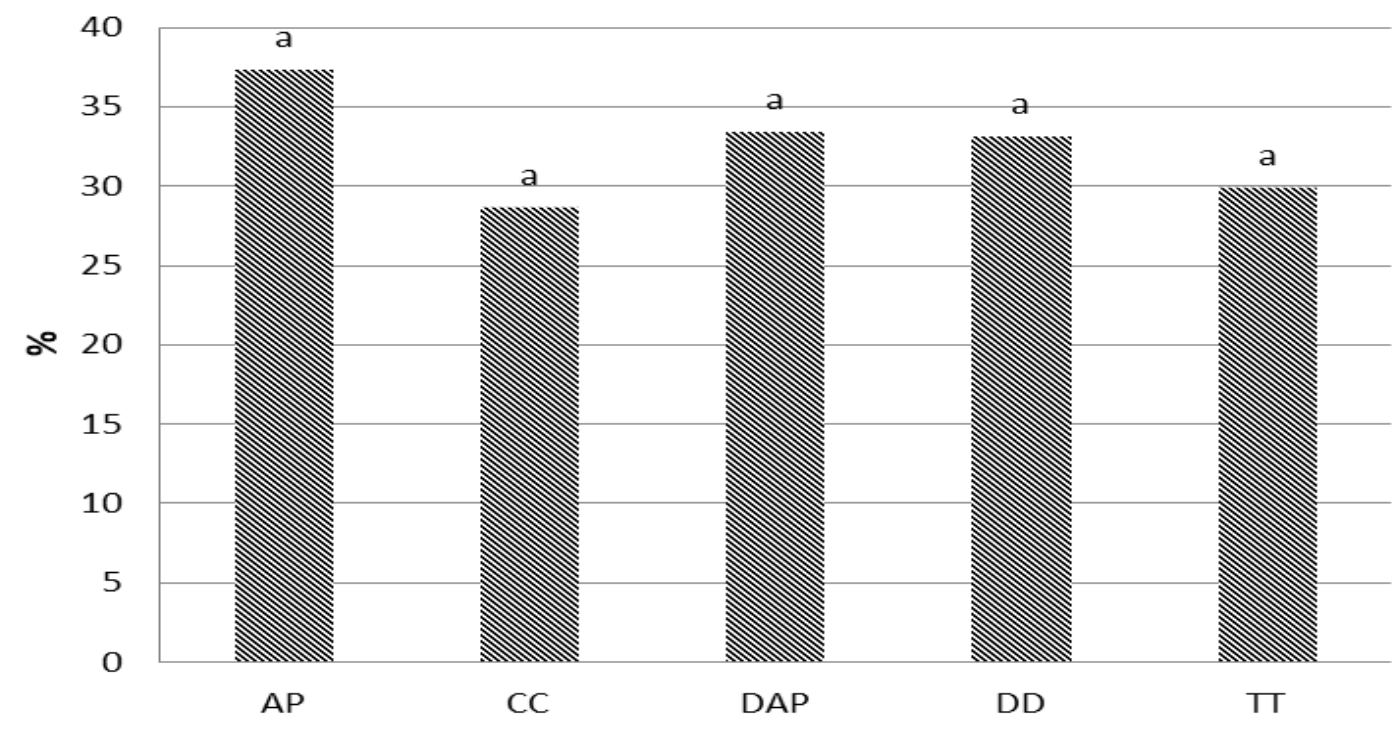

Figuras 14: Eficiencia (\%). Promedio de todas las posiciones del banco objetivo. AP: abanico plano, CC: cono convencional, DAP: doble abanico plano inducido, DD: abanico angulado simple alternado y TT: deflectora. Letras diferentes presentan diferencias significativas ( $p$-value $\leq 0,05$ ), para test de Ranks de Kruskal Wallis.

Los menores registros correspondieron a la CC y los mayores a AP. Las pastillas CC y TT poseen valores similares al igual que DAP y DD. No obstante, como se ha consignado en forma precedente, este análisis pierde relevancia, puesto que las distintas posiciones se relacionan con distintos objetivos de aplicación y dificulta la valoración en relación a otros antecedentes de deposición. Al realizar la partición de los datos por posiciones verticales y horizontales (figura 15) se puede observar que estas diferencias no significativas en la figura 14, comienzan a profundizarse y se vuelven significativas para algunas pastillas tanto en las posiciones verticales como en las horizontales. Ello demuestra la importancia de la ubicación de las tarjetas hidrosensibles según sea el objeto de aplicación, relacionado también al modo de acción del herbicida utilizado, la cantidad de depósito necesario para el control y su disposición respecto a la proyección de la pulverización. Los niveles de eficiencia alcanzados sobre los objetivos horizontales son algo superiores a los 
indicados por Mur et al., (2018b) quienes encuentran valores de eficiencia de $50 \%$ máximo, y promedios de $30 \%$, sobre el estrato superior en cultivos de soja. En otro ensayo similar, pero sobre rastrojo de sorgo, Mur et al., (2017) hallaron valores similares con $60 \%$ de eficiencia de recuperación en estratos superiores y $50 \%$ en inferiores. Sin embargo, estos valores se hallan corregidos por un factor citado en Domper et al., (2015), en acuerdo con resultados obtenidos en ensayos comparativos de tasa de recuperación con el uso de tarjetas hidrosensibles y el trazador Natrisol sódico. Si se calculan los valores medios sin corregir son superiores a los encontrados en este ensayo siendo para Mur et al., (2018a) 83,5\% y 50\%, y para Mur et al., (2017) 100 \% y 83 \%. Estos valores más elevados pueden deberse a la menor altura de botalón que presentan una menor área de expansión del abanico con mayor concentración del producto. Rodríguez Vassallo (2017) también menciona valores del orden del $50 \%$ al $60 \%$ para pastillas de tipo cono convencional, cono inducido y abanico inducido. Las diferencias con estos valores, levemente menores, pueden deberse a que el ensayo de este trabajo fue realizado en condiciones sin viento y alta humedad relativa, disminuyendo como consecuencia la evaporación del caldo. 


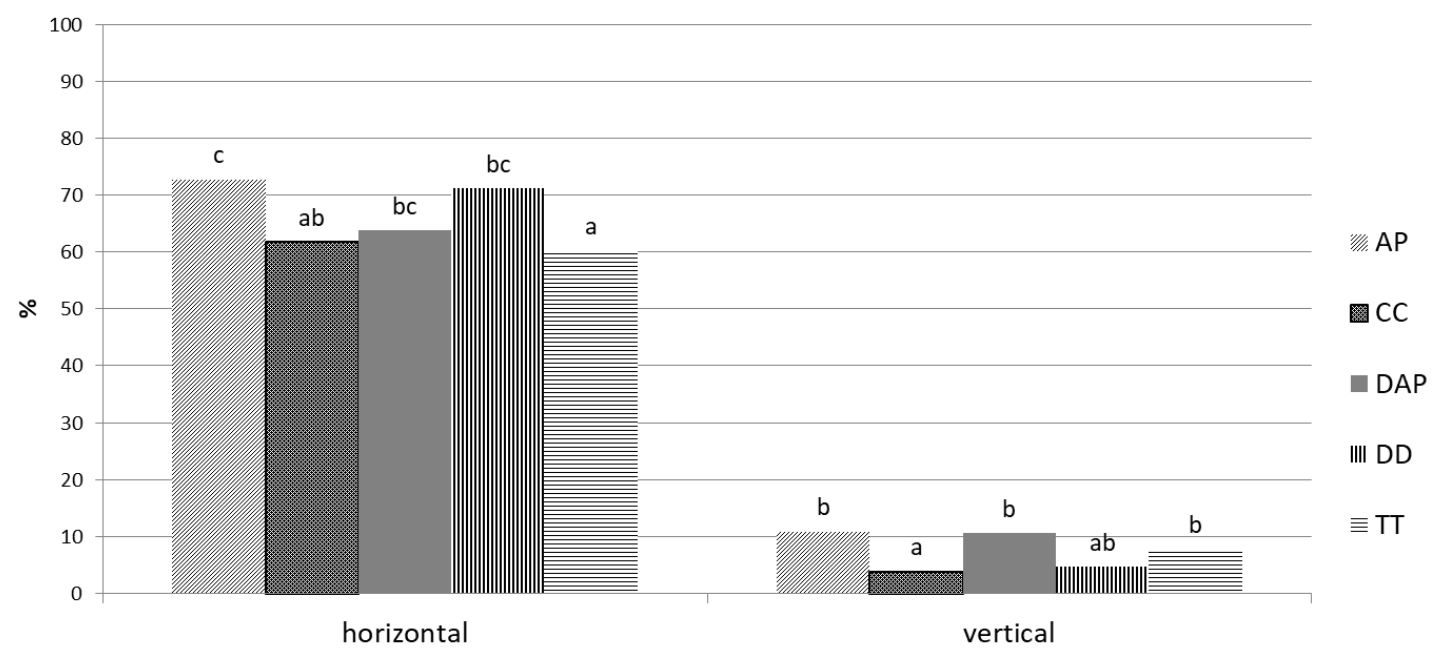

Figuras 15: Eficiencia (\%) particionada en posiciones Horizontales y Verticales dentro del banco objetivo. AP: abanico plano, CC: cono convencional, DAP: doble abanico plano inducido, DD: abanico angulado simple alternado y TT: deflectora. Letras diferentes presentan diferencias significativas ( $p$-value $\leq 0,05$ ), para test de Ranks de Kruskal Wallis, entre pastillas dentro de la posición.

En las posiciones horizontales las pastillas AP se diferencian de TT y CC, pero su eficiencia es similar a DD y DAP, mientras que TT presenta valores significativamente menores a todas las pastillas a excepción de CC. Los valores, no obstante, no comprometen la eficiencia de control sobre estos objetivos, pero plantean cuidados sobre la liberación de producto al medio ambiente, ya sea por endoderiva como por exoderiva, puesto que sobre el objeto de aplicación se encuentran entre el 60 \% y el 72 \% de la solución aplicada, lo que implicarían pérdidas del $28 \%$ al $40 \%$ para objetivos de posiciones horizontales (figura 15), similares a las cuantificadas por Valenzuela (2016). Estos resultados implican pérdidas de producto de aproximadamente 14 a $20 \mathrm{I} \mathrm{ha}{ }^{-1}$, en aplicaciones de $50 \mathrm{I} \mathrm{ha} \mathrm{h}^{-1}$ de herbicida en barbecho, lo que generaría grandes riesgos de contaminación ambiental e importantes pérdidas de dinero. En realidad, estas eficiencias se alcanzarían solamente si 
la totalidad de la superficie del suelo estuviera cubierta por malezas. En la medida que la superficie del lote tuviese un menor porcentaje de cobertura con malezas los riesgos son mayores y la eficiencia menor, acercándose a los valores citados por Courshee (1960) para algunos herbicidas.

En las posiciones verticales las pastillas AP, DAP y $T T$ son las que consiguen la mayor eficiencia, sin diferencias significativas entre las mismas. CC es la de menor eficiencia y DD se encuentra en un valor intermedio. Estos resultados de eficiencia contradicen las afirmaciones de Wolf \& Caldwell (2004); Goseen et al., (2008), Sayinci \& Bastaban (2011) y Wolf \& Peng (2011) quienes hallaron que las pastillas de doble abanico presentan un mejor comportamiento, ya que las mismas no lograron diferenciarse de las pastillas de AP en este parámetro de evaluación. Por otro lado, como ya se ha mencionado, este comportamiento también contradice a los resultados de Densidad de impactos, lo que indicaría los riesgos de tomar a la Densidad de impactos como único valor de referencia para referirse a la Cobertura y a la cantidad necesaria de producto para alcanzar el control biológico buscado.

Cuando se realiza la partición de los datos de eficiencia por posición relativa (Figura 16), es posible observar que no existen diferencias significativas para las diferentes pastillas en las posiciones $\mathrm{AdH}$ y $\mathrm{AtH}$; pero si se diferencian AP y DD de CC y TT en la posición Ar, mientras que DAP se ubica en una posición intermedia. Este comportamiento es similar al encontrado por Wolf \& Caldwell (2013), quienes describen que al aumentar la altura del botalón al objetivo las diferencias entre las posiciones horizontales van disminuyendo. En 
este caso diferencias que se observan entre pastillas, en posiciones más elevadas, se pierden al encontrarse el objetivo más bajo; esto puede deberse en parte a que los programas estiman este parámetro en función de la Densidad de impactos y el DVM, los cuales con las diferencias de altura pueden variar (Nuyttens et al., 2007b; Villalba \& Hetz, 2010; Matthews et al., 2014 y Domper et al., 2015). En las Figuras 3 y 5 se puede observar que las pastillas con alta Densidad de impactos son las de menor DVM, lo cual genera un proceso de compensación en la estimación de la eficiencia, ya que el programa transforma las áreas de las improntas medidas en las tarjetas en un volumen que se correlaciona con un determinado diámetro volumétrico de la gota; este factor de conversión entre impronta y volumen no siempre es preciso (Domper et al., 2015) y esto puede generar una mayor dispersión de los datos debido a las variaciones de altura del botalón lo que no permitiría encontrar diferencias significativas.

En forma concordante con las dificultades encontradas en Densidad de impactos para la disposición de objetivos en sentido vertical, los valores de Eficiencia rondan el $10 \%$ mientras que en las posiciones horizontales estos valores son del orden del $60-70 \%$ coincidiendo con Gadea (2018), Wolf \& Cadwell (2013), Ozkan et al., (2012), Wolf \& Peng (2011), Lake (1977) y Spillman (1984). 


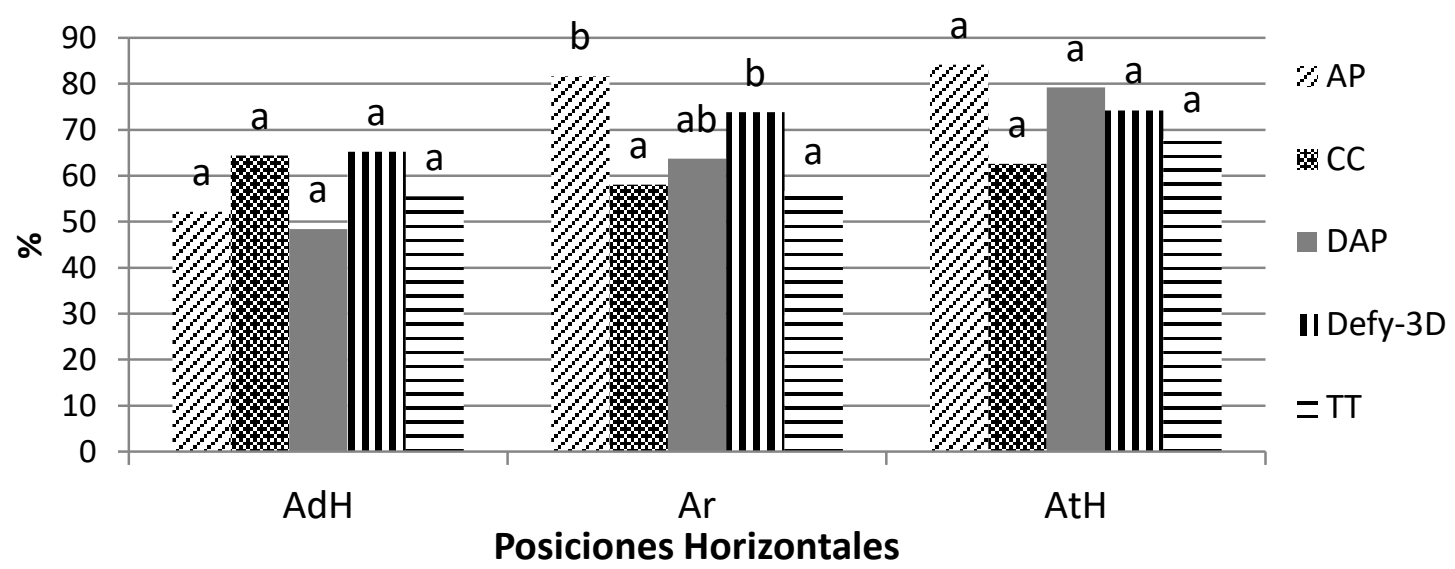

¡Error! Marcador no definido.

Figuras 17: Eficiencia (\%) particionado para todas las posiciones horizontales dentro del banco objetivo. AP: abanico plano, CC: cono convencional, DAP: doble abanico plano inducido, DD: abanico angulado simple alternado y TT: deflectora. AdH: adelante horizontal, Ar: arriba, AtH: atrás horizontal. Letras diferentes presentan diferencias significativas ( $p$-value $\leq 0,05$ ), para test de Ranks de Kruskal Wallis, entre pastillas dentro de las posiciones.

No obstante, en la posición Ar de la figura 16 se observan diferencias, siendo las pastillas abanico (AP y DD) las que presentan significativamente mayores valores; esto puede deberse, en parte, a la forma de pulverización en abanico de AP. Las pastillas DD por su parte, poseen un gran Densidad de impactos en esa posición, mayor que CC, y no poseen gotas tan pequeñas, por lo que el análisis por estimación de eficiencia es elevado, sin llegar a ser los valores de AP, pero sin que esa reducción alcance significancia estadística, y permite que se diferencie del resto. TT por su parte posee el menor número de impactos en esa posición y un DVM no tan elevado, lo que explicaría los valores bajos de eficiencia. Las pastillas DAP son de inducción de aire por lo que su cálculo de Eficiencia presentaría una importante sobreestimación (Domper et al., 2015; Barone, 2017.).

Uno de los factores de la sobreestimación puede ser dado por los factores de corrección utilizados por los programas para transformar las improntas en el papel hidrosensible en 
volúmenes. El programa CIR1.5 no aporta datos sobre cuantos factores de corrección toma en función del tamaño de gotas. Syngenta ${ }^{\circledR}$ menciona 5 factores de corrección para gotas entre 100 y $600 \mu \mathrm{m}$, (Tabla 6) pero el comportamiento de esta variación entre la impronta generada y el volumen real de la gota, es más variable entre los 0 y $200 \mu \mathrm{m}$ (Imagen 7).

Tabla 6: Factores de corrección de diámetros de gotas desde impronta en papel hidrosensible Syngenta ${ }^{\circledR}$

\begin{tabular}{|c|c|c|}
\hline Diámetro de mancha $\mu \mathrm{m}$ & factor Corrección & Diámetro de gota $\mu \mathrm{m}$ \\
\hline 100 & 1.7 & 59 \\
\hline 200 & 1.8 & 109 \\
\hline 300 & 1.9 & 155 \\
\hline 400 & 2.0 & 200 \\
\hline 500 & 2.1 & 243 \\
\hline 600 & 2.1 & 285 \\
\hline
\end{tabular}

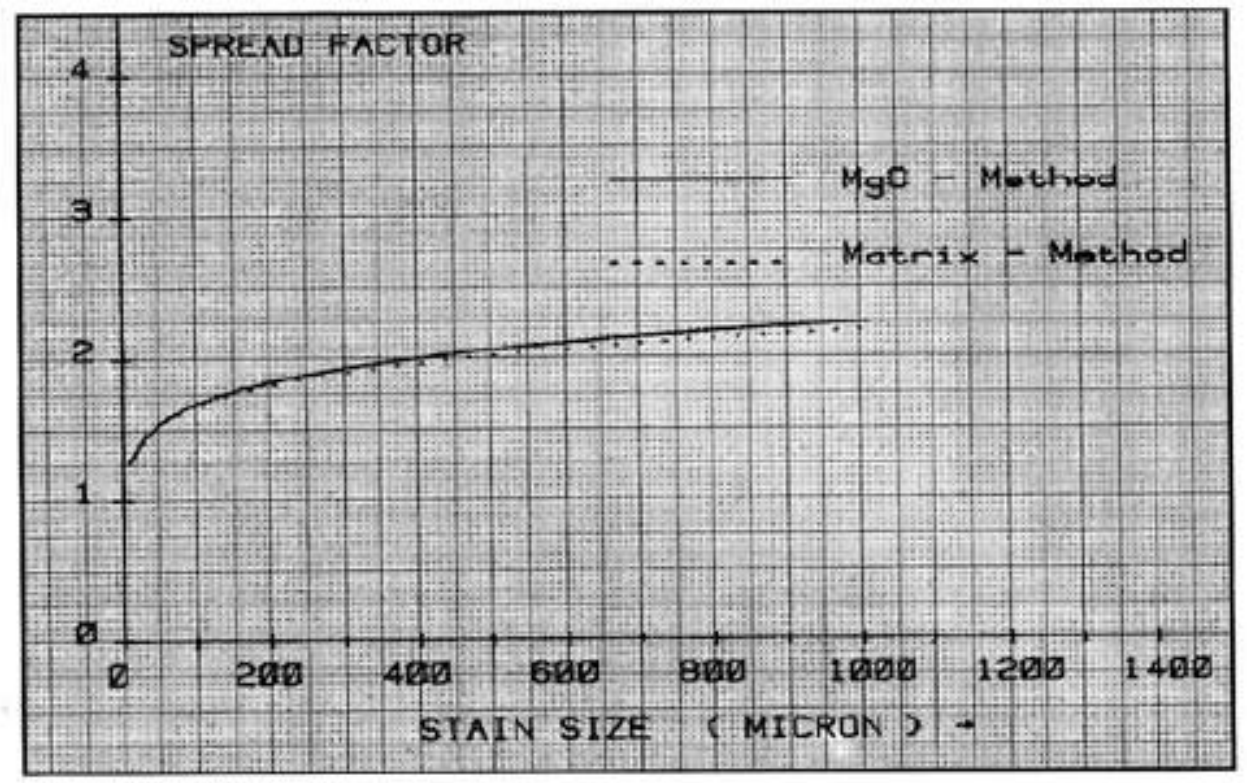

Imagen 7: Coeficiente de dispersión de agua en papel sensible al agua medido por el MgO y el método de siliconoil (Syngenta, 2002) 
Sin embargo muchos programas trabajan con ecuaciones de conversión de impronta a gota que poseen un comportamiento de conversión más lineal en la sección de 0-250 $\mu \mathrm{m}$ (Imagen 8) (Hoffmann \& Hewitt, 2005).

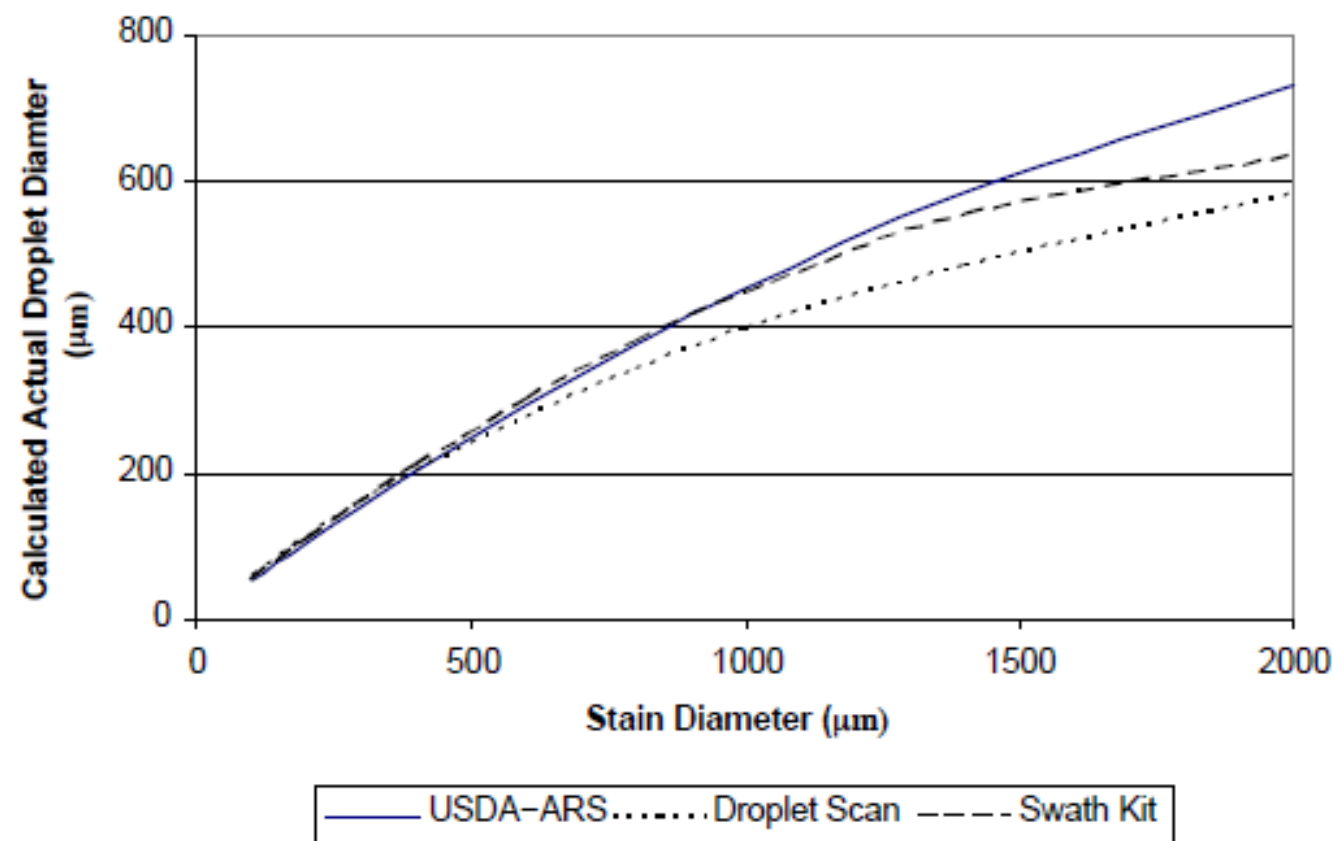

Imagen 8: Valores calculados para el tamaño de gota real $(\mu \mathrm{m})$ a partir del tamaño de la mancha usando las ecuaciones de Coeficiente de expansión de tres sistemas de imágenes Extraído de Hoffmann \& Hewitt, 2005

Cuando se analiza la eficiencia en los objetivos verticales (figura 17) se pueden observar mayores diferencias entre las pastillas en todas las posiciones. En la posición AdV las pastillas AP y TT son las de menor eficiencia. De manera opuesta a lo esperado DAP, CC y DD poseen los mayores valores; si bien DAP tuvo una eficiencia $14 \%$ mayor no logró diferenciarse significativamente de CC y DD, lo que indicaría una alta variabilidad de los registros; al respecto, debe tenerse en cuenta que DAP es una pastilla con aire inducido, que puede sobreestimar en 3,38 veces la eficiencia según lo determinado por Domper et 
al., (2015). En la posición AtV, AP es la que presentó los mejores resultados, y es la pastilla que junto a DAP y TT consigue una Densidad de impactos en esta ubicación que permitiría el control a través de la aplicación de productos tanto sistémicos como de contacto (figura 3) y alcanzar control independientemente de la plaga (Weber, 1982). La misma tuvo un DVM de más de $350 \mu \mathrm{m}$ (Figura 7) y una eficiencia del 25\%, lo cual es superior a cualquier otra pastilla en todas las posiciones verticales y más de $15 \%$ por encima de la media de las pastillas para esa posición. CC presenta valores con menos de $1 \%$ en forma contrapuesta a los resultados de Sayinci \& Bastaban (2011), quienes recomiendan este diseño de pastillas para lograr mayor cantidad de depósitos en lugares de difícil acceso, pese a esto no obtuvo los mejores resultados de eficiencia en ninguna de las posiciones verticales y solo alcanza Densidad de impactos adecuada para control en la posición AdV (Figura 3). Estos datos tan diferentes a los que menciona la bibliografía pueden deberse a brisas de viento que afectaron la pulverización durante la pasada, si bien el lugar del ensayo es un galpón cerrado, el mismo no es hermético y es posible que se haya generado en esta pasada alguna corriente de aire, pese a esto sería recomendable seguir trabajando sobre este resultado en futuros ensayos y sumarles pruebas a campo con viento. 


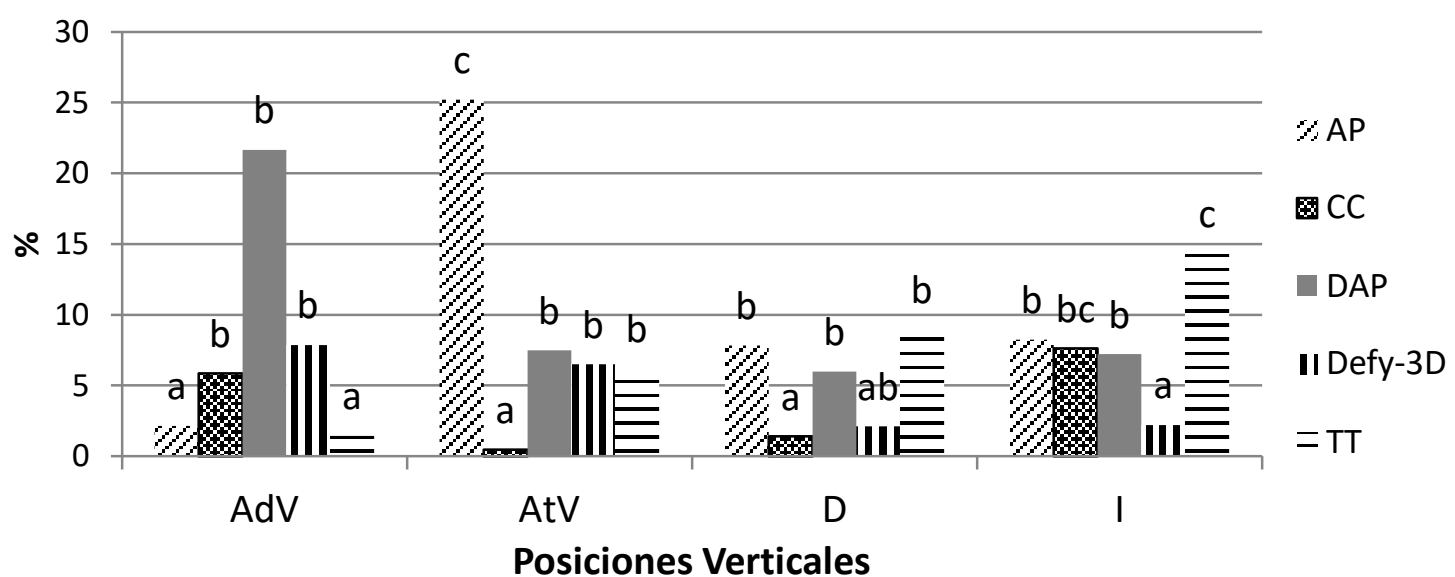

Figuras 18: Eficiencia (\%) particionada para todas las posiciones Verticales dentro del banco objetivo. AP: abanico plano, CC: cono convencional, DAP: doble abanico plano inducido, DD: abanico angulado simple alternado y $\mathrm{TT}$ : deflectora. AdV: adelante vertical, AtV: atrás vertical, D: derecha, I: izquierda. Letras diferentes presentan diferencias significativas ( $p$-value $\leq 0,05)$, para test de Ranks de Kruskal Wallis, entre pastillas dentro de las posiciones.

Los resultados son llamativos y discrepan con mucha de la bibliografía que cita a las pastillas anguladas como la mejor alternativa para alcanzar objetivos verticales tanto delanteros como traseros; así también mencionan mayor dificultad en llegar a las posiciones traseras, sombreadas, por el objetivo (Wolf \& Cadwell, 2013; Ozkan et al., 2012 y Wolf \& Peng, 2011). Sin embargo, los resultados concuerdan en parte con Zhu et al. (1996) quienes indican que la eficiencia de recolección en objetivos verticales aumenta a medida que aumenta el diámetro de la gota, la velocidad del viento y el ancho del objetivo, pero disminuye a medida que aumenta la intensidad de la turbulencia. En este ensayo CC fue la pastilla con menor tamaño de gotas y el viento fue mínimo debido a que el ensayo se realizó en galpón, DAP presentó el mejor comportamiento en la posición AdV como sería factible esperar, pero no consiguió buenos resultados en la posición AtV donde 
sí se destacó AP. Otro factor importante a tener en cuenta para el análisis es la altura del botalón; tanto Wolf \& Cadwell (2013) como Wolf \& Peng (2011) concuerdan en que la altura del botalón posee un efecto muy importante en las deposiciones de los objetivos tanto verticales como horizontales la cual pudo incidir sobre los resultados de las pastillas anguladas.

Teniendo en cuenta los resultados de la eficiencia de deposición de las distintas pastillas evaluadas en la figura 15 , en las posiciones horizontales no es posible establecer claras ventajas de ninguna alternativa tecnológica por sobre otra. Las diferencias entre las pastillas no superan el $12 \%$; mientras la mayoría de los antecedentes recomiendan el trabajo con pastillas anguladas con respecto a la vertical, para solucionar los problemas de escasa deposición en el lado de la sombra de las pastillas de abanico plano convencionales, los resultados obtenidos parecieran contrarios. Las únicas diferencias significativas entre todas las pastillas se encontraron en los objetivos superiores, pero no en los delanteros y traseros, donde no existieron diferencias estadísticas significativas. Ello no implica que, dentro de esa ausencia de diferencias estadísticas significativas, se encuentre alguna pastilla que supera a otra en un $15 \%$, aproximadamente, en los objetivos delanteros y del $20 \%$ en los traseros. No obstante, dichas diferencias no significativas se encuentran en un marco de relativamente alta eficiencia de deposición. Por lo tanto, las alternativas evaluadas no se presentan como una mejora en la meta de alcanzar una mayor deposición de caldo en el lado de la sombra. Estos resultados parecen indicar que los obstáculos interpuestos no tuvieron un grado de dificultad elevado para ninguna de las pastillas. Es posible hipotetizar que la presencia de malezas bajas de 
disposición horizontal y de escasa altura pueden ser eficientemente controladas, independientemente de su disposición espacial, ya sean dispersas, aisladas o en matas. De allí la importancia que revisten las recomendaciones de aplicaciones de control temprano, no solo por el hecho de poder trabajar con menores tasas de aplicación y niveles de resistencia de las malezas, sino porque, en esos estadios, la distribución horizontal no se ve fuertemente impedida por la altura de las mismas (Barros \& Freixial, 2010; Vigna, et al., 2012; Metzler, et al., 2013). Esto cobra mayor importancia aún en condiciones de campo, con mayores alturas de botalón y condiciones atmosféricas más desfavorables (Uk \& Courshee, 1982; Spillman, 1984; Boller \& Schlosser, 2010).

Contrariamente a ello, la eficiencia sobre objetivos verticales presenta una mayor variabilidad de la deposición. La evaluación de los objetivos verticales de manera conjunta indica que ninguna pastilla superó en deposición al abanico plano y solamente DAP la igualó. De todas formas, los porcentajes de deposición variaron entre el $4 \%$ y el $10 \%$ aproximadamente, lo cual no hace más que demostrar las dificultades encontradas en Densidad de impactos para alcanzar los mínimos requeridos en ese parámetro. En este caso existen diferencias significativas, que no existían en Densidad de impactos, y la pastilla DAP alcanza la eficiencia de la pastilla AP. Evidentemente, la posibilidad de control de malezas con disposición vertical y estructuras estrechas, será de escaso éxito si llega menos del $10 \%$ de la dosis prescripta. En cuanto a la disposición con ángulos diferentes de las pastillas las DD resultan las de mayor uniformidad entre caras delanteras y traseras, mientras que el AP alcanza la mayor des uniformidad manteniéndose las tendencias generales para estas dos posiciones que las obtenidas en Densidad de impactos. 


\section{Tasa de recuperación}

En la figura 18 se observan los volúmenes recuperados de la aplicación, cuantificados por medio del trazador, y expresado como porcentaje de lo erogado por unidad de superficie; este resultado sería equivalente al valor expresado por el CIR1.5 como Eficiencia (\%). La tasa de recuperación no presenta diferencias significativas en el análisis general entre las diferentes pastillas evaluadas. Dichos valores medios resultan Ilamativamente bajos para las condiciones ambientales dentro del galpón en el que se realizaron los ensayos y encuentran explicación en las dificultades de captación de producto en los objetivos verticales. La ausencia de viento, con velocidades de $0,2 \mathrm{~ms}^{-1}$, temperatura de $15,2{ }^{\circ} \mathrm{C}$ a $18,4{ }^{\circ} \mathrm{C}$ y humedad relativa superior al $89 \%$, permiten suponer que la evaporación, la deriva de sedimentación y la exoderiva no deberían constituir un problema importante. Estos valores tan bajos pueden deberse a que la evaluación en conjunto de posiciones verticales y horizontales disminuyen el valor como consecuencia de los bajos valores de recuperación en posiciones verticales (figura 19).

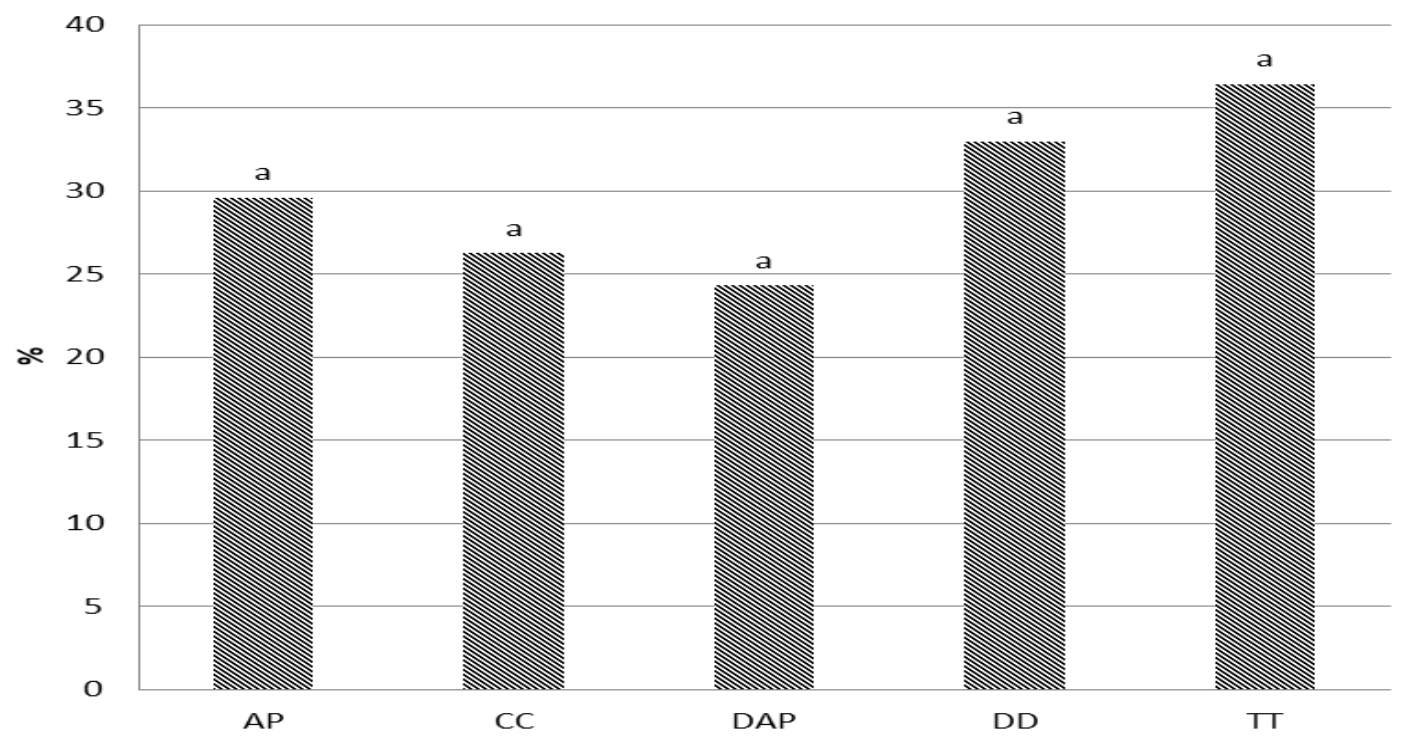


Figuras 19: Tasa de Recuperación TR (\%) promedio de todas las posiciones del banco objetivo. AP: abanico plano, CC: cono convencional, DAP: doble abanico plano inducido, DD: abanico angulado simple alternado y TT: deflectora. Letras diferentes presentan diferencias significativas ( $p$-value $\leq 0,05$ ), para test de Ranks de Kruskal Wallis.

En las posiciones verticales, AP fue la de mejor comportamiento excepto en la posición $A d V$, en un marco de análisis de valores inferiores al $10 \%$ del volumen erogado por unidad de superficie; DAP por su parte no presentó buenos resultados al igual que DD que solo se diferenciaron en la posición AdV (figuras 19 y 20). Esto no coincide con los datos obtenidos por Villalba et al., (2011) quienes encuentran una deposición en espiga con pastillas twin muy superior a abanico plano, esto se podría atribuir a las características del banco en relación a las espigas. Etiennot et al., (1998), al comparar las boquillas doble abanico plano (TJ) con las abanico plano (XR), obtuvieron mayores depósitos con la primera y una mejor uniformidad en todas las partes de las plantas de Lotus tenuis. Estos autores explican sus resultados sólo por la formación de gotas más finas de la boquilla TJ, lo cual difiere con las pastillas utilizadas en este trabajo ya que la pastilla DAP al ser de aire inducido presentó gotas de 200-350 $\mu \mathrm{m}$ y DD presentó gotas de 180-250 $\mu \mathrm{m}$ (Figura 5).

Díaz de Ackermann et al., (2002) determinaron un mejor control de la enfermedad (evaluado como porcentaje de infección), cuando el fungicida se aplicó con boquillas de tipo doble abanico plano y en un ángulo de $30^{\circ}$ con respecto a la vertical.

Igualmente, Nicholson et al., (2003) comprobaron que las boquillas de doble abanico plano presentaron una distribución más uniforme sobre las espigas comparadas a las boquillas de abanico plano convencional, lo que determinó una mayor cobertura de los fungicidas en las espigas. En este trabajo, si bien DAP y DD fueron las pastillas de mayor 
uniformidad (Figura 22) no necesariamente fueron las de mayor deposición en las posiciones verticales (Figura 20 y 21 ).

En concordancia con los resultados de este trabajo Panisson et al., (2003) no encontraron ventajas con el uso de boquillas de doble abanico (TJ60) comparado con las de abanico convencional (XR). Tampoco el aumento de la tasa de aplicación de 200 a $400 \mathrm{I} \mathrm{ha}^{-1}$ y el uso de las boquillas con diferente posicionamiento con respecto a la vertical, $30^{\circ} \mathrm{o} 45^{\circ}$, mejoraron el control de la enfermedad ni lograron mayor respuesta en rendimiento de trigo. Esto confirma las observaciones hechas por Mc Mullen et al., (1998) sobre la aplicación de fungicidas utilizando diferentes boquillas hidráulicas, que si bien pueden proporcionar diferentes niveles de control, difícilmente presentan diferencias significativas.

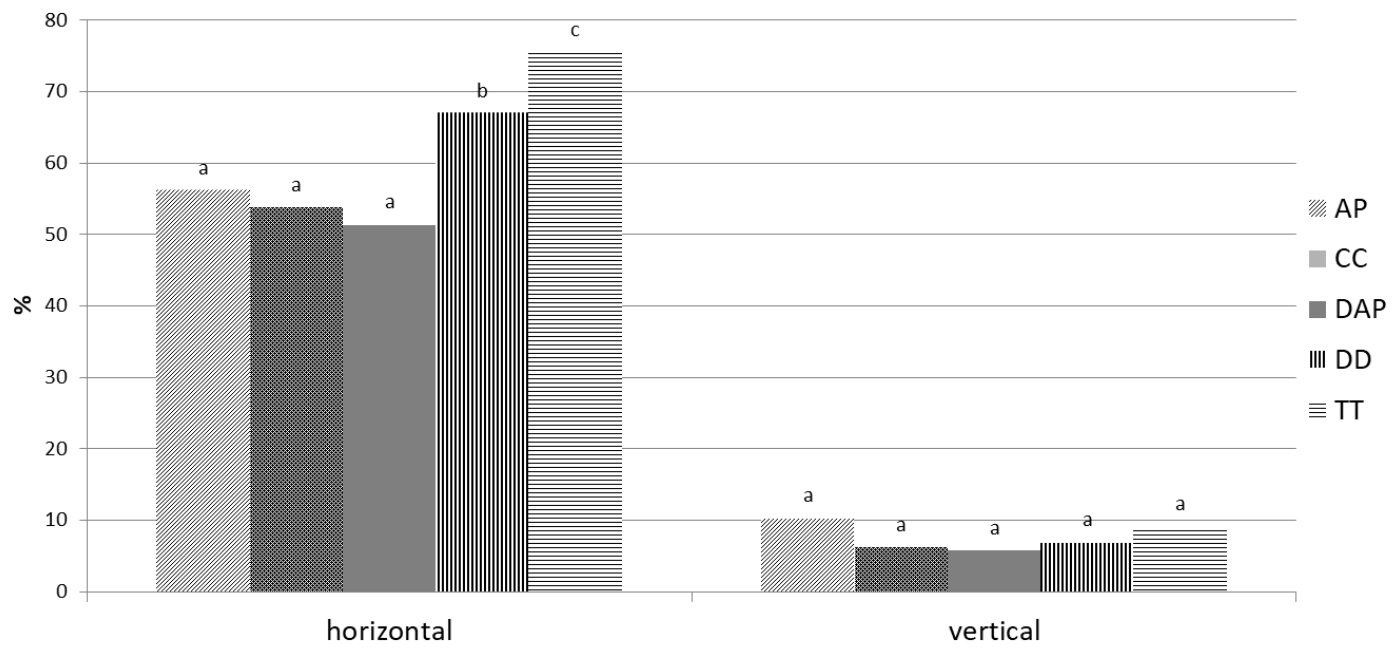

Figura 20: Tasa de Recuperación TR (\%). Particionado por posiciones Verticales y Horizontales dentro del banco objetivo. AP: abanico plano, CC: cono convencional, DAP: doble abanico plano inducido, DD: abanico angulado simple alternado y TT: deflectora. Letras diferentes presentan diferencias significativas ( $p$-value $\leq 0,05$ ), para test de Ranks de Kruskal Wallis, entre pastillas dentro de la posición. 
La tasa de recuperación de producto puede calificarse como aceptable sobre los objetivos horizontales, en general, para las tres posiciones evaluadas (Figura 20), con valores mínimos del $40 \%$ para el AP en AdH y máximos cercanos al $80 \%$ en TT en AtH. Solamente esta última pastilla en $\mathrm{Ar}$ y $\mathrm{AtH}$ supera el $70 \%$ del producto distribuido por unidad de superficie. Los resultados permiten presuponer que en condiciones de campo, con diferentes condiciones atmosféricas, mayor altura del botalón y suelo irregular, se producirán mayores pérdidas de producto y una menor tasa de recuperación (Uk \& Courshee, 1982; Spillman, 1984; Boller \& Schlosser, 2010). Los resultados de la tasa de recuperación de trazador sobre los objetivos horizontales anteriores y posteriores resulta comparable con los de otros ensayos efectuados en condiciones de barbecho, pese a la presencia de obstáculos que pueden limitar en parte la llegada a alguno de ellos, según sea la dirección de la población de gotas al pasar por los distintos objetivos (Tomazella, 1997; Silva, 2000; Villalba et al., 2011; Gadea, 2018). 

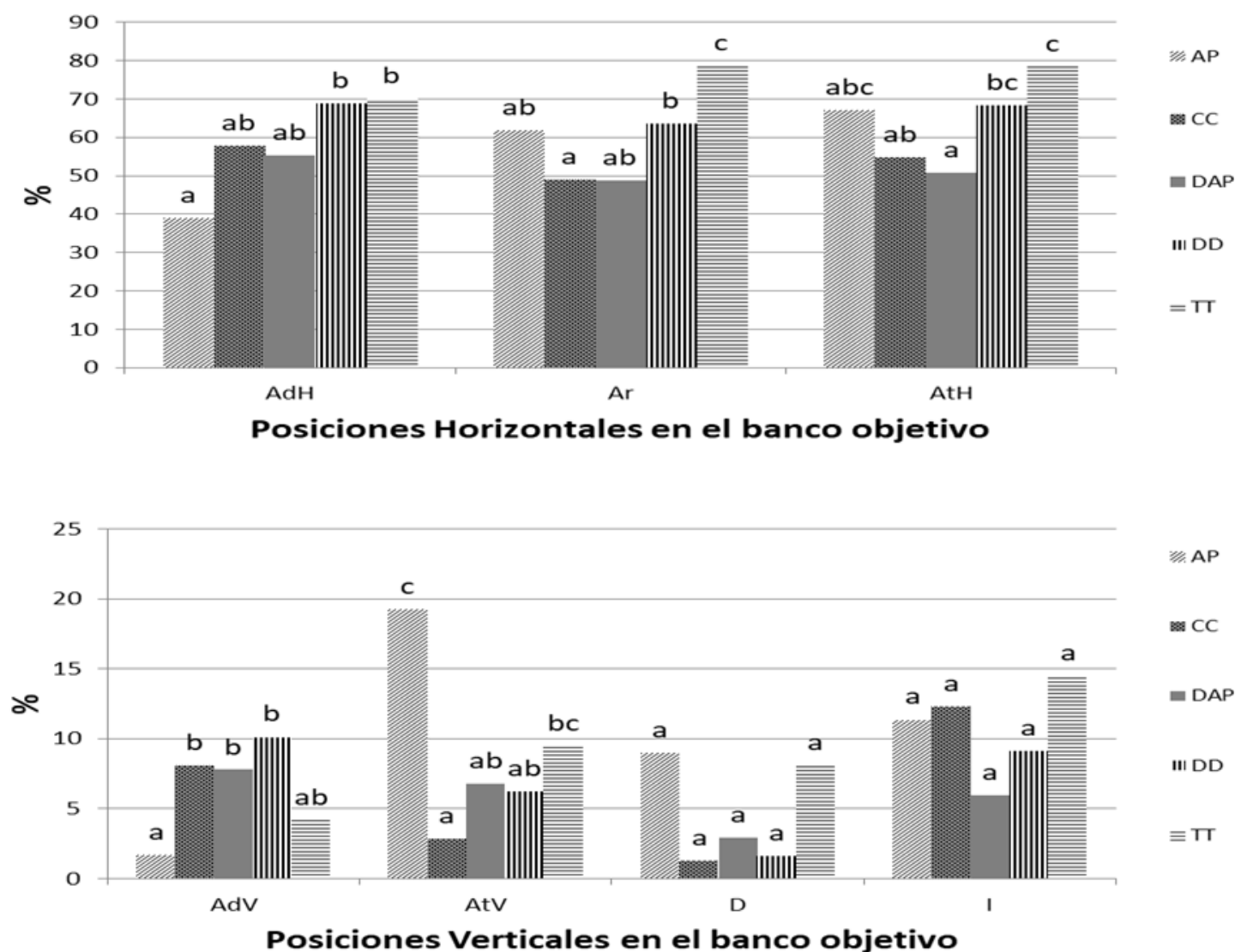

Figuras 21: Tasa de Recuperación TR (\%) particionada por todas las posiciones relativas dentro del banco objetivo. AP: abanico plano, CC: cono convencional, DAP: doble abanico plano inducido, DD: abanico angulado simple alternado y TT: deflectora. AdH: adelante horizontal, Ar: arriba, AtH: atrás horizontal, AdV: adelante vertical, AtV: atrás vertical, D: derecha, I: izquierda. Letras diferentes presentan diferencias significativas ( $p$-value $\leq 0,05)$, para test de Ranks de Kruskal Wallis, entre pastillas dentro de las posiciones

En la posición Ar las pastillas con mejores prestaciones fueron primero TT y luego DD, que alcanzó a diferenciarse de CC, pero no del resto de las alternativas de diseño de pastillas, mientras que el resto de los tratamientos no se diferenciaron entre sí. CC y DAP tuvieron en esta posición los registros más bajos, al igual que en AtH y fueron similares, pero algo mayores, que AP en AdH. En general dichas pastillas tuvieron valores menores al $60 \%$ como límite máximo y algo inferiores o cercanos al 50 \% como registros mínimos. 
Los valores obtenidos sobre $\mathrm{AdH}, \mathrm{Ar}$ y $\mathrm{AtH}$ resultan superiores a los porcentajes medios de eficiencia sobre barbecho medidos por Domper (2015) quienes en su trabajo de Tesis cita valores de $25-45 \%$ para pastillas $\mathrm{CH}$ convencional e inducidas, lo cual puede explicarse en parte por las diferencias de viento y potencial de exoderiva con respecto a los mismos al trabajar en un ambiente semiconfinado. Barone (2017) cita valores de recupero similares a este trabajo, de $60-80 \%$ en promedio para las diferentes pastillas que evaluó. Por su lado Martens (2012) cita valores desde $25 \%$ a $60 \%$ denotando la variabilidad de la eficiencia de la labor, según el tipo de objetivo y las condiciones de trabajo, correspondiendo los mayores a la condición de barbecho.

Por el contrario, en las posiciones verticales, en todas sus variables, los valores resultan extremadamente bajos para todas las pastillas ensayadas. La mayor recuperación de producto en posición vertical se alcanzó, inesperadamente, con la pastilla AP en AtV (19\%) en contraposición a los resultados de Wolf \& Peng, (2011) y Wolf \& Cadwell, (2013). En cambio, para la posición AdV dicha pastilla tuvo los menores valores, significativamente diferentes a DAP, CC y DD y no significativos con TT. En general, ninguna pastilla salvo AP en AtV superó el $10 \%$ en AdV, AtV y D, en tanto en I los valores variaron entre el $6 \%$ y el 14\% de la Tasa de aplicación. La escasa tasa de recuperación en estas posiciones pone en riesgo las posibilidades de control de malezas que se presenten principalmente en forma vertical, agrupada y con diferentes estados de desarrollo al momento de realizar la aplicación tal como menciona Knoche (1994), Cawood et al., (1995), Enfält et al., (1997), Jensen, (1999), Jensen et al., (2001). Estos resultados, menos visibles en el parámetro de Eficiencia, son relevantes a partir del producto efectivamente recuperado. 
En función de los mismos es posible cuestionar dos aspectos comunes en las aplicaciones para el control de malezas en situaciones productivas de la Argentina. Por un lado, la tasa de aplicación con volúmenes reducidos y, por otro, la velocidad de desplazamiento del pulverizador para alcanzar una mayor capacidad de trabajo del conjunto. Esto genera características en la pulverización que aumentan el potencial de deriva del producto, disminuyendo la cantidad que alcanza los objetivos y aumentando la contaminación en zonas no deseadas (Uk \& Courshee, 1982; Spillman, 1984; Wolf et al., 2000; Liu et al., 2006; Boller \& Schlosser, 2010; Maski \& Durairaj, 2010; Cavalieri et al., 2015).

En un análisis general de las posiciones verticales, se encuentran resultados contradictorios con los antecedentes de deposición de las caras delanteras y traseras de objetivos verticales de Wolf \& Cadwell (2013), quienes informaron valores más altos en la cara delantera, o frontal, que en la cara trasera de los objetivos, explicados por la componente horizontal del abanico de pulverización en el sentido de avance de la máquina. En la búsqueda de alcanzar una mayor uniformidad de distribución entre ambas caras los trabajos de Ozkan et al., (2012), Wolf \& Peng, (2011), Scudeler \& Raetano (2006), Friesen \& Wall (1991), Panneton et al., (2000), De Souza Christovam et al., (2010), Combellack \& Richardson (1985), Richardson (1987) y Jensen \& Nielsen (2008) muestran mejoras para las pastillas que poseen una proyección de abanicos simples o dobles con ángulos diferentes de $0^{\circ}$ con respecto a la vertical, que para este ensayo fueron 3 de las pastillas CC, DD y DAP. Sin embargo, solo se observaron mejoras en la posición AdV. No obstante, Shaw et al., (2000) mencionan que obtuvieron similares valores a los obtenidos con pastillas anguladas con modificación de las tasas y velocidad de aplicación, y Jensen \& 
Nielsen (2014) mencionan que no hallaron diferencias en sus ensayos con angulación de las pastillas de $+45^{\circ}$, lo que fortalecería la idea de que la angulación no es, por si solo, el principal factor que afecta la calidad de pulverización.

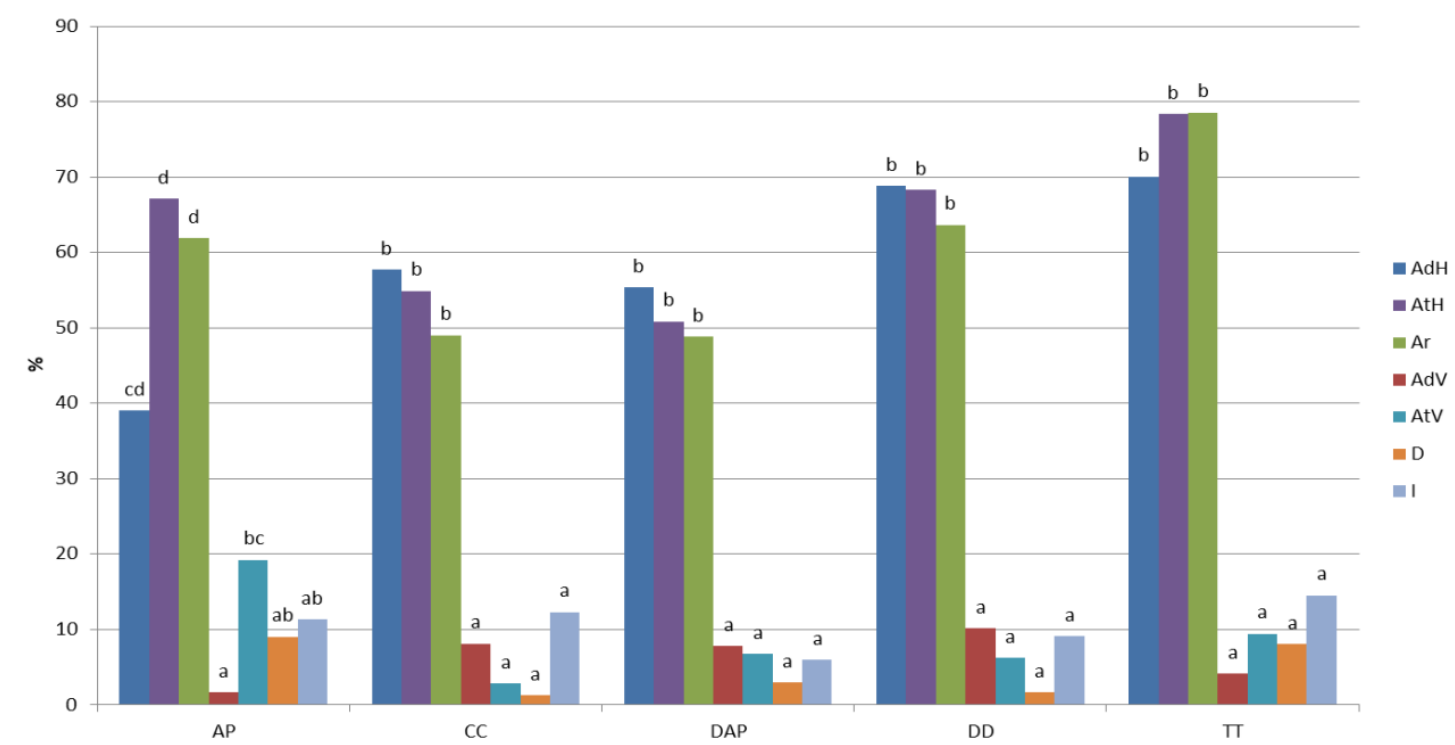

Figura 22: Uniformidad en la Tasa de Recuperacion TR (\%). AP: abanico plano, CC: cono convencional, DAP: doble abanico plano inducido, DD: abanico angulado simple alternado y TT: deflectora. AdH: adelante horizontal, Ar: arriba, AtH: atrás horizontal, AdV: adelante vertical, AtV: atrás vertical, D: derecha, I: izquierda. Letras diferentes presentan diferencias significativas ( $p$-value $<0,05$ ), para test de Ranks de Kruskal Wallis, entre posiciones dentro de las pastillas.

En la figura 21 se observa que la uniformidad en la tasa de aplicación mantiene la misma tendencia que la observada para Densidad de impactos; independientemente de los valores, las pastillas DD y DAP son las de mayor uniformidad seguida por TT y las pastillas AP y CC son las que alcanzan los objetivos en forma más desuniforme. Esto es importante de tener en cuenta al momento de aplicar productos con baja capacidad de translocación dentro de la planta y que requieren llegar a todas las posiciones del objetivo para conseguir eficiencia biológica tal como mencionan Vázquez \& Rodrigues (2010). 
Los valores expresados en las figuras 14, 15, 16 y 17 (correspondientes a la variable eficiencia) deberían presentar valores similares a los obtenidos en las figuras 18,19 y 20 de Tasa de recuperación; sin embargo, se visualiza que solamente la pastilla DD presenta valores similares, cercanos al $33 \%$. CC, AP y DAP tuvieron valores menores tal como es de esperarse según Domper et al., (2015) y Gadea (2018); TT en cambio registró valores mayores que los que se obtuvieron con el CIR 1.5. Esto es llamativo ya que Domper et al., (2015) han encontrado datos diferentes, los cuales demuestran una sobreestimación de la eficiencia de aplicación realizada a través del CIR con respecto al trazador y mencionan un factor de corrección de 1,67 para pastillas CC y 3,38 para pastillas CC con inducción de aire, entre lo obtenido con trazador y lo arrojado por el programa CIR1.5. Dichas diferencias entre los valores obtenidos por medio de un trazador y de tarjetas hidrosensibles mencionadas por Domper et al., (2015), mucho más marcadas, pueden deberse a varios parámetros. Debe tenerse en cuenta que la metodología utilizada por dichos autores para la captación del trazador difiere de la usada en este trabajo, al igual que la adición de coadyuvantes que en este caso no se efectuó. Por ejemplo, en este trabajo se utilizó trazador colorimétrico el cual fue recogido en papeles de filtro con las mismas dimensiones que las tarjetas hidrosensibles, Domper et al., (2015), utilizaron trazadores fluorimetricos que fueron recogidos en cajas de Petri de mayor dimensión. Por otro lado, en este trabajo no se utilizó ningún tipo de coadyuvante mientras que Domper et al., (2015), usó un tensioactivo marca Rino ${ }^{\circledR}$ en concentraciones del $10 \%$ v/v; este producto pudo influir en la expansión de la gota sobre el papel hidrosensible generando diferencias en las evaluaciones ya que las tarjetas están calibradas con agua, sin ningún 
tipo de agregados. En función de los resultados obtenidos sería recomendable avanzar en la investigación sobre el uso de tarjetas hidrosensibles con productos coadyuvantes y su sobre o subestimación de la eficiencia.

Como se ha mencionado y se puede ver en la figura 22 existen pocas posiciones puntuales en las que se presentan diferencias significativas entre las metodologías de evaluación. En el resto de las posiciones encontramos situaciones con valores mayores del trazador y valores mayores de la eficiencia evaluada por CIR1.5, sin poder encontrar una tendencia de sobreestimación por parte del programa informático.

En la posición AdH, AP obtiene $40 \%$ de tasa recuperación contra un $52 \%$ del valor de Eficiencia; esta misma relación se observa en $\mathrm{Ar}$ y AtH con valores de 62-67 \% para trazador contra 82-84\% para Eficiencia. En general es posible mencionar que no se observan grandes diferencias entre Eficiencia y Tasa de recuperación denotando un buen comportamiento de ambas metodologías de evaluación. 

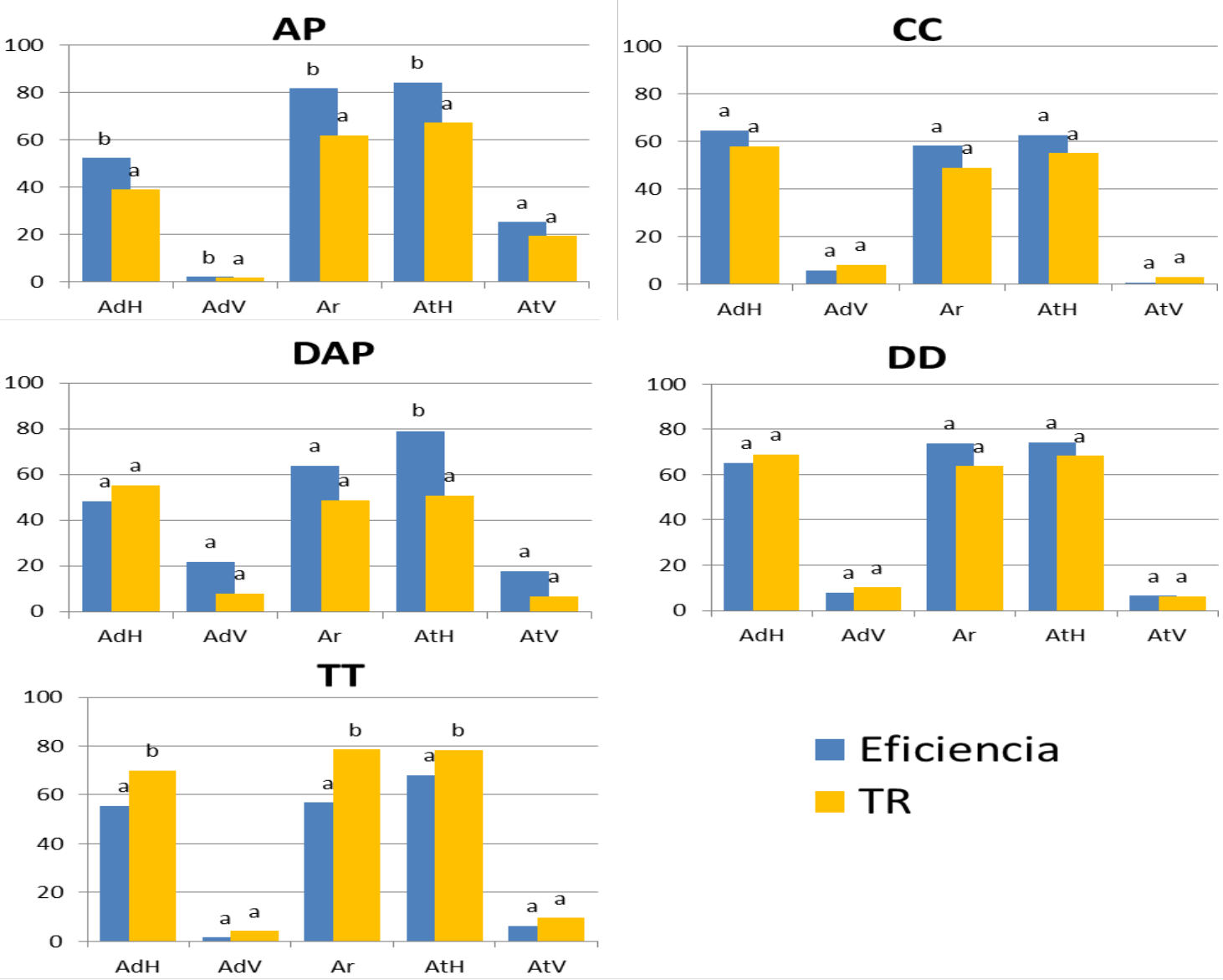

Eficiencia

TR

Figura 23: Tasa de Recuperación TR (\%) versus Eficiencia (\%) particionada por las posiciones relativas dentro del banco objetivo AP: abanico plano, CC: cono convencional, DAP: doble abanico plano inducido, DD: abanico angulado simple alternado y TT: deflectora. AdH: adelante horizontal, Ar: arriba, AtH: atrás horizontal, AdV: adelante vertical, AtV: atrás vertical. Letras diferentes presentan diferencias significativas ( $p$ value $\leq 0,05)$, para test de Ranks de Kruskal Wallis, entre metodologías de evaluación dentro de las posiciones.

En la figura 22 se visualiza que en la mayoría de las pastillas existe una sobreestimación por parte del parámetro eficiencia, que varía según las caras, existiendo siempre alguna cara en la que se invierte salvo en AP y en TT que presentan resultados completamente diferentes. En CC y DD no existen diferencias significativas y los valores son cercanos; estas pastillas presentan, a diferencia del resto, valores de Densidad de impactos y DVM 
muy similares y sobre todo los mejores comportamientos en cuanto a uniformidad (amplitud relativa y coeficiente de dispersión) principalmente en las posiciones horizontales, lo que permitiría hipotetizar que estos parámetros son un requisito importante a la hora de evaluar pulverizaciones por medio de tarjetas hidrosensibles. Por otro lado, la pastilla AP presenta diferencias significativas en casi todas sus posiciones situación diferente de la de DAP, que si bien presenta un comportamiento similar y en algunos casos incluso más marcado no llega a presentar diferencias en casi ninguna posición. Este comportamiento puede deberse a dos cosas, primero una gran dispersión de valores tanto de los Diámetros como de la Densidad de impactos y por otro lado la des uniformidad de la familia de gotas en las caras del objetivo lo que lleva a sobreestimaciones por parte del programa CIR1.5 ya que evalúa gotas en un rango mayor al de 150-250 $\mu$ m (Imágenes 7 y 8 ) aumentando de esta manera el error.

TT es la pastilla más conflictiva en esta evaluación, ya que el programa CIR 1.5, contradiciendo a toda la bibliografía, presentó valores de subestimación frente a la metodología de trazador. Esta pastilla presentó bajos valores de Densidad de impactos y de DVM, pero fue la pastilla más desuniforme en cuanto a Coeficiente de dispersión y amplitud relativa, por lo que debería seguirse estudiando este comportamiento en ensayos posteriores.

\section{Conclusiones parciales Eficiencia y Tasa de recuperación}

Estos resultados permiten rechazar la hipótesis planteada, pese a una clara tendencia general, en cuanto a que el uso de trazador indica una menor tasa de recuperación que la estimada por medio de tarjetas hidrosensibles, ya que esto pareciera depender más de 
variables de diseño de pastilla y las características de la población de gotas, que de la metodología de evaluación propiamente dicha. Por otra parte, los valores de eficiencia como de tasa de recuperación muestran que existen pérdidas de producto de importancia en todas las pastillas, aún en condiciones de alta humedad relativa, temperaturas medias y ausencia de viento. Es claro también que los valores de eficiencia se referencian al objetivo de aplicación $y$, por lo tanto, los mismos son variables con los objetivos establecidos. Los valores de eficiencia se modifican sustancialmente según los objetivos sea horizontales o verticales. No debe perderse de vista que todo lo que no se encuentra sobre el objeto de aplicación deberá considerarse pérdida de producto y tanto mayor sea dicha diferencia mayor será la ineficiencia de la aplicación y el riesgo de daño ambiental.

\section{Cobertura (\%)}

El porcentaje de Cobertura es un parámetro evaluado por el programa de análisis de tarjeta a partir de diferencias de color entre manchas y fondo, con lo cual, a partir del tamaño de las improntas medidas, se construyen el tamaño de las gotas y el número de impactos. Es posible observar en la figura 23 que no se encuentran diferencias estadísticas entre los diferentes tratamientos. Si comparamos estos datos con los de DVM es posible concordar con Mc Mullan (1995), Etheridge et al., (1999), Ramsdale \& Messersmith

(2001), Wolf \& Daggupati (2009) y Massaro et al., (2014) quienes afirman que la diferencia de tamaño de las gotas, si bien puede afectar la deposición, no es suficiente para afectar la cobertura. 


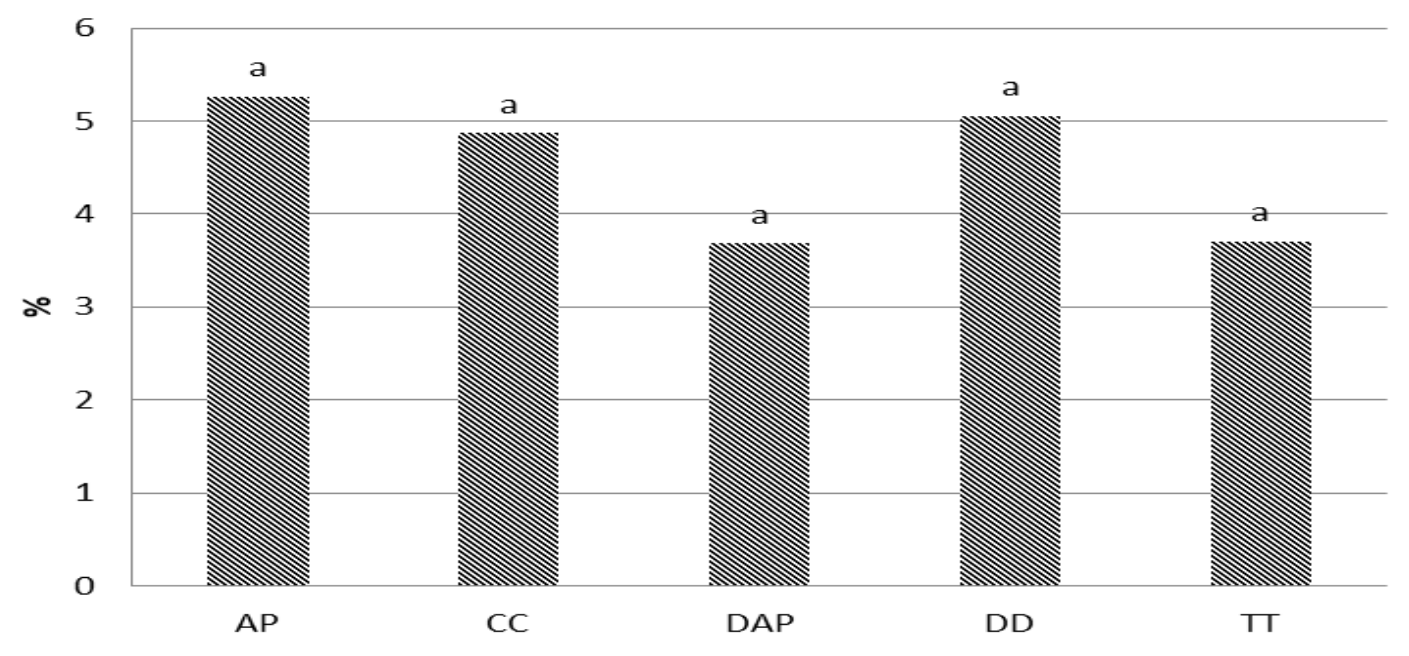

Figura 24: Cobertura (\%).AP: abanico plano, CC: cono convencional, DAP: doble abanico plano inducido, DD: abanico angulado simple alternado y TT: deflectora. Promedio de todas las posiciones del banco objetivo. Letras diferentes presentan diferencias significativas ( $p$-value $\leq 0,05)$, para test de Ranks de Kruskal Wallis.

Esto se puede deber como en el resto de las variables a la dispersión de valores que se observan al analizar todas las posiciones juntas. En la figura 24 se puede observar que, al dividir los objetivos en cada una de las posiciones relativas, los que se hallan en posición vertical poseen un porcentaje de Cobertura mucho más bajo que los de posición horizontal, lo cual es lógico y coincide con el resto de los resultados evaluados hasta el momento. 


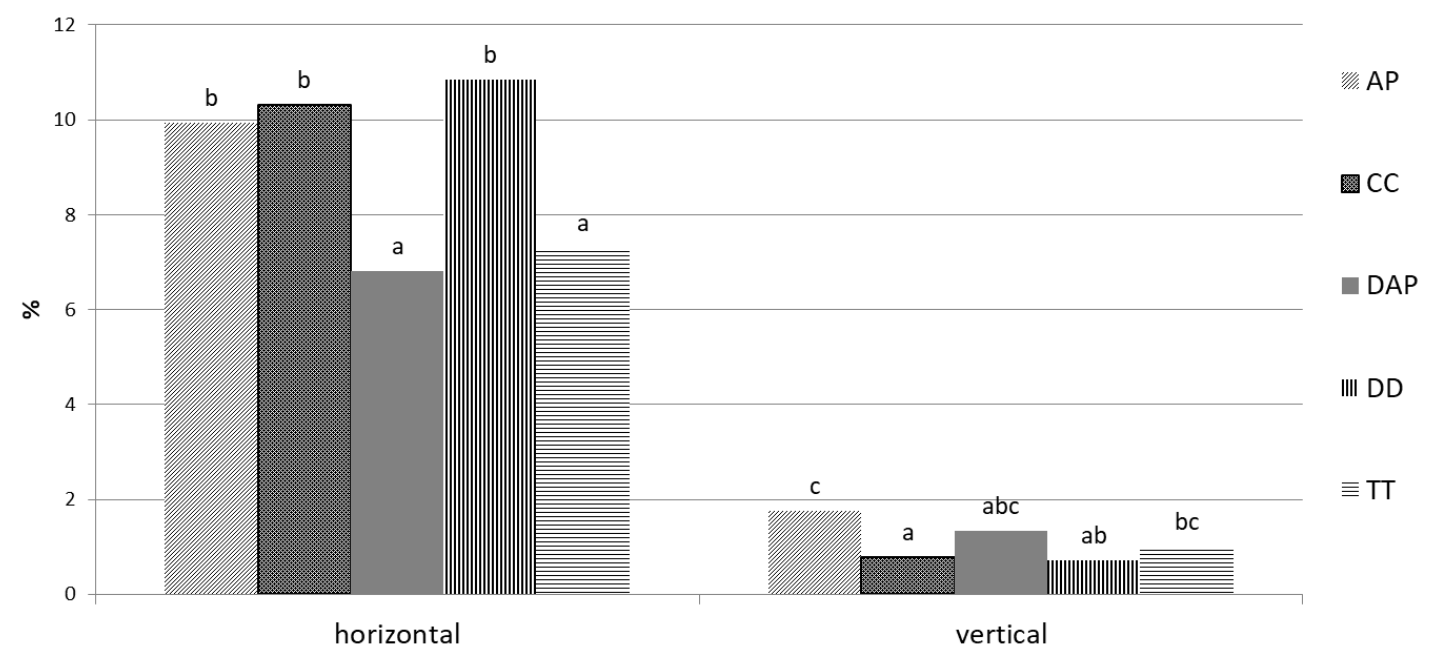

Figura 25: Cobertura (\%) particionada por posiciones Verticales y Horizontales dentro del banco objetivo. AP: abanico plano, CC: cono convencional, DAP: doble abanico plano inducido, DD: abanico angulado simple alternado y TT: deflectora. Letras diferentes presentan diferencias significativas ( $p$-value $\leq 0,05)$, para test de Ranks de Kruskal Wallis, entre pastillas dentro de la posición.

Barone (2017) y Roncaglia (2018) han encontrado resultados de Cobertura similares a los hallados en este ensayo, entre $14 \%$ y $16 \%$ para posiciones horizontales, con algunas pastillas iguales a las usadas (AP, CC, TT y DAP) pero con tasas de aplicación levemente superiores (aprox. $70 \mathrm{I} \mathrm{ha}^{-1}$ ) y en condiciones de campo.

Por otro lado, Valenzuela (2016) trabajando con alto y bajo volumen (70 I ha $\mathrm{y}^{-1} 30 \mathrm{I} \mathrm{ha} \mathrm{h}^{-1}$ ) obtuvo Coberturas de aproximadamente $16 \%$ y 5-6 \% respectivamente para pastillas TT y CC, cercanas a los valores reportados por Tesouro et al., (2006). Se debe tener en consideración que estos trabajos, si bien utilizaron mayores tasas de aplicación, fueron realizados a campo con diferentes condiciones de viento, temperatura y humedad, lo cual podría haber contrarrestado los aspectos diferenciales entre los mismos, dando como resultado valores de Cobertura similares. También Gorordo \& Roncati (2017) evaluando 
software, para determinar la calidad de aplicación de plaguicidas en condiciones similares a las que se utilizaron en este trabajo, hallaron valores de $19 \%$ a $14 \%$ para tasas de 125 I $\mathrm{ha}^{-1}$ a 89 I ha $\mathrm{h}^{-1}$ con pastillas TT 11002 y de $17 \%$ a $15 \%$ para las mismas tasas, pero para pastillas XR 11002.

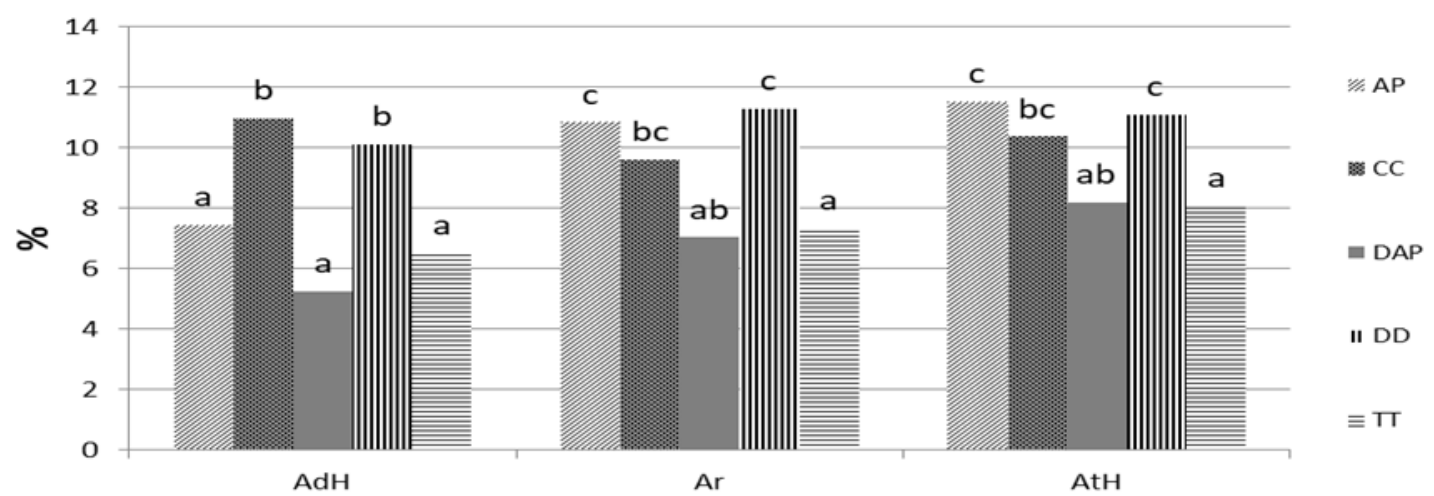

Posiciones Horizontales en el banco objetivo

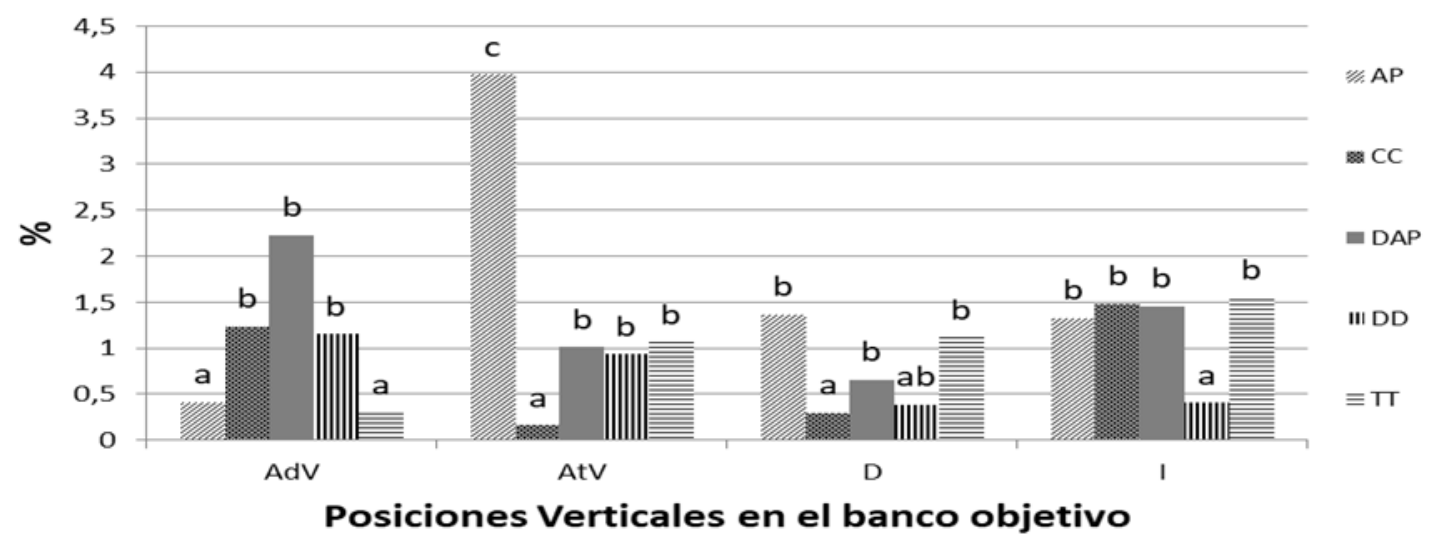

Figuras 26: Cobertura (\%) particionada por todas las posiciones relativas dentro del banco objetivo. AP: abanico plano, CC: cono convencional, DAP: doble abanico plano inducido, DD: abanico angulado simple alternado y TT: deflectora. AdH: adelante horizontal, Ar: arriba, AtH: atrás horizontal, AdV: adelante vertical, AtV: atrás vertical, D: derecha, I: izquierda. Letras diferentes presentan diferencias significativas ( $p$-value $\leq 0,05)$, para test de Ranks de Kruskal Wallis, entre pastillas dentro de las posiciones.

En la figura 25 se puede observar que AP sigue manteniendo la dificultad observada en Densidad de impactos, Eficiencia y Tasa de Recuperación para alcanzar las posiciones relativas delanteras, tanto verticales como horizontales, y presenta los mejores resultados 
en las posiciones traseras. CC por su lado posee buenos resultados en las posiciones Horizontales concordando con Fritz et al., (2007), pero no en las Verticales coincidiendo con Zhu et al., (2004); quienes determinaron que la penetración de pulverización de la boquilla hidráulica de cono era mayor que la boquilla de abanico plano pero, en estratos superiores, tanto AP como el doble abanico presentaron mejores resultados que el cono hueco. También Parkin et al. (2006), evaluando diferentes boquillas y angulaciones de las mismas, concluyeron que, a pesar de no obtener claras relaciones entre los niveles de micotoxinas y rendimiento en trigo con la tecnología de aplicación utilizada, los mejores resultados se lograron con el uso de boquillas orientadas hacia atrás y la utilización de gotas medias o con aire inducido en lugar de pulverizaciones con gotas finas. Esta discrepancia en los resultados para la pastilla de AP puede deberse a la falta de viento. La necesidad de viento es un factor importante para ayudar a la rápida llegada al objetivo por parte de las gotas, disminuyendo el tiempo desde la salida de la pastilla hasta el objetivo (Hardi, 2003; Tepper, 2014) y, por el pequeño tamaño que poseen las gotas de CC, es posible que requiera de este para alcanzar posiciones relativas complicadas por sombras de objetos. DAP junto con TT fueron las que presentaron los valores más bajos de Cobertura en posiciones horizontales, sin diferenciarse entre ellas en ninguna de las posiciones.

En las posiciones verticales el comportamiento es similar al observado para eficiencia y se puede denotar la diferencia de comportamiento de las pastillas para alcanzar los objetivos verticales delanteros y traseros; en AdV DAP fue superior a TT, siendo también superior a todas las demás en esa posición, lo cual como ya se mencionó, posiblemente se deba al 
mayor tamaño de las gotas de estas pastillas inducidas lo que permite mantener la inercia de las gotas generada por la velocidad de avance del tractor por más tiempo y, en conjunto con su ángulo de salida, permite que estas gotas alcancen el objetivo en forma más perpendicular pese a la altura del botalón. DD fue la pastilla que presentó la mejor performance en Cobertura (\%) en todas las posiciones horizontales, pero no así en las posiciones verticales donde presentó dificultades para alcanzar los objetivos $D$ e I y estuvo en la media en el resto de las posiciones. Los resultados disienten con los obtenidos por Wolf \& Peng (2011) quienes hallaron que angulaciones hacia adelante o atrás mejoraban las deposiciones en objetivos verticales y con Derksen et al., (2012), quienes mencionan en su trabajo, que los objetivos verticales, se beneficiaron de un ángulo de rociado hacia delante de la boquilla, lo cual no fue así en este ensayo y solo se observó en la posición AdV para DAP y DD, pero sin diferenciarse de CC. Por otro lado DAP tuvo menores valores en las posiciones horizontales lo que difiere con lo hallado por Sayinci \& Bastaban, (2011) quienes encontraron los mayores depósitos con estas pastillas al igual que Zhu et al., (2004); esto puede explicarse posiblemente en el efecto del viento ya que los ensayos mencionados fueron realizados a campo con diferentes velocidades de viento $(0,5$ a $6,0 \mathrm{~m}$ $\mathrm{s}^{-1}$ ) lo que probablemente generó la pérdida de las gotas más chicas resultando en un menor número de impactos y área de Cobertura en las pastillas sin inducción de aire. 


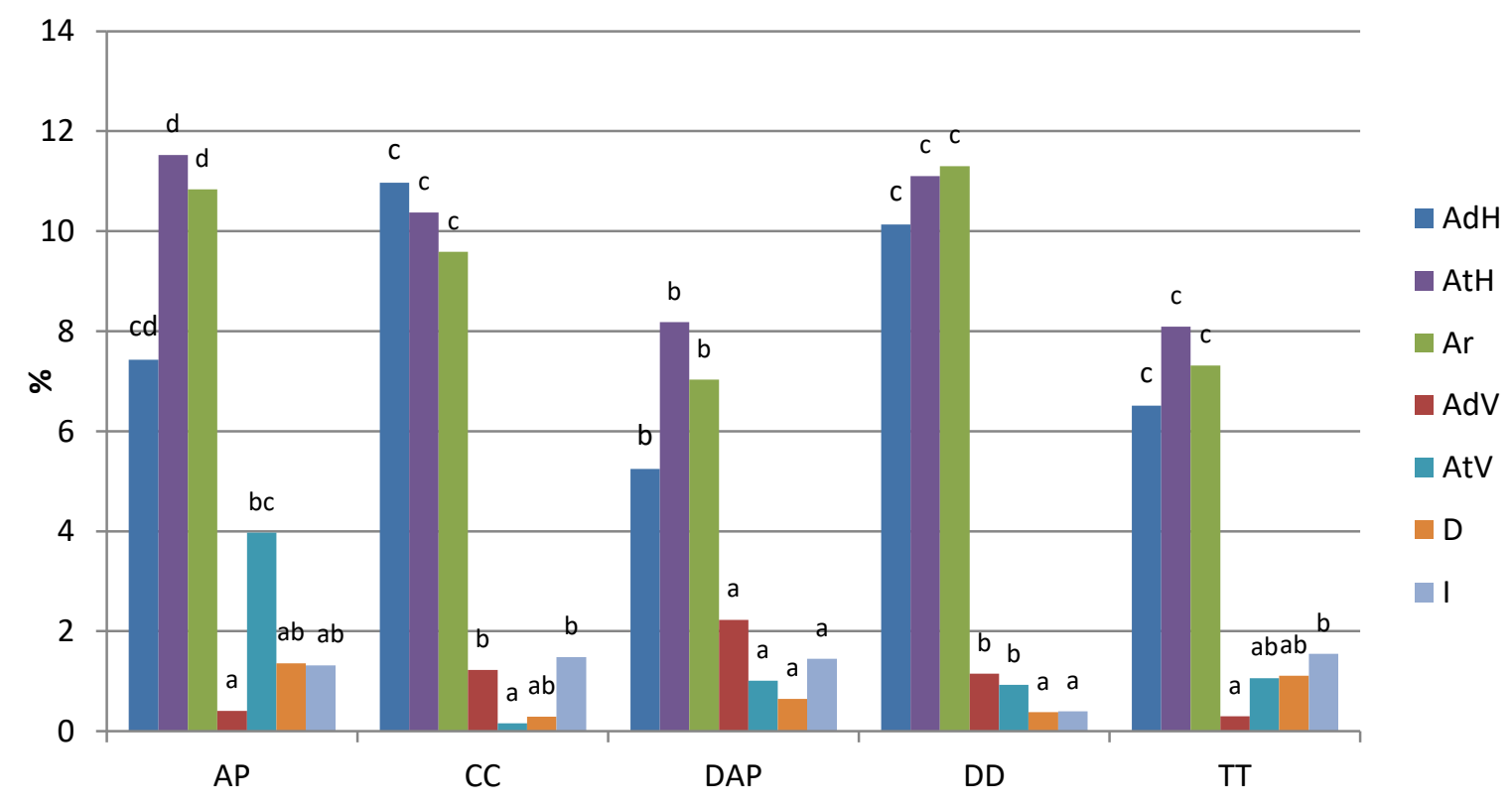

Figuras 27: Cobertura (\%). Uniformidad. AP: abanico plano, CC: cono convencional, DAP: doble abanico plano inducido, DD: abanico angulado simple alternado y TT: deflectora. AdH: adelante horizontal, Ar: arriba, AtH: atrás horizontal, AdV: adelante vertical, AtV: atrás vertical, $\mathrm{D}$ : derecha, I: izquierda. Letras diferentes presentan diferencias significativas ( $p$-value $<0,05$ ), para test de Ranks de Kruskal Wallis, entre posiciones dentro de las pastillas.

En la figura 26 se puede observar que nuevamente las pastillas con mejores relaciones de uniformidad son DAP y DD, siendo DAP las de menores diferencias estadísticas pero de más rango de variación en las posiciones horizontales. AP y CC poseen diferencias entre las posiciones verticales pero, como era de esperar, las posiciones horizontales son muy uniformes. AP nuevamente es la pastilla con llegada más desuniforme a las caras de los objetivos planteados.

También es notable, al igual que en los gráficos anteriores en los que se diferencian objetivos horizontales y verticales, que la cobertura es sustancialmente menor en estos últimos. 
Jensen (2007; 2010; 2012) menciona que, a partir de consideraciones teóricas, se podría esperar que la deposición sobre objetivos verticales podría mejorarse cambiando la trayectoria de pulverización de la vertical estándar a una inclinación que sea más perpendicular al objetivo de pulverización, pero explica que esto solo ocurrirá si el ángulo del abanico de pulverización se mantiene igual desde la punta de la boquilla hasta el objetivo. Los videos de alta velocidad de las pulverizaciones en ángulo muestran que el ángulo inicial de la pulverización se mantiene hacia el objetivo para una proporción de las gotas en la zona de pulverización en función del tamaño de las mismas. Jensen (2007), Jensen (2012), Wolf \& Peng (2011), Wolf \& Caldwell (2013) y Parkin et al., (2006) han demostrado que la angulación en realidad aumenta la deposición de rociado en objetivos verticales. Sin embargo, hasta ahora no se ha demostrado ninguna ventaja en la eficacia de los herbicidas. La eficacia generalmente aumentó al aumentar los cambios en el ángulo de la pulverización con respecto al estándar vertical y a su vez se incrementó cuando la pulverización estaba inclinada hacia atrás o hacia adelante, aunque la mayor mejora se obtuvo utilizando la pulverización en ángulo hacia adelante, siendo ésta la que generó una mayor deposición pero la peor uniformidad. Al cambiar el ángulo de rociado desde la vertical, la distancia desde la boquilla al objetivo aumenta y la pluma debe bajarse correspondientemente para mantener la misma distancia de viaje que proporciona una distribución uniforme. Aunque los resultados no fueron inequívocos, la mejora más grande se obtuvo utilizando un rociado en ángulo hacia adelante a $60^{\circ}$ en combinación con una altura de la boquilla de 0,25 m por encima del objetivo. Con ésta configuración, la tasa de dosis de herbicida podría reducirse en un 31,5 \% en comparación con el montaje 
vertical estándar en los pulverizadores de campo. Resultados similares fueron hallados por Wolf \& Peng, (2011) quienes encontraron que la deposición de caldo disminuye a medida que aumentaron la altura del botalón de 0,3 $\mathrm{m}$ a 0,75 $\mathrm{m}$ para diferentes DVM, de forma más marcada en objetivos verticales que horizontales.

\section{Conclusiones parciales Cobertura}

Es posible validar la hipótesis que expresa que "la Cobertura y la Densidad de impactos en los objetivos verticales son menores independientemente de la tecnología de aplicación utilizada o diseño y disposición de las pastillas usadas" en el marco de trabajo del presente ensayo, realizado en condiciones semi-controladas.

Además, similares tendencias se observaron en las evaluaciones de Eficiencia de aplicación y Tasa de recuperación, las cuales en parte sustentan las conclusiones relacionadas a densidad de impactos y cobertura.

En una valoración de los distintos parámetros de caracterización de la calidad de la aplicación, en cuanto a la incidencia de la disposición relativa de la pulverización con los objetivos de aplicación, pone de manifiesto que los objetivos verticales presentan dificultades en los procesos de aplicación que no alcanzan a ser solucionados por la angulación de las distintas alternativas de pastillas de pulverización de abanico plano, ni

por las características de proyección de las pastillas de cono hueco. Estos resultados muestran contradicciones con los resultados de ensayos realizados con pastillas anguladas. En el análisis de diferentes aspectos, que puedan explicar dichas diferencias, se estableció la hipótesis ad-hoc que la altura de aplicación utilizada, frecuente en el medio 
productivo, resulta excesiva para el uso de las pastillas anguladas con tamaño de gotas fino. Esta hipótesis fue contrastada una vez finalizados los ensayos y los resultados obtenidos se adjuntan en el Anexo I, como complemento del cuerpo de esta Tesis. Dicha hipótesis se fundamenta en aspectos ya analizados en la discusión del presente trabajo como ser:

a) la distancia recorrida por las gotas aumenta con el aumento de la altura del botalón.

b) los diferentes tamaños de gotas que conforman el espectro de pulverización no mantienen la misma dirección desde que salen de la pastilla de pulverización hasta que llegan al objeto de aplicación, y se acerca a la posición vertical en la medida que la misma se aleja del punto de emisión del abanico de pulverización.

c) Las pastillas $\mathrm{DD}$, con tamaño de gota $\mathrm{F}$ y ángulo de $+20^{\circ}$ y $-20^{\circ}$ serían más afectadas que las DAP, pese al mayor ángulo $\left(+30^{\circ}\right.$ y $\left.-30^{\circ}\right)$, principalmente por el mayor tamaño de las gotas al ser pastillas con inducción de aire.

En las fotos 1 y 2 puede visualizarse el efecto del cambio de dirección y la nube de gotas de pulverización de la pastilla $\mathrm{DD}$, junto al ancho de la aspersión en la vista lateral, que permite inferir las diferentes angulaciones que las gotas adquieren antes de llegar a los objetivos, aumentando los valores para el sector horizontal en detrimento de los sectores verticales. 


\section{CONCLUSIONES}

En el marco de las condiciones de realización del ensayo, en un ambiente semi controlado y con simulación de posibles ubicaciones de objetivos de aplicación, en relación a la interferencia de residuos y malezas, se establecen las siguientes conclusiones.

La disposición relativa de los objetivos es determinante de la calidad de pulverización, en base a la densidad de impactos, cobertura y tasa de recuperación del caldo de pulverización.

La proyección de los abanicos de pulverización en ángulos diferentes de la vertical no posee un efecto positivo sobre la densidad de impactos y la cobertura, cuando se analiza integralmente el objeto de aplicación.

La altura del objetivo no incide sobre la calidad de aplicación del sector de sombra en el rango evaluado, representativo de malezas en sus estadios iniciales de crecimiento.

La disposición angulada alternada de los abanicos de pulverización no mejora la uniformidad de distribución sobre los objetivos anteroposteriores en la totalidad de los parámetros de calidad de aplicación.

Todas las pastillas evaluadas tienen una mayor uniformidad en el espectro de gotas sobre los objetivos verticales, pero solamente las pastillas anguladas alcanzan diferencias significativas entre la totalidad de las posiciones verticales y horizontales.

Los objetivos verticales presentan mayores dificultades para alcanzar una adecuada calidad de control o pulverización en base a la Densidad de impactos, la Cobertura y la 
eficiencia de aplicación (tasa de recuperación) independientemente del diseño y la angulación de las pastillas

La eficiencia de deposición del caldo sobre el objetivo de aplicación varía con la metodología de evaluación y la pastilla de pulverización. Tanto el uso de software de análisis de imágenes como la determinación colorimétrica otorgan resultados confiables a nivel comparativo entre diferentes técnicas de aplicación, siendo las diferencias entre los mismos de escasa significación. 


\section{BIBLIOGRAFÍA}

Adámoli, J. \& Solbrig, O. (2008). Agro y ambiente: una agenda compartida para el desarrollo sustentable. Buenos Aires: Foro de la Cadena Agroindustrial Argentina. 34pp. Disponible en: http://www.foroagroindustrial.org.ar/home.php.

Agrotop. (2008). Düsen und Zubehor für den Pflanzenschutz: Produktkatalog 106. Obertraubling: Agrotop $\mathrm{GmbH}, 128 \mathrm{pp}$.

Arvidsson, T., Bergström, L., \& Kreuger, J. (2011). Spray drift as influenced by meteorological and technical factors. Pest management science, 67(5): 586-598.

ASABE (2009). Droplet Size Classification S572.1. 1pp.

Bache D. H. \& Johnstone D R. (1992). Microclimate and Spray Dispersion. Ellis Horwood, Chichester, U.K. ISBN 0-13-217910-5. 238pp.

Balzarini, M. G., Gonzalez, L., Tablada, M., Casanoves, F., Di Rienzo, J. A., \& Robledo, C. W. (2008). InfoStat. Infostat. Manual del Usuario (Editorial Brujas). Córdoba, Argentina. 336pp.

Barone, G. (2017). Control de calidad de pulverizaciones agrícolas. Comparación de metodologías de evaluación. Teisi de grado. FCAyF. UNLP. Repositorio SEDICI. 35pp. Disponible en: http://sedici.unlp.edu.ar/handle/10915/74064.

Barros, JB. \& Freixial, R. (2010). El control de malezas en agricultura de conservación y siembra directa. Congreso Europeo de agricultura de conservación. Madrid Octubre 2010. Instituto de Ciências Agrárias E Ambientais Mediterrânicas (ICAA), Universidade de Évora, Évora, Portugal. pp. 7002-7554

Bauer, F.C., \& C.G. Raetano. (2004). Distribuição Volumétrica de Calda Produzidas Pelas Pontas Pulverização XR, TP E TJ Sob Diferentes Condições Operacionais. Sociedade Brasileira da Ciência das Plantas Daninhas. Planta Daninha 22 (2): 275-284 https://doi.org/10.1590/S0100-83582004000200015.

Bayer, T., Arrué, A., Dressler da Costa, I. F., Lenz, G., Sari, B. G., Pizzuti Pes, M., \& Cezar, C. (2012). Aplicação aérea de fungicidas na cultura do arroz irrigado com diferentes bicos de pulverização Aerial fungicide application on irrigated lowland rice with varying spraying nozzles. Ciência Rural, 42(12): 2185-2191.

BBC Research. (2010). Global Markets for Agrochemicals. Report Code: CHMO54A. Published: January 2010. Disponible en: https://www.bccresearch.com/marketresearch/chemicals/agrochemicals-fertilizer-pesticide-markets-chm054a.html.

Bedmar, F. (2011). Que son los plaguicidas. Ciencia Hoy, Buenos Aires. 21 (122): 10-16.

Bernardos, J. \& M. E. Zaccagnini. (2011). El uso de insecticidas en cultivos agrícolas y su riesgo potencial para las aves en la región pampeana. Revista Hornero. 26 (1): 55-64.

Bird, S. L., Esterly, D. M. \& S. G. Perry. (1996). Off-targe deposition of pesticides from agricultural aerial spray application. J. Environ. Qual. 25(5): 1095-1104.

Bode L.E. (1984). Downwind drift deposits by ground applications. En: Proceedings Pesticide Drift Management. Symposium. South Dakota University Brookings. Pp: 4952.

Boller W \& J.F. Schlosser. (2010). Consideraciones operativas de las boquillas 
pulverizadoras. En: Tecnología de Aplicación de agroquímicos Magdalena C, Castillo Herrán B, Di Prinzio A, Homer I, Villalba J.[Eds.]. Alto Valle Rio Negro: INTA Alto Valle. pp: 89-96

Boller, W. (2011). Avanços tecnológicos em pontas de pulverização. In: Sintag- $5^{\circ}$ Simpósio Internacional de Tecnologia de Aplicação de Agrotóxicos 2011, Cuiabá, MT, Brasil. Trabalhos apresentados. 19pp.

Bouse, L. F., Kirk, I. W., \& Bode, L. E. (1990). Effect of spray mixture on droplet size. Transactions of the American Society of Agricultural Engineers, 33(3): 783-788.

Branford, S. (2004). Argentina's bitter harvest. New Scientist. 182(2443): 1-4.

Brechelt, A. (2004). Manejo Ecológico de Plagas y Enfermedades. Red de Acción en Plaguicidas y sus Alternativas para América Latina (RAP-AL). Fundación Agricultura y Medio Ambiente (FAMA) República Dominicana. 36pp. Disponible en: https://webzoom.freewebs.com/rentawebscr/alonsocr2013/descargas/Manejo_Ecol ogico_de_Plagas_A.Bretchel.pdf. Último acceso: Junio de 2020.

Bueno, M. R., Da Cunha, J. P. A. R., \& Roman, R. A. A. (2013). Tamanho De Gotas De Pontas De Pulverização Em Diferentes Condições Operacionais Por Meio Da Técnica De Difração Do Raio Laser. Eng. Agríc. Jaboticabal. 34(5): 976-985. https://doi.org/10.1590/S0100-69162013000500009

Bulacio, L.G.; Sarubbi, C.S.; Panelo, M.S. \& Etiennot, A. (2005). Pastillas pulverizadoras: Análisis de deriva. In: Aplicar eficientemente los agroquímicos. Bogliani, M.; Hilbert, J. eds. Buenos Aires, INTA. pp: 56-60.

Byass, J.B. \& Lake, J.R., (1977). Spray drift from a tractor-powered field sprayer. Pesticide Science. 8(2): 117-126.

Cabrini S.M., CalcaterraC.P. \& Lema D. (2013). Costos ambientales y eficiencia productiva en la producción agraria del partido de Pergamino. Revista iberoamericana de Economía Ecológica. 20: 27-43.

Cabrini S.M., Cristeche E., De Prada J., Dupleich J., Engler P., Espósito M., Manchado J. C., Mathey D., Natinzon P., Schutz P., Tello D. \& Vicente G. (2014). Percepción sobre el Impacto Ambiental de la Producción Agropecuaria de la Región Pampeana Argentina. En Primer Congreso Latinoamericano de Conflictos Ambientales.Buenos Aires pp: 387-410. Disponible en: https://ediciones.ungs.edu.ar/wpcontent/uploads/2018/10/9789876303668-completo.pdf

Cajamarca Carrazco D. I., Paredes Godoy M. M., Cabrera Escobar C. P., Velasco Matveev L. A. \& Vaca Cárdenas M. L. (2020) Agroquímicos: enemigos latentes para los polinizadores y la producción de alimentos primarios que agoniza. Revista Contribuciones a las Ciencias Sociales. pp: 1. Disponible en: https://www.eumed.net/rev/cccss/2020/03/agroquimicos-enemigospolinizadores.html

Calle Salvador, C. (2019). Impactos generados por la fumigación con agroquimicos en el cultivo de maíz (Zea mays), Tesis de Grado, Caserio Pueblo Viejo, Distrito De PacoraLambayeque, Chiclayo-Perú 2019. 27pp. Disponible en: https://repositorio.udl.edu.pe/xmlui/handle/UDL/258

Carlsen, S. C. K., Spliid, N. H. \& B. Svensmark. (2006). Drift of 10 herbicides after tractor spray application: 2. Primary drift (droplet drift). Chemosphere. 64(5): 778-786. 
Carriquiriborde, P. (2010). Toxicidad de Glifosato en Peces Autóctonos: Estudios de Laboratorio y Campo. Taller Aspectos Ambientales del Uso de Glifosato. Ed. Myriam Camino y Virginia Aparicio. Ediciones de Tecnología Agropecuaria. INTA. Balcarce, pp: 53-64

Carvalho, F.P. (2006). Agriculture, pesticides, food security and food safety. Environmental Science \& Policy. 9: 685-692.

CASAFE. (2015). Estudio de Mercado 2014 de Productos de Protección de Cultivos. Disponible en: https://www.casafe.org/pdf/2018/ESTADISTICAS/Informe-MercadoFitosanitarios-2014.pdf. Último acceso: Junio del 2020.

CASAFE. (2018). El mercado de agroquímicos se mantuvo estable respecto de 2015. Disponible en: https://www.casafe.org/pdf/2018/ESTADISTICAS/Informe-MercadoFitosanitarios-2018.pdf. Último acceso: Junio de 2020.

Cavalieri, J. D., Raetano, C. G., Madureira, R. P., \& Moreira, L. L. (2015). Spraying systems and traveling speed in the deposit and spectrum of droplets in cotton plant. Engenharia Agrícola, 35(6): 1042-1052.

Cawood, P.N.; Robinson, T.H. \& Whittaker, S. (1995). An investigation of alternative application techniques for the control of black-grass. In: Brighton crop protection conference: weeds. Proceedings of an international conference, Brighton, UK, 20-23 November 1995. Farnham (United Kingdom): British Crop Protection Council, 1995.ISBN 0-948404-91-4. pp: 521-527

Chapple, A. C.; Hall, F. R. \& Bishop, B. L. (1993). Assessment of single-nozzle patternation and extrapolation to moving booms. Crop Protection.12: 207-213.

Chorbadjian, R., \& Kogan, M. (2001). Pérdida de actividad del glifosato debido a la presencia de suelo en el agua de aspersión. Ciencia e investigación agraria: revista latinoamericana de ciencias de la agricultura, 28(2): 83-87.

Christofoletti J. C. (1992). Manual Shell de máquinas e técnicas de aplicação de defensivos. Em: Programa de manutenção segura de productos. São Paulo. Shell Brasil. 122pp.

Christofoletti, J. C. (1997). Bicos de pulverização-seleção e uso. Diadema: Spraying Systems do Brasil. 9pp.

Christofoletti J. C. (1999). Considerações sobre deriva nas pulverizações agrícolas e seu controle. TeeJet Soth América. 1. pp: 1-15.

Cid, R., Moltoni, A. F., \& Fuica, A. M. (2010). El camino hacia una agricultura con maquinarias autónomas. El control de malezas. Curso Internacional de Agricultura de Precisión. 9. Expo de Máquinas Precisas 4. 14, 15 y 16 de julio de 2010. Manfredi, Córdoba. AR. 23pp.

Combellack, J.H. \& Richardson, R.G. (1985). Effect of changing droplet trajectory on collection efficiency. In: British Crop Protection Monograph 28, Symposium on Application and Biology. BCPC, Croydon, UK, pp: 227-233.

Combellack J.H; N.M. Western \& R.G. Richardson. (1996). A comparison of the drift potential of a novel twin fluid nozzle with conventional low volume flat fan nozzles when using a range of adjuvants. Crop Protection. 15( 2): 147-152

Conover, W.J. (1999). Practical Nonparametric Statistics. John Wiley \& Sons, Inc., New York. $3^{\circ}$ edition Texas Tech University. 584pp. 
Courshee, R.J. (1960). Some aspects of the application of insecticides. Annual Review of Entomology, Palo Alto. 5: 327-352

Cunha Rodrigues Da, J. P. A., Teixeira, M. M., Coury, J. R., \& Ferreira, L. R. (2003). Avaliação de estratégias para redução da deriva de agrotóxicos em pulverizações hidráulicas. Planta Daninha, 21(2): 325-332.

Cunha Rodrigues Da, J. P. A., Teixeira, M. M., Vieira, R. F., Fernandes, H. C., \& Coury, J. R. (2004). Espectro de gotas de bicos de pulverização hidráulicos de jato plano e de jato cônico vazio. Pesquisa Agropecuaria Brasileira, 39(10): 977-985. https://doi.org/10.1590/S0100-204X2004001000005

David, J. \& Peña, S. (2014). Evaluación de la calidad de aplicación de plaguicidas en un cultivo de espinaca.Tesis de Maestria. Universidad Nacional de Colombia Facultad de Ingeniería 177pp. disponible en: https://repositorio.unal.edu.co/handle/unal/52003

De Cock, N., Massinon, M., Salah, S. O., \& Lebeau, F. (2017). Investigation on optimal spray properties for ground based agricultural applications using deposition and retention models. Biosystems engineering, 162: 99-111.

De Souza Christovam, R. C., Raetano, M., De Amaral Dal Pogetto, Evandro P., Hélio J., Gimenes, M. \& M., Serra. (2010). Effect of nozzle angle and air-jet parameters in airassisted sprayer on biological effect of soybean asian rust chemical protection Journal of Plant Protection Research. 50(3): 347-353 https://doi.org/10.2478/v10045-0100059-4.

Derksen, R. C., Paul, P. A., Ozkan, H. E., \& Zhu, H. (2012). Field evaluations of application techniques for fungicide spray deposition on wheat and artificial targets. Applied Engineering in Agriculture, 28(3): 325-331.

Derksen, R. C., Zhu, H., Ozkan, H. E., Hammond, R. B., Dorrance, A. E., \& Spongberg, A. L. (2008). Determining the influence of spray quality, nozzle type, spray volume, and air-assisted application strategies on deposition of pesticides in soybean canopy. Transactions of the ASABE, 51(5): 1529-1537.

Di Rienzo, J.A., Casanoves F., Balzarini M.G., Gonzalez L., Tablada M., Robledo C.W. (2017). InfoStat versión 2017. Grupo InfoStat, FCA, Universidad Nacional de Córdoba, Argentina. Disponible en: URL http://www.infostat.com.ar. Ultimo acceso: Julio 2019.

Díaz de Ackermann, M. \& Kohli M.M. (2013). Fusarium Head Blight in Latin America. Chapter 11: Chemical Control of Fusarium Head Blight of Wheat. Teresa M. Alconada Magliano Sofía Noemí Chulze Editors. New York London. 311pp. https://doi.org/10.1007/978-94-007-7091-1

Dombrowski, N., \& W. R. Johns. (1963). The aerodynamic instability of viscous liquid sheets. Chemical Engineering Science. 18: 203-214.

Domper, G. N. (2015). Eficiencia de aplicación de pastillas de pulverización con inducción de aire en el cultivo de soja. Tesis de grado. 54pp. FCAyF UNLP.

Domper, G. N., Mur, M., \& Balbuena, R. H. (2015). Eficiencia de aplicación de pastillas de pulverización con inducción de aire en el cultivo de soja. Revista de la Facultad de Agronomía, La Plata, 113(2): 202-210.

Dorr, G. J. (1990). The effect of orientation and fan angle on spray deposition by flat fan noozles. In: Agricultural Engineers Conference, 1990. Proceedings. Toowoomba. pp. 30-32. 
Downer R. A., Ebert T. A., Thompson R. S. \&, Hall, F. R. (1997). Herbicide Spray Distribution, Quality and Interactions: Conflicts in Requirements. Aspects of Applied Biology 48: 79-89.

Durão C. F. \& Boller, W. (2017). Spray nozzles performance in fungicides applications for asian soybean rust control. Journal of the Brazilian Association of Agricultural Engineering. 37 (4): 709-716. Disponible en: http://dx.doi.org/10.1590/1809-4430Eng.Agric.v37n4p709-716/2017.

Elliott, J. G., \& Wilson, B. J. (1983). The Influence of Weather on the Efficiency and Safetyof Pesticide Application: the Drift of Herbicides.British Crop Protection CouncilOccasional Publication 3: 66pp. Report of the Working Party of the BCPC Research Development Committee.

Elliott, R.H. \& Mann, L.W. (1997). Control of wheat midge, Sitodiplosis mosellana (Gehin), at lower chemical rates with small-capacity sprayer nozzles. Crop Prot. 16: 235-242.

Enfält, P.; Enqvist, A.; Bengtsson, P. \& Alness, K. (1997). The influence of spray distribution and drop size, on the dose response of herbicides. Proceedings of Brighton Crop Protection Conference Weeds, pp: 381-389.

Etheridge, R.E.; Womac, A.R. \& Mueller, T.C. (1999). Characterization of the spray droplet spectra and patterns of four Venturi-type drift reduction nozzles. Weed Technol. 13: 765-770.

Etiennot, A.E. (1990). Cuarto Curso de Actualización para Pilotos Aeroaplicadores. Nacional de Aviación Civil (INAC), Buenos Aires. 119pp.

Etiennot, A.E., \& Jalil-maluf, E.L. Mazza-rossi, S. \& Pataro, A. (1998). Introduction to the study of spray penetration from hydraulic nozzles and CDA system in cultivated pastures: Lotus tenuis. Malezas. 16: 63-65.

FAO. (1996). Cumbre mundial sobre la alimentación. Disponible en: http://www.fao.org/wfs/index_es.htm. Último acceso: Junio de 2020.

FAO. (2007). La agricultura y el medio ambiente: es hora de intervención mundial. Disponible en: http://www.fao.org/ag/esp/revista/0704sp1.htm. Último acceso: Junio de 2020.

FAO. (2015). Perspectivas para el medio ambiente. Disponible en: http://www.fao.org/3/y3557s/y3557s11.htm. Último acceso: Junio de 2020.

FAO (2020). FAOSTAT. Pesticides Use. Disponible en: http://www.fao.org/faostat/en/\#data/RP Último acceso: Junio de 2020.

Farooq, M., R. Balachandar, D. Wulfsohn, \& T. M. Wolf. (2001). Agricultural sprays in cross flow and drift. J. Agric. Eng. Res. 78(4): 347-358.

Ferguson, J.C., O'Donnell, C.C., Chauhan, B.S., Adkins, S.W., Kruger, G.R., Wang, R., Urach Ferreira, P.H., Hewitt, A.J., (2015). Determining the uniformity and consistency of droplet size across spray drift reducing nozzles in a wind tunnel. Crop Protection. 76: 1-6.

Flores, C.C. \& Sarandon, S.J. (2002). ¿Racionalidad económica versus sustentabilidad ecológica?. Revista de la Facultad de Agronomía, ISSN 0041-8676, Facultad de Ciencias Agrarias y Forestales. UNLP, Argentina.105(1): 52-67

Friesen, G.H. \& D.A. Wall. (1991). "Effect of Application Factors on Efficacy of Fluazifop-PButyl in Flax Effect of Application Factors on Efficacy of Fluazifop-P-Butyl in Flax'." 
Source: Weed Technology 5(3): 504-508.

Fritz, B.K.; W.C. Hoffmann, D.E. Martin \& S.J. Thomson. (2007). "Aerial Application Methods for Increasing Spray Deposition on Wheat Heads." Applied Engineering in Agriculture 23(6): 709-715.

Frola, E. (2013). Manejar tamaño, número y distribución de impactos para lograr aplicaciones de calidad. Disponible en: http://www.todoagro.com.ar/noticias/ nota.asp?nid=25566. Ultimo Acceso Julio 2020.

Gadea, J.S. (2018). Prestación de pastillas en el control de enfermedades de trigo (Triticum aestivum L.). Tesis de grado. 68pp. FCAyF. UNLP. Disponible en: http://sedici.unlp.edu.ar/handle/10915/67247

Galli, J.C.; T. Matuo \& E.C. Siqueira. (1983). Padrão de distribuição de alguns bicos hidráulicos. Planta Daninha. 4(2): 144-150.

Gálvez, M.R., H.F. Vinciguerra, W. Rodríguez, S. Sabaté, E.A. Soldini, M.R. Devani, I.L. Olea \& L.D. Ploper. (2005). Evaluación de la penetración del asperjado producido por diferentes boquillas en aplicaciones terrestres orientadas al control de la roya de la soja. Estación Experimental agroindustrial Obispo Colombres, Tucumán Argentina. Publicación especial $n^{\circ} 27,12 p p$.

Goering, C. E., L. E. Bode, \& M. R. Gebhardt. (1972). Mathematical model of spray droplet deceleration and evaporation. Trans. ASAE 15(2): 220-225.

Gorordo, J.J. \& Roncati, P.S. (2017). Uso de softwares para la determinación de la calidad de aplicación de plaguicidas. SEMIÁRIDA Revista de la Facultad de Agronomía UNLPam. 27(1): 45-57.

Gossen, B.D., Peng, G., Wolf, T. M., Mcdonald, M. R., Gossen, B. D., Peng, G., Mcdonald, M. R. (2008). Improving spray retention to enhance the efficacy of foliar-applied disease-and pest-management products in field and row crops. Can. J. Plant Pathol, 30: 505-516.

Grau, H.; Aide, M. \& Gasparri, N. (2008). Globalization and soybean expansion into semiarid ecosystems of Argentina. AMBIO A journal of the human environment, 2008. 34(3): 265-266.

Grover, R., Kerr, L.A., Maybank, J., Yoshida, K., (1978). Field measurements of dropletdrift from ground sprayers. Canadian Journal of Plant Science. 58: 611-622

Guzmán-Plazola, P., Guevara-Gutiérrez, R. D., Olguín-López, J. L., \& Mancilla-Villa, O. R. (2016). Perspectiva campesina, intoxicaciones por plaguicidas y uso de agroquímicos. Idesia (Arica), 34(3): 69-80.

Hang, S. (2010). Comportamiento de Agroquímicos en el Suelo. Cátedra de Edafología. Universidad Nacional de Córdoba y Universidad Católica de Córdoba. Revista del Colegio de Ingenieros Agrónomos de la provincia de Córdoba. 20(82): 1980-2018.

Hanna, H.M.; Robertson, A.E.; Carlton, W.M. \& Wolf, R.E., (2009). Nozzle and carrier application effects on control of soybean leaf spot diseases. Applied Engineering in Agriculture. 25(1): 5-13.

Hardi. (2003). Técnicas de Atomización. N 673705. Manual de usuario. Edicion 2003. $41 \mathrm{pp}$.

Hewitt, A.J., (1997). Droplet size and agricultural spraying, part 1: atomization, spray transport, deposition, drift, and droplet size measurements techniques. Atomization 
Spray 7: 235-244.

Hobson P.A., P.C.H. Miller, P.J. Walklate, C.R. Tuck, N.M. Western. (1993). Spray drift from hydraulic spray nozzles: the use of a computer simulation model to examine factors influencing drift. Journal of Agricultural Engineering Research. 54: 293-305.

Hoffmann, W. C., \& Hewitt, A. J. (2005). Comparison of three imaging systems for watersensitive papers. In 2004 ASAE Annual Meeting (1). American Society of Agricultural and Biological Engineers. 21(6): 961-964

Holterman, H. J., Van De Zande, J. C., Porskamp, H. A. J., \& Huijsmans, J. F. M. (1997). Modelling spray drift from boom sprayers. Computers and Electronics in Agriculture. 19(1): 1-22.

Hughes, R. R. \& E. R. Gilliland. (1952). The mechanics of drops. Chemical Engineering Progress 48(10): 497-504.

Hypro. (2013). Hypro nozzles guardian air tm finer air-induction nozzles with shallow rear incline. Folleto técnico. United Kingdom. 4pp. Disponible en: https://www.agratech.co.uk/files/attachments/726/Guardian Air datasheet.pdf. Ultimo acceso: Julio 2020.

Hypro Pentair. (2017). Spray Parts Guide. Manuel de repuestos y pastillas. Folleto técnico. United Kingdom. 280pp. Disponible en: https://www.pentair.com/content/dam/extranet/flow/catalogs/HYP01-Catalog.pdf. Ultim acceso: Julio 2020.

Ibarra, J. A., López, C. A. V., Moreno, M. R. C., Reyes, P. D. L., Servin, J. A. B., Apodaca, M. E. M., \& Sandoval, N. C. R. (2019). Agroquímicos organofosforados y su potencial daño en la salud de trabajadores agrícolas del campo sonorense. CIENCIA ergo-sum, 26(1): 8

INDEC. (2019). Exportación por grandes rubros: Años 1980-2018. Disponible en: https://www.indec.gob.ar/nivel4_default.asp?id_tema_1=3\&id_tema_2=2\&id_tema _3=40. Último acceso: febrero de 2020.

Iriarte Barbosa J.I., S. Paiva De Vargas \& J.M. Rabino Long. (2013). Tecnología de aplicación para el control de enfermedades en trigo. Tesis de grado. Universidad de la Republica. Montevideo, Uruguay. 50pp. Disponible en: https://www.colibri.udelar.edu.uy/jspui/bitstream/20.500.12008/8773/1/3967iri.pdf

ISAAA. (2012). Top ten facts about biotech/GM crops in 2012. A new overview of biotech in 2012. Disponible en: www.isaaa.org. Ultimo acceso Agosto de 2020.

Jensen, P.K. (1999). Herbicide performance with low volume low-drift and air-inclusion nozzles. Proceedings of Brighton Crop Protection Conference Weeds, pp: 453-460.

Jensen, P.K. (2007). Nonvertical spray angles optimize graminicide efficacy. Weed Technol. 21: 1029-1034.

Jensen, P.K. (2010). Improved control of annual grass weeds with foliar acting herbicides using angled applications Aspects of Applied Biology. 99: 81-88.

Jensen, P.K. (2012). Increasing efficacy of graminicides with a forward angled spray. Crop Protection. 32: 17-23.

Jensen, P.K. \& Nielsen, B.J. (2008). Influence of volume rate and nozzle angling on control of potato late blight with flat fan, pre-orifice and air induction nozzles. International Advances in Pesticide Application. Association of Applied Biologists. 84: 447-452. 
Jensen, P.K. \& Nielsen, B.J. (2014). Influence of application technique on control of potato early blight (Alternaria solani) Cap 9. In Applied Crop Protection 2014, pp: 121-124. Aarhus Universitet-DCA-Nationalt Center for Fødevarer og Jordbrug.

Jensen, P. K., Jørgensen, L. N. \& Kirknel, E. (2001). Biological efficacy of herbicides and fungicides applied with low-drift and twin-fluid nozzles. Crop Protection, 20(1): 57-64.

John Deere. (2017) Spray Parts Guide. Spray Nozzles and Accessories Guide Manuel de repuestos y pastillas. 64pp. USA. Folleto técnico. Disponible en: https://docplayer.net/33970746-John-deere-spraying-solutions-spray-nozzles-andaccessories-guide-technozzlegy-tek-noz-uhl-jee.html. Ultimo acceso septiembre 2020.

King, H. W., C. O. Wisler \& J. G. Woodburn. (1953). Hydraulics. 5th ed. John Wiley \& Sons, Inc. New York. 351pp.

Klein, R.N. \&; Johnson, A.K. (2002). Nozzle tip selection and its effects on drift and efficacy. In: International Advances in Pesticide Application (2002, Guildford, Surrey). Scientific papers. Wellesbourne, UK, Association of Applied Biologists. Aspect of Applied Biology no. 66: 217-230

Knoche, Moritz. (1994). Effect of Droplet Size and Carrier Volume on Performance of Foliage-Applied Herbicides. Crop Protection. 13(3): 163-178. https://doi.org/10.1016/0261-2194(94)90075-2.

Lake, J.R. (1977). The effect of drop size and velocity on the performance of agricultural sprays. Pesticide science. 8(5): 515-520.

Leiva, P.D. (1995). Manejo de la deriva en la aplicación de agroquímicos. Carp. Produc. Vegetal. INTA, EEA Pergamino, SERIE: Generalidades, Tomo XIV. Información N 139, Septiembre, Ed: Puig, R. 6pp.

Leiva, P.D. (1996). Calidad de aplicación de plaguicidas. En: primera Jornada de Control Químico de Enfermedades del trigo en sistemas de manejo para alta productividad. Bolsa de Cereales de Buenos Aires. Estación Experimental Agropecuaria Pergamino, INTA, 12pp.

Leiva, P.D. \& Picapietra, G.I. (2012). Compatibilidad para mezclas de tanque de tres herbicidas utilizados en barbecho químico Pergamino. Grupo Protección VegetalINTA, Estación Experimental Agropecuaria Pergamino. Disponible en: https://inta.gob.ar/documentos/compatibilidad-para-mezclas-de-tanque-de-tresherbicidas-utilizados-en-barbecho-quimico. Ultima consulta: 29 de enero 2020.

Lenz, G., Silveiro, R., Gripa, S., Tormen, N. \& Nascimento, L. (2011). Espectro de gotas e idade de trifólios na taxa de absorção e efeito residual de fungicidas em soja. Ciência Rural, 41(10): 1702-1708.

Liu, Q., Cooper, S. E., Qi, L., \& Fu, Z. (2006). Experimental study of droplet transport time between nozzles and target. Biosystems engineering, 95(2): 151-157.

March G.J., Oddino C.M \& Marinelli A.D. (2010). Manejo de Enfermedades de los Cultivos según Parámetros Epidemiológicos. Córdoba, Biglia Impresores. 191pp.

Márquez, L. (1997). Tecnología para la aplicación de defensivos agricolas. In: Congresso Brasileiro de Engenharia Agrícola. 26pp. Campina Grande. Anais. Palestra.

Marquez, L. (2005). El control de la deriva en la aplicación de fitosanitarios. Agrotecnica. 5. $\mathrm{pp}$ :

32-39.

Disponible

en: 
https://www.mapa.gob.es/ministerio/pags/biblioteca/revistas/pdf_Agrotec/Agrotec _2006_5_32_38.pdf.

Martens, F. (2012). Guía para el uso adecuado de plaguicidas y la correcta disposición de sus envases. Boletín de divulgación. N41: $26 \mathrm{pp}$.

Masiá, G. \& R. Cid. (2010). Las boquillas de pulverización. Capítulo 6 En: Tecnología de aplicación de agroquimicos. 200pp. Argentina. pp: 77-87.

Maski, D. \& D. Durairaj (2010). "Effects of charging voltage, application speed, target height, and orientation upon charged spray deposition on leaf abaxial and adaxial surfaces," Crop Protection. 29: 134-141.

Massaro, R.A., García A. \& Magnano L. (2014). Evaluación de técnicas de pulverización antideriva para el control de malezas en barbecho químico. En Para mejorar la producción, 52: 147-150 INTA EEA Oliveros 2014. Disponible en: http://inta.gob.ar/sites/default/files/script-tmp-inta-evaluacin-tcnicas-pulverizacinantideriva-barbec.pdf.

Matthews, G. A. (2000). Pesticide application methods. 3.ed. London: Blackwell, 2000. $432 \mathrm{pp}$.

Matthews, G. A. (2004). How was the pesticide applied? Crop Protection 23: 651-653.

Matthews, G.A; R. Bateman \& P. Miller. (2014). Pesticide Application Methods. 4.Ed. Wiley-Blackwell. 545pp.

Mc Mullen M., Jones R., Draper M., Sweets L., Lipps P., Shaner G., Hershman D., Gregoire T., Endres G., Harbour J., Lukach J., McKay K., Schatz B., Halley S., Pederson J., Hofman V. \& Panigrahi S. (1998). Fungicide technology network of the national FHB initiative. In: Proceedings of the 1998 National Fusarium Head Blight Forum. October 26-27 Michigan State University, East Lansing, MI. pp: 47-50

Metzler, M., Puricelli, E., Papa, J. C., \& Peltzer, H. (2013). Manejo y control de rama negra. Ediciones INTA 27pp.

Miller, P. C. H., \& Hadfield, D. J. (1989). A simulation model of the spray drift from hydraulic nozzles. Journal of Agricultural Engineering Research. 42(2): 135-147 https://doi.org/10.1016/0021-8634(89)90046-2

Moltoni, L.; Masiá G. \& A. Moltoni. (2008). Cost and income analysis of agricultural labors: the role of agricultural machinery services providers in Argentina. International Conference of Agricultural Engineering - XXXVII Congresso Brasileiro de Engenharia Agrícola, Foz do Iguaçu, Brasil. 4pp.

Montesanto, A. (2018). Aumentó $5,6 \%$ el consumo de agroquímicos y fertilizantes en 2017. Disponible en: https://www.infocampo.com.ar/aumento-56-el-consumo-deagroquimicos-y-fertilizantes-en-2017/. Último acceso: Junio de 2019.

Mur, M., Ponce, M., Vázquez, J. M., Guilino, F., Merani, V., Palancar, T., \& Balbuena, R. H. (2017). Control de malezas en pre siembra. Alternativas tecnológicas y riesgos ambientales de la aplicación. Revista de La Facultad de Ciencias Agrarias y Forestales, 116(2): 267-277.

Mur, M., Ponce, M. J., Vázquez, J. M., Guilino, F., Merani, V., Palancar, T., \& Balbuena, R. H. (2018a). Aplicación de agroquímicos en cultivos de soja (Glycine max L Merr); evaluación del efecto de diferentes técnicas sobre la eficiencia de distribución. Revista de la Facultad de Agronomía, La Plata (2018). 117(1): 77-88 
Mur, M., Ponce, M. J., Guilino, F., Merani, V. H., \& Balbuena, R. H. (2018b). Pulverización con alto y bajo volumen en rastrojo de sorgo. Eficiencia y riesgos ambientales de la aplicación. UNR. Ciencias Agronómicas. 32: 34-42.

Muzlera, J. (2018). Agroquímicos y salud. Estudios Rurales. 8(14): 2pp.

Nicholson, P., Turner, J. A., Jenkinson, P., Jennings, P., Stonehouse, J., Nuttall, M., Thomsett, M. (2003). Maximising control with fungicides of Fusarium ear blight (FEB) in order to reduce toxin contamination of wheat. London (United Kingdom) : Home Grown Cereals Authority. HGCA Project Report. 85pp.

Nordbo, E. (1992). Effects of nozzle size, travel speed and air assistance on deposition on artificial vertical and horizontal targets in laboratory experiments. Crop Protection. 11(3): 272-278.

Nuyttens, D., De Schampheleire, M., Baetens, K. \& B. Sonck. (2007a). The influence of operator-controlled variables on spray drift from field crop sprayers. Trans. ASABE 50(4): 1129-1140.

Nuyttens, D., Baetens, K., De Schampheleire, M., \& Sonck, B. (2007b). Effect of nozzle type, size and pressure on spray droplet characteristics. Biosystems Engineering, 97(3): 333-345. https://doi.org/10.1016/j.biosystemseng.2007.03.001.

Nuyttens, D., De Schampheleire, M., Verboven, P., Brusselman, E., \& Dekeyser, D. (2009). Droplet size and velocity characteristics of agricultural sprays. Transactions of the ASABE, 52(5): 1471-1480.

Onorato, A. \& Tesouro, O. (2006). Pulverizaciones agrícolas terrestres. Edit. INTA.163pp

Otero, G. (2008). Food for the Few. Neoliberal Globalism and Biotechnology in Latin America. Austin: University of Texas Press. 321pp.

Ozeki, Y. \& Kunz R. (1998). Tecnologia de aplicação aérea aspectos práticos. En: Tecnologia e segurança na aplicação de agrotóxicos: novas tecnologias aplicação aérea-aspectos práticos. Santa Maria: Departamento de Defesa Fitossanitária. UFMS. pp: 65-78.

Ozkan H.E. (1998). Effects of major variables on drift distances of spray droplets. Food, Agricultural and Biological Engineering. Extension FactSheet. pp: 525-598.

Ozkan, H. E., Miralles, H. Zhu, H. Reichard, D. R. \& R. D. Fox. (1997). Shields to reduce spray drift. J. Agric. Eng. Res. 67(4): 311-322.

Ozkan, H. E., Paul, P., Derksen, R. C., \& Zhu, H. (2012). Influence of application equipment on deposition of spray droplets in wheat canopy. Aspects of applied biology, 114: 317-324.

Palladini, L. A., C. G. Raetano, \& E. D. Velini. (2005). Choice of tracers for the evaluation of spray deposits. Scientia Agricola 62: 440-445.

Panisson E., Boller W., Melo Reis E., Hoffmann L. (2003). Técnicas de aplicação de fungicida em trigo para o controle de giberela (Gibberella zeae). Ciencia Rural. 33: 1320

Panneton, B.; H. Philion; R. Thériault \& M. Khelifi. (2000). Spray Chamber Evaluation of Air-Assisted Spraying on Broccoli. Crop Science. 40(2): 444-448. https://doi.org/10.2135/cropsci2000.402444x.

Parkin, C. S., Miller, P. C. H., Powell, E. S., Orson, J. H., Gill, J., Magan, N., \& Aldred, D. (2006). Improving the deposition and coverage of fungicides on ears to control 
Fusarium ear blight and reduce mycotoxin contamination of grain. Project Report $\mathrm{N}^{\circ}$ 383. The Home-Grown Cereals Authority (HGCA). 38pp.

Paul, H. \& Steinbrecher, R. (2003). Hungry Corporations. Transnational Biotech Companies Colonise the Food Chain. Londres: Zed Books. 242pp.

Perecin, D.; Peressin, V.A.; Matuo, T.; Barbosa, J.C.; Pio, L.C.; Braz, B.A. (1994). Padrões de distribuição obtidos com bicos Twinjet, em função da altura e do espaçamento entre bicos. Engenharia Agrícola, Jaboticabal. 14: 19-30,

Pórfido, O. D. (2014). Los plaguicidas en la República Argentina. 1a ed. - Buenos Aires: Ministerio de Salud de la Nación. 192pp.

Pretty J. (2008). Agricultural sustainability: concepts, principles and evidence. Philosophical Transactions of the Royal Society B: Biological Sciences. 363(1491): 447465.

Ramos, H. H. (2010). Com cautela. Cultivar Máquinas, Pelotas. 3: 22-25.

Ramsdale, B.K. \& Messersmith, C.G. (2001). Drift-reducing nozzle effects on herbicide performance. Weed Technol. 15: 453-460.

Richardson, B. \& Newton, M. (2000). Spray deposition within plant canopies. New Zealand Plant Protection. 53: 248-252.

Richardson, R.G., (1987). Effect of drop trajectory on spray deposits on crop and weeds. Plant Protection Quarterly (Australia). 2: 108-111.

Rodrigues, A.C.P., Filho, S.I.B.S., Martins, D., Costa, N.V. , Rocha, D.C. \& Souza, G.S.F. (2010). Avaliação qualitativa e quantitativa na deposição de calda de pulverização em Commelina benghalensis. Viçosa-MG. Planta Daninha. 28(2): 421-428.

Rodríguez Vassallo, M. (2017). Control de malezas. Evaluación de la eficiencia y riesgos ambientales de distintas pastillas. Tesis de Grado. UNLP. 50pp. Disponible en: http://sedici.unlp.edu.ar/handle/10915/65502

Roncaglia, F. (2018). Evaluación de software para el análisis de tarjetas hidrosensibles y del efecto de la adición de un coadyuvante tensioactivo utilizando diferentes pastillas de pulverización. Tesis de Grado. UNLP. 48pp. Disponible en: http://sedici.unlp.edu.ar/handle/10915/80750

Saccone, V. (2018). América Latina, un continente infestado por los pesticidas. Disponible en: https://www.esglobal.org/america-latina-continente-infestado-los-pesticidas/. Último acceso: Junio de 2019.

Santos J. (1992). Aviação agrícola. Manual de tecnologia de aplicação de agroquímicos. São Paulo: Rhodia Agro. 100pp.

Sarandón S.J. (2002). "La agricultura como actividad transformadora del ambiente. El Impacto de la Agricultura intensiva de la Revolución Verde". En "Agroecologia: El camino hacia una agricultura sustentable", S.J. Sarandon (Editor), Ediciones Científicas Americanas, La Plata. 1: 23-48.

Sayinci, B., \& Bastaban, S. (2011). Spray distribution uniformity of different types of nozzles and its spray deposition in potato plant. African Journal of Agricultural Research, 6(2): 352-362. https://doi.org/10.5897/AJAR10.480

Scudeler F. \& Raetano C.G. (2006). Spray Deposition an Losses in Potato. Spray deposition and losses in potato as a function of air-assistance and sprayer boom angle deposição e perdas na pulverização da batata em função da assistência de ar e angulação da 
barra pulverizadora. Piracicaba. Scientia Agricola. 63(6): 515-521.

Shaw D.R., William H.M., Webster E.P., \& Smith D.B. (2000). Effects of Spray Volume and Droplet Size on Herbicide Deposition and Common Cocklebur (Xanthium strumarium) Control Weed Technology. 14(2): 321-326 https://doi.org/10.1614/0890037X(2000)014[0321:EOSVAD]2.0.CO;2

Sidahmed, M. M., R. B. Brown, \& M. Darvishand. (1999). Drop-size/velocity correlations at formation of sprays from fan nozzles. Transactions of the ASAE. 42(6): 1557-1564.

Silva, M.A.S. (2000). Depósitos da calda de pulverização no solo e em plantas de tiririca (Cyperus rotundus L.) em diferentes condições de aplicação. Tese (Doutorado em Agronomia-Agricultura), Faculdade de Ciências Agronômicas, UNESP, Botucatu. $57 p p$.

Simoniello, M. F., E. C. Kleinsorge \& M. A. Carballo. (2010). Evaluación bioquímica de trabajadores rurales expuestos a pesticidas. Medicina (Buenos Aires). 70(6): 489-498.

Smith, D. B., Askew, S. D., Morris, W. H., Shaw, D. R., \& Boyette, M. (2000). Droplet size and leaf morphology effects on pesticide spray deposition. Transactions of the ASAE, 43(2): 255-259.

Southcombe, E.S.E.; P.C.H. Miller; H. Ganzelmeier; De Zande \& A.J. Hewitt. (1997). The international (bcpc) spray classification system including a drift potential factor, In Proceedings of the Brighton Crop Protection Conference-Weeds. pp: 371-380

Spillman, J.J. (1984). Spray impaction, retention and adhesion: an introduction to basic characteristics. Pesticide Science. 15: 97-106.

Spraying Systems Co. (1992). Spray Nozzles and Accessories. Data Sheets $N^{\circ} 37043-1 M$, $\mathrm{XR}$ Teejet extended range flat spray tip drop size data in microns versus pressure capacities XR11001 thru XR11008 spraying water at $21{ }^{\circ} \mathrm{C}$. Disponible en: https://www.teejet.com/literature/technical-documents.aspx. Ultimo acceso julio 2020.

Spraying Systems Co. (2004). Catálogo 49A-E. Productos de sistemas móviles. 176pp. Wheaton, Illinois. Disponible en: https://www.teejet.com/literature/technicaldocuments.aspx. Ultimo acceso julio 2020.

Spraying Systems Co. (2016). Spray Nozzles and Accessories. Data Sheets $N^{\circ} 37043-14 M$, TURBO TEEJET flat spray tips dropsize (micrometers) capacities TT11001-vp thru TT11008-vp spraying water at $70{ }^{\circ} \mathrm{F}$. Disponible en: https://www.teejet.com/literature/technical-documents.aspx. Ultimo acceso julio 2020.

Spraying Systems Co. (s.f.) Spray Nozzles and Accessories. Data Sheets $N^{\circ} 37043-16 M$, TXA-VK \& TXB-VK ceramic visiflo conejet hollow cone spray tips drop size data in micrometers versus pressure (metric) capacities 800050 thru 8004 spraying water at $21{ }^{\circ} \mathrm{C}$. Disponible en: https://www.teejet.com/literature/technical-documents.aspx. Ultimo acceso julio 2020.

Srivastava A.K.; C.E. Goering; R.P. Rohrbach \& D. R. Buckmaster. (2006). Engineering Principles of Agricultural Machines, 2nd Edition. ASABE, St. Joseph, MI. 601pp.

Stainier, C., Destain, M. F., Schiffers, B., \& Lebeau, F. (2006). Droplet size spectra and drift effect of two phenmedipham formulations and four adjuvants mixtures. Crop Protection. 25(12): 1238-1243. 
Standard, I.S.O. (2018). 10625: Equipment for crop protection--sprayer nozzles-colour coding for identification. International Organization for Standardization. Switzerland. Disponible en: https://www.iso.org/standard/70624.html.

Stefanelo, M. S., Sari, B. G., Lenz, G., Arrué, A., Pes, M. P. y Costa, I. F. D. (2014). Caracterização da fungicida na cultura do trigo com pontas hidráulicas e atomizadores rotativos de discos. Engenieria Agrícola. 34(5): 1012-1018.

Stoletniy Bergalli I.V. (2013). Tamaño de gota, volumen de aplicación y uso de adyuvantes en la deposición del pulverizado y el control de mancha amarilla causada por pyrenophora tritici-repentis en trigo. Tesis maestria. Montevideo Uruguay. Universidad De La República Facultad De Agronomía. 58pp. Disponible en: https://www.colibri.udelar.edu.uy/jspui/bitstream/20.500.12008/1863/1/0105sto.pd $f$

Syngenta (2002). Ficha técnica. Water-sensitive paper for monitoring spray distribution. Syngenta crop protection. Germany. 1pp. Disponible en: https://www.syngenta.com.au/awri. Ultimo acceso Noviembre 2019.

Syngenta. (2015). Syngenta Nozzle Range and Application Guidelines Free Nozzle Claim Form inside. Folleto tecnico 6pp. Disponible en: https://www.advanceagriculture.co.nz/files/678/file/Syngenta-nozzle-range-and-application-guidlines-pdf. Ultimo acceso Septiembre 2020.

TEEJET. (2014). Spraying Sistems Corporation. Catálogo 50-E. (en línea). Wheaton, Illinois. pp: 174-175. Disponible en http://www.teejet.com. Ultimo acceso Agosto 2020.

Teixeira M.M. (2010). Tecnología de aplicación de agroquímicos. Capitulo 5: Estudio de la población de gotas de pulverización. Ed: Magdalena J.C., Castillo Herran B., Di Prinzio A., Homer Bannister I, Villalba J. 200pp. Argentina pp. 67-77.

Tepper, G. (2014). Weather Essentials for Pesticide Application $2^{\text {da }}$ revisión. Grains Research \& Development Corporation Project. General meteorology for pesticide application booklet. 28pp.

Tesouro, M.O., G. Masiá, L. Venturelli \& A.M. Fuica. (2006). Ensayo de tecnologías de aplicación de fungicidas para roya de la soja. Centro de investigación en agroindustrias Centro nacional de investigaciones agropecuarias. 35pp.

Tilman D., Cassman K.G., Matson P.A., Naylor R., \& Polasky S. (2002). Agricultural sustainability and intensive production practices. Nature 418: 671-676.

Tomazella, M.S. (1997). Avaliação da deposição da calda de pulverização em função da densidade populacional de Brachiaria plantaginea (Link) Witc., volume e ângulo de aplicação. Dissertação (Mestrado em Agronomia-Agricultura), Faculdade de Ciências Agronômicas, UNESP, Botucatu. 78pp Disponible em: https://repositorio.unesp.br/handle/11449/100043

Tomazella, M.S. (2001). Efeitos do estádio de desenvolvimento de brachiaria plantaginea (link) witch, ângulo de aplicação e tipo de ponta na deposição da calda de pulverização. Tesis doctoral. Universidade Estadual Paulista Julio De Mesquita Filho Faculdade De Ciências Agronômicas Câmpus de Botucatu. SPMarço-2001. 200pp. Disponible en: https://repositorio.unesp.br/handle/11449/100043.

Uk, S. \& R.J. Courshee. (1982). "Distribution and Likely Effectiveness of Spray Deposits within a Cotton Canopy from Fine Ultralow-volume Spray Applied by Aircraft." 
Pesticide Science 13(5): 529-36. https://doi.org/10.1002/ps.2780130511.

Valenzuela, L.M. (2016). Pulverización con máquinas de botalón y bajo volumen. Características, eficiencia y riesgos ambientales de la aplicación. Tesis de grado FCAyF UNLP. 68pp. Disponible en: http://sedici.unlp.edu.ar/handle/10915/53023.

Vázquez, J. \& Rodrigues, J. (2010). Avaliação das aplicações. In: Manual de aplicação de produtos fitossanitários. Viçosa, MG, Aprenda Fácil. pp. 565-570.

Viglizzo E.F., Frank F., Bernardos J. \& Buschiazzo D.E. (2006). "A rapid method for assessing the environmental performance of commercial farms in the Pampas of Argentina". Environmental Monitoring and Assessment. 117: 109-134.

Vigna, M. R.; Gigón, R.; Vallati, A.; Robledo, L.; López, R. L. (2012). Posibilidad de control químico de malezas en el cultivo de colza (Brassica napus) en el SO de Buenos Aires. En Actas de XIV Jornada Fitosanitarias Argentinas. 3, 4 y 5 Octubre 2012 Potrero de Los Funes, San Luis, Argentina.

Villalba, J. \& Hetz, E. (2010). Deriva de productos agroquímicos-Efecto de las condiciones ambientales. In: Magdalena, J.C., Castillo Herrán, B.; Di Prinzio, A.; Homer Benister, I.; Villalba, J. eds. Tecnología de aplicación de agroquímicos. Alto Valle, INTA. pp: 45-54.

Villalba, J., Olivet, J. J., Cassanello, M. E., Bentancur, O., \& Cunha, J. P. (2011). Evaluation of deposition of spray nozzles for control of fusarium in wheat. / Evaluación de la deposición de boquillas de aplicación para el control de fusariosis en trigo. Agrociencia (Montevideo), 15(2): 69-75.

Weber, R. (1982). La quatrième session du panel FAO sur la mécanisation agricole: matériels et méthodes pour l'application de pesticides pour la préparation des sols et la protection des cultures. Machinisme Agricole Tropical. 77: 54-63.

Wolf, T.M. \& Caldwell, B.C. (2004). Evaluation of double nozzle spray deposits on vertical targets. Aspects of applied biology. 71: 99-106

Wolf, T.M. \& Caldwell B.C. (2013). Spray Deposition of TeeJet Al3070VS on Vertical Targets. A Study Conducted for TeeJet Technologies. 78pp.

Wolf, R.E. \& P.N. Daggupati. (2009). "Nozzle Type Effect on Soybean Canopy Penetration." Applied Engineering in Agriculture 25 (1): 23-30. https://doi.org/10.13031/2013.25426.

Wolf, T.M. \& Peng G. (2011). Improving Spray Deposition on Vertical Structures: The Role of Nozzle Angle, Boom Height, Travel Speed, and Spray Quality. Pest Technology Global Science Books. 5(Special Issue 1): 67-72

Wolf, T. M., S. K. Harrison, F. R. Hall, \& J. Cooper. (2000). "Optimizing Postemergence Herbicide Deposition and Efficacy through Application Variables in No-till Systems." Weed Science 48 (6): 761-68.

Zhu, H., Reichard, D. L., Fox, R. D., Brazee, R. D., \& Ozkan, H. E. (1994). Simulation of drift of discrete sizes of water droplets from field sprayers. Transactions - American Society of Agricultural Engineers, 37(5): 1401-1407.

Zhu, H., Reichard, D. L., Fox, R. D., Brazee, R. D., \& Ozkan, H. E. (1996). Collection efficiency of spray droplets on vertical targets. Transactions of the American Society of Agricultural Engineers. 39(2): 415-422.

Zhu, H., Dorner, J. W., Rowland, D. L., Derksen, R. C., \& Ozkan, H. E. (2004). Spray penetration into peanut canopies with hydraulic nozzle tips. Biosystems Engineering, 
87(3): 275-283.

Zhu, Heping, Salyani, M., \& Fox, R. D. (2011). A portable scanning system for evaluation of spray deposit distribution. Computers and Electronics in Agriculture, 76(1): 38-43. https://doi.org/10.1016/i.compag.2011.01.003 
ANEXO I

\section{Variación de la altura de botalón para las pastillas Defy-3D}

Las pastillas DD son las que presentan recomendaciones de menor altura del botalón para alcanzar una mayor deposición en la aplicación de herbicidas. Por ello, en función de lo hallado por Jensen (2007) y Wolf \& Peng (2011) se efectuaron pasadas con diferentes alturas de botalón para las pastillas DD utilizando las distancias máxima y mínima recomendadas para estas pastillas por el fabricante $(0,5 \mathrm{~m}$ y $0,7 \mathrm{~m})$ para el distanciamiento entre pastillas de este ensayo (Hypro, 2017). Para la evaluación de dichas alternativas, se tomaron solamente las posiciones verticales y horizontales, delanteras y traseras, dada la alta variabilidad de los resultados y escasa incidencia de las caras laterales verticales y de la cara superior de las horizontales. Al ser una única pastilla, se tomó como respuesta la Densidad de impactos, la eficiencia de aplicación y el porcentaje de Cobertura.

Los resultados se observan en la Figura 27 y la Figura 28
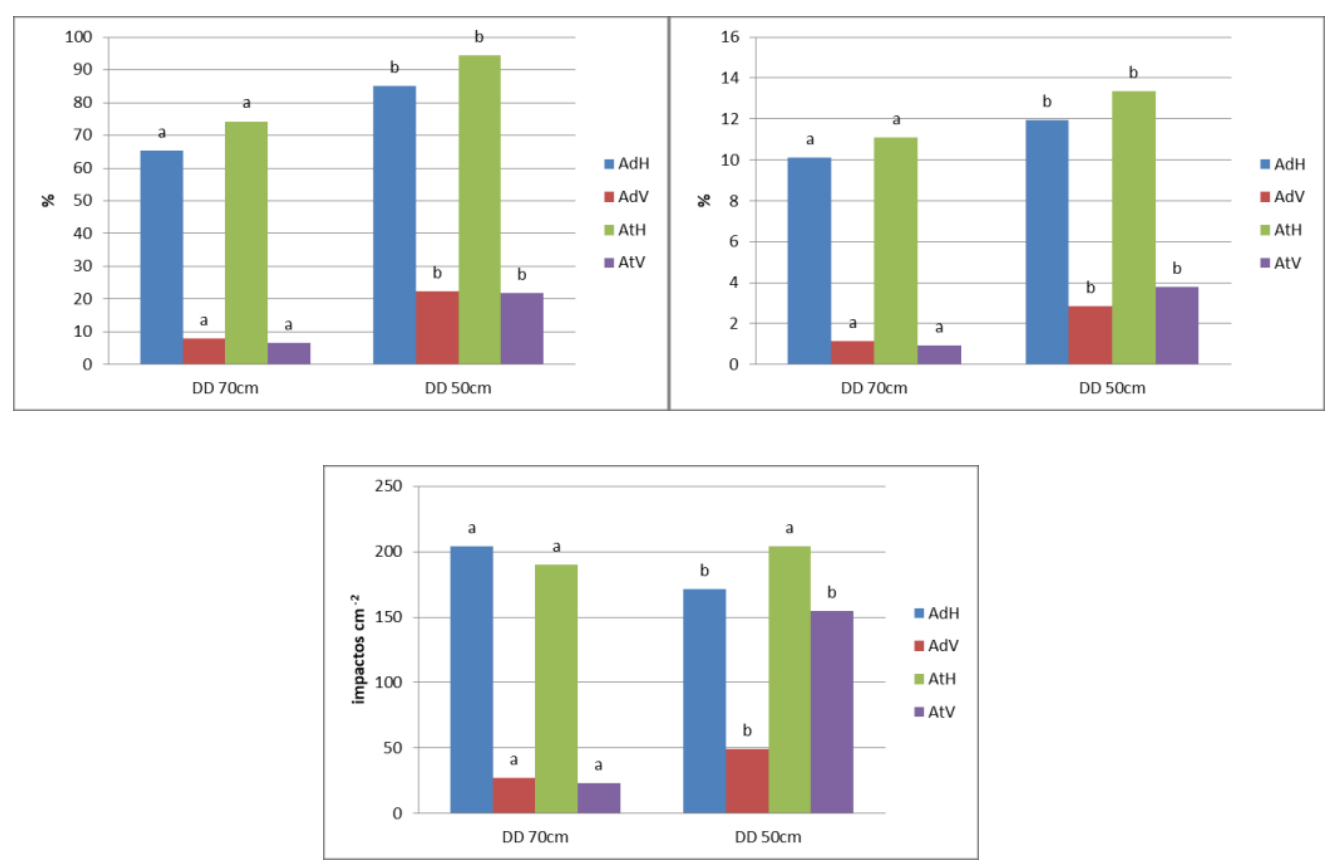
Figuras 28: Eficiencia (\%), Cobertura (\%) y Densidad de impactos (Impactos $\mathrm{cm}^{-2}$ ) entre diferentes pasadas con las pastillas DD con diferentes alturas de botalón $70 \mathrm{~cm}$ y $50 \mathrm{~cm}$. $\mathrm{AdH}$ : adelante horizontal, AtH: atrás horizontal, AdV: adelante vertical, AtV: atrás vertical. Letras diferentes presentan diferencias significativas ( $p$-value $\leq 0,05$ ), para test de Ranks de Kruskal Wallis, para cada posición entre alturas del botalón.

En las mismas se puede observar como al acercar el botalón al objetivo se mejoran sustancialmente los parámetros evaluados en casi todas las posiciones, concordando con lo hallado por Wolf \& Caldwell (2013) quienes citan que la deposición horizontal del objetivo disminuyó significativamente con la altura de la pluma, y con botalones más altos recibieron depósitos hasta un 20 \% más bajos, de manera similar a lo ocurrido con los objetivos verticales. En este caso los aumentos porcentuales de Eficiencia (\%) para la reducción de la altura del botalón de 0,7 m a 0,5 m fue de 183-236 \% para objetivos verticales y de $27-30 \%$ para los horizontales; asimismo, en la Cobertura (\%) el aumento fue de $148-307 \%$ para los objetivos verticales y $20-21 \%$ para los horizontales. En el parámetro Densidad de impactos las variaciones no son tan marcadas o uniformes aunque se observan aumentos de hasta 573 \% en objetivos verticales, y una reducción en AdH para la menor altura en relación a la mayor. Esto resulta lógico, ya que las gotas que alcanzan los objetivos verticales del lado de la sombra no llegan a los horizontales delanteros. Esto último también demuestra que el efecto del aumento de Eficiencia (\%) y Cobertura (\%) no solo puede estar dado por una mayor Densidad de impactos, sino también por un tamaño de gotas mayor.

Ante estos resultados se decide realizar un análisis estadístico particionando, los valores de la pasada de pulverización con altura de botalón de 0,5 m, entre objetivos 
sobre cubos pequeños y cubos grandes que se había descartado en un análisis inicial para la altura de pasada de 0,7 m (Tabla 2 y 3 del Anexo II). Los resultados al igual que en la primera altura no presentaron diferencias significativas para los parámetros Eficiencia (\%), Densidad de impactos (Imp. $\mathrm{cm}^{-2}$ ) y Cobertura (\%). Esto nos permite refutar la Hipótesis, La eficiencia de aplicación sobre el sector de sombra tiene una relación directa con la altura del objetivo y nos permiten suponer que se relacionan más con la distancia entre botalón y objetivo pero siempre en relación con el resto de los parámetros de pulverización. 


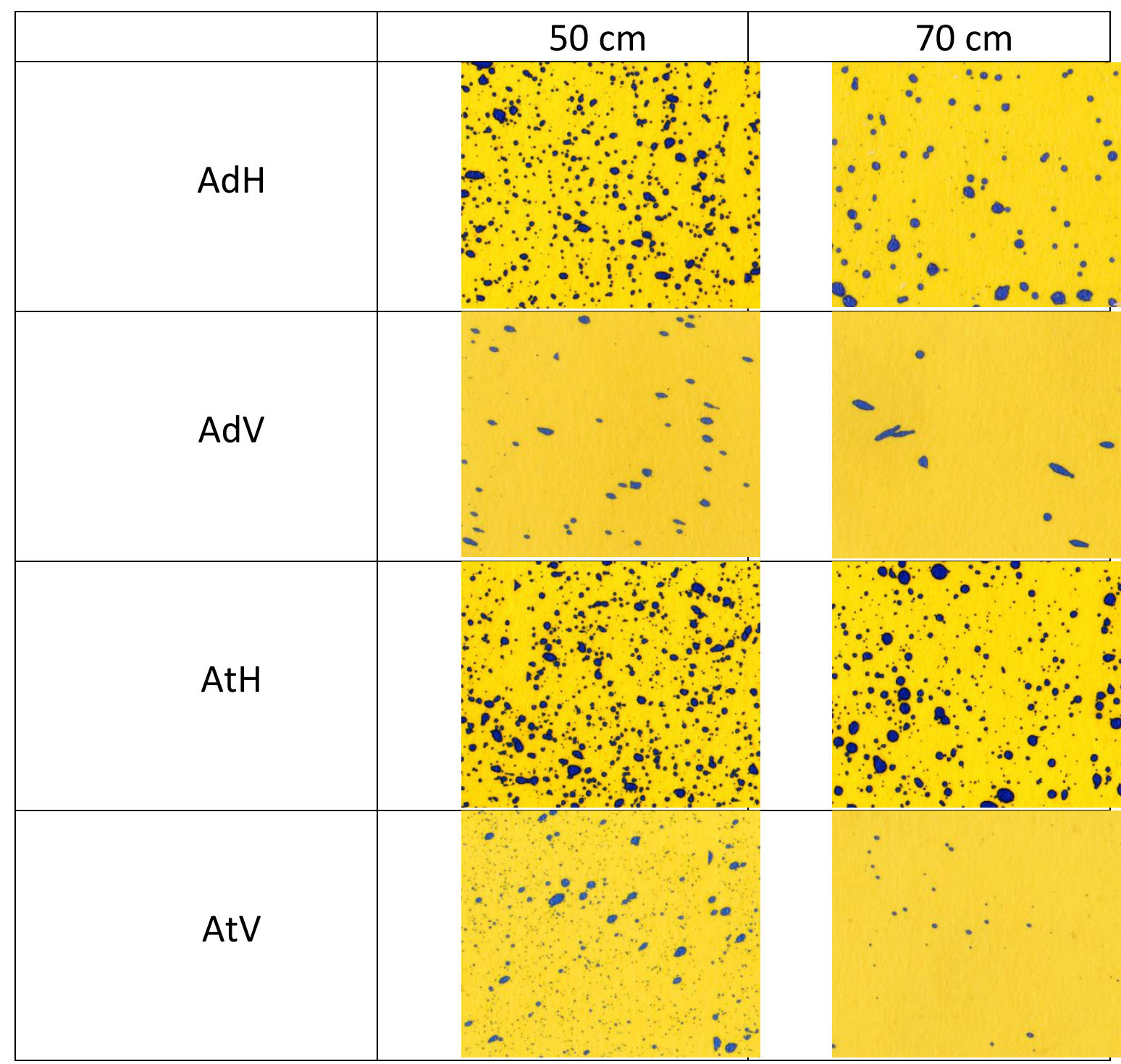

Figuras 29: Tarjetas de las diferentes posiciones relativas, en las dos alturas de botalón utilizadas. AdH: adelante horizontal, AtH: atrás horizontal, AdV: adelante vertical, AtV: atrás vertical.

Este efecto puede deberse a dos variables; por un lado, como ya se mencionó anteriormente, el ángulo con el cual salen las gotas de la pastilla disminuye por el efecto de la gravedad, perdiéndose producto y cayendo en forma más perpendicular al suelo; por otro lado Wolf \& Caldwell (2013) mencionan el efecto de pérdida de gotas de producto de mediar un mayor tiempo para alcanzar el objetivo, facilitando el desvío de su 
trayectoria y la pérdida de parte de la solución aplicada, por disminución del tamaño de la mismas. Como ya se mencionó, Jensen (2007) explica que cambiar la trayectoria de la pulverización desde la vertical con angulaciones aumenta la distancia desde la pluma hasta el objetivo; por lo tanto, se debe bajar el botalón si se desea mantener la distancia de la pastilla hasta el objetivo (Imagen 4). Por otro lado, diferentes autores mencionan que la altura de la pluma o de la boquilla es uno de los principales factores que influyen en el potencial de deriva de la pulverización (Holterman et al., 1997; Miller, 1989; Zhu et al., 1994). Los cambios en el ángulo de pulverización podrían influir por lo tanto en el potencial de deriva, pero hasta el momento no se han encontrado investigaciones sobre el tema.

Todo esto permite establecer que, si bien la disposición de los objetivos en relación a la dirección de los abanicos de pulverización no es por si sola determinante de la calidad de pulverización en cuanto a la cantidad de impactos y cobertura, cobra importancia si se lo relaciona con la altura del botalón al objetivo, pese a que menores alturas disminuyen la superposición de los abanicos (Galli et al., 1983; Matthews, 2000; Christofoletti, 1997). Por otro lado, se hipotetizó en este trabajo que, la eficiencia de aplicación sobre el sector de sombra tiene una relación directa o inversa con la altura del objetivo. A fin de contrastar esta hipótesis se buscó generar objetivos con diferentes alturas que generasen diferente nivel de sombra sobre las tarjetas. En el análisis posterior de los datos no se encontraron diferencias significativas para ninguna variable en relación a la altura de los obstáculos, por lo que se decide tomar los diferentes tamaños de cubos como repeticiones y se rechaza la hipótesis que la eficiencia de aplicación sobre el sector de 
sombra tiene una relación con la altura del objetivo. Pese a esto, cuando se generó una variación en la altura de botalón si se encontraron diferencias significativas para las diferentes alturas del mismo; esto permitiría inferir en parte que pequeñas variaciones de altura no generarían dificultades en alcanzar los objetivos pero, cuando estas diferencias aumentan, se profundizarían las dificultades llegando a requerir modificaciones en las configuraciones de los equipos a fin de alcanzar los objetivos buscados.

\section{Conclusiones}

La altura del botalón posee un efecto marcado en la calidad de pulverización con el uso de pastillas anguladas alternadas.

La calidad de aplicación de las pastillas anguladas alternadas presenta mejores valores de densidad de impactos, cobertura y eficiencia cuando se reduce la altura de trabajo del botalón.

ANEXO II

Tabla 1: Valores estadísticos de DVM, Densidad de impactos, Eficiencia, \% de Cobertura y Tasa de recuperación. Para las distintas Tamaños de cubo y Pastillas. Método de análisis no paramétricos de Kruskal Wallis.

\begin{tabular}{|c|c|c|c|c|c|c|c|c|}
\hline Pastilla & Variable & cubo & $\mathrm{N}$ & Medias & D.E. & Medianas & $\mathrm{H}$ & $\mathrm{p}$ \\
\hline \multirow{5}{*}{ DP } & DVM & Chico & 42 & 250,87 & 55,48 & 261,92 & 0,09 & 0,761 \\
\cline { 2 - 10 } & DVM & Grande & 42 & 244,59 & 59,82 & 254,19 & & \\
\cline { 2 - 10 } & $\mathrm{N}^{\circ}$ Impac & Chico & 42 & 99,26 & 69,1 & 112,5 & 2,01 & 0,1561 \\
\cline { 2 - 10 } & $\mathrm{N}^{\circ}$ Impac & Grande & 42 & 82,48 & 65,31 & 76,5 & & \\
\cline { 2 - 10 } & Eficiencia & Chico & 42 & 40,65 & 38,02 & 29,75 & 0,59 & 0,4443 \\
\cline { 2 - 10 } & Eficiencia & Grande & 42 & 34,09 & 32,44 & 28,29 & & \\
\cline { 2 - 10 } & AC\% & Chico & 42 & 5,68 & 4,91 & 5 & 0,65 & 0,4205 \\
\cline { 2 - 10 } & AC\% & Grande & 42 & 4,85 & 4,41 & 4,35 & & \\
\hline
\end{tabular}




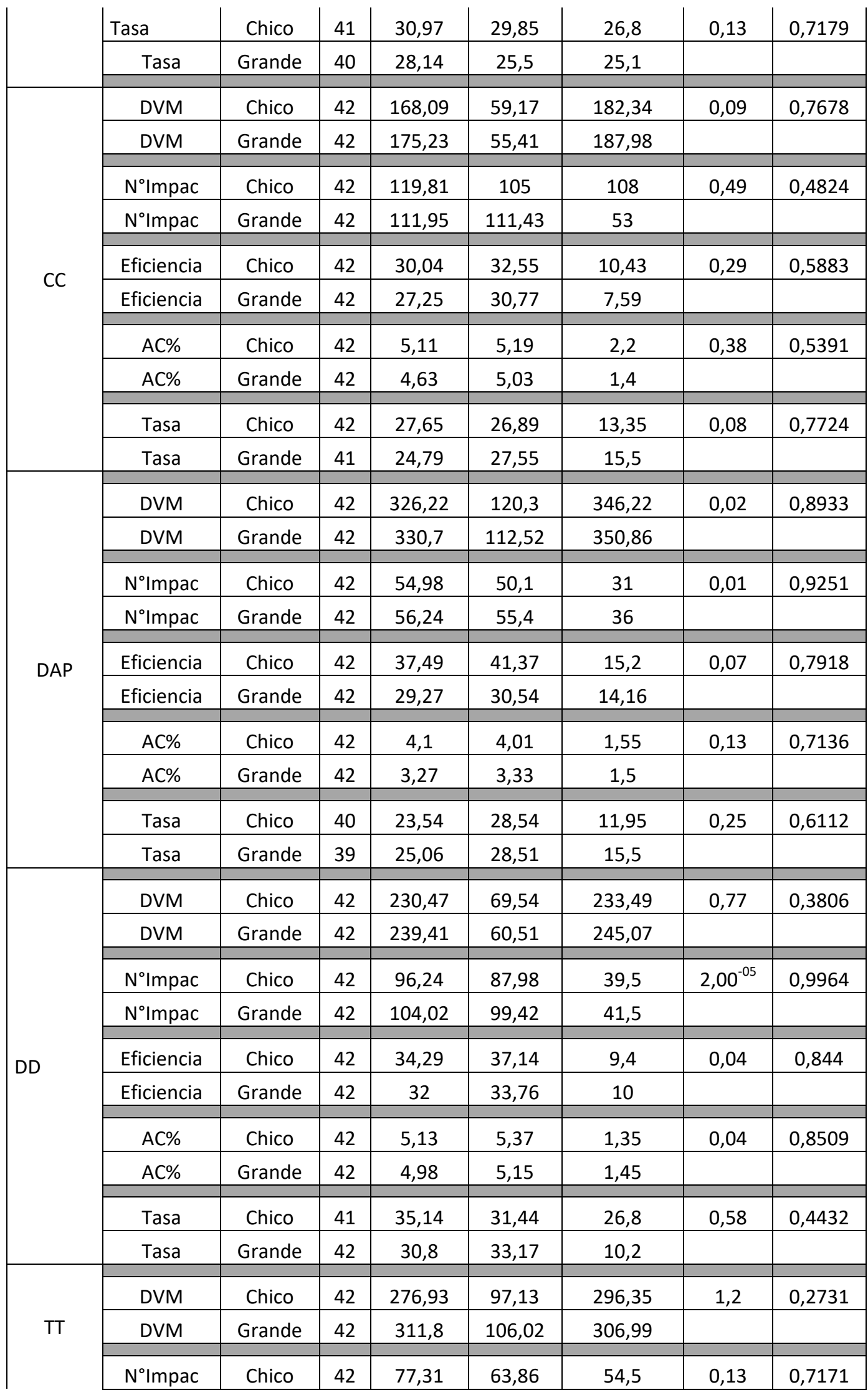




\begin{tabular}{|c|c|c|c|c|c|c|c|c|} 
& $\mathrm{N}^{\circ}$ Impac & Grande & 42 & 75,86 & 73,13 & 31,5 & & \\
\cline { 2 - 9 } & Eficiencia & Chico & 42 & 29,23 & 27,7 & 15,44 & 0,38 & 0,5357 \\
\cline { 2 - 10 } Eficiencia & Grande & 41 & 30,5 & 28,4 & 18,44 & & \\
\hline & AC\% & Chico & 42 & 3,69 & 3,35 & 2,15 & 0,32 & 0,5698 \\
\hline AC\% & Grande & 42 & 3,72 & 3,4 & 1,8 & & \\
\cline { 2 - 9 } & Tasa & Chico & 37 & 35,99 & 37,67 & 18,3 & 0,25 & 0,6197 \\
\hline & Tasa & Grande & 41 & 36,77 & 33,8 & 22,6 & & \\
\hline
\end{tabular}

Tabla 2: Valores estadísticos de DVM, Densidad de impactos, Eficiencia, \% de Cobertura y Tasa de recuperación. Para las distintas Pastillas y Tamaños de cubo en posiciones delanteras Verticales $(\mathrm{AdV})$, Horizontales $(\mathrm{AdH})$ y traseras Verticales (AtV) y horizontales (AtH). Método de análisis no paramétricos de Kruskal Wallis.

\begin{tabular}{|c|c|c|c|c|c|c|c|c|c|}
\hline Pastilla & Ubicación & Variable & cubo & $\mathrm{N}$ & Medias & D.E. & Medianas & $\mathrm{H}$ & $p$ \\
\hline \multirow{27}{*}{ AP } & $\mathrm{AdH}$ & DVM & Chico & 6 & 284,31 & 32,99 & 281,68 & 0,03 & 0,8777 \\
\hline & $\mathrm{AdH}$ & DVM & Grande & 6 & 276,66 & 26,35 & 276,28 & & \\
\hline & $\mathrm{AdH}$ & $\mathrm{N}^{\circ}$ Impac & Chico & 6 & 171,5 & 45,39 & 173 & 1,64 & 0,2403 \\
\hline & $\mathrm{AdH}$ & $\mathrm{N}^{\circ}$ Impac & Grande & 6 & 144,67 & 41,03 & 131 & & \\
\hline & $\mathrm{AdH}$ & Eficiencia & Chico & 6 & 54,83 & 12,98 & 56,23 & 0,92 & 0,3939 \\
\hline & $\mathrm{AdH}$ & Eficiencia & Grande & 6 & 49,56 & 17,2 & 46,47 & & \\
\hline & $\mathrm{AdH}$ & AC\% & Chico & 6 & 7,68 & 1,45 & 7,85 & 0,78 & 0,4264 \\
\hline & $\mathrm{AdH}$ & AC\% & Grande & 6 & 7,18 & 2,74 & 6,4 & & \\
\hline & $\mathrm{AdH}$ & Tasa & Chico & 5 & 38,14 & 13,7 & 35,3 & 0,21 & 0,697 \\
\hline & $\mathrm{AdH}$ & Tasa & Grande & 6 & 39,82 & 13,81 & 38,15 & & \\
\hline & AdV & DVM & Chico & 6 & 209,74 & 103,74 & 239,1 & 0 & $>0,9999$ \\
\hline & AdV & DVM & Grande & 6 & 197,49 & 127,51 & 180,65 & & \\
\hline & AdV & $\mathrm{N}^{\circ}$ Impac & Chico & 6 & 27,17 & 26,29 & 18,5 & 0,16 & 0,6948 \\
\hline & AdV & $\mathrm{N}^{\circ}$ Impac & Grande & 6 & 16,5 & 6,53 & 16 & & \\
\hline & $\mathrm{AdV}$ & Eficiencia & Chico & 6 & 2,78 & 2,55 & 1,6 & 0,1 & 0,7587 \\
\hline & $\mathrm{AdV}$ & Eficiencia & Grande & 6 & 1,54 & 1,13 & 1,74 & & \\
\hline & $\mathrm{AdV}$ & AC\% & Chico & 6 & 0,53 & 0,6 & 0,3 & 0,23 & 0,6688 \\
\hline & $\mathrm{AdV}$ & AC\% & Grande & 6 & 0,28 & 0,16 & 0,3 & & \\
\hline & AdV & Tasa & Chico & 6 & 2,57 & 5,67 & 0 & 0 & $>0,9999$ \\
\hline & AdV & Tasa & Grande & 6 & 0,82 & 1,28 & 0 & & \\
\hline & AtH & DVM & Chico & 6 & 275,85 & 17,97 & 279,5 & 1,26 & 0,3095 \\
\hline & AtH & DVM & Grande & 6 & 257,93 & 36,67 & 278,02 & & \\
\hline & AtH & $\mathrm{N}^{\circ}$ Impac & Chico & 6 & 164,67 & 27,76 & 159 & 0,03 & 0,8777 \\
\hline & AtH & $\mathrm{N}^{\circ}$ Impac & Grande & 6 & 164,83 & 38,48 & 156 & & \\
\hline & AtH & Eficiencia & Chico & 6 & 87,91 & 19,28 & 94,66 & 0,92 & 0,3939 \\
\hline & AtH & Eficiencia & Grande & 6 & 80,53 & 15,89 & 84,1 & & \\
\hline & AtH & AC\% & Chico & 6 & 11,93 & 2,14 & 12,75 & 0,92 & 0,3961 \\
\hline
\end{tabular}




\begin{tabular}{|c|c|c|c|c|c|c|c|c|c|}
\hline & AtH & AC\% & Grande & 6 & 11,1 & 1,67 & 11,2 & & \\
\hline & AtH & Tasa & Chico & 6 & 74,85 & 10,83 & 72,95 & 2,41 & 0,1364 \\
\hline & AtH & Tasa & Grande & 5 & 57,78 & 18,66 & 62,3 & & \\
\hline & AtV & DVM & Chico & 6 & 221,36 & 24,7 & 215,33 & 0 & $>0,9999$ \\
\hline & AtV & DVM & Grande & 6 & 221,55 & 20,06 & 229,12 & & \\
\hline & AtV & $\mathrm{N}^{\circ}$ Impac & Chico & 6 & 74,67 & 31,26 & 83,5 & 0,41 & 0,5887 \\
\hline & AtV & $\mathrm{N}^{\circ}$ Impac & Grande & 6 & 67,5 & 19,66 & 71 & & \\
\hline & AtV & Eficiencia & Chico & 6 & 24,11 & 12,68 & 21,16 & 0,1 & 0,8182 \\
\hline & AtV & Eficiencia & Grande & 6 & 26,32 & 14,36 & 28,45 & & \\
\hline & AtV & AC\% & Chico & 6 & 3,85 & 1,89 & 3,45 & 0,03 & 0,9372 \\
\hline & AtV & AC\% & Grande & 6 & 4,08 & 2,05 & 4,35 & & \\
\hline & AtV & Tasa & Chico & 6 & 10,78 & 13,03 & 8,4 & 4,33 & 0,0346 \\
\hline & AtV & Tasa & Grande & 6 & 27,72 & 15,87 & 23,7 & & \\
\hline \multirow{32}{*}{ CC } & $\mathrm{AdH}$ & DVM & Chico & 6 & 205,04 & 20,33 & 210,7 & 0,23 & 0,6991 \\
\hline & $\mathrm{AdH}$ & DVM & Grande & 6 & 205,41 & 28,88 & 195,43 & & \\
\hline & $\mathrm{AdH}$ & NImpac & Chico & 6 & 234 & 50,09 & 243,5 & 0,03 & 0,9372 \\
\hline & $\mathrm{AdH}$ & $\mathrm{N}^{\circ}$ Impac & Grande & 6 & 251,17 & 75,6 & 256 & & \\
\hline & $\mathrm{AdH}$ & Eficiencia & Chico & 6 & 67,24 & 19,03 & 76,3 & 1,26 & 0,3095 \\
\hline & $\mathrm{AdH}$ & Eficiencia & Grande & 6 & 61,61 & 15,72 & 60,7 & & \\
\hline & $\mathrm{AdH}$ & AC\% & Chico & 6 & 11,32 & 2,61 & 12,2 & 0,03 & 0,8777 \\
\hline & $\mathrm{AdH}$ & AC\% & Grande & 6 & 10,62 & 2,64 & 10 & & \\
\hline & $\mathrm{AdH}$ & Tasa & Chico & 6 & 58,95 & 16,11 & 60,15 & 0,21 & 0,7186 \\
\hline & $\mathrm{AdH}$ & Tasa & Grande & 5 & 56,3 & 24,73 & 49,5 & & \\
\hline & $\mathrm{AdV}$ & DVM & Chico & 6 & 157,4 & 23,58 & 158,67 & 0,92 & 0,3939 \\
\hline & $\mathrm{AdV}$ & DVM & Grande & 6 & 173,34 & 25,86 & 165 & & \\
\hline & AdV & $\mathrm{N}^{\circ}$ Impac & Chico & 6 & 57,83 & 45,29 & 36 & 0,31 & 0,5887 \\
\hline & $\mathrm{AdV}$ & $\mathrm{N}^{\circ}$ Impac & Grande & 6 & 52,67 & 55,85 & 32 & & \\
\hline & AdV & Eficiencia & Chico & 6 & 7,27 & 3,29 & 7,56 & 2,56 & 0,132 \\
\hline & AdV & Eficiencia & Grande & 6 & 4,43 & 2,67 & 3,83 & & \\
\hline & $\mathrm{AdV}$ & AC\% & Chico & 6 & 1,48 & 0,74 & 1,45 & 2,31 & 0,1494 \\
\hline & $\mathrm{AdV}$ & AC\% & Grande & 6 & 0,97 & 0,68 & 0,75 & & \\
\hline & AdV & Tasa & Chico & 6 & 6,52 & 5,72 & 6,95 & 0,64 & 0,4545 \\
\hline & $\mathrm{AdV}$ & Tasa & Grande & 6 & 9,75 & 9,55 & 7,4 & & \\
\hline & AtH & DVM & Chico & 6 & 207,42 & 23,95 & 216,99 & 0,03 & 0,9372 \\
\hline & AtH & DVM & Grande & 6 & 213,41 & 18,49 & 217,85 & & \\
\hline & AtH & $\mathrm{N}^{\circ}$ Impac & Chico & 6 & 230 & 92,9 & 209,5 & 0,1 & 0,7587 \\
\hline & AtH & $\mathrm{N}^{\circ}$ Impac & Grande & 6 & 222,33 & 88,82 & 198 & & \\
\hline & AtH & Eficiencia & Chico & 6 & 63,9 & 21,49 & 67,55 & 0,23 & 0,6991 \\
\hline & AtH & Eficiencia & Grande & 6 & 61,37 & 24,03 & 56,73 & & \\
\hline & AtH & AC\% & Chico & 6 & 10,67 & 2,48 & 10,6 & 0,31 & 0,5887 \\
\hline & AtH & AC\% & Grande & 6 & 10,07 & 3,26 & 8,8 & & \\
\hline & AtH & Tasa & Chico & 6 & 57,23 & 11,52 & 52,4 & 0,41 & 0,5433 \\
\hline & AtH & Tasa & Grande & 6 & 52,62 & 26,01 & 47,05 & & \\
\hline & AtV & DVM & Chico & 6 & 95,65 & 61,6 & 65,98 & 0,92 & 0,3939 \\
\hline & AtV & DVM & Grande & 6 & 121,1 & 58,98 & 114,24 & & \\
\hline
\end{tabular}




\begin{tabular}{|c|c|c|c|c|c|c|c|c|c|}
\hline & AtV & $\mathrm{N}^{\circ}$ Impac & Chico & 6 & 19,83 & 20,25 & 12,5 & 0,23 & 0,6861 \\
\hline & AtV & $\mathrm{N}^{\circ}$ Impac & Grande & 6 & 13 & 5,97 & 11,5 & & \\
\hline & AtV & Eficiencia & Chico & 6 & 0,47 & 0,33 & 0,32 & 0,64 & 0,4848 \\
\hline & AtV & Eficiencia & Grande & 6 & 0,47 & 0,12 & 0,44 & & \\
\hline & AtV & AC\% & Chico & 6 & 0,17 & 0,12 & 0,1 & 0,06 & $>0,9999$ \\
\hline & AtV & AC\% & Grande & 6 & 0,15 & 0,05 & 0,15 & & \\
\hline & AtV & Tasa & Chico & 6 & 2,1 & 5,14 & 0 & 0,78 & 0,4242 \\
\hline & AtV & Tasa & Grande & 6 & 3,65 & 6,97 & 0,7 & & \\
\hline \multirow{38}{*}{ DAP } & $\mathrm{AdH}$ & DVM & Chico & 6 & 380,68 & 65,09 & 398,13 & 0,64 & 0,4848 \\
\hline & $\mathrm{AdH}$ & DVM & Grande & 6 & 372,69 & 40,92 & 378,26 & & \\
\hline & $\mathrm{AdH}$ & NImpac & Chico & 6 & 74,17 & 51,96 & 74,5 & 0,78 & 0,4199 \\
\hline & $\mathrm{AdH}$ & $\mathrm{N}^{\circ}$ Impac & Grande & 6 & 99,5 & 45,82 & 89 & & \\
\hline & $\mathrm{AdH}$ & Eficiencia & Chico & 6 & 42,35 & 28,31 & 48,33 & 0,23 & 0,6991 \\
\hline & $\mathrm{AdH}$ & Eficiencia & Grande & 6 & 54,41 & 12,34 & 57,32 & & \\
\hline & $\mathrm{AdH}$ & AC\% & Chico & 6 & 4,48 & 2,84 & 5,15 & 0,41 & 0,5584 \\
\hline & $\mathrm{AdH}$ & AC\% & Grande & 6 & 6,02 & 1,34 & 6,25 & & \\
\hline & $\mathrm{AdH}$ & Tasa & Chico & 5 & 47,8 & 39,68 & 45,2 & 0,38 & 0,6032 \\
\hline & $\mathrm{AdH}$ & Tasa & Grande & 4 & 64,75 & 10,32 & 62,25 & & \\
\hline & AdV & DVM & Chico & 6 & 402,07 & 53,93 & 394,5 & 0,64 & 0,4848 \\
\hline & $\mathrm{AdV}$ & DVM & Grande & 6 & 362,42 & 66,56 & 374,3 & & \\
\hline & AdV & $\mathrm{N}^{\circ}$ Impac & Chico & 6 & 39,83 & 42,18 & 15 & 0,23 & 0,697 \\
\hline & $\mathrm{AdV}$ & $\mathrm{N}^{\circ}$ Impac & Grande & 6 & 19,67 & 13,25 & 12,5 & & \\
\hline & AdV & Eficiencia & Chico & 6 & 34,27 & 40,26 & 13,45 & 0,92 & 0,3939 \\
\hline & $\mathrm{AdV}$ & Eficiencia & Grande & 6 & 9,06 & 5,74 & 8,86 & & \\
\hline & AdV & AC\% & Chico & 6 & 3,48 & 4,18 & 1,25 & 0,52 & 0,5043 \\
\hline & AdV & AC\% & Grande & 6 & 0,97 & 0,49 & 1,05 & & \\
\hline & AdV & Tasa & Chico & 6 & 4,88 & 7,29 & 1,3 & 1,64 & 0,2056 \\
\hline & $\mathrm{AdV}$ & Tasa & Grande & 6 & 10,7 & 5,71 & 11,65 & & \\
\hline & AtH & DVM & Chico & 6 & 407,55 & 97,48 & 402,4 & 0,92 & 0,3939 \\
\hline & AtH & DVM & Grande & 6 & 352,11 & 21,84 & 354,31 & & \\
\hline & AtH & $\mathrm{N}^{\circ} \mathrm{Impac}$ & Chico & 6 & 89,83 & 48,25 & 75,5 & 0 & $>0,9999$ \\
\hline & AtH & $\mathrm{N}^{\circ}$ Impac & Grande & 6 & 87,17 & 35,22 & 94 & & \\
\hline & AtH & Eficiencia & Chico & 6 & 91,48 & 45,54 & 99,15 & 1,64 & 0,2403 \\
\hline & AtH & Eficiencia & Grande & 6 & 66,92 & 29,89 & 70,97 & & \\
\hline & AtH & AC\% & Chico & 6 & 8,92 & 3,11 & 9,55 & 0,78 & 0,4177 \\
\hline & AtH & $\mathrm{AC} \%$ & Grande & 6 & 7,45 & 3,23 & 8,05 & & \\
\hline & AtH & Tasa & Chico & 5 & 54,76 & 13,37 & 59,4 & 0,53 & 0,5368 \\
\hline & AtH & Tasa & Grande & 6 & 47,63 & 18,67 & 40,7 & & \\
\hline & AtV & DVM & Chico & 6 & 215,19 & 86,2 & 185,09 & 0,23 & 0,6991 \\
\hline & AtV & DVM & Grande & 6 & 172,14 & 65,19 & 181,3 & & \\
\hline & AtV & $\mathrm{N}^{\circ} \mathrm{Impac}$ & Chico & 6 & 41,17 & 59,2 & 18 & 0,1 & 0,7576 \\
\hline & AtV & $\mathrm{N}^{\circ}$ Impac & Grande & 6 & 58,17 & 107,81 & 17,5 & & \\
\hline & AtV & Eficiencia & Chico & 6 & 12,54 & 24,82 & 2,68 & 0,1 & 0,7587 \\
\hline & AtV & Eficiencia & Grande & 6 & 2,45 & 1,89 & 1,95 & & \\
\hline & AtV & AC\% & Chico & 6 & 1,57 & 2,69 & 0,5 & 0,1 & 0,7597 \\
\hline & AtV & AC\% & Grande & 6 & 0,45 & 0,29 & 0,45 & & \\
\hline
\end{tabular}




\begin{tabular}{|c|c|c|c|c|c|c|c|c|c|}
\hline & AtV & Tasa & Chico & 6 & 8,67 & 10,91 & 4,2 & 0,01 & 0,9481 \\
\hline & AtV & Tasa & Grande & 5 & 4,48 & 5,54 & 1,4 & & \\
\hline \multirow{40}{*}{ DD } & $\mathrm{AdH}$ & DVM & Chico & 6 & 239,51 & 25,99 & 239,74 & 0,03 & 0,8777 \\
\hline & $\mathrm{AdH}$ & DVM & Grande & 6 & 242,12 & 14,23 & 246,17 & & \\
\hline & $\mathrm{AdH}$ & $\mathrm{N}^{\circ}$ Impac & Chico & 6 & 204,83 & 32,61 & 200 & 0,01 & 0,974 \\
\hline & $\mathrm{AdH}$ & $\mathrm{N}^{\circ}$ Impac & Grande & 6 & 203,67 & 19,49 & 202,5 & & \\
\hline & $\mathrm{AdH}$ & Eficiencia & Chico & 6 & 67,19 & 17,28 & 63,82 & 0,1 & 0,7587 \\
\hline & $\mathrm{AdH}$ & Eficiencia & Grande & 6 & 63,27 & 19,02 & 64,33 & & \\
\hline & $\mathrm{AdH}$ & $\mathrm{AC} \%$ & Chico & 6 & 10,38 & 1,77 & 10,3 & 0,23 & 0,6991 \\
\hline & $\mathrm{AdH}$ & $\mathrm{AC} \%$ & Grande & 6 & 9,87 & 2,52 & 10,1 & & \\
\hline & $\mathrm{AdH}$ & Tasa & Chico & 6 & 70,98 & 19,45 & 75 & 0,16 & 0,6991 \\
\hline & $\mathrm{AdH}$ & Tasa & Grande & 6 & 66,73 & 18,4 & 72,85 & & \\
\hline & AdV & DVM & Chico & 6 & 256,84 & 50,15 & 255,3 & 0,64 & 0,4848 \\
\hline & AdV & DVM & Grande & 6 & 290,96 & 70,1 & 266,96 & & \\
\hline & $\mathrm{AdV}$ & $\mathrm{N}^{\circ}$ Impac & Chico & 6 & 29,33 & 12,47 & 26,5 & 0,92 & 0,3701 \\
\hline & $\mathrm{AdV}$ & $\mathrm{N}^{\circ}$ Impac & Grande & 6 & 25,5 & 16,06 & 19,5 & & \\
\hline & $\mathrm{AdV}$ & Eficiencia & Chico & 6 & 7,39 & 3,97 & 9,23 & 0,23 & 0,6991 \\
\hline & $\mathrm{AdV}$ & Eficiencia & Grande & 6 & 8,35 & 2,52 & 9,1 & & \\
\hline & AdV & AC\% & Chico & 6 & 1,13 & 0,61 & 1,25 & 0,16 & 0,7381 \\
\hline & AdV & AC\% & Grande & 6 & 1,17 & 0,38 & 1,15 & & \\
\hline & AdV & Tasa & Chico & 6 & 15,02 & 16,92 & 8,4 & 1,44 & 0,2576 \\
\hline & AdV & Tasa & Grande & 6 & 5,27 & 5,25 & 4,2 & & \\
\hline & AtH & DVM & Chico & 6 & 249,54 & 20,96 & 250,15 & 0 & $>0,9999$ \\
\hline & AtH & DVM & Grande & 6 & 248,98 & 17,06 & 246,32 & & \\
\hline & AtH & $\mathrm{N}^{\circ}$ Impac & Chico & 6 & 183,33 & 34,33 & 179 & 0,31 & 0,6234 \\
\hline & AtH & $\mathrm{N}^{\circ}$ Impac & Grande & 6 & 196,33 & 47,53 & 189 & & \\
\hline & AtH & Eficiencia & Chico & 6 & 76,93 & 20,46 & 78,45 & 0,23 & 0,6991 \\
\hline & AtH & Eficiencia & Grande & 6 & 71,62 & 21,23 & 68,81 & & \\
\hline & AtH & AC\% & Chico & 6 & 11,53 & 2,45 & 11,65 & 0,41 & 0,5887 \\
\hline & AtH & $\mathrm{AC} \%$ & Grande & 6 & 10,67 & 2,73 & 10,65 & & \\
\hline & AtH & Tasa & Chico & 6 & 69,18 & 13,46 & 66,25 & 0,06 & 0,8463 \\
\hline & AtH & Tasa & Grande & 6 & 67,42 & 14,04 & 68,7 & & \\
\hline & AtV & DVM & Chico & 6 & 289,04 & 93,58 & 261,27 & 0,41 & 0,5887 \\
\hline & AtV & DVM & Grande & 6 & 256,08 & 45,93 & 235,98 & & \\
\hline & AtV & $\mathrm{N}^{\circ}$ Impac & Chico & 6 & 17,17 & 5,34 & 16,5 & 1,44 & 0,2576 \\
\hline & AtV & $\mathrm{N}^{\circ}$ Impac & Grande & 6 & 29,17 & 15,72 & 28,5 & & \\
\hline & AtV & Eficiencia & Chico & 6 & 5,91 & 4,99 & 4,8 & 1,26 & 0,3095 \\
\hline & AtV & Eficiencia & Grande & 6 & 7,09 & 3,28 & 7,59 & & \\
\hline & AtV & AC\% & Chico & 6 & 0,78 & 0,52 & 0,7 & 1,26 & 0,2857 \\
\hline & AtV & $\mathrm{AC} \%$ & Grande & 6 & 1,07 & 0,45 & 1,15 & & \\
\hline & AtV & Tasa & Chico & 6 & 6,3 & 6,9 & 6,3 & 0 & $>0,9999$ \\
\hline & AtV & Tasa & Grande & 6 & 6,22 & 9,29 & 1,7 & & \\
\hline \multirow{3}{*}{$T$} & $\mathrm{AdH}$ & DVM & Chico & 6 & 344,19 & 41,74 & 345,53 & 0,1 & 0,8182 \\
\hline & $\mathrm{AdH}$ & DVM & Grande & 6 & 352,44 & 52,52 & 367,87 & & \\
\hline & $\mathrm{AdH}$ & $\mathrm{N}^{\circ}$ Impac & Chico & 6 & 159,83 & 38,72 & 162 & 0,23 & 0,6991 \\
\hline
\end{tabular}




\begin{tabular}{|c|c|c|c|c|c|c|c|c|}
\hline $\mathrm{AdH}$ & NImpac & Grande & 6 & 135 & 72,7 & 137,5 & & \\
\hline $\mathrm{AdH}$ & Eficiencia & Chico & 6 & 58,28 & 4,56 & 57,26 & 0,53 & 0,5368 \\
\hline $\mathrm{AdH}$ & Eficiencia & Grande & 5 & 52,2 & 18,03 & 48,04 & & \\
\hline $\mathrm{AdH}$ & AC\% & Chico & 6 & 7,27 & 0,61 & 7,05 & 0,41 & 0,5628 \\
\hline $\mathrm{AdH}$ & AC\% & Grande & 6 & 5,75 & 2,77 & 6,65 & & \\
\hline $\mathrm{AdH}$ & Tasa & Chico & 5 & 81,14 & 13,94 & 73,6 & 6,08 & 0,0108 \\
\hline $\mathrm{AdH}$ & Tasa & Grande & 6 & 60,83 & 9,87 & 62,25 & & \\
\hline $\mathrm{AdV}$ & DVM & Chico & 6 & 133,3 & 72,58 & 103,81 & 1,64 & 0,2403 \\
\hline $\mathrm{AdV}$ & DVM & Grande & 6 & 201,5 & 84,62 & 211,37 & & \\
\hline $\mathrm{AdV}$ & $\mathrm{N}^{\circ}$ Impac & Chico & 6 & 14 & 3,41 & 14 & 0,41 & 0,5628 \\
\hline AdV & NImpac & Grande & 6 & 22 & 16,53 & 21 & & \\
\hline $\mathrm{AdV}$ & Eficiencia & Chico & 6 & 1 & 0,95 & 0,62 & 1,64 & 0,2403 \\
\hline AdV & Eficiencia & Grande & 6 & 1,87 & 1,32 & 1,79 & & \\
\hline AdV & AC\% & Chico & 6 & 0,22 & 0,15 & 0,2 & 0,78 & 0,381 \\
\hline $\mathrm{AdV}$ & $\mathrm{AC} \%$ & Grande & 6 & 0,38 & 0,26 & 0,4 & & \\
\hline $\mathrm{AdV}$ & Tasa & Chico & 5 & 1,68 & 3,76 & 0 & 1,63 & 0,21 \\
\hline $\mathrm{AdV}$ & Tasa & Grande & 6 & 6,22 & 6,61 & 4,55 & & \\
\hline AtH & DVM & Chico & 6 & 341,68 & 43,5 & 336,32 & 0 & $>0,9999$ \\
\hline AtH & DVM & Grande & 6 & 338,8 & 46,88 & 334,6 & & \\
\hline AtH & $\mathrm{N}^{\circ}$ Impac & Chico & 6 & 148 & 31,71 & 145,5 & 1,26 & 0,3095 \\
\hline AtH & NImpac & Grande & 6 & 117,33 & 61,45 & 124,5 & & \\
\hline AtH & Eficiencia & Chico & 6 & 66,92 & 10,56 & 66,82 & 0,64 & 0,4848 \\
\hline AtH & Eficiencia & Grande & 6 & 69,07 & 14,72 & 74,53 & & \\
\hline AtH & AC\% & Chico & 6 & 8,05 & 0,9 & 8,15 & 0,23 & 0,6688 \\
\hline AtH & AC\% & Grande & 6 & 8,13 & 1,24 & 8,3 & & \\
\hline AtH & Tasa & Chico & 5 & 83,6 & 8,92 & 83,6 & 0,03 & 0,9221 \\
\hline AtH & Tasa & Grande & 6 & 74,02 & 30,41 & 85,7 & & \\
\hline AtV & DVM & Chico & 6 & 202 & 27,81 & 197,93 & 0,64 & 0,4848 \\
\hline AtV & DVM & Grande & 6 & 220,09 & 33,84 & 211,14 & & \\
\hline AtV & $\mathrm{N}^{\circ}$ Impac & Chico & 6 & 47,83 & 45,04 & 31,5 & 0 & $>0,9999$ \\
\hline AtV & $\mathrm{N}^{\circ}$ Impac & Grande & 6 & 68,5 & 108,24 & 23,5 & & \\
\hline AtV & Eficiencia & Chico & 6 & 5,81 & 3,91 & 4,5 & 0,41 & 0,5887 \\
\hline AtV & Eficiencia & Grande & 6 & 6,54 & 3,76 & 4,6 & & \\
\hline AtV & AC\% & Chico & 6 & 1,08 & 0,8 & 0,75 & 0,23 & 0,671 \\
\hline AtV & AC\% & Grande & 6 & 1,03 & 0,44 & 0,85 & & \\
\hline AtV & Tasa & Chico & 6 & 9,08 & 6,38 & 9,8 & 0 & $>0,9999$ \\
\hline AtV & Tasa & Grande & 5 & 988 & 9.19 & 56 & & \\
\hline
\end{tabular}

Tabla 3: Valores estadísticos de Densidad de impactos, Eficiencia y \% de Cobertura. Para las distintas Tamaños de cubo en posiciones delanteras Verticales, Horizontales y traseras Verticales y horizontal para pastillas DD con botalon a $0,5 \mathrm{~m}$ del suelo. Método de análisis no paramétricos de Kruskal Wallis

\begin{tabular}{|c|c|c|c|c|c|c|c|c|c|}
\hline ubicación & posición & Variable & cubo & N & Medias & D.E. & Medianas & H & p \\
\hline adelante & horizontal & $\mathrm{N}^{\circ}$ Impac & Chico & 4 & 182 & 21,89 & 180,5 & 0,75 & 0,4857 \\
\hline adelante & horizontal & $\mathrm{N}^{\circ}$ Impac & Grande & 4 & 161,25 & 39,41 & 155 & & \\
\hline
\end{tabular}




\begin{tabular}{|c|c|c|c|c|c|c|c|c|c|}
\hline adelante & horizontal & Eficiencia & Chico & 4 & 96,24 & 10,66 & 94,34 & 3 & 0,1143 \\
\hline adelante & horizontal & Eficiencia & Grande & 4 & 73,95 & 17,93 & 76,09 & & \\
\hline adelante & vertical & $\mathrm{N}^{\circ}$ Impac & Chico & 4 & 43,75 & 20,37 & 45,5 & 0,52 & 0,5429 \\
\hline adelante & vertical & $\mathrm{N}^{\circ}$ Impac & Grande & 4 & 54,75 & 26,09 & 47,5 & & \\
\hline adelante & vertical & Eficiencia & Chico & 4 & 21,6 & 12,94 & 17,37 & 0,33 & 0,6857 \\
\hline adelante & vertical & Eficiencia & Grande & 4 & 22,96 & 8,92 & 21,19 & & \\
\hline atrás & horizontal & $\mathrm{N}^{\circ}$ Impac & Chico & 4 & 204 & 14,54 & 200,5 & 0,08 & 0,8857 \\
\hline atrás & horizontal & $\mathrm{N}^{\circ}$ Impac & Grande & 4 & 204,75 & 23,49 & 214,5 & & \\
\hline atrás & horizontal & Eficiencia & Chico & 4 & 96,9 & 7,86 & 97,74 & 0,33 & 0,6857 \\
\hline atrás & horizontal & Eficiencia & Grande & 4 & 92,11 & 18,24 & 90,29 & & \\
\hline atrás & vertical & $\mathrm{N}^{\circ}$ Impac & Chico & 4 & 115,5 & 34,04 & 125,5 & 1,69 & 0,2286 \\
\hline atrás & vertical & $\mathrm{N}^{\circ}$ Impac & Grande & 4 & 194,5 & 100,57 & 210 & & \\
\hline atrás & vertical & Eficiencia & Chico & 4 & 20,62 & 4,6 & 20,28 & 0,08 & 0,8857 \\
\hline atrás & vertical & Eficiencia & Grande & 4 & 23,11 & 14,07 & 22,81 & & \\
\hline
\end{tabular}

